\author{
Universidade de São Paulo \\ Instituto de Física
}

\title{
Termodinâmica da Água e Dobramento de Proteínas: Estudo de Modelos em Rede
}

\author{
Marco Aurélio Alves Barbosa \\ Orientadora: Profa. Dra. Vera Bohomoletz Henriques (IFUSP) \\ Co-orientador: Prof. Dr. Antônio Francisco Pereira de Araújo (UnB) \\ Tese de doutorado \\ apresentada ao Instituto de Física \\ da Universidade de São Paulo \\ para a obtenção do título de Doutor \\ em Ciências.
}

Comissão examinadora:

Profa. Dra. Vera Bohomoletz Henriques (IFUSP)

Prof. Dr. Carlos Seihiti Orii Yokoi (IFUSP)

Prof. Dr. Jürgen Fritz Stilck (UFF)

Profa. Dra. Márcia Cristina Bernardes Barbosa (UFRGS)

Prof. Dr. Mário Noboru Tamashiro (UNICAMP)

São Paulo 
FICHA CATALOGRÁFICA

Preparada pelo Serviço de Biblioteca e Informação do Instituto de Física da Universidade de São Paulo

Barbosa, Marco Aurélio Alves

Termodinâmica da água e dobramento de proteínas:

estudo de modelos em rede - São Paulo - 2008

Tese (Doutorado) - Universidade de São Paulo.

Instituto de Física - Depto. de Física Geral

Orientador: Profa. Dra. Vera Bohomoletz Henriques

Área de Concentração: Física

Unitermos: 1. Mecânica estatística; 2. Física do estado

líquido; 3. Fluídos complexos.

USP/IF/SBI-071/2008 


\section{Sumário}

Prefácio $\quad$ V

Agradecimentos vii

Resumo ix

1 Água - Termodinâmica e Modelos Estatísticos 1

1.1 Cenários termodinâmicos da água . . . . . . . . . . . . . . . . . . . 2

1.2 Estrutura da água e ligação de hidrogênio . . . . . . . . . . . . . 5

1.3 Modelos de água em rede . . . . . . . . . . . . . . . . . . 6

2 O Modelo Bell-Lavis 11

2.1 Hamiltoniano efetivo . . . . . . . . . . . . . . . . . 11

2.2 Comparação com o modelo Blume-Emery-Griffiths antiferromagnético . . . 14

2.3 Estado fundamental . . . . . . . . . . . . . . . . . . . . . . . 17

2.4 Histórico do modelo . . . . . . . . . . . . . . . . . . . . . . . . 20

3 Rede de Bethe para o Modelo Bell-Lavis 23

3.1 Árvores hierárquicas simétricas e seqüenciais . . . . . . . . . . . . . . . . 24

3.2 Sistemas frustrados: modelo de Ising antiferromagnético . . . . . . . . . 26

3.3 Hamiltoniano de spin-1 no cacto de Husimi seqüencial . . . . . . . . . . . . 34

3.3.1 Prescrição de Gujrati para a energia livre . . . . . . . . . . . . . . 36

3.3.2 Valores médios no interior do cacto . . . . . . . . . . . . . 38

3.3.3 Funções termodinâmicas de resposta . . . . . . . . . . . . . . . . . 40

4 Resultados e Discussão $\quad 43$

4.1 Diagramas de fase e propriedades termodinâmicas . . . . . . . . . . . . 43

$4.1 .1 \quad \mathrm{O}$ caso $\zeta=1 / 4 \ldots \ldots \ldots \ldots$. . . . . . . . . . . . 47

4.2 Discussão . . . . . . . . . . . . . . . . . . . . . . . . . . . . . . . . 49

4.2 .1 Coexistência líquido-líquido . . . . . . . . . . . . . . . 52

4.2.2 Propriedades anômalas do líquido de alta densidade . . . . . . . . . 53 
4.2 .3 Frustração . . . . . . . . . . . . . . . . . . . . . 57

5 Efeito Hidrofóbico $\quad 59$

5.1 Termodinâmica de solvatação: conceitos básicos . . . . . . . . . . . . . 60

5.2 O modelo Bell-Lavis para solvente com soluto apolar . . . . . . . . . . 63

5.2 .1 Hamiltoniano efetivo . . . . . . . . . . . . . . 63

5.2 .2 Aproximação de Bethe . . . . . . . . . . . . . . 64

5.2 .3 Solubilidade . . . . . . . . . . . . . . . 66

5.2 .4 Função de correlação de pares . . . . . . . . . . . . . . . . 69

5.2.5 Técnica da Matriz de Transferência - funções de correlação . . . . . 70

6 Modelos de Água: Conclusões $\quad 83$

7 Enovelamento de Proteínas $\quad 85$

7.1 Introdução . . . . . . . . . . . . . . . . . . 85

7.2 Cooperatividade calorimétrica: conceitos básicos . . . . . . . . . . . 89

7.3 Paralelo com a transição de fase de primeira ordem . . . . . . . . . . . . 94

7.4 O modelo de polímero estendido em rede . . . . . . . . . . . . . . . . 99

7.4.1 Pontes de hidrogênio em um modelo de proteínas . . . . . . . . . . 99

7.4.2 Pontes de hidrogênio e cooperatividade em um homopolipeptídio

hidrofóbico em rede . . . . . . . . . . . . . . . . . 105

7.5 Conclusões . . . . . . . . . . . . . . . . . . . . 113

A Independência da Escolha do Percurso na Função de Correlação de Pares

$\begin{array}{ll}\text { Referências Bibliográficas } & 117\end{array}$

$\begin{array}{ll}\text { Lista de Figuras } & 125\end{array}$

$\begin{array}{ll}\text { Lista de Tabelas } & 128\end{array}$

Anexo I: Frustration and anomalous behavior in the Bell-Lavis model of liquid water 131

Anexo II: Alternative hydrogen bond implementations produce opposite effects on collapse cooperativity of lattice homopolypeptide models 133

Anexo III: Entropic reduction effect imposed by hydrogen bond formation on folding 


\section{Prefácio}

Neste trabalho realizamos dois estudos independentes sobre a termodinâmica de modelos de água e o dobramento de proteínas em rede. Embora a intenção original tenha sido alcançar um ponto de convergência entre os dois trabalhos, a extensão e a complexidade destes dois temas não permitiram, neste momento, uma descrição unificada da água e do dobramento através de modelos minimalistas em rede.

A parte deste trabalho relacionada à termodinâmica da água tem sua origem no estudo da água quadrada [1, 2], que é essencialmente uma versão do modelo do gelo [3], generalizado com a inclusão de buracos. Estes estudos levaram a profa. Vera Henriques a desenvolver dois modelos: i) um gás de rede orientacional, com braços doadores e receptores de elétron, na rede triangular [4] e, numa tentativa de simplificar este último, ii) um modelo de água com apenas três braços ligantes e sem distinção de doadores e receptores, que é o modelo de água estudado nesta tese.

Seguindo a abordagem adotada no estudo da água quadrada [2], investigamos este modelo de água na árvore de Cayley, sem sucesso. Em seguida utilizamos o cáctus de Husimi simétrico, sem distinção de sub-redes, e obtivemos uma série de resultados mostrando que o modelo apresentava várias das propriedades da água na fase líquida. Apesar dos resultados encorajadores, descobrimos, em algum momento posterior, que este modelo também tinha sido proposto por G. M. Bell e D. A. Lavis $[5,6]^{1}$, e estudado com diferentes metodologias $[7,8,9,10,11]$. Diante desta descoberta fez-se necessário uma reflexão, que resultou em uma extensa revisão sobre as teorias e os modelos que procuraram descrever as propriedades da água na fase líquida. Então percebemos a necessidade de revisitar o modelo Bell-Lavis de água, face aos cenários propostos para descrever a termodinâmica da água e, além disso, que seria possível simplificar ainda mais o modelo ${ }^{2}$, retirando a

\footnotetext{
${ }^{1}$ De agora em diante denominaremos este modelo de Bell-Lavis.

${ }^{2}$ Até onde temos conhecimento, o modelo Bell-Lavis é o modelo de água mais simples já proposto em uma rede bidimensional.
} 
anisotropia da ligação de hidrogênio. Nesta tese, estes estudos correspondem aos capítulos de 1 a 4, e resultaram no artigo incluído como anexo I.

Também estudamos o efeito hidrofóbico no modelo Bell-Lavis, com a inclusão de um soluto apolar no limite de diluição infinita. Este trabalho está sendo realizado em colaboração com o prof. Benjamin Widom, do Departamento de Química da Universidade de Cornell, e os resultados preliminares, obtidos até o momento, estão descritos no capítulo 5.

A parte deste trabalho ligada ao dobramento de proteínas foi feita em colaboração com o prof. Antônio F. Pereira de Araújo, do Instituto de Biologia da Universidade de Brasília. Neste trabalho procuramos generalizar a função de energia hidrofóbica $[12,13$, 14] incluindo a ponte de hidrogênio. Estes estudos resultaram na publicação dos artigos incluídos como anexos II e III e estão brevemente descritos no capítulo 7. 


\section{Agradecimentos}

Este trabalho não teria sido possível sem o apoio de várias pessoas que estão ao meu lado. Gostaria de agradecer à minha família, ao meu pai e minha mãe, Marcos Barbosa e Mary Alves, por terem me ensinado a sonhar, e à Fernanda e Noaue Bittencourt, por serem tão especiais, companheiros, por me apoiarem, estarem presentes na minha vida e compreenderem os momentos difíceis em que estive escrevendo este trabalho.

Várias pessoas me guiaram e inspiraram ao longo deste percurso, mas duas foram particularmente especiais: a prof. Vera me ensinou, guiou e me deixou cheio de inspiração para indagar sobre o mundo, e o prof. Antônio Francisco me estimulou e ensinou a ter perseverança nos momentos mais difíceis. Agradeço muito por tudo que aprendi com ambos.

Certamente o ambiente do Grupo de Física Estatística contribuiu muito para o desenvolvimento deste trabalho. Gostaria de agradecer aos profs. Mário de Oliveira e Sílvio Salinas, e aos meus colegas Tiago Peixoto, Carlos Fiore e Eduardo do Carmo, pelas inúmeras discussões sobre física estatística.

Também quero agradecer ao prof. Benjamin Widom, da Universidade de Cornell, por todas as discussões sobre física, que tanto me inspiraram, e por ter me recebido com tanto carinho e respeito nas duas oportunidades em trabalhamos juntos.

A defesa desta tese foi extremamente proveitosa por ter permitido uma melhora significativa da qualidade deste trabalho mas, muito mais do que isso, também por ter sido um momento de discussão, sugestões, idéias e indicações de leituras que me serão muito úteis no futuro. A profa. Márcia Barbosa e o prof. Jürgen Stilck, com os quais também tive oportunidade de conversar em outras ocasiões e que me inspiraram muito com o seus trabalhos, me indicaram correções e referências muito úteis para este texto. Ao prof. Carlos Yokoi, agradeço todas as correções e sugestões mas, principalmente, por ter convencido a banca de que este trabalho deveria ser aprovado! Certamente o prof. Mário 
Tamashiro gastou muitas horas para fazer uma leitura cuidadosa e detalhada deste texto, que contribui muito para a melhoraria de sua qualidade (Mário, muito obrigado!). Não posso deixar de citar novamente minha orientadora, Vera Henriques, por ter me apoiado do início ao fim, mesmo nos momentos mais difíceis!

Nos momentos finais deste trabalho recebi um grande apoio de meu supervisor de pós-doutorado, o prof. Fernando Albuquerque de Oliveira da Universidade de Brasília. Sem esta ajuda, certamente eu não teria a tranqüilidade necessária para a defesa e para a correção deste manuscrito. Fernando, valeu!

Muitos contribuíram para tornar mais agradável o dia-a-dia no Instituto de Física: Dirce, Wilson, Francislene, Danilo, Evaldo, Marcus e todos os colegas com quem tive contato no IFUSP: obrigado pela atenção e pelos inúmeros momentos de descontração.

Por fim, gostaria de agradecer ao Fabiano Ribeiro, pela amizade, companheirismo, e inúmeras discussões sobre a vida e a ciência, regadas à cerveja, na Banca do Portão 1. Também a Luciano, Marina, Elisa, Ivone, Renata e Aldair, sem a presença de vocês, a minha vida entre São Paulo e Brasília ficaria bem mais difícil.

A todos vocês:

\section{Muito obrigado!}

Este trabalho foi financiado pela FAPESP, sob projeto de número 03/06026-0. 


\section{Resumo}

Nós reconsideramos o modelo Bell-Lavis de água e investigamos sua ligação com a versão isotrópica do modelo, o modelo de Blume-Emery-Griffiths antiferromagnético na rede triangular. O sistema foi estudado através de uma solução exata no interior do cacto de Husimi seqüencial. Mostramos que o estado fundamental dos dois modelos compartilham a mesma topologia e que as fases fluidas (gás e líquidos de baixa e alta densidade) podem ser mapeadas nas fases magnéticas (paramagnética, antiferromagnética e paramagnética densa, respectivamente). Os dois modelos apresentam uma coexistência entre líquidos e diversas anomalias termodinâmicas. Este resultado sugere que a anisotropia introduzida por variáveis orientacionais não é importante para o aparecimento da anomalia na densidade. Explicamos a presença das anomalias termodinâmicas através da frustração energética, uma característica comum aos dois modelos.

Além disso, investigamos as restrições conformacionais impostas pela formação da ligação de hidrogênio durante o dobramento de proteínas, através de simulações de Monte Carlo em um modelo hidrofóbico bidimensional. A enumeração completa de cadeias poliméricas com volume excluído em duas dimensões foi utilizada para investigar detalhadamente o efeito de implementações alternativas da ligação de hidrogênio sobre a cooperatividade do colapso homopolipeptídico. A cooperatividade calorimétrica aumenta dramaticamente quando a ligação de hidrogênio é acoplada à formação de contatos hidrofóbicos em modelos de heteropolipeptídios e homopolipeptídios. Nos dois casos, o aumento na cooperatividade está correlacionado ao aumento na convexidade da entropia microcanônica do sistema. Simulações em um modelo tridimensional também apresentaram um pequeno aumento na cooperatividade de um modelo hidrofóbico com 40 monômeros. Estes resultados sugerem que as ligações de hidrogênio são de fundamental importância para a cooperatividade de dobramento, mas que as ligações provavelmente estão acopladas à formação de contatos durante o colapso não-específico da cadeia polipeptídica. 


\section{Abstract}

We have reconsidered the Bell-Lavis model of liquid water and investigated its relation to its isotropic version, the antiferromagnetic Blume-Emery-Griffiths model on the triangular lattice. Our study was carried out by means of an exact solution on the sequential Husimi cactus. We show that the ground states of both models share the same topology and that fluid phases (gas and low- and high-density liquids) can be mapped onto magnetic phases (paramagnetic, antiferromagnetic, and dense paramagnetic, respectively). Both models present liquid-liquid coexistence and several thermodynamic anomalies. This result suggests that anisotropy introduced through orientational variables play no specific role in producing the density anomaly. We explain the presence of liquid anomalies throuth energetic frustration, a feature common to both models.

In addition to this, conformational restrictions imposed by hydrogen bond formation during protein folding are investigated by Monte Carlo simulations of a non-native-centric, two-dimensional, hydrophobic model. Complete enumeration of self-avoiding chains in two-dimensional lattices were also used to investigate in detail the effect of alternative implementations of backbone hydrogen bonds on the cooperativity of homopolypeptide collapse. The calorimetric cooperativity is found to increase dramatically when the hydrogen bond is coupled to the formation of hydrophobic contacts in heteropolypeptide and homopolypeptide models. The observed increase in folding cooperativity is found to be correlated to an increase in the convexity of the underlying microcanonical conformational entropy as a function of energy, in both cases. Simulations in three dimensions also display a slight increase in cooperativity for a hydrophobic model of 40 monomers. These results suggest that hydrogen bonds are of fundamental importance for folding cooperativity, but that hydrogen bonds are more likely to be coupled to the formation of contacts during the unspecific collapse of the polymer chain. 


\section{Capítulo 1}

\section{Água - Termodinâmica e Modelos}

\section{Estatísticos}

A água é um dos fluidos mais intrigantes na natureza devido à peculiaridade de suas propriedades como líquido e como solvente, a sua abundância relativa em nosso planeta e pela sua relevância para os processos ligados à vida na Terra [15]. Na fase líquida, possui várias propriedades termodinâmicas e dinâmicas que são reconhecidas como anômalas, no sentido de que possuem um comportamento diferente do que acontece com líquidos com peso molecular semelhante.

Em condições de temperatura e pressão ambiente o volume molecular, a capacidade térmica a pressão constante e a compressibilidade isotérmica apresentam mínimos em função da temperatura [16]. Na figura 1.1 o comportamento de algumas propriedades da água é comparado com o comportamento das mesmas propriedades em um líquido 'simples'. Certamente a mais conhecida destas propriedades é o aumento na densidade com a temperatura que ocorre à pressão ambiente. O ponto em que a densidade pára de aumentar com a temperatura, $4^{\circ} \mathrm{C}$ a pressão ambiente, é conhecido como a temperatura de máximo de densidade (TMD). A TMD varia com a pressão formando uma linha com inclinação negativa, no diagrama de fases temperatura vs. pressão, que entra na fase líquida metaestável em altas pressões [17].

A linha de coexistência da água líquida com o gelo (Ih) também é diferente da maioria das transições sólido-líquido porque ela apresenta inclinação negativa [16]. Esta inclinação negativa está relacionada ao fato de que o líquido é mais denso que o gelo, no ponto de fusão. Juntamente com a anomalia na densidade, isto é muito importante para a 

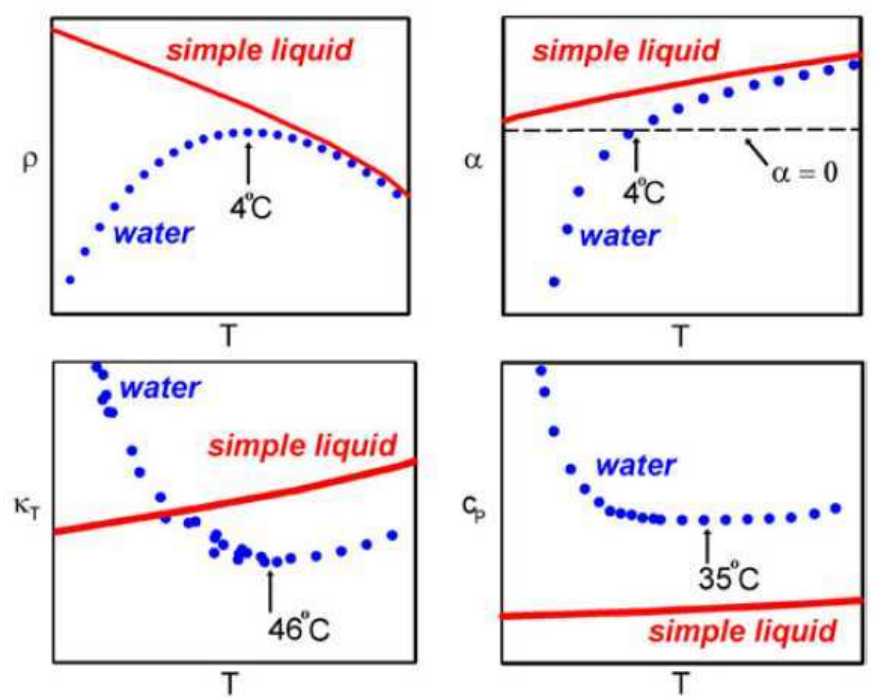

Figura 1.1: O comportamento da densidade, $\rho$, do coeficiente de expansão térmica, $\alpha$, da compressibilidade isotérmica, $\kappa_{T}$, e da capacidade térmica a pressão constante, $c_{P}$, são comparados para a água (pontos) e para um fluido simples (linha). A pressão ambiente a água apresenta um máximo em $\rho$ e mínimos em $\kappa_{T}$ e $c_{P}$. Retirado da ref. [17].

existência da vida por possibilitar que o gelo não se precipite no fundo do oceano quando a temperatura alcança valores abaixo de $0^{\circ} \mathrm{C}$ [15]. Caso estas duas propriedades não existissem, toda a água dos oceanos e rios teria sido congelada na primeira era glacial acabando, provavelmente, com a vida no planeta.

O comportamento anômalo da água se torna mais evidente quando a temperatura do líquido é diminuída em direção à região metaestável. No líquido super-resfriado a compressibilidade isotérmica, o calor específico a pressão constante e o coeficiente de expansão térmica aumentam em magnitude com a diminuição da temperatura, indicando que a origem das anomalias da água pode estar relacionada a alguma criticalidade na região metaestável [18, 17]. Outra ligação entre anomalias termodinâmicas e metaestabilidade se baseia no fato de que a linha de máximos de densidade encontra a coexistência com o gelo e persiste no líquido super-resfriado, adentrando aquela região com inclinação negativa, em pressões maiores do que $40 \mathrm{MPa}$ [19].

\subsection{Cenários termodinâmicos da água}

A primeira formulação teórica que considerou a possibilidade de alguma criticalidade no líquido super-resfriado foi a 'Conjectura do Limite de Estabilidade' (CLE), proposta 


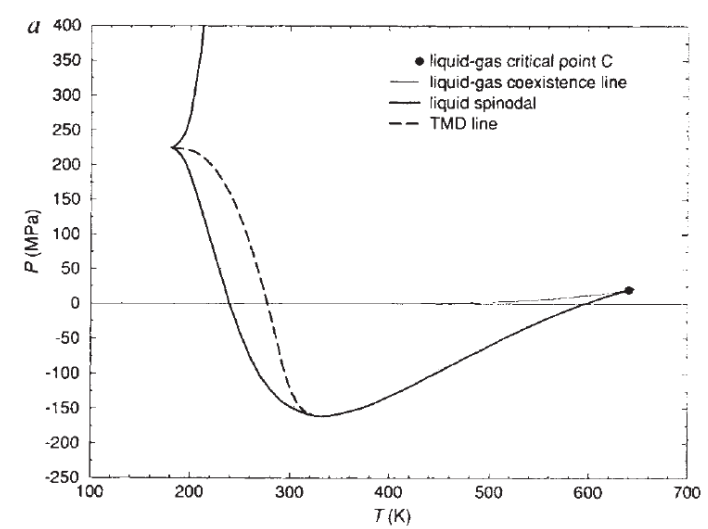

a

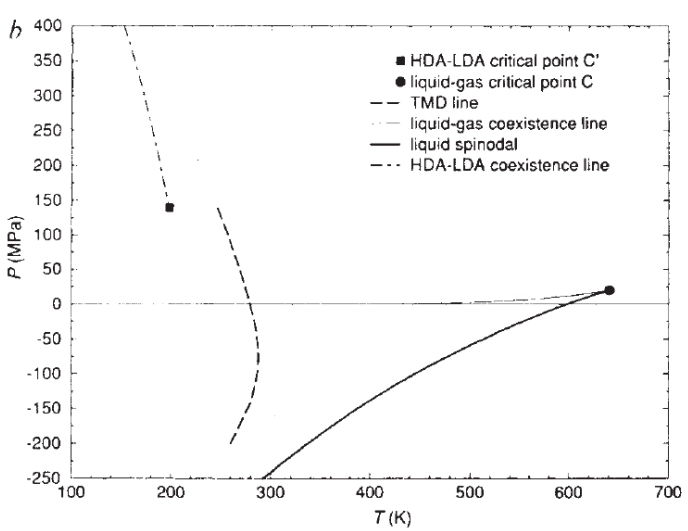

Figura 1.2: Cenários termodinâmicos que prevêem algum tipo de criticalidade na região metaestável da fase líquida da água: (a) conjectura do limite de estabilidade e (b) hipótese do segundo ponto crítico. Retirado da ref. [25].

por Speedy [20] há mais de vinte anos. Segundo a CLE, as anomalias termodinâmicas da água super-resfriada estão relacionadas à linha de limite de estabilidade do líquido, que parte do ponto crítico da coexistência gás-líquido e envolve as regiões com líquido super-aquecido, esticado e super-resfriado. Nesta conjectura, o formato da espinodal seria diferente na água porque existe uma relação termodinâmica que indica uma mudança de sinal na curvatura da espinodal quando há um encontro com a linha de máximos de densidade, em baixas temperaturas e pressões negativas. Isto faria com que a espinodal, em temperaturas baixas, se voltasse na direção de pressões mais altas, eventualmente adentrando na região do líquido super-resfriado, como ilustrado na figura 1.2 (a).

Recentemente foi argumentado que é impossível para o fluido ser instável a pequenas flutuações termodinâmicas e coexistir com outra fase em uma binodal [17, 21, 22]. Assim, o encontro de uma espinodal com uma binodal só poderia ocorrer em um ponto crítico, como no ponto crítico da coexistência líquido-gás. A inexistência de evidências experimentais para um segundo ponto crítico ao longo da linha de coexistência líquido-gás tornaria muito improvável o cenário proposto pela CLE. No entanto, a validade termodinâmica da CLE ainda precisa ser mais estudada, pois existem modelos que estão de acordo com este cenário [23, 24].

Em outro cenário termodinâmico para a água, que tem recebido muita atenção nos últimos anos, propõe-se a existência de um segundo ponto crítico no líquido superresfriado. Este segundo ponto crítico estaria relacionado à coexistência entre dois líquidos metaestáveis e, por estar localizada abaixo da temperatura de nucleação espontânea, 
não poderia ser observado experimentalmente. Proposto originalmente com simulações de dinâmica molecular do modelo realístico ST2 [25, 26], um segundo ponto crítico também foi encontrado em outros modelos de água com detalhe atômico, como os modelos TIP4P [27] e TIP5P [28]. Além disso, transições líquido-líquido também foram encontradas em simulações com modelos realísticos de $\mathrm{SiO}_{2}$ [29] e sílica [30, 31, 32], e existem evidências experimentais de que possam ocorrer em outros sistemas, como fósforo [33, 34] e fosfato de trifenil e n-butanol [35]. Também existem evidências de que uma transição entre duas fases amorfas da água [36, 37], assim como em outras substâncias [36, 37], pode estar relacionada à continuidade de uma transição líquido-líquido. Este cenário é ilustrado na fig. 1.2 (b).

Um cenário termodinâmico sem a existência de singularidades também foi proposto por Sastry e colaboradores [38, 39], baseado em um conjunto de equações termodinâmicas conectando o aumento em magnitude nas funções termodinâmicas de resposta à presença de uma linha de máximos de densidade com inclinação negativa, no diagrama de fases pressão vs. temperatura. Este cenário não exclui nenhuma possibilidade de criticalidade no líquido super-resfriado, e existem modelos que apresentam uma transição entre os cenários sem singularidade e com segundo ponto crítico [40, 41], dependendo de algum parâmetro do modelo.

Embora o cenário do segundo ponto crítico possua mais evidências experimentais que os outros cenários propostos para a água, ainda não existe, atualmente, consenso sobre o comportamento metaestável de sua fase líquida. Além das dificuldades experimentais, também contribuem para esta indefinição a existência de modelos condizendo com cada um dos cenários propostos [38, 39, 42, 23, 43], e questionamentos sobre a necessidade de um comportamento crítico para a existência das anomalias termodinâmicas típicas da água $[44,45]$. Nos modelos de Jagla [46, 47] e Franzese [40], por exemplo, as anomalias na densidade e na compressibilidade isotérmica precedem a formação de um ponto crítico, no sentido de que as anomalias estão presentes para um determinado conjunto de parâmetros do modelo, e um segundo ponto crítico passa a existir, em baixas temperaturas e na mesma região em que ‘surgem' as anomalias, quando uma interação extra é inserida nestes modelos. No modelo de Jagla esta interação extra é uma energia atrativa proporcional à densidade do sistema e no modelo de Franzese se trata de uma correlação intermolecular entre as pontes de hidrogênio. 


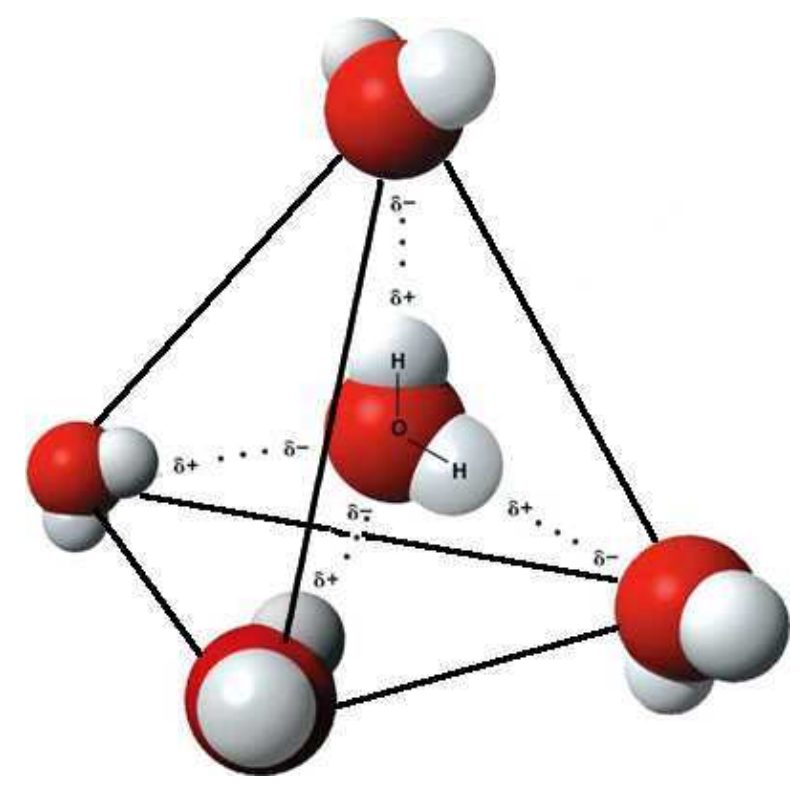

Figura 1.3: Molécula de água formando ligações de hidrogênio com quatro moléculas vizinhas. A estrutura tetraédrica da distribuição de cargas da molécula e, consequentemente, da rede de pontes de hidrogênio, é enfatizada. Adaptado a partir de uma figura do site: http://en.wikipedia.org/wiki/Light_water (Acessado em junho de 2008).

\subsection{Estrutura da água e ligação de hidrogênio}

A molécula de água possui duas ligações covalentes e, na fase gasosa, estas ligações fazem um ângulo de aproximadamente $104^{\circ} \mathrm{com}$ os átomos de oxigênio e hidrogênio separados por uma distância de aproximadamente 0,0985 nm. Devido à eletronegatividade do oxigênio, esta geometria induz uma distribuição eletrostática tetraédrica na molécula de água, com os átomos de hidrogênio (que são mais eletropositivos) formando um plano com o átomo de oxigênio, que por sua vez possui dois orbitais eletrônicos fora deste plano, em lados opostos numa direção contrária à dos átomos de hidrogênio. Esta distribução tetraédrica é ilustrada na figura 1.3.

Apesar da ausência de consenso sobre o cenário termodinâmico ligado às anomalias da água, as ligações de hidrogênio são geralmente tidas como responsáveis por este comportamento. Em condições ambientes de pressão, as pontes de hidrogênio criam uma estrutura tetraédrica preenchida por ligações de pontes de hidrogênio, no gelo Ih, que é menos densa do que a fase líquida. Como o calor latente de fusão não é suficiente para quebrar todas as pontes, estas estruturas são parcialmente preservadas no líquido. Ao mesmo tempo, a existência de uma 'estrutura líquida normal', que é menos ligada e mais densa que o gelo Ih, cria uma competição de energia livre entre diferentes estruturas líquidas que resulta 
na anomalia na densidade [48].

Embora esta visão qualitativa do que ocorre na água seja bem aceita, os detalhes de como ocorre este processo, e os mecanismos moleculares que resultam neste tipo de comportamento, são passíveis de discussão. Como veremos a seguir, vários modelos diferentes foram utilizados para entender os comportamentos anômalos da água líquida.

\subsection{Modelos de água em rede}

Vários tipos de interação foram utilizados para implementar a descrição feita acima em modelos estatísticos de água. Estes modelos, que reproduzem a anomalia na densidade e outras propriedades da água, podem ser classificados em duas grandes categorias: isotrópicos e orientacionais. Nos dois grupos encontramos representações no contínuo e representações em rede, estas últimas mais fáceis de serem estudadas analiticamente e com simulações.

Modelos com núcleo amaciado no contínuo e em rede, assim como modelos em rede com variáveis de Potts com volume variável, pertencem ao primeiro grupo. O ingrediente relevante dos modelos com núcleo amaciado é a presença de duas distâncias características: o comprimento da interação atrativa e o comprimento da região repulsiva, além do núcleo duro $[49,50,51,52,53,54,55]$. Alguns destes modelos não possuem interação atrativa, mas mesmo assim apresentam algumas das anomalias da água $[47,46,56]$. A interpretação usual para o comportamento destes modelos é que a presença de duas escalas cria uma competição entre as estruturas fluidas com diferentes densidades. Desta competição surgiria a anomalia na densidade. Alguns poucos modelos com núcleo amaciado em rede foram implementados com interações de primeiros e segundos vizinhos, em 1D [57, 49] e em 2D [58]. Os modelos com núcleo amaciado podem apresentar anomalia na densidade e nas funções resposta e/ou transições líquido-líquido, dependendo da forma da parte repulsiva do potencial e da presença de interações atrativas.

Um modelo estatístico diferente destes modelos, mas ainda isotrópico, foi proposto por Sastry e colaboradores: as partículas são representadas por variáveis de Potts com ligações isotrópicas, que estão acopladas a uma variação ad hoc do volume molecular [38, 39]. Este modelo foi utilizado como um exemplo da CLE. Uma variante deste modelo foi proposta por Franzese e colaboradores [40, 41], em que uma correlação intramolecular entre as pontes de hidrogênio é inserida para representar a anisotropia das pontes de hidrogênio. 
Com isto foi possível mostrar que, neste modelo, a anisotropia da ponte de hidrogênio possibilita o aparecimento de uma transição líquido-líquido, que desaparece no limite isotrópico com o ponto crítico tendendo a temperatura nula.

O segundo grupo de modelos enfatiza o caráter orientacional da ligação de hidrogênio, que há muito tempo tem sido reconhecida como responsável pelas anomalias da água. No modelo bidimensional Mercedez-Benz [59], no espaço contínuo, as moléculas de água são representadas por partículas com três braços ligantes, sem distinção entre doadores e receptores de hidrogênio, e tanto as anomalias da água quanto uma transição líquidolíquido puderam ser encontradas, em várias aproximações diferentes [60, 61, 62, 63].

Um modelo em rede proposto muito antes por Bell e Lavis $[5,6]$ pode ser considerado uma versão discreta do modelo Mercedez-Benz. Diferentemente dos modelos isotrópicos de rede, este modelo permite variações explícitas de volume, relacionadas a uma estrutura líquida com o número máximo de pontes de hidrogênio por molécula. O modelo de Bell e Lavis (BL) foi investigado em vários trabalhos [7, 10, 11], e apresentou anomalias na densidade e nas funções termodinâmicas de resposta. Como o modelo Bell-Lavis é o principal objeto de estudo desta tese deixaremos uma discussão mais detalhada sobre o seu histórico para o final do capítulo 2. Um gás de rede orientacional em três dimensões também foi proposto por Bell e colaboradores, sendo estudado com soluções aproximadas de primeira ordem [64, 65]. Além da dimensionalidade, este modelo difere do modelo de Bell-Lavis $[5,6]$ pela distinção entre doadores e receptores e pelo uso de uma interação repulsiva de três corpos para desestabilizar uma fase densa e com o número máximo de pontes de hidrogênio em cada partícula. Posteriormente, este modelo foi estudado com o Método de Monte Carlo [66] e uma versão simplificada, sem distinção de doadores e receptores, foi investigada com o Grupo de Renormalização no Espaço Real [67].

Dois modelos criados posteriormente podem ser vistos como variações do modelo em 3D discutido acima. O modelo proposto por Besseling e Lyklema [68] utiliza apenas interações de dois corpos, mas inclui uma interação de van der Waals repulsiva para desestabilizar o estado denso. Este modelo foi descrito em uma aproximação conhecida como quasi-química (equivalente à aproximação de Bethe) e apresentou anomalia na densidade, bem como propriedades de solvatação e de interface vapor-água comparáveis com dados experimentais da água [68, 69]. Recentemente, uma versão deste modelo sem distinção de doadores e receptores foi investigada por Girardi e colaboradores com simulações de 
Monte Carlo [70], e utilizada para estudar a relação entre as anomalias na densidade e na difusão [71]. Apesar deste modelo ter-se mostrado promissor, resultados mais recentes, obtidos com o Método Variacional de Cluster e simulações de Monte Carlo, mostraram que os dois pontos críticos deste modelo são na verdade dois pontos tricríticos, conectados por uma transição de fase de segunda ordem que separa as fases de baixa densidade e alta densidade [72]. Além disso, mostrou-se que a fase gasosa também é separada da fase de alta densidade por uma transição de fase de segunda ordem. Embora este resultado mostre que o diagrama de fases do modelo é muito mais rico do que originalmente suposto, ele invalida o seu uso para a descrição da água.

O modelo proposto por Roberts e Debenedetti, que também pode ser visto como uma generalização do modelo de Bell [64], adiciona um conjunto $q$ de estados à molécula de água para permitir uma maior entropia aos estados não ligados e inclui uma diminuição na energia de uma ponte de hidrogênio quando uma terceira molécula se aproxima do par ligante $[73,74]$. Este modelo foi utilizado para investigar uma possível ligação entre as anomalias da densidade e um segundo ponto crítico na fase líquida metaestável da água, sendo favorável à existência de um segundo ponto crítico.

Um gás de rede orientacional, bidimensional, com interação de van der Waals e distinção entre doadores e receptores na ligação de hidrogênio, adaptado do modelo do gelo para permitir variações explícitas de volume, foi utilizado para investigar a relação entre a transição de fase líquido-líquido e a anomalia na densidade [4]. Foi notado neste modelo que a inclusão de uma degenerescência para os estados não ligados, e a exclusão da distinção entre doadores e receptores alteram as propriedades termodinâmicas do modelo apenas de forma quantitativa [75]. Este modelo também foi utilizado para investigar a ligação entre as anomalias na difusão e na densidade [76]. Contudo, simulações de Monte Carlo mais recentes mostraram que este modelo também apresenta uma transição de fase de segunda ordem conectando os pontos críticos das transições líquido-líquido e líquidogás [77]. Eventualmente existe algum conjunto de parâmetros para o qual a transição líquido-gás volte a existir, mas esta é uma possibilidade que ainda precisa ser investigada.

Embora todos os modelos isotrópicos e orientacionais em rede discutidos acima apresentem algumas das anomalias típicas da água líquida, vários destes modelos possuem elementos incluídos ad hoc, e que levam as partículas do sistema a possuírem características intrínsecas que forçam o aparecimento da anomalia na densidade [78, 38, 39, 40, 41, 23, 
43, 73]. Em alguns casos, um estado líquido mais denso é energeticamente desestabilizado com uma interação de três corpos $[64,65,73,23,43]$ ou com uma interação de van der Waals ligeiramente repulsiva $[4,68,70]$. Em outros modelos, um número adicional de $q$ estados não-ligados é atribuído a cada molécula de água, para forçar um aumento na entropia de uma fase líquida desordenada e menos ligada [73, 23, 43, 78, 38, 39, 40, 41].

Como mencionamos anteriormente, em alguns casos uma densidade local menor é associada às partículas que formam pontes de hidrogênio [38, 39, 40, 41]. Neste último exemplo, um vício de modelagem pode ser notado claramente: a existência de um estado de baixa densidade é forçada, no estado fundamental, já que a ligação de hidrogênio é mais forte do que as outras interações.

Devido à complexidade inerente a alguns modelos, torna-se difícil associar propriedades termodinâmicas similares às da água a uma determinada interação ou geometria utilizada para representar as moléculas. Por este motivo, acreditamos que um programa interessante para o estudo da água seja a investigação de modelos extremamente simples, com estrutura molecular clara e com poucos parâmetros, que permitam uma análise detalhada do diagrama de fases e do estado fundamental.

\section{O modelo Bell-Lavis de água}

Nesta tese damos um passo adicional no sentido de encontrar os requisitos mínimos para um modelo de água em rede. Realizamos uma análise detalhada do modelo BellLavis (BL), que é o modelo em rede de fluido ligante mais simples que conhecemos, e o comparamos com a sua versão isotrópica, um antiferromagneto frustrado.

Reconsideramos o modelo BL fazendo uma análise do seu estado fundamental e de seus diagramas de fase para várias razões entre a interação de van der Waals e da ligação de hidrogênio. Além disso, consideramos uma versão simplificada do modelo, retirando do seu Hamiltoniano o termo que introduz a anisotropia das pontes de hidrogênio. Com estas mudanças, obtemos o modelo de spin-1 antiferromagnético de Blume-Emery-Griffiths (BEG) na rede triangular [79, 80]. Várias semelhanças foram encontradas entre os modelos Bell-Lavis e Blume-Emery-Griffiths, particularmente no que diz respeito ao estado fundamental e à localização da anomalia na densidade.

Estes dois modelos foram estudados na rede de Bethe [81], que foi obtida em sua versão recursiva através do cáctus de Husimi seqüencial [82]. Esta metodologia é apropriada para 
o tratamento de sistemas frustrados e será discutida de forma detalhada no capítulo 3. Discussões adicionais sobre a descrição de sistemas frustrados em árvores hierárquicas podem ser encontradas nos artigos [82,83].

Em nossa análise verificamos que tanto o modelo BL quanto o modelo BEG possuem frustração energética e que, além disso, esta propriedade é responsável pelo aparecimento da anomalia na densidade nos dois casos. Isto ocorre porque a frustração possibilita o aparecimento de duas estruturas que competem entre si dentro da fase líquida em que ocorre as anomalias. De acordo com nossa interpretação, que é válida para os modelos BL e BEG e está discutida em detalhe no capítulo 4, a TMD é o ponto intermediário de uma 'transição' entre estas duas estruturas líquidas.

Esta tese é organizada da seguinte maneira. No capítulo 2 introduzimos o modelo, estudamos o seu Hamiltoniano e uma comparação é feita com o modelo de Blume-EmeryGriffiths antiferromagnético. No capítulo 3 apresentamos a rede de Bethe, discutimos a descrição de sistemas frustrados tendo o modelo de Ising antiferromagnético na rede triangular como exemplo, obtemos as equações que descrevem um modelo de spin-1 e calculamos algumas propriedades extensivas e intensivas. No capítulo 4 comparamos os diagramas de fase, as propriedades estruturais e as funções termodinâmicas de resposta nos dois modelos; estes resultados também são interpretados neste capítulo. No capítulo 5 , apresentamos o cálculo de duas quantidades ligadas ao efeito hidrofóbico no modelo: a energia livre de solvatação e a função de correlação entre moléculas de soluto. Estes resultados são preliminares e investigações adicionais encontram-se em andamento sobre o tema. Uma conclusão sobre a parte deste trabalho relacionada à termodinâmica da água é apresentada no capítulo 6 e no capítulo 7 discutimos dois trabalhos na área de dobramento de proteínas, feitos em colaboração com o co-orientador desta tese. 


\section{Capítulo 2}

\section{O Modelo Bell-Lavis}

O modelo Bell-Lavis de água foi proposto há quase 40 anos [5, 6] com o intuito de reproduzir o comportamento anômalo observado na fase líquida da água. Este modelo foi estudado com vários métodos analíticos, ao longo da década de 1970, incluindo soluções aproximadas $[6,7]$ (compatíveis com a rede de Bethe), técnica de matriz de transferência [9] e grupo de renormalização no espaço real $[10,11]$.

Neste capítulo, iremos apresentar o modelo com enfoque na construção do Hamiltoniano em uma linguagem de spin-1 e na comparação com o modelo Blume-EmeryGriffiths[79]. Também analisaremos o estado fundamental, deixando para o final uma revisão dos trabalhos feitos por G. M. Bell, D. A. Lavis e colaboradores sobre este modelo.

\subsection{Hamiltoniano efetivo}

O modelo Bell-Lavis (BL) é definido em uma rede triangular cujos vértices podem ser ocupados por uma molécula ou estarem vazios[6]. Cada molécula possui três braços ligantes separados $120^{\circ}$ e duas configurações diferentes, ilustradas na figura 2.1. A descrição energética do modelo é simples e inclui apenas termos que mimetizam as interações de van der Waals e as ligações de hidrogênio entre moléculas vizinhas. As ligações de hidrogênio dependem de orientações moleculares específicas e ocorrem apenas quando os braços ligantes de duas moléculas vizinhas apontam um para o outro. A figura 2.1 (c) mostra dois exemplos de moléculas em que as ligações de hidrogênio (a) ocorrem e (b) não ocorrem. O modelo também pode ser visto como uma versão discreta do modelo Mercedez-Benz, utilizado pelo grupo de Ken A. Dill para estudar o comportamento anômalo da fase líquida 
a)

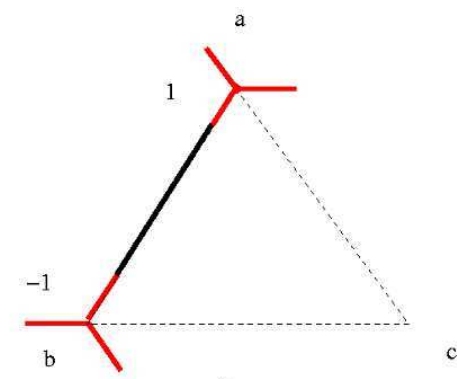

b)

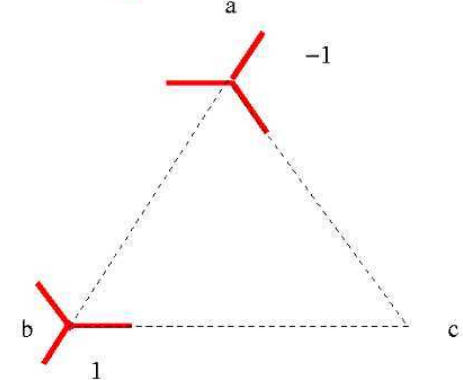

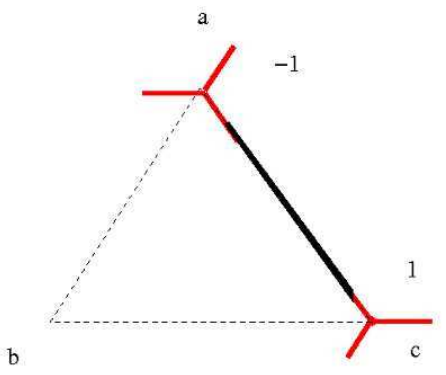
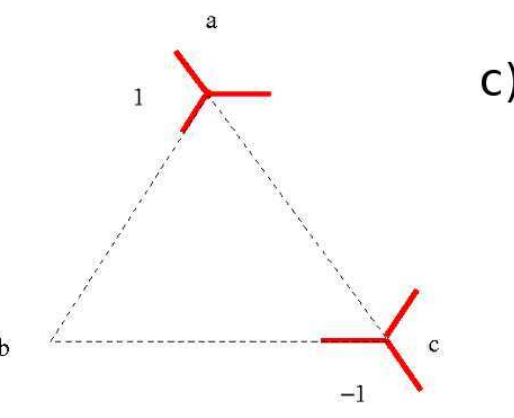

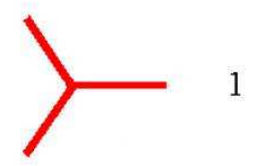

c)

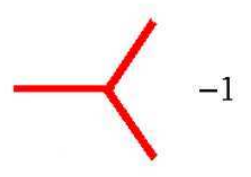

Figura 2.1: Interações no modelo Bell-Lavis de água. (a) Moléculas de água formando uma ligação de hidrogênio com uma energia de interação do par $-\left(\epsilon_{\mathrm{vdw}}+\epsilon_{\mathrm{hb}}\right)$ e (b) moléculas interagindo apenas pela atração de van der Waals, com uma energia de interação do par $-\epsilon_{\mathrm{vdw}}$. (c) Estados da molécula de água e os valores correspondentes na representação de spin.

da água [60] e o efeito hidrofóbico[59].

Os estados de uma molécula podem ser representados por variáveis ocupacionais e orientacionais, $\theta_{i}$ e $\tau_{i}^{i j}$. $\theta_{i}$ indica a presença ou a ausência de uma partícula no sítio $i$ ( $\theta_{i}=1$ ou $\theta_{i}=0$, respectivamente) e $\tau_{i}^{i j}$ indica a presença ou a ausência de um braço ligante apontando do sítio $i$ para o sítio $j\left(\tau_{i}^{i j}=1\right.$ ou $\tau_{i}^{i j}=0$, respectivamente). Com estas definições, o Hamiltoniano efetivo do sistema, no ensemble grande canônico, pode ser escrito como

$$
\mathcal{H}_{\mathrm{BL}}=-\sum_{(i, j)} \theta_{i} \theta_{j}\left(\epsilon_{\mathrm{vdW}}+\epsilon_{\mathrm{hb}} \tau_{i}^{i j} \tau_{j}^{j i}\right)-\mu \sum_{i} \theta_{i}
$$

onde $\epsilon_{\mathrm{vdW}}$ se refere à magnitude da interação de van der Waals, $\epsilon_{\mathrm{hb}}>0$ à magnitude da ligação de hidrogênio, que é atrativa por definição, e $\mu$, ao potencial químico. A primeira soma é feita sobre todos os pares $(i, j)$ de primeiros vizinhos e a segunda, sobre todos os sítios $i$.

Este Hamiltoniano efetivo também pode ser escrito em uma representação de spin1 [10], que será útil por tornar evidente a relação entre os modelos BL e BEG. Para simplificar os cálculos, o Hamiltoniano efetivo do sistema pode ser subdividido entre os 
Tabela 2.1: Condições para a formação de ligações de hidrogênio entre moléculas vizinhas, de acordo com as figuras 2.1 (A)-(C). A primeira coluna foi repetida para enfatizar a simetria da ligação de hidrogênio.

\begin{tabular}{cccc}
\hline$S_{a}$ & $S_{b}$ & $S_{c}$ & $S_{a}$ \\
\hline \hline+ & - & & + \\
& + & - & \\
- & & + & - \\
\hline
\end{tabular}

triângulos da rede da seguinte forma:

$$
\begin{aligned}
\mathcal{H}_{\mathrm{BL}} & =\frac{1}{2} \sum h_{\mathrm{BL}}, \\
& =\frac{1}{2} \sum\left(h_{\mathrm{vdW}}+h_{\mathrm{hb}}+h_{\mu}\right),
\end{aligned}
$$

onde a soma é sobre todos os triângulos da rede e o fator $1 / 2$ evita a dupla contagem das ligações em triângulos adjacentes. Na eq. (2.2) nós separamos as contribuições das interações de van der Waals, ligações de hidrogênio e do potencial químico, representadas pelos termos $h_{\mathrm{vdw}}, h_{\mathrm{hb}}$ e $h_{\mu}$.

Para escrever estes termos em uma representação de spin supomos que o estado de cada sítio $k$, em um triângulo, é representado por um spin $S_{k}$ com valores inteiros para as diferentes orientações moleculares e 0 para um buraco, como na fig. 2.1. Como será mostrado posteriormente, é necessário o uso de três sub-redes - $a, b$ e $c$ - para distinguir entres os estados possíveis. Dadas estas definições, os termos da interação de van der Waals e potencial químico na eq. (2.2) podem ser escritos como:

$$
h_{\mathrm{vdw}}=-\epsilon_{\mathrm{vdw}}\left(S_{a}^{2} S_{b}^{2}+S_{b}^{2} S_{c}^{2}+S_{c}^{2} S_{a}^{2}\right)
$$

e

$$
h_{\mu}=-\frac{\mu}{3}\left(S_{a}^{2}+S_{b}^{2}+S_{c}^{2}\right) .
$$

Perceba que cada sítio é compartilhado por 6 triângulos e que, por isso, o fator $1 / 3$ foi utilizado para absorver a contribuição do potencial químico em um único triângulo na eq. (2.2).

Já para obter o termo da ligação de hidrogênio vamos notar que nem todas as moléculas vizinhas com orientações distintas satisfazem uma ligação de hidrogênio. A tabela 2.1 mostra os estados compatíveis com a formação de ligações entre as diferentes sub-redes, usando os estados moleculares e as sub-redes definidas nas figuras 2.1 (A)-(C). Vamos 
definir os projetores de spin

$$
P_{ \pm}\left(S_{k}\right)=\frac{1}{2}\left(S_{k}^{2} \pm S_{k}\right)
$$

que resultam em 1 , se o spin $S_{k}$ é igual ao índice sub-escrito do projetor, ou 0 se diferente. Usando estes projetores e a tabela 2.1 o termo $h_{\mathrm{hb}}$ fica dado por

$$
\begin{aligned}
h_{\mathrm{hb}}= & -\epsilon_{\mathrm{hb}}\left[P_{-}\left(S_{a}\right) P_{+}\left(S_{b}\right)+P_{-}\left(S_{b}\right) P_{+}\left(S_{c}\right)\right. \\
& \left.+P_{-}\left(S_{c}\right) P_{+}\left(S_{a}\right)\right] .
\end{aligned}
$$

Utilizando as equações (2.3)-(2.4) e reagrupando os termos por ordem de acoplamento de spin, obtemos o seguinte Hamiltoniano efetivo:

$$
\begin{aligned}
h_{\mathrm{BL}}= & \frac{\epsilon_{\mathrm{hb}}}{4}\left(S_{a} S_{b}+S_{b} S_{c}+S_{c} S_{a}\right) \\
& -\left(\epsilon_{\mathrm{vdW}}+\frac{\epsilon_{\mathrm{hb}}}{4}\right)\left(S_{a}^{2} S_{b}^{2}+S_{b}^{2} S_{c}^{2}+S_{c}^{2} S_{a}^{2}\right) \\
& -\frac{\mu}{3}\left(S_{a}^{2}+S_{b}^{2}+S_{c}^{2}\right) \\
& -\frac{\epsilon_{\mathrm{hb}}}{4}\left(S_{a}-S_{b}\right)\left(S_{b}-S_{c}\right)\left(S_{c}-S_{a}\right) .
\end{aligned}
$$

\subsection{Comparação com o modelo Blume-Emery-Griffiths antifer- romagnético}

Como indicado por Young e Lavis [10], o Hamiltoniano da eq. (2.7) é obtido adicionando uma interação anisotrópica, dada por

$$
h_{\mathrm{ANI}}=-\frac{\epsilon_{\mathrm{hb}}}{4}\left(S_{a}-S_{b}\right)\left(S_{b}-S_{c}\right)\left(S_{c}-S_{a}\right) .
$$

ao Hamiltoniano do modelo BEG [79] na rede triangular, que é dado por

$$
h_{\mathrm{BEG}}=-J\left(S_{a} S_{b}+S_{b} S_{c}+S_{c} S_{a}\right)-K\left(S_{a}^{2} S_{b}^{2}+S_{b}^{2} S_{c}^{2}+S_{c}^{2} S_{a}^{2}\right)+\frac{\Delta}{3}\left(S_{a}^{2}+S_{b}^{2}+S_{c}^{2}\right) .
$$

Os parâmetros do Hamiltoniano BEG estão ligados aos parâmetros do fluido, no modelo BL, através das seguintes relações

$$
\begin{aligned}
J & =-\frac{\epsilon_{\mathrm{hb}}}{4}<0, \\
K & =\epsilon_{\mathrm{vdw}}+\frac{\epsilon_{\mathrm{hb}}}{4}, \\
\Delta & =-\mu .
\end{aligned}
$$

Podemos perceber que a eq. (2.10a) conecta as ligações de hidrogênio no modelo BL ao antiferromagnetismo, visto que $J=-\epsilon_{\mathrm{hb}} / 4<0$. No modelo de Ising antiferromagnético 
este tipo de interação faz com que haja uma frustração energética que impossibilita, na rede triangular, a realização simultânea de todas as interações antiferromagnéticas entre as ligações da rede [84]. Neste modelo esta interação impossibilita a existência de uma transição ferromagnético-paramagnética, a campo nulo, como foi mostrado por Wannier em uma solução exata [84, 85]. Já para o modelo BL, a frustração é muito importante por impedir que ocorram ligações de hidrogênio entre os sítios de cada triângulo na rede. Esta restrição permite o surgimento de um máximo de densidade, como será discutido em detalhe na seção 4.2 ..

Para permitir uma comparação entre o modelo BL e o modelo de BEG antiferromagnético definimos o seguinte Hamiltoniano interpolador:

$$
h_{\mathrm{I}}(\lambda)=h_{\mathrm{BEG}}+\lambda h_{\mathrm{ANI}},
$$

que reproduz os Hamiltonianos BEG ou BL, quando se assume $\lambda$ igual a 0 ou 1, respectivamente $^{1}$.

Além disso, será conveniente definir dois parâmetros interpoladores: o parâmetro de interação

$$
\zeta(\lambda)=\frac{K-\lambda|J|}{(1+3 \lambda)|J|}
$$

e o potencial químico reduzido

$$
\mu^{*}(\lambda)=-\frac{\Delta}{(1+3 \lambda)|J|}
$$

com $J$ e $K$ definidos como nas eqs. (2.10). Assim, para o modelo BL teremos $\zeta(1)=$ $\epsilon_{\mathrm{vdw}} / \epsilon_{\mathrm{hb}}$ e $\mu^{*}(1)=\mu / \epsilon_{\mathrm{hb}}$, enquanto para o modelo BEG as eqs. (2.12) e (2.13) levam a $\zeta(0)=K /|J|$ e $\mu^{*}(0)=-\Delta /|J|$. Como estes parâmetros foram escolhidos para descrever univocamente os estados fundamentais dos dois modelos, a dependência em $\lambda$ de $\zeta(\lambda)$ e $\mu^{*}(\lambda)$ será deixada implícita. De agora em diante, toda referência a $\zeta$ e $\mu^{*}$ implica no uso das eqs. (2.12) e (2.13), com $\lambda=1$ para a análise do modelo BL e $\lambda=0$ para a análise do modelo BEG. 


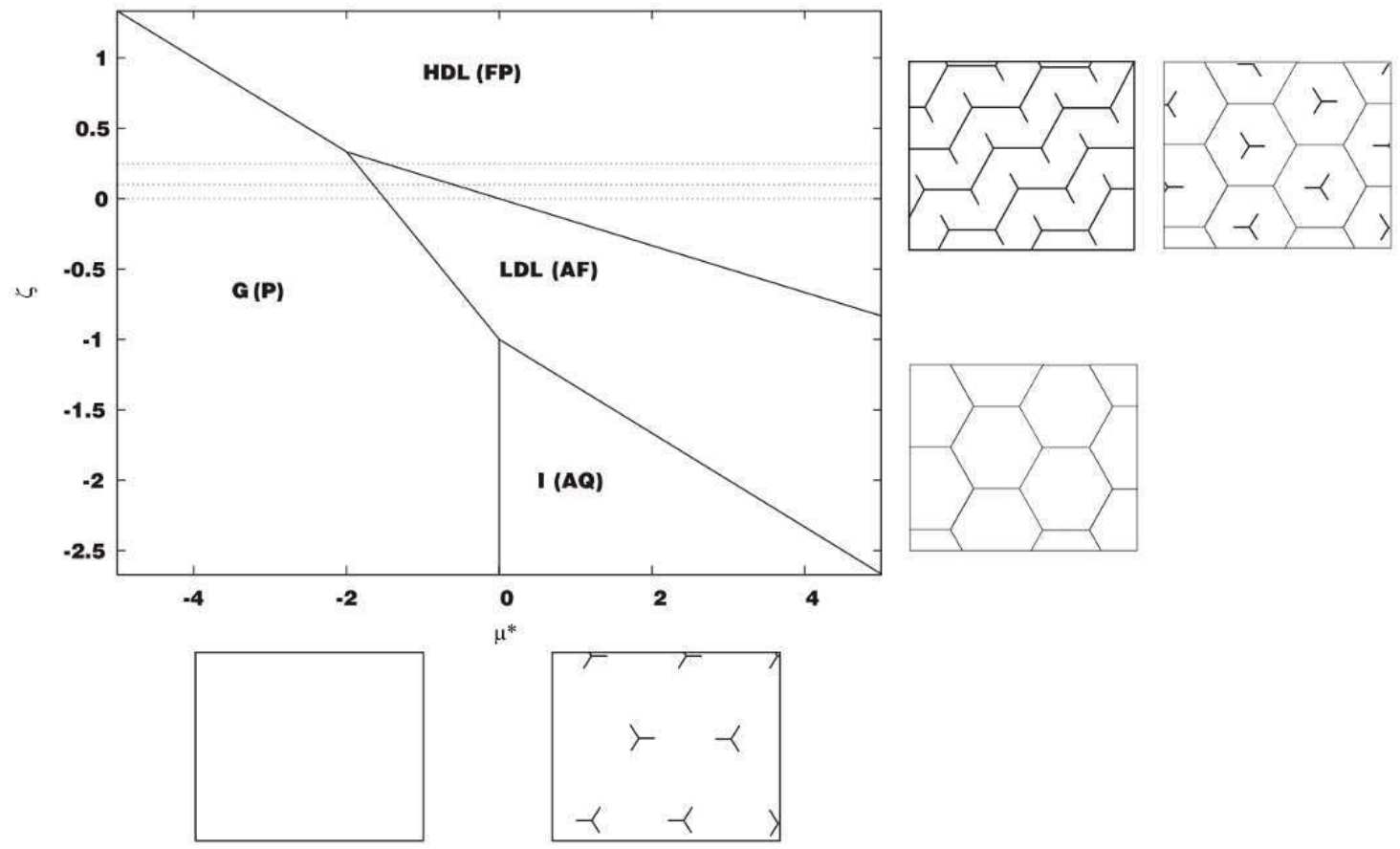

Figura 2.2: Estado fundamental dos modelos Bell-Lavis e Blume-Emery-Griffiths antiferromagnético, com as hipóteses discutidas no texto, em termos do parâmetro de interação $\zeta$ e do potencial químico reduzido $\mu^{*}$. Configurações representativas do modelo Bell-Lavis são mostradas nos lados do diagrama, com linhas retas conectando os sítios em que ocorrem as ligações de hidrogênio. A fase líquida de alta densidade é degenerada e é representada através de duas configurações, dentre as várias possíveis. Linhas pontilhadas indicam os parâmetros $(\zeta=1 / 4$, $1 / 10$ e 0 ) estudados nesta tese. 


\subsection{Estado fundamental}

\subsection{Estado fundamental}

As similaridades entres os modelos BL e BEG podem ser melhor visualizadas se inspecionarmos os estados possíveis de spin em um único triângulo. Assumindo que os microestados a temperatura nula são formados pela repetição dos estados das três sub-redes do sistema, podemos calcular os potenciais grande canônicos do estado fundamental do sistema. Com estes pressupostos, obtemos quatro fases fluidas estáveis para o modelo BL, em $T=0$ : gás $(\mathrm{G})$, líquido de baixa densidade (LDL), líquido de alta densidade (HDL) e líquido intercalado (I). As fases líquidas do modelo BL podem ser mapeadas nas fases magnéticas apresentadas pelo modelo BEG: paramagneto $(\mathrm{P})$, paramagneto frustrado (FP), antiferromagneto (AF) e antiquadrupolo (AQ).

Algumas configurações possíveis destas fases, no modelo BL, são ilustradas com linhas nas ligações de hidrogênio na fig. 2.2. A fase líquida de baixa densidade (LDL) possui o aspecto da superfície de uma colméia, com os vértices dos hexágonos correspondendo às moléculas de água. O centro de cada hexágono possui uma vacância, resultando em uma densidade $\rho_{H D L}=2 / 3$. A fase líquida de alta densidade (HDL) consiste em uma rede totalmente preenchida com um total de duas ligações de hidrogênio por partícula. De fato, esta fase é altamente degenerada e várias configurações diferentes apresentam o mesmo potencial grande canônico. Duas configurações possíveis desta fase são mostradas na fig. 2.2. De agora em diante utilizaremos a relação entre os dois modelos e passaremos a denominar as fases termodinâmicas do modelo BEG com a notação de fluido do modelo BL.

O espectro do potencial grande canônico por sítio a temperatura nula, $\phi=\Phi / V=$ $U / V-\mu \rho$, é mostrado na tabela 2.2 , com a nomenclatura de fluido indicada na primeira coluna. As linhas de transição de fase no estado fundamental podem ser obtidas comparando-se os potenciais grande canônicos da tabela 2.2 e pode ser notado que, em $T=0$, os diagramas de fase dos dois modelos apresentam a mesma topologia, como visto na fig. 2.2. As fases HDL e gasosa coexistem em um intervalo de $\mu^{*}$, para todo valor de $\zeta$. Existe um ponto triplo em $\left(\mu^{*}=2, \zeta=1 / 3\right)$ indicando o surgimento da fase LDL. Esta fase será estável em algum intervalo de potencial químico, $\mu^{*}$, para $\zeta<1 / 3$, e irá

\footnotetext{
${ }^{1}$ É necessário lembrar que o Hamiltoniano interpolador, utilizado neste trabalho, é passível de escolha. Seria possível, por exemplo, interpolar entre os Hamiltonianos BL e BEG através de uma ligação de hidrogênio estendida do tipo $g_{h b}=-\epsilon_{\mathrm{hb}}\left[P_{L D L}\left(S_{a}, S_{b}, S_{c}\right)+(1-\lambda) P_{u L D L}\left(S_{a}, S_{b}, S_{c}\right)\right]$, com $P_{L D L}$ e $P_{u L D L}$ correspondendo aos projetores dos estados líquido de baixa densidade e líquido de baixa densidade não-ligado, que são descritos na tabela 2.2.
} 
coexistir com a fase gasosa para parâmetros de interação no intervalo $-1<\zeta<1 / 3$, até que apareça outro ponto triplo em $\left(\mu^{*}=0, \zeta=-1\right)$. Este ponto triplo está relacionado à estabilidade da fase intercalada, ocorrendo apenas quando a interação de van der Waals é repulsiva e mais forte que a ligação de hidrogênio, no modelo BL, ou seja, quando a interação média entre as moléculas é repulsiva. O diagrama de fases do sistema não será estudado quando existe a fase intercalada porque nesta região de parâmetros as moléculas tornam-se extremamente distintas da água. Apesar disto, nada impede que anomalias termodinâmicas similares às apresentadas pela água também possam ser encontras quando $\zeta<-1$. 
Tabela 2.2: Estado fundamental do Hamiltoniano efetivo na eq. (2.11), com as hipóteses discutidas no texto. As configurações estáveis e instáveis são mostradas com a notação de fluido, juntamente com representações ilustrativas do estado de spin no triângulo, o potencial grande canônico por sítio (usando os parâmetros de interação na notação fluida e magnética, em colunas diferentes), densidade, $\rho$, o número de ligações de hidrogênio por partícula, $\rho_{\mathrm{hb}}$, a quantidade equivalente no modelo BEG $\Delta \rho_{\mathrm{f}}$, degenerescência, $\Omega$, e o peso de Boltzmann de cada configuração. O líquido de baixa densidade não-ligado está enfatizado porque ele é instável no modelo BL mas estável (estado antiferromagnético), no modelo BEG.

\begin{tabular}{|c|c|c|c|c|c|c|c|c|}
\hline Fase & $\left(S_{a}, S_{b}, S_{c}\right)$ & $\begin{array}{l}h_{\mathrm{I}}\left(S_{a}, S_{b}, S_{c}\right) \\
\quad \text { fluída }\end{array}$ & magnética & $\rho$ & $\rho_{h b}$ & $\Delta \rho_{\mathrm{f}}$ & $\bar{\Omega}$ & $e^{-\beta h_{\mathrm{I}}\left(S_{a}, S_{b}, S_{c}\right)}$ \\
\hline \multicolumn{9}{|l|}{ Fases estáveis } \\
\hline gas & $(0,0,0)$ & 0 & 0 & 0 & 0 & 0 & 1 & 1 \\
\hline líquida de alta densidade & $(+,-, \pm)$ & $-\epsilon_{\mathrm{hb}}-3 \epsilon_{\mathrm{vdW}}-\mu$ & $J-3 K+\Delta$ & 1 & 1 & 1 & 6 & $a_{0}$ \\
\hline $\begin{array}{l}\text { líquida de baixa densidade } \\
\text { intercalada }\end{array}$ & $\begin{array}{c}(+,-, 0) \\
(0, \pm, 0)\end{array}$ & $\begin{array}{c}-\frac{(1+\lambda)}{2} \epsilon_{\mathrm{hb}}-\epsilon_{\mathrm{vdW}}-\frac{2}{3} \mu \\
-\frac{1}{3} \mu\end{array}$ & $\begin{array}{c}(1+2 \lambda) J-K+\frac{2}{3} \Delta \\
\frac{1}{3} \Delta\end{array}$ & $\begin{array}{l}2 / 3 \\
1 / 3\end{array}$ & $\begin{array}{c}3 / 2 \\
0\end{array}$ & $\begin{array}{c}3 / 2 \\
0\end{array}$ & $\begin{array}{l}3 \\
6\end{array}$ & $\begin{array}{l}a_{1}^{b} \\
a_{2}\end{array}$ \\
\hline $\begin{array}{l}\text { líquida de baixa densidade não-ligada } \\
\text { Fases instáveis }\end{array}$ & $(-,+, 0)$ & $-\frac{(1-\lambda)}{2} \epsilon_{\mathrm{hb}}-\epsilon_{\mathrm{vdW}}-\frac{2}{3} \mu$ & $(1-2 \lambda) J-K+\frac{2}{3} \Delta$ & $2 / 3$ & 0 & $3 / 2$ & 3 & $a_{1}^{u}$ \\
\hline densa orientada & $(+,+,+)$ & $-3 \epsilon_{\mathrm{vdW}}-\mu$ & $-3 J-3 K+\Delta$ & 1 & 0 & $-3 / 2$ & 2 & $a_{3}$ \\
\hline leve orientada & $(+, 0,+)$ & $-\epsilon_{\mathrm{vdW}}-\frac{2}{3} \mu$ & $-J-K+\frac{2}{3} \Delta$ & $2 / 3$ & 0 & -1 & 6 & $a_{4}$ \\
\hline
\end{tabular}

rientada

$(+, 0,+)$ 
Apesar da equivalência topológica entre os estados fundamentais dos modelos BL e BEG, existe uma diferença importante entre a fase LDL e a fase antiferromagnética que é causada pelo termo de interação anisotrópico, apresentado na eq. (2.8). Como pode ser visto na tabela 2.2, os únicos estados alterados por este termo foram o líquido de baixa densidade e líquido de baixa densidade não-ligado (ambos estados antiferromagnéticos). O potencial grande canônico, por sítio, destes estados diferem por $\Delta \phi=-4 \lambda J=\lambda \epsilon_{\mathrm{hb}}$. Se considerarmos $\lambda=0$, estes estados irão se unir formando o estado antiferromagnético, indicando que o maior efeito da anisotropia é distinguir os estados líquidos de baixa densidade ligados e não-ligados, através da quebra da degenerescência entre os estados antiferromagnéticos. Isto é ilustrado na figura 2.1, onde todos os estados representados são antiferromagnéticos. Nesta figura, estão representadas configurações do (a) líquido de baixa densidade ligado, de menor energia, e do (b) líquido de baixa densidade não-ligados, de maior energia.

\subsection{Histórico do modelo}

No artigo original [6], as propriedades do modelo BL foram calculadas em uma aproximação de Bethe com um triângulo como célula base, sem sub-redes, nomeada pelos autores de aproximação com 'ordem de curto alcance'. Neste contexto, foi mostrado que o modelo apresentava uma linha com temperaturas de máximos de densidade (TMD) para $\zeta=1 / 4$. Posteriormente, a aproximação de Bethe foi estendida, com a inclusão de subredes, e surgiu uma fase de baixa densidade, ordenada e altamente ligada, no diagrama de fases, que os autores identificaram como gelo [7]. Neste trabalho, não denominamos esta fase de gelo, uma vez que outros resultados indicam que a linha de coexistência termina em um ponto crítico $[10,11]$. Alternativamente, chamamos esta fase de líquido de baixa densidade (LDL), diferenciando-a do líquido de alta densidade (HDL), que coexiste com o gás em altas temperaturas. Com a descoberta da fase LDL, verificou-se que a TMD ocorre numa região metaestável, o que pode ser considerado um defeito do modelo. Esta característica do modelo será discutida novamente no capítulo 4.

Em seguida, uma transformação de simetria foi utilizada para obter uma forma explícita para as propriedades do sistema na coexistência gás-líquido, dentro do contexto da aproximação com 'ordem de curto alcance', sem sub-redes. Desta forma foi possível obter expressões analíticas para as funções termodinâmicas de resposta e observar que as posições 
dos mínimos de compressibilidade isotérmica e da densidade ocorriam em posições similares aos da água, quando comparados com a temperatura do ponto crítico [8]. Estes achados tornaram o modelo interessante, apesar da metaestabilidade da TMD.

Um estudo do modelo BL com o grupo de renormalização no espaço real também foi realizado, desta vez indicando que a transição entre as fases LDL e HDL era crítica $[10,11]$. Além disso, este estudo indicava que a TMD ocorria na fase LDL (ou no sólido, segundo a nomenclatura adotada por Lavis), em contradição com os resultados anteriores.

Alguns modelos recentes podem ser considerados generalizações do modelo BL. O modelo estudado por Patrykiejew e colaboradores [86] inclui uma interação de três corpos que diminui a energia da ligação de hidrogênio sempre que uma terceira molécula se aproxima de um par ligante. No entanto, os autores deste trabalho não estavam interessados nas propriedades anômalas do fluido, mas na ordem da transição que ocorre na fase líquida do modelo. Este modelo será discutido novamente no capítulo 4, no qual os resultados das simulações da referência [86] serão comparados com os do modelo BL.

Uma outra variante do modelo BL inclui um número extra de estados não ligados em cada molécula de água. Este modelo foi proposto pelo grupo de Carla Buzano e utilizado para estudar as propriedades anômalas da água [43] e o efeito hidrofóbico [87], tendo sido investigado com o Método Variacional de Cluster e com simulações de Monte Carlo. Neste caso, os vários parâmetros do modelo foram investigados e foi possível encontrar um conjunto de valores que resulta em um diagrama de fases parecido com o da água, inclusive com a TMD localizada em uma região estável. 


\section{Capítulo 3}

\section{Rede de Bethe para o Modelo}

\section{Bell-Lavis}

Os modelos BL e BEG serão estudados neste trabalho através de uma abordagem recursiva [83] da rede de Bethe [81]. A rede de Bethe é conhecida por capturar as características básicas de diferentes modelos, particularmente quando a descrição obtida com o tratamento usual de campo médio falha [81]. Na abordagem recursiva o sistema é estudado em uma árvore hierárquica infinita e as propriedades termodinâmicas são calculadas no interior desta. Como a árvore é auto-similar, podemos escrever relações de recorrência envolvendo quantidades como densidade, magnetização ou função de partição parcial normalizada em gerações sucessivas. Desta forma, para estudar um sistema no interior de uma árvore hierárquica, no limite termodinâmico, deve-se encontrar o ponto fixo de um mapeamento dinâmico escrito em termos de quantidades apropriadas.

Embora o procedimento para encontrar estas relações de recorrências seja bem estabelecido [81], nem sempre as relações encontradas nos permitem localizar os pontos fixos $[88,89]$. Geralmente este problema ocorre quando o sistema apresenta algum tipo de frustração impedindo que as interações favoráveis se realizem, como no caso do modelo de Ising antiferromagnético na rede triangular $[82,83]$. Neste exemplo, podem surgir pontos bicíclicos, numa indicação de que o equilíbrio termodinâmico não está sendo alcançado pelas relações de recorrência no formato utilizado. Outro exemplo em que ocorre frustração é o modelo de Ising com interações de três corpos na rede triangular [88]. Neste modelo, a solução do sistema em um cacto de Husimi simétrico apresenta pontos multicíclicos e até mesmo caos. 
Em alguns casos mais simples, este problema pode ser solucionado se for possível obter uma equação polinomial de grau pequeno para o ponto fixo [81]. Contudo, quando o sistema possui algum estado ordenado com mais de uma sub-rede, as relações de recorrência começam a depender de mais de uma variável e torna-se inviável encontrar os pontos fixos desta forma.

Uma solução para este problema, proposta por Monroe [82], consiste em construir a árvore hierárquica de uma forma que não seja simétrica, mas seqüencial. Como estamos interessados em descrever modelos antiferromagnéticos na rede triangular, conforme os Hamiltonianos nas eqs. (2.7) e (2.11), vamos utilizar a solução proposta por Monroe para estudar o modelo BL. Embora o modelo BL seja de spin-1, a presença de buracos não altera o cenário observado para o modelo de Ising antiferromagnético: em baixas temperaturas e pressões as relações de recorrência obtidas no cacto de Husimi simétrico também levam a pontos bicíclicos, ao invés de pontos fixos.

No que se segue discutimos brevemente a construção de uma árvore hierárquica. Em seguida, discutiremos a inexistência de pontos fixos nas relações de recorrência que descrevem o modelo de Ising antiferromagnético no cacto de Husimi simétrico, em baixas temperaturas e campos magnéticos. Nosso intuito é justificar o uso do cacto de Husimi seqüencial para descrever sistemas frustrados, usando, como exemplo, um modelo para o qual a solução analítica a campo nulo é bem conhecida [84]. Tendo apresentado estes resultados, estudaremos um modelo de spin-1 geral no cacto de Husimi seqüencial e obteremos as expressões de algumas propriedades extensivas e intensivas dos modelos BL e BEG.

\section{1 Árvores hierárquicas simétricas e seqüenciais}

Os ramos de uma árvore hierárquica simétrica com conectividade $c$ são construídos partindo de uma célula base e adicionando $c$ novas células a cada sítio externo da célula, excetuando-se o sítio da base. Repetindo este procedimento $M$ vezes teremos um ramo com $M$ gerações de células. Uma árvore hierárquica pode então ser construída se juntarmos os sítios da base de $c$ ramos com infinitas gerações a cada sítio de uma célula central. Na figura 3.1 exemplificamos a construção de redes hierárquicas mostrando três árvores hierárquicas diferentes.

Já que estamos interessados em descrever sistemas na rede triangular iremos utilizar 

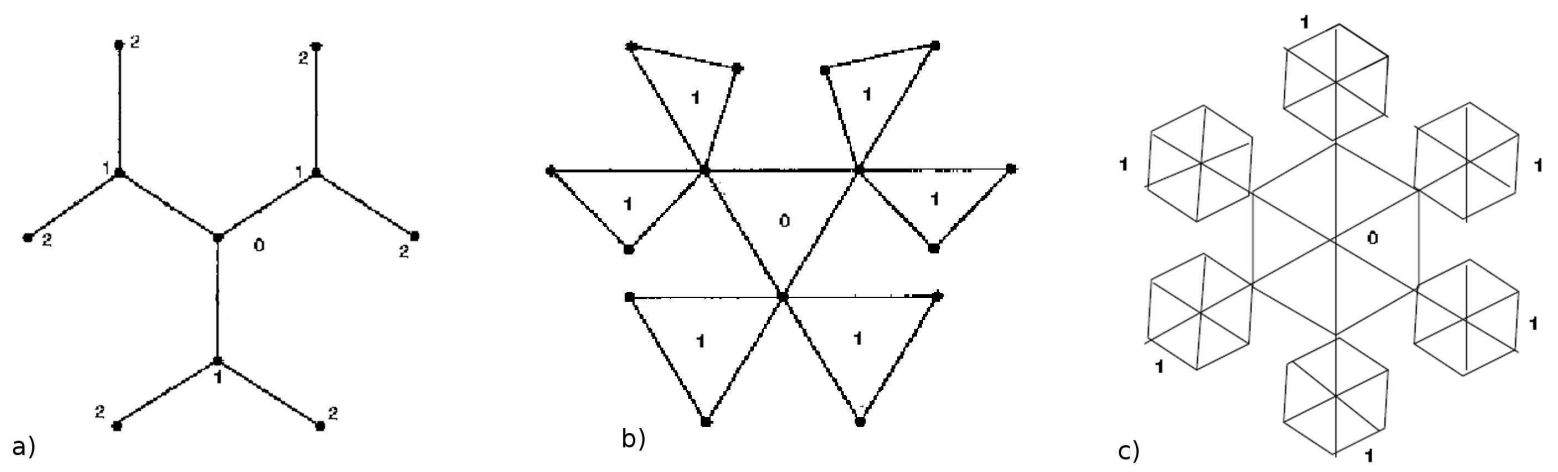

Figura 3.1: Exemplos de árvores hierárquicas: (a) árvore de Cayley, cáctus de Husimi feitos com (b) triângulos e (c) hexágonos na célula base.

o cacto de Husimi com um triângulo na célula base, com conectividade $c=2$ para que a coordenação da árvore seja idêntica à da rede triangular, $q=6$, veja a fig. 3.1 (b). É conhecido que as árvores hierárquicas possuem uma fração finita de sítios na sua superfície e, por este motivo, não apresentam as propriedades esperadas para os sistemas termodinâmicos mais usuais, onde a fração de sítios na superfície tende a zero. Para contornar este problema, devemos considerar apenas o interior da árvore, que é mais conhecido como a rede de Bethe [81].

Este procedimento serve para descrever um número muito grande de sistemas, desde que a célula base seja escolhida de forma apropriada $[81]^{1}$. No entanto, quando existe algum tipo de frustração energética, as relações de recorrência obtidas com a construção simétrica do cacto não levam a pontos fixos em baixas temperaturas. Uma solução para este problema é introduzir uma distorção na estrutura do cacto, crescendo os seus ramos de forma seqüencial [82].

Enquanto no procedimento simétrico todos os ramos crescem simultaneamente partindo do sítio central, no procedimento seqüencial as gerações com sub-redes diferentes crescem em uma sequência cuja ordem é especificada previamente. Neste trabalho iremos sempre adotar a ordem $a \rightarrow b \rightarrow c \rightarrow a$. Na figura 3.2 mostramos dois ramos de um cacto de Husimi: um construído com o procedimento simétrico usual e outro com o

\footnotetext{
${ }^{1}$ Para que uma célula base seja apropriada para descrever um determinado sistema é necessário que as configurações esperadas para o estado fundamental se encaixem de forma natural na árvore hierárquica criada com aquela célula. Como nem sempre é tão simples descobrir as configurações possíveis do estado fundamental de um sistema, muitas vezes, a escolha da célula base acaba sendo influenciada pela experiência pessoal e/ou por alguma intuição sobre o problema.
} 

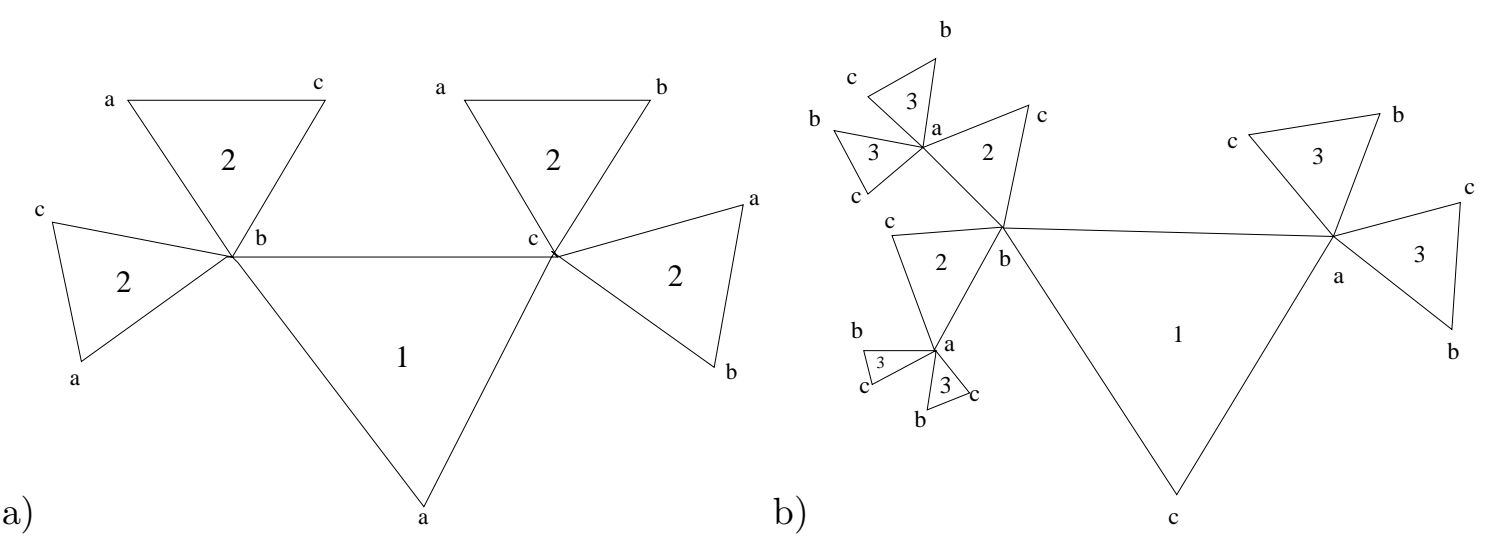

Figura 3.2: Construções (a) simétrica e (b) seqüencial dos ramos de um cacto de Husimi.

procedimento seqüencial.

\subsection{Sistemas frustrados: modelo de Ising antiferromagnético}

Vamos começar separando o Hamiltoniano em termos referentes a cada triângulo do cacto como na equação (2.2). Para o modelo de Ising, o Hamiltoniano de um único triângulo é:

$$
h_{I S I}\left(S_{a}, S_{b}, S_{c}\right)=-J\left(S_{a} S_{b}+S_{b} S_{c}+S_{c} S_{a}\right)-\frac{H}{3}\left(S_{a}+S_{b}+S_{c}\right),
$$

onde $H$ é o campo magnético. Estamos interessados no caso em que existe frustração devido a um acoplamento bilinear de spins antiferromagnético, $J<0$. O diagrama de fases deste modelo, obtido por vários métodos na referência [83] e mostrado na figura 3.3, possui uma coexistência entre as fases paramagnética e antiferromagnética que ocorre a campos não nulos. Este modelo possui uma solução exata a campo nulo [84], sendo que, neste caso, a fase paramagnética é estável em todas as temperaturas e não existe transição de fase a temperaturas finitas. Para campos não nulos, existiam algumas controvérsias sobre o diagrama de fases deste modelo [90, 91], mas não investigamos na literatura o status mais recente desta discussão.

No modelo de Ising antiferromagnético na rede triangular, existe uma frustração energética que ocorre devido à impossibilidade topológica de se formar todas as interações antiferromagnéticas um único triângulo. Esta restrição é muito similar à impossibilidade de se formar três ligações de hidrogênio em um único triângulo, no modelo BL. Neste modelo, a frustração é essencial para o aparecimento de uma fase líquida de baixa densidade 
e de propriedades similares à da água, como veremos no capítulo 4 .

\section{Cacto simétrico}

A função de partição de um modelo com o Hamiltoniano (3.1) em um cacto de Husimi simétrico que começa com uma célula central, com sítios na geração 0 , cujos ramos crescem por $M$ gerações é dada por:

$$
\Xi_{0}^{(M)}=\sum_{S_{a}, S_{b}, S_{c}} e^{-\beta h_{\mathrm{ISI}}\left(S_{a}, S_{b}, S_{c}\right)} \Lambda_{0}^{2}\left(a, S_{a}\right) \Lambda_{0}^{2}\left(b, S_{b}\right) \Lambda_{0}^{2}\left(c, S_{c}\right)
$$

onde $\beta=1 / k_{B} T$ e $\Lambda_{k}\left(l, S_{l}\right)$ é a função de partição parcial que descreve um ramo do cacto que começa com um spin $S_{l}$ em um sítio com sub-rede $l$ na geração $k$, e que origina ramos que crescem simetricamente por $M-k$ gerações. Note que as funções de partição parcial dos ramos são rotuladas tanto pelo spin no sítio base quanto pela sub-rede daquele sítio. O uso de sub-redes é necessário para descrever a fase antiferromagnética que aparece no modelo de Ising na rede triangular com $J<0$. Esta fase é observada em baixas temperaturas quando há um campo magnético e apresenta, em cada triângulo, dois spins paralelos e um spin antiparalelo. Caso as sub-redes não sejam utilizadas, apenas a fase paramagnética, em que todos os sítios possuem a mesma magnetização, aparecerá como solução do sistema.

Usando a auto-similaridade dos ramos do cacto de Husimi, podemos escrever relações de recorrência entre as funções de partição partial $\Lambda_{k}\left(l, S_{l}\right)$ de ramos sucessivos. Na sub-rede $a$ esta relação é dada por:

$$
\Lambda_{k}\left(a, S_{a}\right)=\sum_{S_{b}^{\prime}, S_{c}^{\prime}} e^{-\beta h_{\mathrm{ISI}}\left(S_{a}, S_{b}^{\prime}, S_{c}^{\prime}\right)} \Lambda_{k+1}^{2}\left(b, S_{b}^{\prime}\right) \Lambda_{k+1}^{2}\left(c, S_{c}^{\prime}\right),
$$

e existem relações similares para as sub-redes $b$ e $c$.

A normalização das probabilidades em cada sub-rede nos permite reduzir o número de equações que descrevem o sistema de seis para três. Isto geralmente é feito com a definição de uma função de partição parcial normalizada que, neste caso, depende unicamente da sub-rede em consideração. Para um modelo de spin-1/2, a função de partição parcial normalizada em uma sub-rede $l$ é definida como:

$$
x_{k}(l)=\frac{\Lambda_{k}(l,+)}{\Lambda_{k}(l,-)}
$$




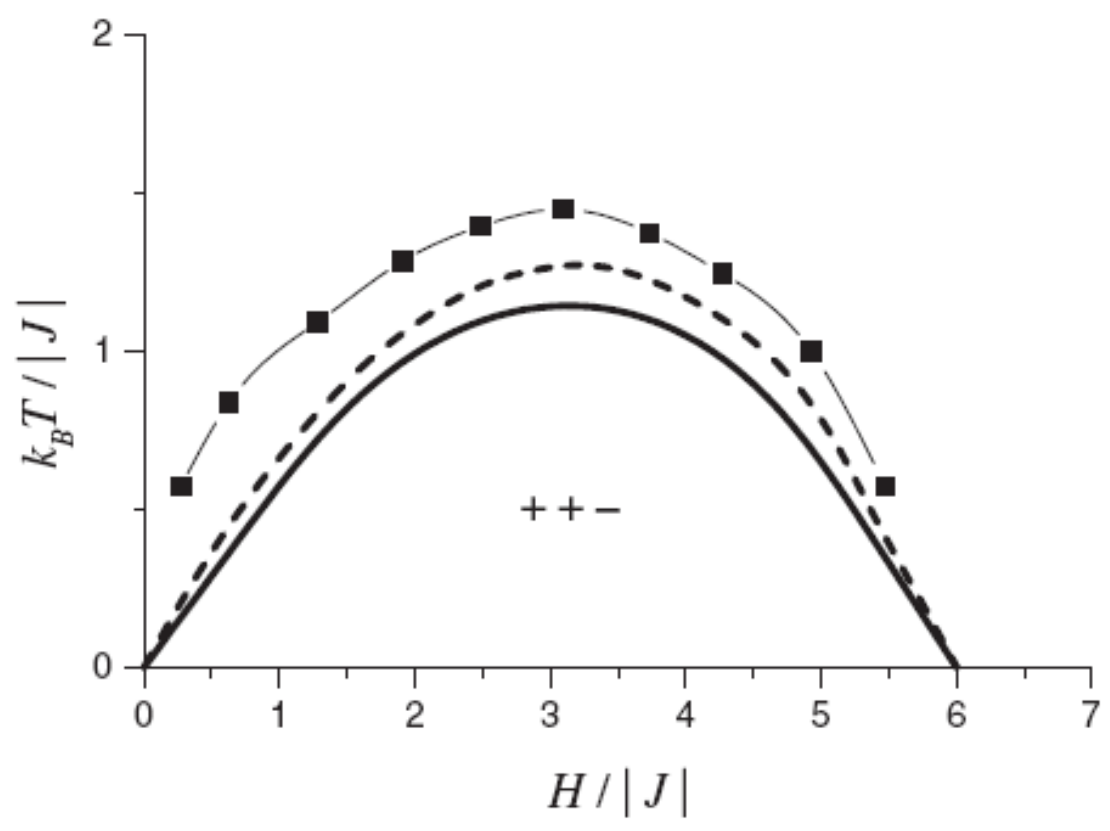

Figura 3.3: Diagrama de fases do modelo de Ising antiferromagnético na rede triangular, indicando a transição entre as fases paramagnética e antiferromagnética $(++-)$. As linhas sólida e tracejada indicam, respectivamente, os resultados obtidos com o Método Variacional de Cluster e com o cálculo de Bethe no cacto de Husimi seqüencial. Quadrados indicam a localização da transição de acordo com simulações de Monte Carlo e as linhas ligando os quadrados foram incluídas para facilitar a visualização. Extraído da ref. [83] 
Definindo $u=e^{\beta J}$ e $v=e^{\beta H / 3}$, as relações de recorrência nas três sub-redes ficam escritas como:

$$
\begin{aligned}
& x_{k}(a)=\frac{u^{4} v^{4} x_{k+1}^{2}(b) x_{k+1}^{2}(c)+v^{2}\left[x_{k+1}^{2}(b)+x_{k+1}^{2}(c)\right]+1}{v^{2} x_{k+1}^{2}(b) x_{k+1}^{2}(c)+x_{k+1}^{2}(b)+x_{k+1}^{2}(c)+u^{4} v^{-2}}, \\
& x_{k}(b)=\frac{u^{4} v^{4} x_{k+1}^{2}(a) x_{k+1}^{2}(c)+v^{2}\left[x_{k+1}^{2}(a)+x_{k+1}^{2}(c)\right]+1}{v^{2} x_{k+1}^{2}(a) x_{k+1}^{2}(c)+x_{k+1}^{2}(a)+x_{k+1}^{2}(c)+u^{4} v^{-2}}, \\
& x_{k}(c)=\frac{u^{4} v^{4} x_{k+1}^{2}(a) x_{k+1}^{2}(b)+v^{2}\left[x_{k+1}^{2}(a)+x_{k+1}^{2}(b)\right]+1}{v^{2} x_{k+1}^{2}(a) x_{k+1}^{2}(b)+x_{k+1}^{2}(a)+x_{k+1}^{2}(b)+u^{4} v^{-2}} .
\end{aligned}
$$

Agora vamos considerar os valores das funções de partição parcial normalizadas em um dos pontos fixos do sistema, com $k \ll M$, de forma que $x_{k}(l)=x_{k+1}(l)=x(l)$. Neste caso, a magnetização na sub-rede $l$ do triângulo central será dada por:

$$
m_{l}=\left\langle\left\langle S_{l}\right\rangle\right\rangle=\frac{\sum_{S_{a}, S_{b}, S_{c}} S_{l} e^{-\beta h_{I S I}} x^{1+S_{a}}\left(S_{a}\right) x^{1+S_{b}}\left(S_{b}\right) x^{1+S_{c}}\left(S_{c}\right)}{\sum_{S_{a}, S_{b}, S_{c}} e^{-\beta h_{I S I}} x^{1+S_{a}}\left(S_{a}\right) x^{1+S_{b}}\left(S_{b}\right) x^{1+S_{c}}\left(S_{c}\right)} .
$$

Usando as eqs. (3.5a)-(3.5c) podemos simplificar esta expressão para

$$
m_{l}=\frac{\sum_{S_{l}} S_{l} x^{3\left(1+S_{l}\right) / 2}(l)}{\sum_{S_{l}} x^{3\left(1+S_{l}\right) / 2}(l)}=\frac{x^{3}(l)-1}{x^{3}(l)+1} .
$$

Na fase paramagnética a magnetização é idêntica nas três sub-redes, $m_{a}=m_{b}=m_{c}=$ $m$, o que implica em $x_{k}(a)=x_{k}(b)=x_{k}(c)=x_{k}$, para $k \ll M$. Com esta simetria as relações (3.5a)-(3.5c) se tornam idênticas e podem ser simplificadas para:

$$
x_{k}=\frac{u^{4} v^{4} x_{k+1}^{4}+2 v^{2} x_{k+1}^{2}+1}{x_{k+1}^{2}\left(v^{2} x_{k+1}^{2}+2\right)+u^{4} v^{-2}} .
$$

No ponto fixo esta relação de recorrência pode ser transformada na seguinte equação polinomial:

$$
v^{2} x^{5}-u^{4} v^{4} x^{4}+2 x^{3}-2 v^{2} x^{2}+u^{4} v^{-2} x-1=0 .
$$

Para checar a consistência desta equação, vamos considerar o modelo de Ising antiferromagnético nos limites de temperatura e campo magnético nulos. Neste caso, que equivale a $u=0$ e $v=1$, a equação (3.9) torna-se simplesmente:

$$
x^{5}+2 x^{3}-2 x^{2}-1=0
$$

e a sua única solução real, $x^{\prime}=1$, corresponde a uma magnetização nula em todas as sub-redes.

Embora a existência de uma magnetização nula esteja de acordo com a solução exata do modelo de Ising antiferromagnético na rede triangular [84] a campo nulo, este resultado 
esconde o fato de que as relações de recorrência nas eqs. (3.5a)-(3.5c) e (3.8) não convergem para um ponto fixo, mas para um ponto bicíclico, para valores baixos de temperatura e campo magnético. Ou seja, a solução obtida com as relações de recorrência do cacto simétrico passam a ser compatíveis com a solução exata do modelo de Ising antiferromagnético na rede triangular [84] a campo nulo apenas para valores altos de temperatura e campo magnético.

Apenas como exercício matemático, vamos verificar a estabilidade do ponto fixo da relação de recorrência (3.8) no limite em que $k_{B} T /|J|$ e $H /|J|$ tendem a 0 , que corresponde ao ponto na origem das figuras 3.5 (a) e (c). Neste caso, com $u=0$ e $v=1$, temos $x_{k}=f\left(x_{k+1}\right) \mathrm{com}$

$$
f(x)=\frac{2 x^{2}+1}{x^{2}\left(x^{2}+2\right)}
$$

Para que o ponto fixo do sistema seja estável frente ao mapeamento devemos ter $\left|f^{\prime}(x)\right|<1$ em $x=x^{\prime}=1$. Não é isto que ocorre, já que $f^{\prime}(1)=-4 / 3$ para temperatura e campo nulos.

Na figura 3.4 (A), calculamos numericamente a magnetização em função da geração no cacto de Husimi simétrico, para temperatura e campo dados por $k_{B} T /|J|=1,0$ e $H /|J|=4,0$. Como pode ser visto, as relações de recorrência no cacto simétrico levam a uma solução uniforme, no sentido de que a magnetização é idêntica em todas as sub-redes, e bicíclica. Este mesmo resultado também pode ser observado nas figuras 3.5 (a) e (c), onde mostramos a magnetização em função da temperatura a campo nulo e em função do campo magnético numa temperatura $k_{B} T /|J|=1,0$. Nas duas figuras os pontos foram obtidos com as relações de recorrência (3.5a)-(3.5c), para mostrar que a imposição da igualdade entre as funções de partição parcial normalizadas não é responsável pelo aparecimento dos pontos bicíclicos. Note que, neste caso, a magnetização é idêntica nas três sub-redes mesmo com o uso das eqs. (3.5a)-(3.5c). No entanto, a magnetização depende da geração no cacto de Husimi simétrico, mesmo no interior da rede.

\section{Cacto seqüencial}

Vamos agora descrever um modelo com Hamiltoniano (3.1) no cacto de Husimi seqüencial. A função de partição desse sistema:

$$
\Xi_{0,1,2}^{(M)}=\sum_{S_{a}, S_{b}, S_{c}} e^{-\beta h_{I S I}\left(S_{a}, S_{b}, S_{c}\right)} \Gamma_{0}^{2}\left(a, S_{a}\right) \Gamma_{1}^{2}\left(b, S_{b}\right) \Gamma_{2}^{2}\left(c, S_{c}\right),
$$


onde a letra $\Gamma$ foi utilizada na função de partição parcial de um ramo, $\Gamma_{k}\left(l, S_{l}\right)$, para enfatizar que os ramos da árvore crescem seqüencialmente e os três índices subscritos em $\Xi_{0,1,2}^{(M)}$ indicam as gerações em que começam os ramos com as sub-redes $a, b$ e $c$ no sítio base. Nas três sub-redes os ramos crescem por $M$ gerações.

Novamente teremos relações de recorrência entre as funções de partição parcial normalizadas dos ramos em diferentes sub-redes. Neste caso, entretanto, o crescimento dos ramos segue a seqüência pré-estabelecida $a \rightarrow b \rightarrow c \rightarrow a$, resultando em

$$
\begin{aligned}
\Gamma_{k}\left(a, S_{a}\right) & =\sum_{S_{b}^{\prime}, S_{c}^{\prime}} e^{-\beta h_{I S I}\left(S_{a}, S_{b}^{\prime}, S_{c}^{\prime}\right)} \Gamma_{k+1}^{2}\left(b, S_{b}^{\prime}\right) \Gamma_{k+2}^{2}\left(c, S_{c}^{\prime}\right), \\
\Gamma_{k}\left(b, S_{b}\right) & =\sum_{S_{a}^{\prime}, S_{c}^{\prime}} e^{-\beta h_{I S I}\left(S_{a}^{\prime}, S_{b}, S_{c}^{\prime}\right)} \Gamma_{k+1}^{2}\left(c, S_{c}^{\prime}\right) \Gamma_{k+2}^{2}\left(a, S_{a}^{\prime}\right), \\
\Gamma_{k}\left(c, S_{c}\right) & =\sum_{S_{a}^{\prime}, S_{b}^{\prime}} e^{-\beta h_{I S I}\left(S_{a}^{\prime}, S_{b}^{\prime}, S_{c}\right)} \Gamma_{k+1}^{2}\left(a, S_{a}^{\prime}\right) \Gamma_{k+2}^{2}\left(b, S_{b}^{\prime}\right) .
\end{aligned}
$$

Usando a definição da função de partição parcial normalizada (3.4) nas eqs. (3.13a)(3.13c), obtemos as seguintes relações de recorrência:

$$
\begin{aligned}
& x_{k}(a)=\frac{u^{4} v^{4} x_{k+1}^{2}(b) x_{k+2}^{2}(c)+v^{2}\left[x_{k+1}^{2}(b)+x_{k+2}^{2}(c)\right]+1}{v^{2} x_{k+1}^{2}(b) x_{k+2}^{2}(c)+x_{k+1}^{2}(b)+x_{k+2}^{2}(c)+u^{4} v^{-2}}, \\
& x_{k}(b)=\frac{u^{4} v^{4} x_{k+2}^{2}(a) x_{k+1}^{2}(c)+v^{2}\left[x_{k+2}^{2}(a)+x_{k+1}^{2}(c)\right]+1}{v^{2} x_{k+2}^{2}(a) x_{k+1}^{2}(c)+x_{k+2}^{2}(a)+x_{k+1}^{2}(c)+u^{4} v^{-2}}, \\
& x_{k}(c)=\frac{u^{4} v^{4} x_{k+1}^{2}(a) x_{k+2}^{2}(b)+v^{2}\left[x_{k+1}^{2}(a)+x_{k+2}^{2}(b)\right]+1}{v^{2} x_{k+1}^{2}(a) x_{k+2}^{2}(b)+x_{k+1}^{2}(a)+x_{k+2}^{2}(b)+u^{4} v^{-2}},
\end{aligned}
$$

que diferem das eqs. (3.5a)-(3.5c) apenas pelo índice de geração nas funções de partição parcial normalizadas das diferentes sub-redes.

Supondo que o sistema está numa fase paramagnética temos novamente uma identidade entre funções de partição parcial normalizadas em diferentes sub-redes mas na mesma geração: $x_{k}(a)=x_{k}(b)=x_{k}(c)=x_{k}$. Com isto, podemos obter uma relação de recorrência similar à eq. (3.8), mas com um mapeamento no formato

$$
x_{k}=f\left(x_{k+1}, x_{k+2}\right),
$$

com $f(x, y)$ assumindo o seguinte formato:

$$
f(x, y)=\frac{u^{4} v^{4} x^{2} y^{2}+v^{2}\left(x^{2}+y^{2}\right)+1}{v^{2} x^{2} y^{2}+x^{2}+y^{2}+u^{4} v^{-2}} .
$$



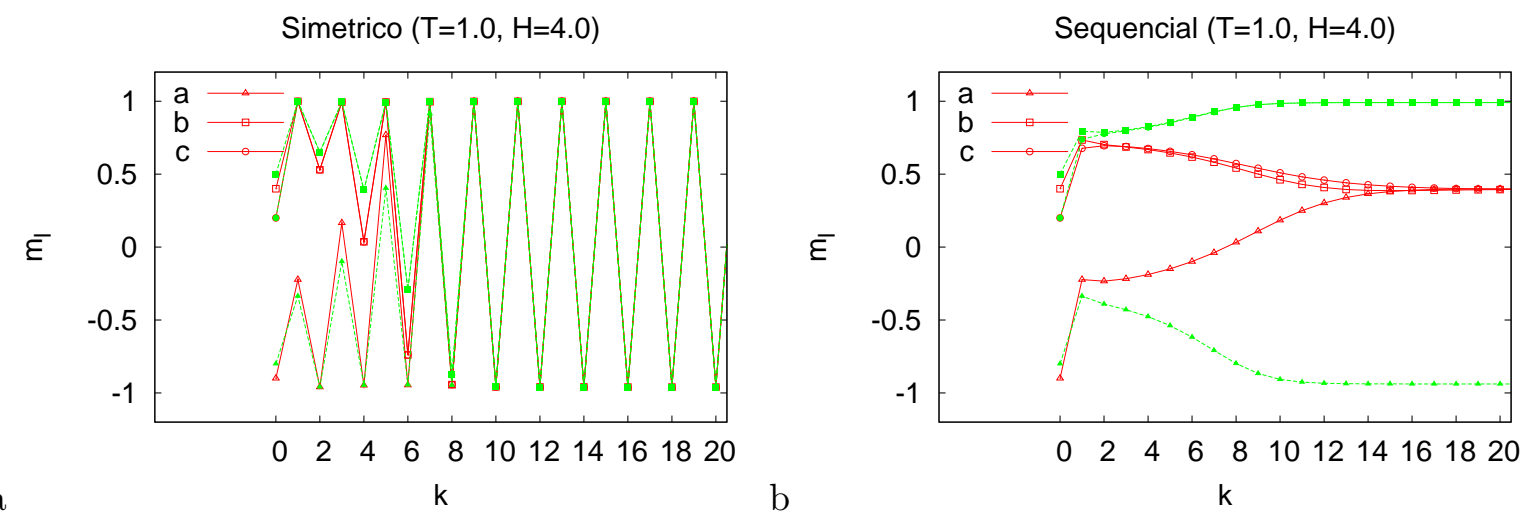

Figura 3.4: Variação da magnetização, do modelo de Ising antiferromagnético, em função da geração no interior dos cacto de Husimi (a) simétrico e (b) seqüencial. A temperatura e o campo, $k_{B} T /|J|=1,0$ e $H /|J|=4,0$, foram escolhidos na vizinhança da coexistência de fases. Condições iniciais diferentes foram utilizadas para encontrar as fases paramagnética (símbolos vazios) e antiferromagnética (símbolos preenchidos) no cacto de Husimi seqüencial (b).
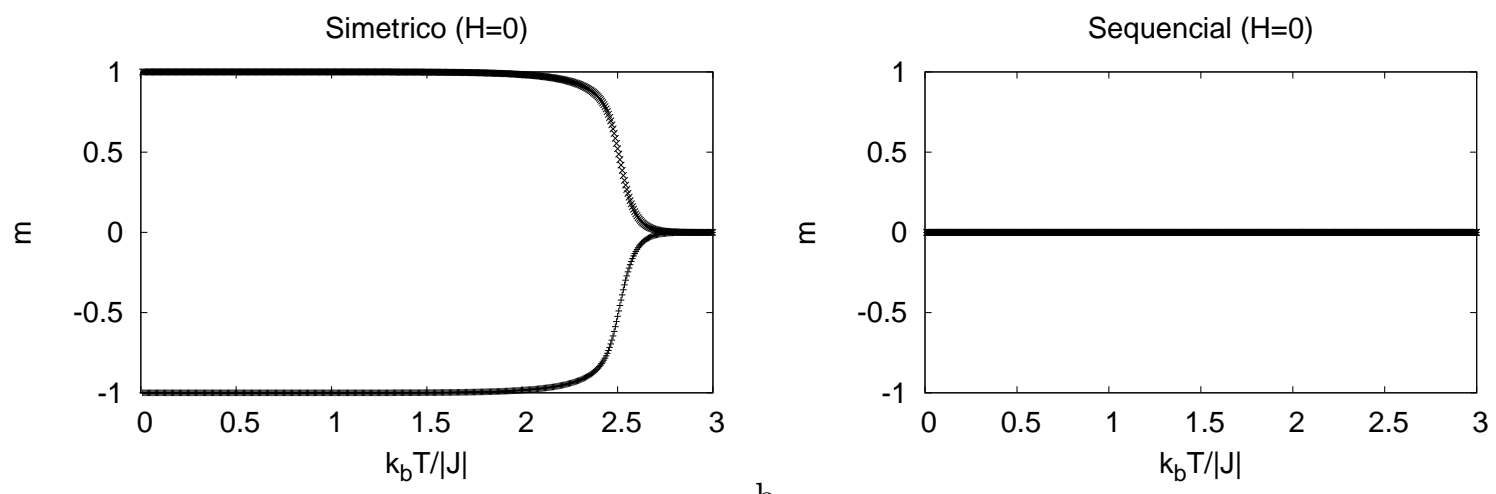

a

$\mathrm{b}$
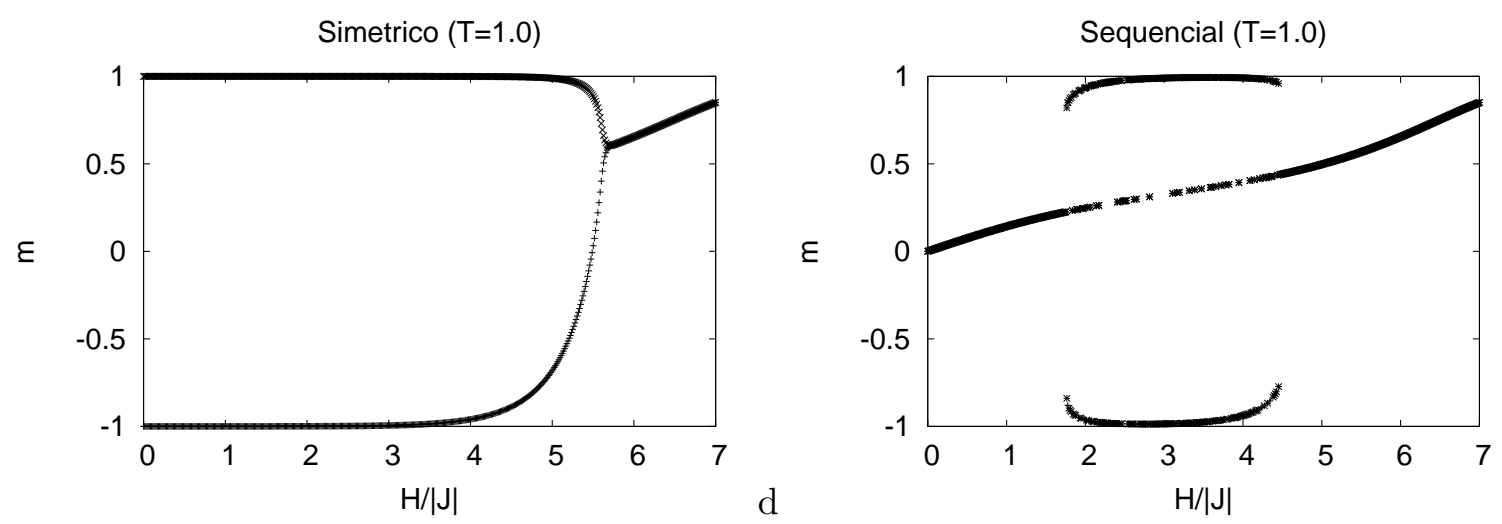

Figura 3.5: Magnetização do modelo de Ising antiferromagnético nos cacto de Husimi simétrico (esquerda) e seqüencial (direita). Campo magnético nulo, (a) e (b), e temperatura fixa a $T=1,0$, (c) e (d). Note que enquanto no cacto simétrico a magnetização é idêntica em todas as subredes mas varia de uma geração para outra, no cacto seqüencial cada sub-rede possui uma magnetização que independe da geração, para $k \ll M$, e que pode ser distinta das outras subredes. Em (d) aparecem soluções paramagnéticas e ferromagnéticas em uma mesma região de parâmetros (veja a discussão no texto). 
Podemos transformar o sistema dinâmico (3.15) de uma variável em um sistema dinâmico com duas variáveis definindo $y_{k}=x_{k+1}$. Desta forma, teremos

$$
\begin{aligned}
& x_{k}=f\left(x_{k+1}, y_{k+1}\right), \\
& y_{k}=f\left(x_{k+2}, y_{k+2}\right) .
\end{aligned}
$$

Note que o ponto fixo paramagnético deste mapeamento é idêntico ao ponto fixo obtido com as relações de recorrência do cacto simétrico e, por isso, também satisfaz a equação (3.9). No caso em que o campo e a temperatura são nulos, temos $x^{\prime}=y^{\prime}=1$. Desta vez, entretanto, para que as relações de recorrência (3.17a) e (3.17b) sejam estáveis, na vizinhança do ponto fixo, é necessário que $|\partial f(x, y) / \partial x|<1$ e $|\partial f(x, y) / \partial y|<1$ em $x^{\prime}=y^{\prime}=1$. Podemos facilmente verificar que estas condições são satisfeitas para $k_{B} T /|J|=0$ e $H /|J|=0$, já que temos:

$$
\left.\frac{\partial f(x, y)}{\partial x}\right|_{x=y=1}=\left.\frac{\partial f(x, y)}{\partial y}\right|_{x=y=1}=-\frac{2}{3} .
$$

Nas figuras 3.4 (a) e (b) mostramos a dependência da magnetização com a geração no interior dos cáctus de Husimi simétrico e seqüencial, respectivamente, para $k_{B} T /|J|=1,0$ e $H /|J|=4,0$. Enquanto as relações de recorrência no cacto de Husimi simétrico levam a um ponto bicíclico, no cacto seqüencial encontramos dois pontos fixos, que são alcançados dependendo da escolha das condições de contorno na superfície do cacto. Repare que, na figura 3.4 (b), escolhemos propositalmente um ponto na vizinhança da transição de fases (veja a fig. 3.3) e utilizamos condições de contorno muito parecidas, mas que levavam a fases distintas.

Na figura 3.5 comparamos a magnetização calculada no interior dos cacto simétrico e seqüencial em função da temperatura a campo nulo, em (a) e (b), e em função do campo magnético na temperatura $k_{B} T /|J|=1$, em (c) e (d). Novamente vemos que enquanto no cacto simétrico a magnetização independe da sub-rede, mas oscila com a geração de forma bicíclica em baixas temperaturas, no cacto seqüencial a magnetização nunca depende da geração no interior do cacto. No último caso, dependendo da temperatura e do campo magnético, existem várias soluções que podem ser encontradas dependendo das condições de contorno utilizadas. Entre essas soluções uma é paramagnética, com a magnetização idêntica e monotônica crescente em função do campo magnético em todos os sítios, e 
outras seis são antiferromagnéticas, com dois spins paralelos e um antiparalelo nas três sub-redes.

Na figura 3.5 (d) os pontos da fase paramagnética também aparecem na região em que existe a fase antiferromagnética. A fase paramagnética passa a ser metaestável, em relação à fase antiferromagnética, em algum ponto no intervalo $2 \lesssim H /|J| \lesssim 4$. A localização exata da transição entre estas duas fases deve ser feita com uma comparação entre as energias livres.

A energia livre pode ser obtida integrando-se a magnetização [92], ou através de alguma prescrição para a energia livre no interior do cacto. Em nosso trabalho optamos pela segunda opção, mas não chegaremos a apresentar estes cálculos para o modelo de Ising porque estamos interessados em estudar o modelo Bell-Lavis, que é consideravelmente mais complexo que este último.

No que se segue estudaremos a descrição de um Hamiltoniano de spin-1 geral no cacto de Husimi seqüencial e na subseção 3.3 .1 utilizaremos a prescrição de Gujrati [81] para calcular a energia livre deste sistema.

\subsection{Hamiltoniano de spin-1 no cacto de Husimi seqüencial}

Vamos considerar um Hamiltoniano de spin-1 qualquer $h\left(S_{a}, S_{b}, S_{c}\right)$ em um único triângulo. A função de partição de um cacto de Husimi seqüencial que cresce por $M$ gerações, começando pela geração 0 na sub-rede $a$ de um triângulo central, é dada por:

$$
\Xi_{0,1,2}^{(M)}=\sum_{S_{a}, S_{b}, S_{c}} e^{-\beta h\left(S_{a}, S_{b}, S_{c}\right)} \Gamma_{0}^{2}\left(a, S_{a}\right) \Gamma_{1}^{2}\left(b, S_{b}\right) \Gamma_{2}^{2}\left(c, S_{c}\right)
$$

onde $\beta=1 / k_{B} T, \Gamma_{k}\left(l, S_{l}\right)$ é a função de partição parcial de um ramo do cacto que começa em um sítio com sub-rede $l$ na geração $k$, com um spin $S_{l}$, e que origina ramos que crescem de forma seqüencial por $M-k$ gerações. Devido à auto-similaridade do cacto, as funções de partição parcial dos ramos em gerações sucessivas satisfazem as seguintes equações:

$$
\begin{aligned}
\Gamma_{k}\left(a, S_{a}\right) & =\sum_{S_{b}^{\prime}, S_{c}^{\prime}} e^{-\beta h\left(S_{a}, S_{b}^{\prime}, S_{c}^{\prime}\right)} \Gamma_{k+1}^{2}\left(b, S_{b}^{\prime}\right) \Gamma_{k+2}^{2}\left(c, S_{c}^{\prime}\right), \\
\Gamma_{k}\left(b, S_{b}\right) & =\sum_{S_{c}^{\prime}, S_{a}^{\prime}} e^{-\beta h\left(S_{a}^{\prime}, S_{b}, S_{c}^{\prime}\right)} \Gamma_{k+1}^{2}\left(c, S_{c}^{\prime}\right) \Gamma_{k+2}^{2}\left(a, S_{a}^{\prime}\right), \\
\Gamma_{k}\left(c, S_{c}\right) & =\sum_{S_{a}^{\prime}, S_{b}^{\prime}} e^{-\beta h\left(S_{a}^{\prime}, S_{b}^{\prime}, S_{c}\right)} \Gamma_{k+1}^{2}\left(a, S_{a}^{\prime}\right) \Gamma_{k+2}^{2}\left(b, S_{b}^{\prime}\right) .
\end{aligned}
$$




\subsection{Hamiltoniano de spin-1 no cacto de Husimi seqüencial}

A normalização das probabilidades em cada sub-rede reduz o número de equações de nove (relacionadas aos três possíveis estados de spin em cada sítio) para seis. A definição

$$
\Gamma_{k}\left(l, S_{l}\right)=B_{k}(l) x_{k}^{S_{l}^{2}}\left(l, S_{l}\right),
$$

pode ser utilizada para reescrever as eqs. (3.20a)-(3.20c) como um mapeamento dinâmico nas funções de partição parcial normalizadas $x_{k}\left(l, S_{l}\right)$, dado por

$$
\begin{aligned}
x_{k}\left(a, S_{a}\right) & =\frac{f_{(k+1, k+2)}\left(a, S_{a}\right)}{f_{(k+1, k+2)}(a, 0)}, \\
x_{k}\left(b, S_{b}\right) & =\frac{f_{(k+1, k+2)}\left(b, S_{b}\right)}{f_{(k+1, k+2)}(b, 0)}, \\
x_{k}\left(c, S_{c}\right) & =\frac{f_{(k+1, k+2)}\left(c, S_{c}\right)}{f_{(k+1, k+2)}(c, 0)}, .
\end{aligned}
$$

onde as funções $f_{(m, n)}\left(l, S_{l}\right)$ são

$$
\begin{aligned}
& f_{(m, n)}\left(a, S_{a}\right)=\sum_{S_{b}^{\prime}, S_{c}^{\prime}} e^{-\beta h\left(S_{a}, S_{b}^{\prime}, S_{c}^{\prime}\right)} x_{m}^{2 S_{b}^{\prime 2}}\left(b, S_{b}^{\prime}\right) x_{n}^{2 S_{c}^{\prime 2}}\left(c, S_{c}^{\prime}\right), \\
& f_{(m, n)}\left(b, S_{b}\right)=\sum_{S_{c}^{\prime}, S_{a}^{\prime}} e^{-\beta h\left(S_{a}^{\prime}, S_{b}, S_{c}^{\prime}\right)} x_{m}^{2 S_{c}^{\prime 2}}\left(c, S_{c}^{\prime}\right) x_{n}^{2 S_{a}^{\prime 2}}\left(a, S_{a}^{\prime}\right), \\
& f_{(m, n)}\left(c, S_{c}\right)=\sum_{S_{a}^{\prime}, S_{b}^{\prime}} e^{-\beta h\left(S_{a}^{\prime}, S_{b}^{\prime}, S_{c}\right)} x_{m}^{2 S_{c}^{\prime 2}}\left(a, S_{a}^{\prime}\right) x_{n}^{2 S_{b}^{\prime 2}}\left(b, S_{b}^{\prime}\right) .
\end{aligned}
$$

Note que $x_{k}(l, 0)$ e $B_{k}(l)$ não aparecem nas eqs. (3.22a)-(3.22c) devido à definição (3.21). As funções $B_{k}(l)=\Gamma_{k}(l, 0)$ satisfazem uma relação de recorrência que depois será utilizada para obter o potencial grande canônico. Para $l=a$ esta relação fica escrita como

$$
B_{k}(a)=B_{k+1}^{2}(b) B_{k+2}^{2}(c) f_{(k+1, k+2)}(a, 0) \text {. }
$$

O conjunto de equações (3.22a)-(3.22c) é iterado seqüencialmente, a partir de valores muito altos de $M$, até que um ponto fixo seja encontrado. A existência de mais de um ponto fixo, que pode ser averiguada com o uso de valores iniciais diferentes nas eqs. (3.22a)(3.22c), indica a presença de mais de uma fase termodinâmica. A região de estabilidade de cada fase é obtida comparando-se os seus potenciais grande canônicos. Na vizinhança de um ponto fixo temos, para $k \ll M, x_{k}\left(l, S_{l}\right)=x_{k-1}\left(l, S_{l}\right)=x\left(l, S_{l}\right)$. De agora em diante o subscrito $k$ não será mais indicado nas funções de partição parcial normalizadas, $x\left(l, S_{l}\right)$, pois assumimos que os seus valores serão obtidos no interior do cacto. 


\subsubsection{Prescrição de Gujrati para a energia livre}

Uma expressão analítica para o potencial grande canônico foi proposta por Gujrati [81], assumindo que o potencial grande canônico do cacto inteiro é aditivo nas contribuições da superfície e do interior, $\Phi_{\text {cacto }}=\Phi+\Phi_{\text {superfície }}$.

Desta forma, o potencial grande canônico no interior do cacto, $\Phi$, é simplesmente a diferença entre os potenciais grande canônicos de um cacto inteiro e da superfície deste cacto. Para aproximar o potencial grande canônico da superfície de um cacto com $M$ gerações, assume-se que este é igual ao potencial grande canônico de um certo número $r$ de cáctus com $M-1$ gerações, onde $r$ é a razão entre o número de sítios na superfície de dois cáctus com números de gerações sucessivas.

A prescrição de Gujrati para a energia livre pode ser visualizada da seguinte forma: tomemos um cacto com $M$ gerações e retiramos dele todos os sítios a partir da primeira geração; com os ramos que emanam dos sítios retirados podemos construir um número $r$ de cáctus com $M-1$ gerações. De fato, este 'corte' nos ramos de um cacto poderia ser feito em qualquer geração $k$. No entanto, sempre adotamos $k=1$, por simplicidade.

Para um cacto de Husimi simétrico com coordenação $q=6$, este procedimento resulta em um potencial grande canônico por unidade de área dado por:

$$
\phi=\frac{\Phi}{A}=\frac{\Phi_{0}^{(M)}-r \Phi_{1}^{(M)}}{\delta a_{0}}
$$

onde $\delta=3$ é a diferença, em número de sítios, entre um cacto com $M$ gerações e $r=4$ cáctus com $M-1$ gerações, e $A=\delta a_{0}$ com $a_{0}$ sendo a área ocupada por um único sítio em um triângulo. Já para o cacto de Husimi seqüencial esta quantidade será ligeiramente diferente porque cada ramo da árvore começa em uma geração diferente, como é mostrado na figura 3.6. Se 'recortarmos' todos os ramos que surgem do cacto além da célula central, obteremos diversos ramos com o sítio base começando em diferentes gerações. Se na célula central os sítios $a, b$ e $c$ forem indexados pelas gerações 0,1 e 2, veremos que, nos triângulos subseqüentes ao triângulo central, existem:

- 4 ramos com sítio base de sub-rede $a$ e geração 3 ;

- 4 ramos com sítio base de sub-rede $c$ e geração 2 ;

- 2 ramos com sítio base de sub-rede $b$ e geração 2 ;

- 2 ramos com sítio base de sub-rede $b$ e geração 4 . 


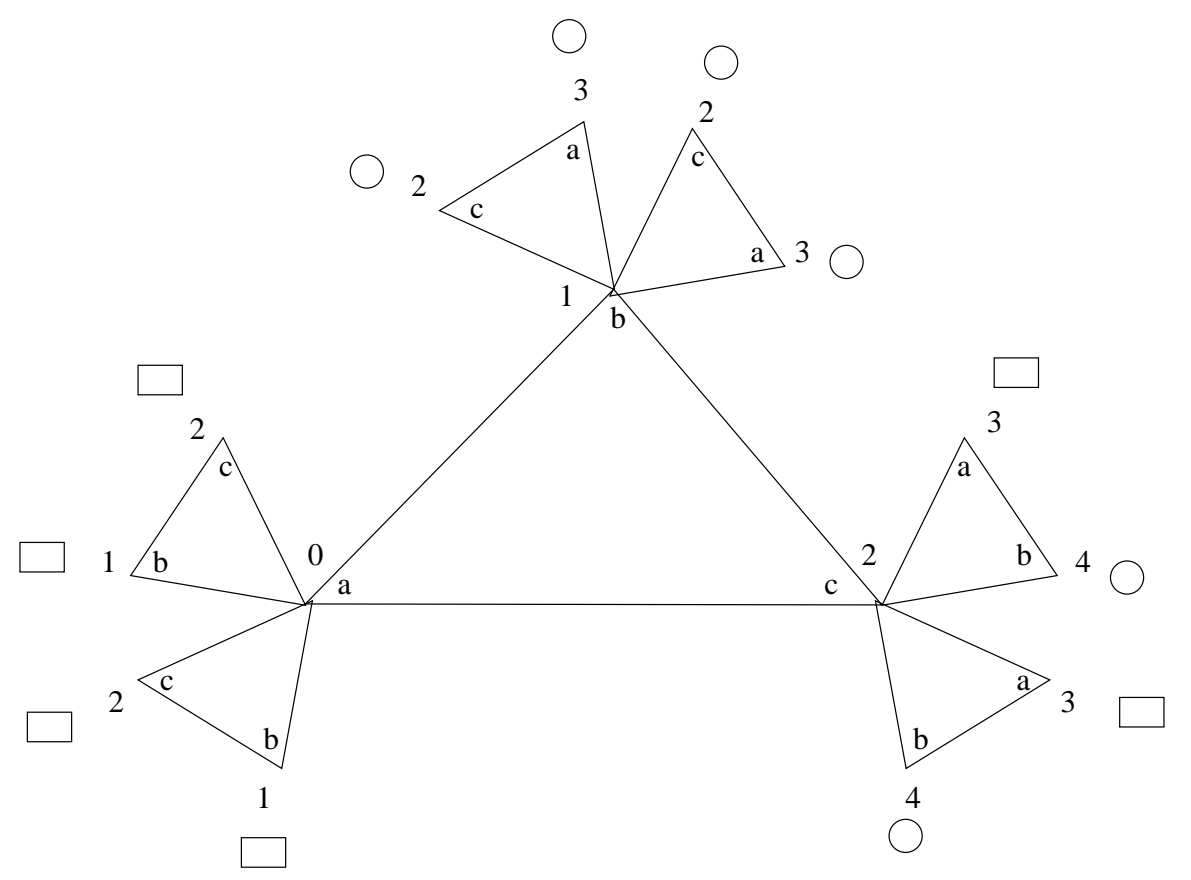

Figura 3.6: Parte central de um cacto de Husimi seqüencial com um triângulo como célula base, juntamente com o primeiro grupo de triângulos após o centro do cacto, são mostrados com os índices de geração e sub-rede em cada sítio. Usando a prescrição de Gujrati os sítios marcados com um quadrado $(\square)$ serão utilizados para construir 2 cáctus de Husimi com $M-1$ gerações e função de partição $\Xi_{3,1,2}^{M}$, enquanto os sítios marcados com um círculo $(\bigcirc)$ serão utilizados para construir 2 cáctus com $M-2$ gerações e função de partição $\Xi_{3,4,2}^{M}$. 
Juntando os quatro tipos de ramos listados acima, podemos montar dois pares de cáctus de Husimi com diferentes tipos: um tipo em que a célula central tem os sítios $a, b$ e $c$ nas gerações 3,1 e 2, e outro com os mesmos sítios nas gerações 3,4 e 2, respectivamente. Os sítios que serão usados para construir estes dois tipos de cacto estão marcados com símbolos diferentes na figura 3.6. Com esta figura também é fácil entender porque $\delta=3$, já que este é o número de sítios que sobra na árvore com $M$ gerações quando 'recortamos' os ramos exteriores ao triângulo central.

Usando os dois tipos de cacto obtidos acima, a prescrição de Gujrati para a energia livre no cacto de Husimi seqüencial resulta em:

$$
\phi=\frac{\Phi}{A}=\frac{\Phi_{0,1,2}^{(M)}-2 \Phi_{3,1,2}^{(M)}-2 \Phi_{3,4,2}^{(M)}}{3 a_{0}} .
$$

Para escrevermos $\phi$ em termos das funções de partição parcial normalizadas, $x\left(a, S_{a}\right)$, é conveniente colocar a função de partição do cacto de Husimi seqüencial no seguinte formato:

$$
\Xi_{0,1,2}^{(M)}=B_{0}^{2}(a) B_{1}^{2}(b) B_{2}^{2}(c) \sum_{S_{a}} x^{2 S_{a}^{2}}\left(a, S_{a}\right) f\left(a, S_{a}\right)
$$

onde o subscrito $k$ também foi omitido em $f\left(a, S_{a}\right)$ porque $k \ll M$.

O potencial grande canônico por unidade de área é obtido usando a relação $\Xi=e^{-\beta \Phi}$ e aplicando as eqs. 3.24 e 3.27 na eq. 3.26. Após alguns cálculos este procedimento resulta em

$$
\phi=-\frac{k_{B} T}{3 a_{0}} \ln \left[\prod_{l=a, b, c} \frac{f(l, 0)}{\sum_{S_{l}} x^{3 S_{l}^{2}}\left(l, S_{l}\right)}\right] .
$$

Finalmente, a pressão em uma dada temperatura $T$ e num potencial químico $\mu$ é simplesmente $P=-\phi$. No que se segue iremos introduzir o valor médio de algumas quantidades que serão investigadas no próximo capítulo.

\subsubsection{Valores médios no interior do cacto}

Para que possamos obter o valor médio de algumas propriedades, iremos definir a probabilidade de encontrar uma configuração molecular com os spins $S_{a}, S_{b}$ e $S_{c}$ no interior do cacto:

$$
P\left(S_{a}, S_{b}, S_{c}\right)=\frac{e^{-\beta h\left(S_{a}, S_{b}, S_{c}\right)} x^{2 S_{a}^{2}}\left(a, S_{a}\right) x^{2 S_{b}^{2}}\left(b, S_{b}\right) x^{2 S_{c}^{2}}\left(c, S_{c}\right)}{\sum_{S_{a}^{\prime}, S_{b}^{\prime}, S_{c}^{\prime}} e^{-\beta h\left(S_{a}^{\prime}, S_{b}^{\prime}, S_{c}^{\prime}\right)} x^{2 S_{a}^{\prime 2}}\left(a, S_{a}^{\prime}\right) x^{2 S_{b}^{\prime 2}}\left(b, S_{b}^{\prime}\right) x^{2 S_{c}^{\prime 2}\left(c, S_{c}^{\prime}\right)}}
$$


Com esta definição o valor médio de qualquer função $g\left(S_{a}, S_{b}, S_{c}\right)$ é simplesmente

$$
\left\langle g\left(S_{a}, S_{b}, S_{c}\right)\right\rangle=\sum_{S_{a}, S_{b}, S_{c}} g\left(S_{a}, S_{b}, S_{c}\right) P\left(S_{a}, S_{b}, S_{c}\right)
$$

Supondo que os estados moleculares correspondem aos valores de spin \pm 1 , a densidade por unidade de área ${ }^{2}$ no sítio $l$ do triângulo central fica dada por

$$
\rho_{l}=\left\langle S_{l}^{2}\right\rangle=\frac{x^{3}(l,+)+x^{3}(l,-)}{x^{3}(l,+)+x^{3}(l,-)+1},
$$

e a densidade média é simplesmente

$$
\rho=\sum_{l} \rho_{l} / 3
$$

Agora vamos considerar o Hamiltoniano interpolador, definido na eq. 2.11, para calcular a sua energia média por partícula, dada por

$$
u(\lambda)=\frac{1}{\rho}\left\langle h_{\mathrm{I}}(\lambda)-h_{\mu}\right\rangle,
$$

com $h_{\mu}$ definido na eq. (2.4).

Uma quantidade que é relevante para o modelo BL é o número de pontes de hidrogênio por partícula:

$$
\rho_{\mathrm{hb}}=-\frac{1}{\epsilon_{\mathrm{hb}} \rho}\left\langle h_{\mathrm{hb}}\right\rangle .
$$

Neste ponto, será interessante definir uma quantidade similar a $\rho_{h b}$ no contexto do modelo BEG. Para isto, vamos notar que o número médio de primeiros vizinhos por partícula é dado por

$$
\rho_{n n}=\frac{1}{\rho}\left\langle S_{a}^{2} S_{b}^{2}+S_{b}^{2} S_{c}^{2}+S_{c}^{2} S_{a}^{2}\right\rangle
$$

e que com esta definição, a eq. (3.33) é reescrita como

$$
u(\lambda=1)=u_{\mathrm{BL}}=-\epsilon_{\mathrm{hb}} \rho_{\mathrm{hb}}-\epsilon_{\mathrm{vdw}} \rho_{\mathrm{nn}},
$$

para o modelo BL, com $\lambda=1$, e

$$
\begin{aligned}
u(\lambda=0)= & u_{\mathrm{BEG}} \\
= & -|J|\left(-\frac{1}{\rho}\left\langle S_{a} S_{b}+S_{b} S_{c}+S_{c} S_{a}\right\rangle\right) \\
& -K \rho_{\mathrm{nn}},
\end{aligned}
$$

para o modelo BEG, $\operatorname{com} \lambda=0$.

\footnotetext{
${ }^{2} \mathrm{~A}$ partir daqui utilizamos uma unidade de área unitária e adimensional, i.e., $a_{0}=1$.
} 
Comparando as eqs. (3.36) e (3.37) podemos perceber que a quantidade

$$
\Delta \rho_{f}=-\frac{1}{\rho}\left\langle S_{a} S_{b}+S_{b} S_{c}+S_{c} S_{a}\right\rangle
$$

realiza, no modelo BEG, o mesmo papel do número de pontes de hidrogênio por partícula no modelo BL. É importante notar que $\Delta \rho_{f}$ possui o comportamento desejado em $T=0$, i.e., $\rho_{h b}=\Delta \rho_{f}$ para todos os estados estáveis da tabela 2.2, e que o líquido de baixa densidade não ligado se torna igual ao estado LDL no modelo BEG. No entanto, as definições $\rho_{h b}$ e $\Delta \rho_{f}$ não são iguais para as configurações instáveis. $\operatorname{Em} T=0$, por exemplo, o líquido orientado denso, da tabela 2.2, possui $\rho_{h b}=0$ enquanto $\Delta \rho_{f}=-1$.

Outra propriedade extensiva relevante é a entropia por partícula. Ela pode ser calculada numericamente da expressão do potencial grande canônico na eq. (3.26), através da seguinte derivada

$$
s=-\frac{1}{N} \frac{\partial \Phi}{\partial T}=-\frac{1}{\rho} \frac{\partial \phi}{\partial T},
$$

onde $N$ é o número de partículas de um sistema com uma área fixa $A$.

\subsubsection{Funções termodinâmicas de resposta}

Na seção 3.3.1 obtivemos o potencial grande canônico por sítio de um sistema de spin1 geral no interior do cacto de Husimi seqüencial. Como este potencial grande canônico foi obtido no ensemble grande canônico, teremos que efetuar uma mudança de variáveis para calcular as funções termodinâmicas de resposta, que são medidas experimentalmente no ensemble de Gibbs. Estes cálculos são relativamente simples e, por este motivo, vamos apenas listar as expressões das funções termodinâmicas de resposta segundo suas definições originais e no ensemble grande canônico. Uma abordagem mais detalhada das transformações de variáveis pode ser encontrada em livros-texto de termodinâmica e mecânica estatística [93].

O coeficiente de expansão térmica, $\alpha$, a compressibilidade isotérmica, $\kappa_{T}$, e o calor específico a volume constante, $c_{v}$, são definidos como:

$$
\begin{aligned}
\alpha & =\frac{1}{v}\left(\frac{\partial v}{\partial T}\right)_{P}, \\
k_{T} & =-\frac{1}{v}\left(\frac{\partial v}{\partial P}\right)_{T}, \\
c_{v} & =\left(\frac{\partial u}{\partial T}\right)_{v},
\end{aligned}
$$


onde $v=1 / \rho$ é o volume molecular e $u$ é a energia média por partícula, dada pela eq. (3.33).

Como as eqs. (3.22a)-(3.22c) estão escritas em termos das variáveis do ensemble grande canônico, é interessante reescrever as funções termodinâmicas de resposta das eqs. (3.40a)(3.40c) na representação adequada. Realizando as mudanças de variáveis adequadas, obtemos as seguintes expressões:

$$
\begin{aligned}
\alpha & =-\frac{1}{\rho}\left[\left(\frac{\partial \rho}{\partial T}\right)_{\mu}-\left(\frac{\partial \rho}{\partial \mu}\right)_{T} \frac{\left(\frac{\partial \phi}{\partial T}\right)_{\mu}}{\left(\frac{\partial \phi}{\partial \mu}\right)_{T}}\right], \\
k_{T} & =-\frac{1}{\rho} \frac{\left(\frac{\partial \rho}{\partial \mu}\right)_{T}}{\left(\frac{\partial \phi}{\partial \mu}\right)_{T}} \\
c_{v} & =\left(\frac{\partial u}{\partial T}\right)_{\mu}-\left(\frac{\partial u}{\partial \mu}\right)_{T} \frac{\left(\frac{\partial \rho}{\partial T}\right)_{\mu}}{\left(\frac{\partial \rho}{\partial \mu}\right)_{T}}
\end{aligned}
$$

onde foram utilizadas as relações $\rho=1 / v$ e $\phi=-P$.

Por fim, o calor específico a pressão constante, $c_{P}$, pode ser obtido das funções termodinâmicas de resposta descritas acima com a seguinte relação termodinâmica:

$$
c_{P}=c_{v}+\frac{T \alpha^{2}}{\rho \kappa_{T}}
$$

que independe da representação utilizada. 


\section{Capítulo 4}

\section{Resultados e Discussão}

\subsection{Diagramas de fase e propriedades termodinâmicas}

Começamos nossa análise comparando os diagramas de fase dos dois modelos, em temperaturas finitas e para diferentes razões entre as magnitudes da interação de van der Waals e da ligação de hidrogênio, na figura 4.1. Estes valores foram escolhidos em um intervalo que, no modelo BL, satisfaz: i) a condição de estabilidade da fase LDL, $\zeta(1)=\epsilon_{\mathrm{vdw}} / \epsilon_{\mathrm{hb}}<1 / 3$, e ii) a restrição de uma interação de van der Waals atrativa (ou um acoplamento biquadrático de spin atrativo, no modelo BEG), $\zeta(1)=\epsilon_{\mathrm{vdw}} / \epsilon_{\mathrm{hb}}>0$. Embora esta última restrição tenha sido utilizada para tornar o sistema fisicamente plausível, o uso de interações de van der Waals repulsivo, neste modelo, tornaria o diagrama de fases do modelo BL menos parecido com a água, por levar o ponto crítico da transição líquido-gás a uma região metaestável profunda.

As unidades reduzidas usadas neste trabalho estão definidas na tabela 4.1. As transições de fase, temperaturas de extremo de densidade e o loci de entropia nula são mostrados com linhas e símbolos diferentes na figura 4.1. O loci de entropia nula foi calculado para

Tabela 4.1: Variáveis reduzidas utilizadas nos modelos Bell-Lavis e Blume-Emery-Griffiths antiferromagnético.

\begin{tabular}{ccc}
\hline \hline & BL & BEG \\
\hline$t$ & $k_{B} T / \epsilon_{\mathbf{h b}}$ & $k_{B} T /|J|$ \\
$p$ & $P a_{0} /\left(\epsilon_{\mathbf{h b}}-3 \epsilon_{\mathrm{vdw}}\right)$ & $P a_{0} /(|J|-3 K)$ \\
$\kappa_{t}$ & $\left(\epsilon_{\mathbf{h b}}-3 \epsilon_{\mathrm{vdw}}\right) \kappa_{T} / a_{0}$ & $(|J|-3 K) \kappa_{T} / a_{0}$ \\
$c_{v}$ & $c_{V} / k_{B}$ & $c_{V} / k_{B}$ \\
$c_{p}$ & $c_{P} / k_{B}$ & $c_{P} / k_{B}$ \\
\hline \hline
\end{tabular}


identificar as temperaturas abaixo da qual o sistema apresenta entropias negativas. Este é um fenômeno físicamente impossível que tipicamente aparece em soluções aproximadas de sistemas estatísticos.

Embora exista um mapeamento perfeito na topologia dos diagramas de fase em $t=0$, a temperatura introduz diferenças no comportamento termodinâmico dos dois modelos. A primeira diferença que notamos é que a anisotropia da interação no modelo BL favorece a fase LDL, visto que esta fase é estável em uma região com temperaturas e pressões maiores que a fase antiferromagnética do modelo BEG. Isto está relacionado ao comportamento da entropia, que pode ser deduzido com a aplicação da equação de Clausius-Clapeyron na coexistência líquido-líquido. Em temperaturas altas, uma inclinação negativa na linha de coexistência entre os dois líquidos indica que, nos dois modelos, a fase HDL é mais entrópica que a fase LDL. Contudo, em baixas temperaturas, o modelo BL apresenta uma inclinação positiva na coexistência entre os dois líquidos, indicando que a fase LDL é mais entrópica do que a fase HDL.

Os dois modelos possuem uma coexistência entre as fases gasosa e HDL terminando em um ponto crítico. A posição deste ponto, no diagrama de pressões e temperaturas, desloca-se para baixo com a diminuição na intensidade da interação de van der Waals (ou do acoplamento biquadratico de spin). No modelo BL este deslocamento produz mudanças sensíveis no diagrama de fases, já que o ponto crítico atravessa a coexistência gás-LDL, tornando-se metaestável para algum $\zeta^{\prime}$ no intervalo $1 / 4<\zeta^{\prime}<1 / 10$. Embora os gráficos 4.1 (a), (b), (d) e (f) aparentem indicar a existência de uma linha contínua ligando as transições gás-HDL e gás LDL, este é apenas um efeito visual causado pela distância do ponto triplo. De fato, no ponto triplo estas duas linhas coexistência formam um ângulo que, embora não tenha sido calculado para este modelo, deve ser menor que $180^{\circ}[94,95]$.

Procuramos pela anomalia na densidade na fase líquida de alta densidade. As linhas de máximo de densidade são mostradas na figura 4.1, e possuem um comportamento similar nos dois modelos, para os mesmos valores de $\zeta$. A linha TMD encontra-se com a coexistência LDL-HDL a temperatura nula e numa pressão $p=1$. É importante lembrar que, no modelo BL, a linha de máximos de densidade sempre ocorre na fase HDL metaestável. No modelo BEG, por outro lado, a TMD ocorre em uma região estável da fase HDL, para $\zeta=1 / 4$, e ela ocorre parcialmente numa região estável e parcialmente numa 


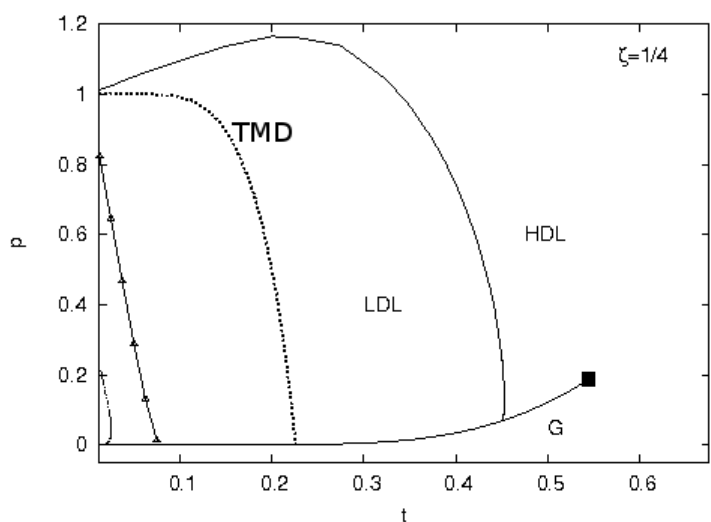

$\mathrm{b}$
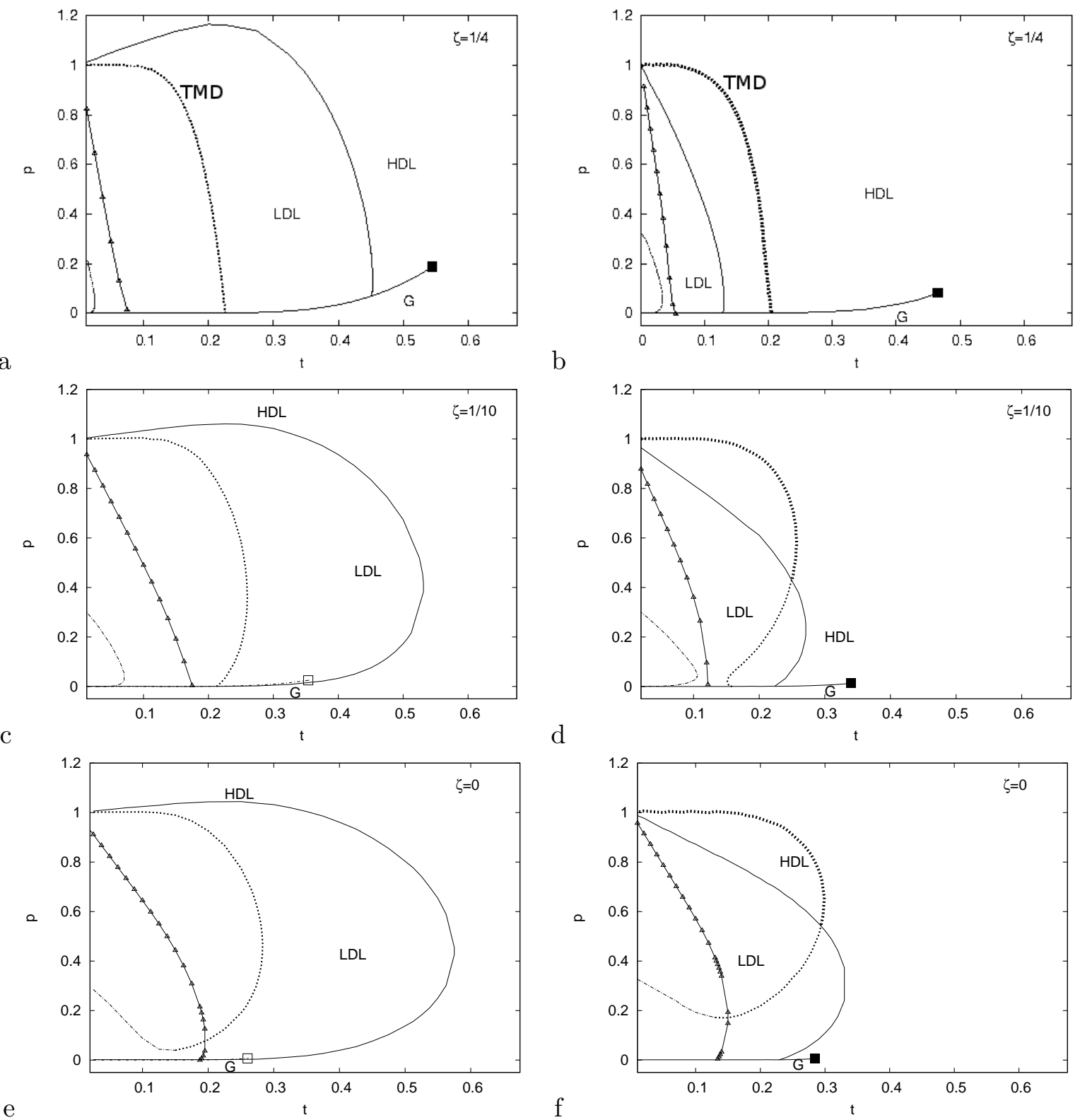

Figura 4.1: Os diagramas de fase temperatura vs. pressão dos modelo Bell-Lavis (esquerda) e Blume-Emery-Griffiths antiferromagnético (direita) são comparados com valores de interação $\zeta$ iguais a $1 / 4,1 / 10$, e 0 . As fases estão indicadas na notação de fluido como G (gás), HDL (líquido de alta densidade) e LDL (líquido de baixa densidade). Transições de fase de primeira ordem são representadas por uma linha e o ponto crítico da coexistência entre o gás e o HDL está marcada com um quadrado. Note que um quadrado não preenchido é utilizado para indicar a metaestabilidade do ponto crítico em (c) e (e). A localização dos máximos e mínimos na densidade, em função da temperatura a pressão constante na fase HDL, são exibidos com linhas pontilhadas e tracejadas pontilhadas, respectivamente. Note que no modelo BEG o máximo de densidade pode ocorrer numa região estável. Uma linha conectada por triângulos indica a temperatura abaixo da qual a entropia na fase HDL é negativa, em cada gráfico. 
região metaestável, da fase HDL, para $\zeta=1 / 10$ e $\zeta=0$. Linhas de mínimo de densidade também foram encontradas em ambos os modelos, numa região metaestável da fase HDL em baixas temperaturas (veja a fig. 4.1).

Para $\zeta=1 / 4$, a linha TMD metaestável possui uma inclinação negativa quando encontra a coexistência do líquido com a fase gasosa, em baixas pressões. Este resultado está de acordo com um estudo anterior realizado por Bell e Lavis (Ref. [6]), onde algumas poucas curvas de densidade, em função da temperatura a pressão fixa, são mostradas.

Para $\zeta=1 / 10$, a linha de mínimos de densidade é deslocada para altas temperaturas e a TMD se desloca para temperaturas mais baixas, a baixas pressões. No caso do modelo BEG, a derivada da linha TMD muda de sinal duas vezes, deslocando-se novamente para altas temperaturas um pouco antes de encontrar a coexistência do líquido com a fase gasosa.

Para $\zeta=0$, as linhas de máximo e mínimo de densidade se fundem em uma única curva, na menor pressão pela qual a curva passa. Um comportamento similar também foi observado em diferentes modelos com interações orientacionais (veja a fig. 4 da ref. [73] e a fig. 5 da ref. [23]). Tanto no modelo BEG quanto no modelo BL, uma única linha de extremos de densidade surge em algum valor de $\zeta$ entre $1 / 10$ e 0 , possivelmente com um valor maior de $\zeta$ no modelo BEG, devido à proximidade das duas linhas com extremos de densidade mostradas na figura 4.1 (d). É importante lembrar que com $\zeta=0$ o modelo BEG torna-se equivalente ao modelo antiferromagnético de Blume-Capel na rede triangular. Mesmo neste caso, em que existe apenas um acoplamento bilinear antiferromagnético de spins, encontramos um máximo na densidade em função da temperatura, a pressão fixa.

Assim como em outros casos, as soluções analíticas obtidas pelo procedimento de Bethe [90] podem apresentar uma região não-física, no diagrama de fases, em que a entropia do sistema se torna negativa.

Nós observamos estas regiões na fase HDL metaestável para todos os valores de $\zeta$, como é mostrado na figura 4.1. Inspecionando estas regiões de entropia negativa, podemos concluir que o mínimo de densidade observado em ambos os modelos não é fisicamente plausível, pelo menos na aproximação utilizada neste trabalho. 


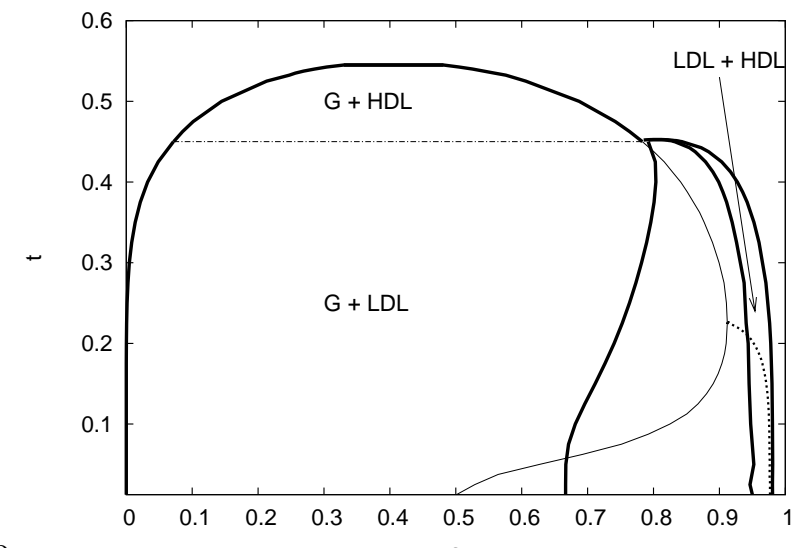

a

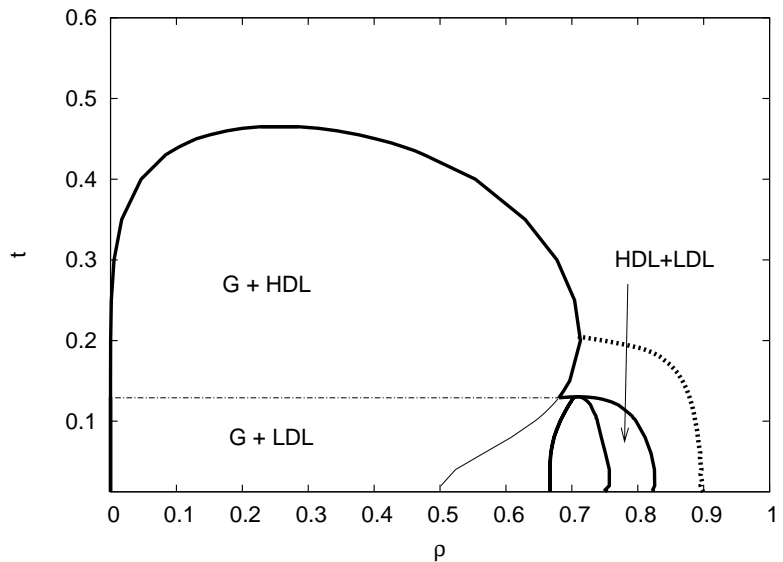

Figura 4.2: Diagrama de fase temperatura vs. densidade dos modelos (a) Bell-Lavis e (b) BlumeEmery-Griffiths antiferromagnético com a interação $\zeta=1 / 4$. Os rótulos das fases são os mesmos utilizados na fig. 4.1. As transições de fase e a continuação metaestável da coexistência entre o gás e a fase HDL são mostradas com linhas largas e estreitas, respectivamente. Os máximos de densidade e o ponto triplo são mostrados com linhas pontilhadas e tracejadas com pontilhados, respectivamente.

\subsection{1 $\mathrm{O}$ caso $\zeta=1 / 4$}

De agora em diante vamos considerar o caso $\zeta=1 / 4$ em detalhe. A fig. 4.2 mostra o diagrama de fase da densidade pela temperatura, nos dois modelos. Apenas as linhas de coexistência, estáveis ou metaestáveis, as linhas de máximo de densidade e o ponto triplo são mostrados, para simplificar a visualização.

No modelo BL a anomalia na densidade ocorre em um regime metaestável e uma reentrância pode ser notada na continuação metaestável da coexistência gás-HDL, quando a linha TMD e a linha da coexistência se encontram. A linha TMD metaestável alcança o limite de temperatura nula em uma densidade $\rho_{0}^{\prime}=0,976 \pm 0,016$, que é compatível com o valor $\rho_{0}=0,9763$, encontrado por Lavis no limite $t=0$ e $p=1[6]$. A coexistência 


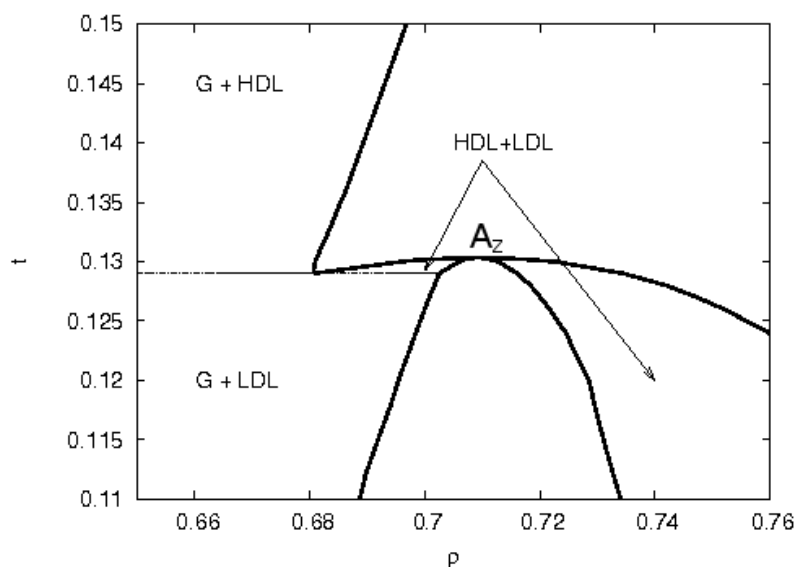

Figura 4.3: Diagrama de fase temperatura vs. densidade do modelo de Blume-Emery-Griffiths antiferromagnético, da fig. 4.2, é mostrado na vizinhança do ponto triplo. O ponto azeotrópico está indicado por $A_{Z}$ e os outros rótulos são os mesmos das figs. 4.1 e 4.2.

entre as fases LDL e HDL é muito fina e ocorre majoritariamente em densidades maiores que 0,7 . Próximo ao ponto triplo existe um ponto azeotrópico, $A_{Z}$, onde duas regiões de coexistência se encontram. Este ponto está relacionado à existência de uma região com densidades relativas invertidas, nas fases líquidas, e corresponde a uma pequena região em que a derivada da linha de coexistência, $d p_{\text {coex }} / d t$, é positiva.

No modelo BEG a linha TMD encontra a coexistência de fase gás-HDL em um regime estável e uma reentrância pode também pode ser vista, como mostrado na fig. 4.2 (b).

A linha TMD encontra o limite de temperatura nula em uma densidade $\rho^{\prime \prime}{ }_{0}=0,89 \pm$ 0,025. A coexistência LDL-HDL ocorre em temperaturas e densidades mais baixas que a coexistência líquido-líquido do modelo BL. Próximo ao ponto triplo também existe um ponto azeotrópico $A_{Z}$ que pode ser melhor visualizado na figura 4.3.

No modelo BEG, a região que apresenta densidades invertidas na coexistência LDLHDL é um pouco maior, correspondendo a $d p_{\text {coex }} / d t>0$ em um intervalo maior de pressões.

No limite de temperatura nula, a coexistência gás-LDL termina em uma densidade $2 / 3$, em ambos os modelos, enquanto a continuação metaestável da linha de coexistência gás-HDL acaba numa densidade $1 / 2$. A densidade $2 / 3$ foi utilizada na análise de estado fundamental do capítulo 2 para descrever a fase LDL. Nesta análise foram encontrados os valores $t=0$ e $p=1$ para as transições gás-LDL e LDL-HDL, respectivamente. Estes valores são idênticos aos encontrados nos diagramas de fase mostrados na figura 4.1.

Contudo, no limite $t=0$, a densidade da fase LDL na coexistência LDL-HDL, obtida 
com os cálculos no cactus de Husimi, é igual a $\rho_{L D L}=0,95 \pm 0,005$. No lado HDL desta coexistência encontramos a densidade $\rho_{H D L}=0,98 \pm 0,0005$. Estas densidades são ligeiramente diferentes dos valores $\rho_{L D L}^{\prime}=0,8963$ e $\rho_{H D L}^{\prime}=0,9763$, encontrados em $t=0$ na aproximação utilizada por Lavis [7]. No modelo BEG as densidades correspondentes são $\rho_{L D L}^{\prime \prime}=0,75 \pm 0,03$ e $\rho_{H D L}^{\prime \prime}=0,83 \pm 0,02$.

Na fig. 4.4 as propriedades estruturais da fase HDL dos dois modelos são comparadas, a pressões equivalentes, em função da temperatura. No estado fundamental, quantidades nos dois modelos tendem para o mesmo valor, exceto pela entropia em pressões pequenas. A anomalia na densidade está presente em todas as pressões $p<1$, mas esta alcança maiores densidades no modelo BL.

Ao mesmo tempo em que ocorre o aumento na densidade existe um decréscimo rápido no número de pontes de hidrogênio por partícula, $\rho_{\mathrm{hb}}$, e na quantidade correspondente do modelo BEG, $\Delta \rho_{\mathrm{f}}$. Este decréscimo é menos acentuado no modelo BEG, que também apresenta um incremento menor na densidade na região anômala. A entropia por partícula geralmente é maior no modelo BEG, mas no limite de temperatura nula, em altas pressões $(p>1)$, a entropia converge para um valor finito idêntico nos dois modelos. Esta entropia residual está associada a uma degenerescência no estado fundamental, que permite que várias configurações com a mesma energia livre estejam presentes nesta região.

O comportamento termodinâmico das funções resposta dos dois modelos na fase HDL é comparado na fig. 4.5. A compressibilidade isotérmica, mostrada nas figs. 4.5 (a) e (b), apresenta um máximo para pressões $p<1$, que aumenta em magnitude na medida em que a pressão $p=1$ é alcançada pelo limite inferior. A capacidade térmica a pressão constante também apresenta máximos cujas posições se deslocam à medida que $p=1$ é aproximado pelo limite inferior. Por outro lado, a capacidade térmica a volume constante possui máximos em pressões baixas, mas o tamanho deste diminui até desaparecer, na medida em que a pressão aumenta se aproximando de $p=1$.

\subsection{Discussão}

Na seção anterior mostramos que uma linha de máximos de densidade existe em uma região extensa de pressões e temperaturas, tanto no modelo BL quanto no modelo BEG (veja fig. 4.1), para interações no intervalo: 
a
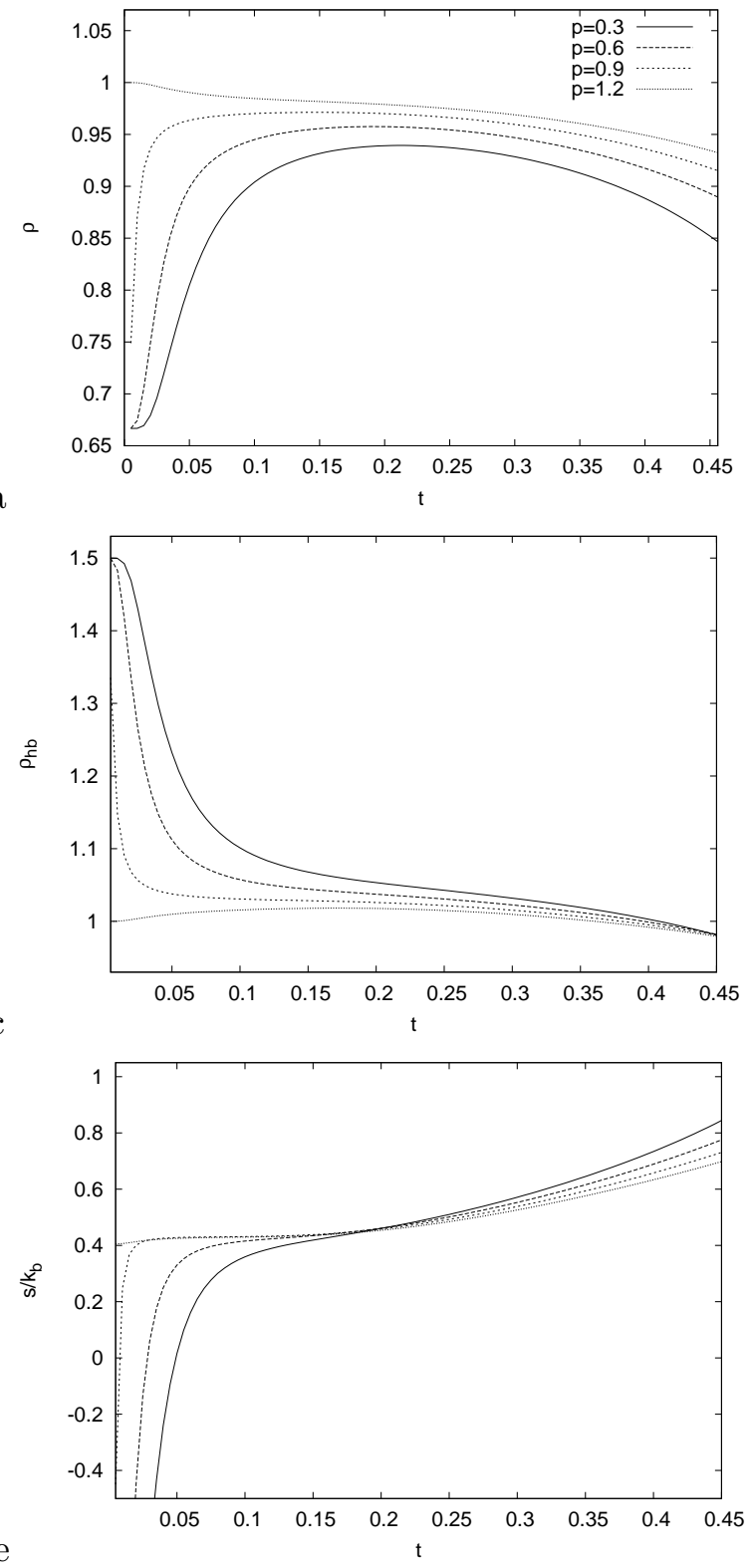
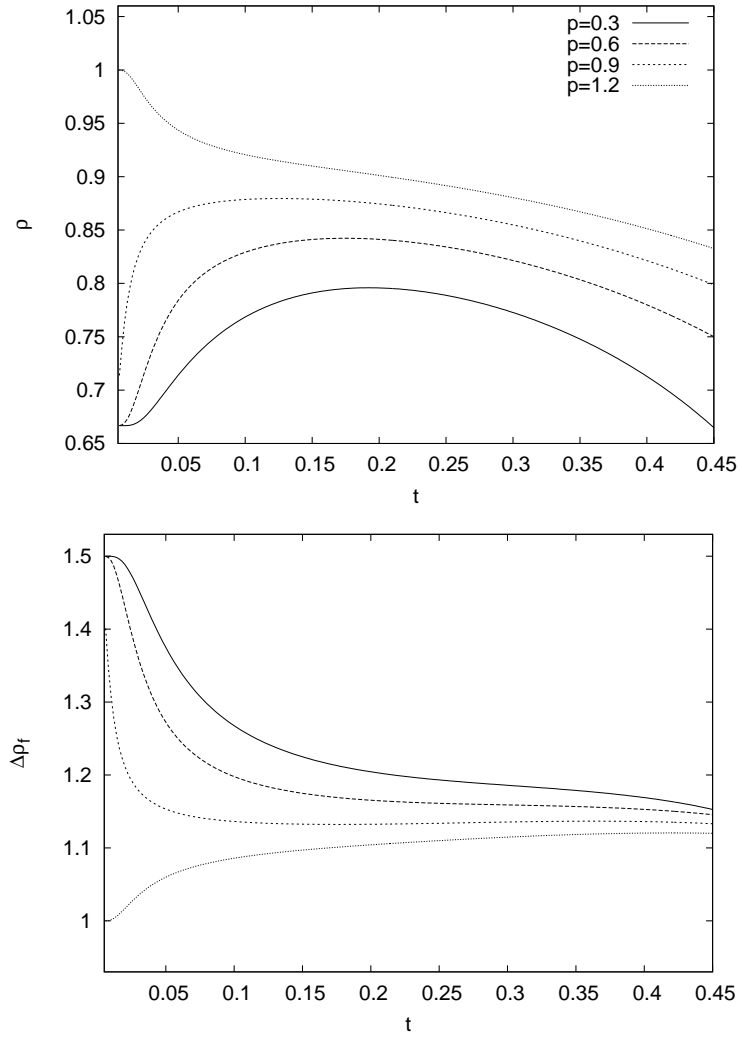

d

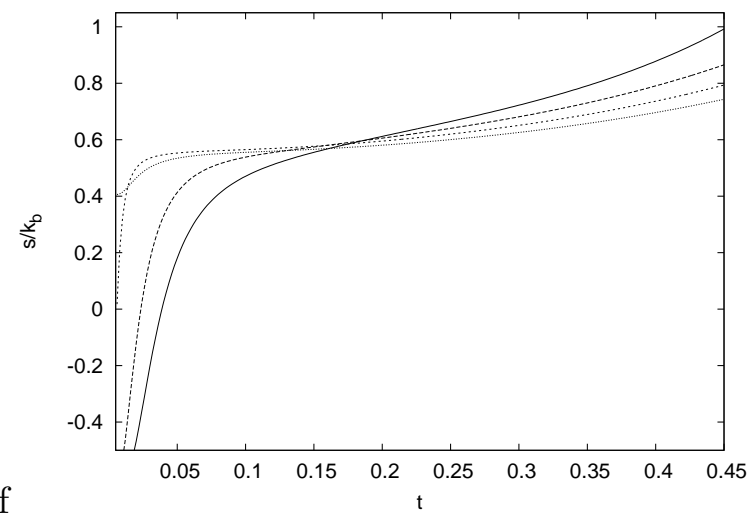

Figura 4.4: As quantidades estruturais, em nível molecular, dos modelos Bell-Lavis (à esquerda) e Blume-Emery-Griffiths (à direita) antiferromagnético são comparados com a interação $\zeta=1 / 4$. De cima para baixo são mostrados: densidade em (a) e (b), o número de pontes de hidrogênio por partícula (c), a quantidade $\Delta \rho_{\mathrm{f}}$ (d), e a entropia por partícula, em (e) e (f). 

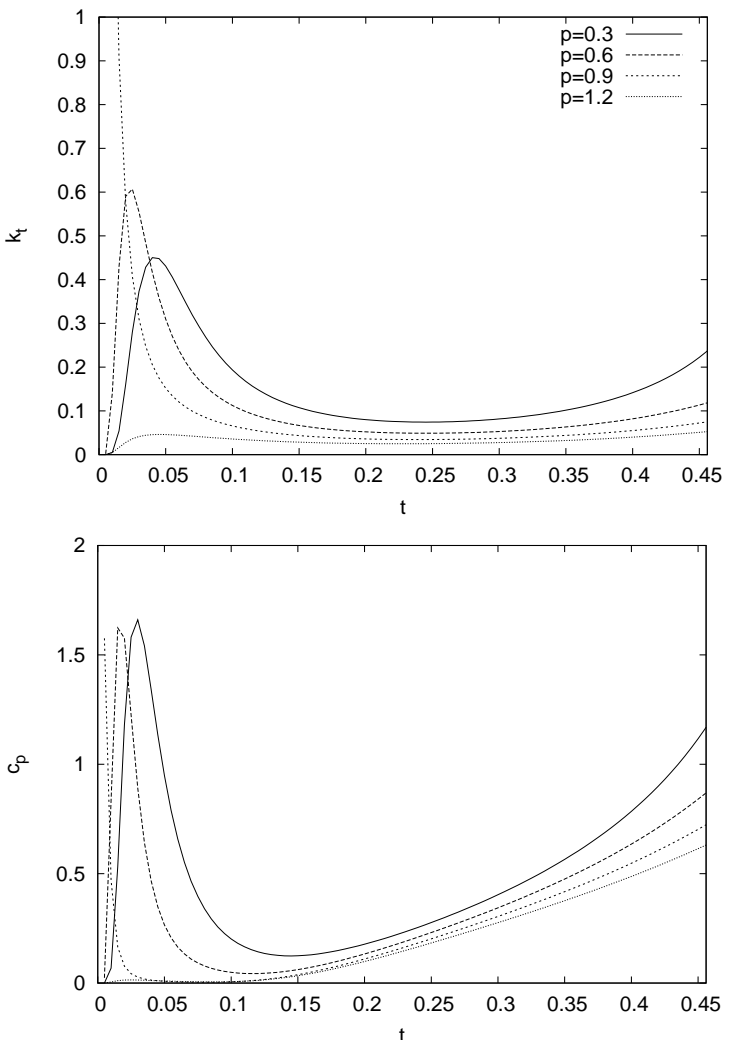

$\mathrm{c}$

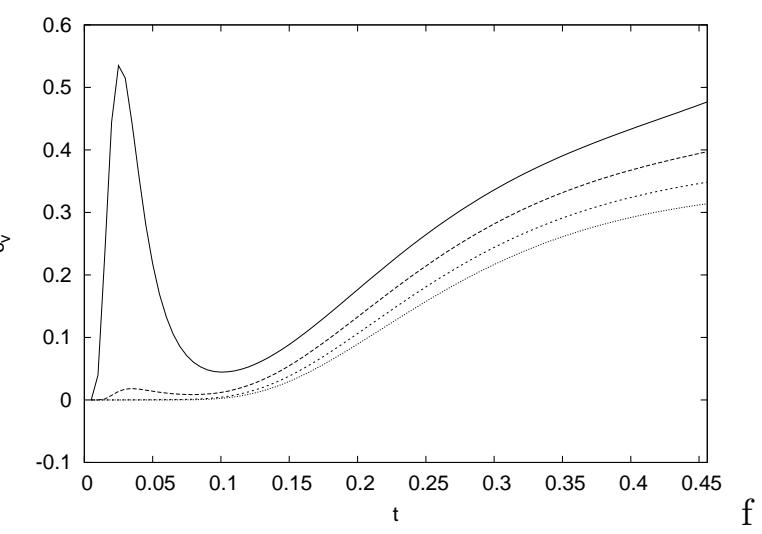

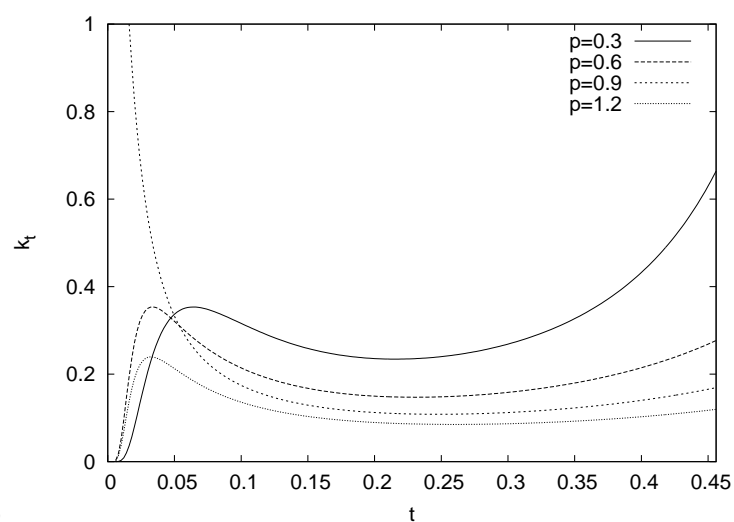
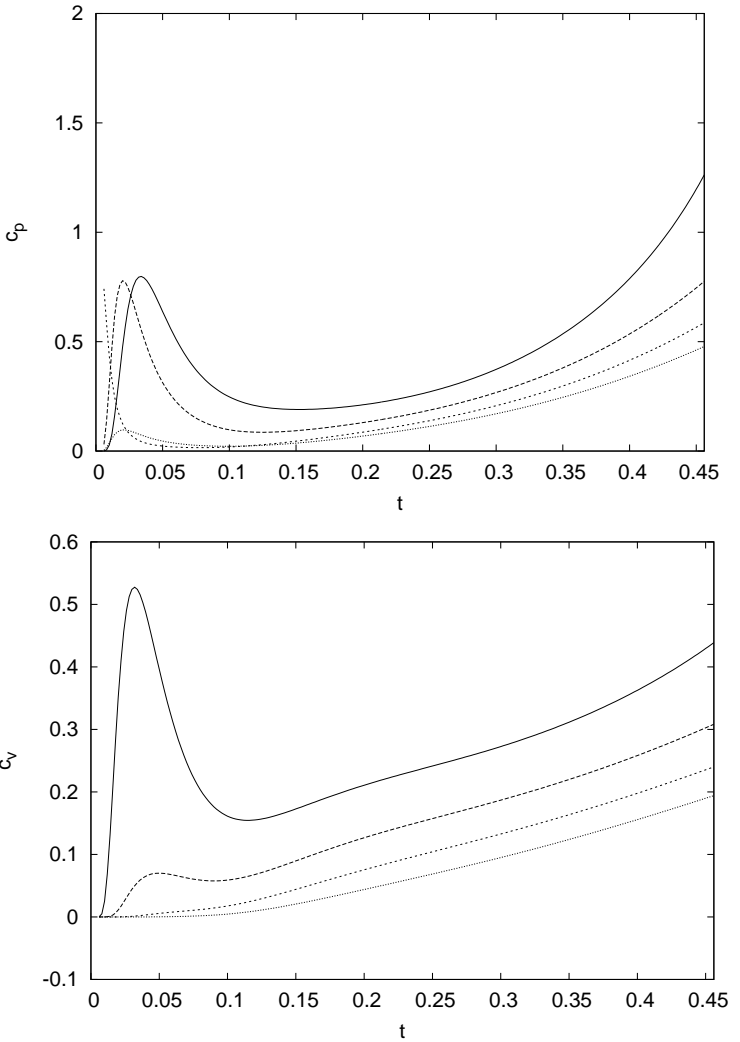

Figura 4.5: As funções termodinâmicas de resposta dos modelos Bell-Lavis (à esquerda) e BlumeEmery-Griffiths antiferromagnético (à direita) são comparadas para a interação $\zeta=1 / 4$ em função da temperatura, a pressão constante. De cima para baixo são exibidas a compressibilidade isotérmica $\kappa_{t}$ e as capacidades térmicas $c_{p}$ e $c_{v}$. 


$$
0 \leq \zeta \leq 1 / 4
$$

É importante enfatizar o significado desta desigualdade. A condição $0 \leq \zeta$ reflete a exigência de que a interação de van der Waals seja atrativa. No outro lado, a condição $\zeta \leq 1 / 4$ garante a estabilidade da fase LDL em $t=0(\zeta<1 / 3$, veja a fig. 2.2).

Aparentemente, a existência da fase LDL é necessária para que exista uma anomalia na densidade nos modelos BL e BEG, por que ela indiretamente cria uma competição entre a energia livre de duas estruturas na fase HDL, uma estrutura normal e uma estrutura ligada. A estrutura HDL normal ocorre em temperaturas altas, enquanto a estrutura HDL ligada aparece como um líquido metaestável, em uma região em que o LDL é estável em baixas pressões $(p<1)$. Esta 'nova' estrutura HDL ligada parece 'emprestar' algumas das propriedades da estrutura do líquido na fase LDL. Esta idéia será melhor discutida logo abaixo.

\subsubsection{Coexistência líquido-líquido}

A estabilidade da fase LDL pode ser facilmente estabelecida se olharmos para a energia livre de Gibbs no estado fundamental. Numa pressão nula e em $t=0$, a energia livre por partícula é dada por $g(p=0, t=0)=u$ e o gás coexiste com a fase líquida que possuir a menor energia. Inspecionando a tabela 2.2 pode-se verificar que a energia da fase LDL é menor que a da fase HDL se a energia de cada ponte de hidrogênio for pelo menos três vezes maior que a energia da interação de van der Waals. Nesta condição, à medida que a pressão aumenta, em um determinado ponto o trabalho realizado pela compressão suprime a diferença de energia livre entre as diferentes estruturas líquidas. Neste ponto, ou seja, em $p=1$, o sistema passa por uma coexistência e entra na fase HDL líquida.

Os dois modelos apresentam uma pequena coexistência líquido-líquido, como é mostrado nos diagramas de fases nas figuras 4.2 e 4.3. No caso do modelo BL, existe uma controvérsia sobre a ordem desta transição. Nos estudos iniciais feitos por Lavis foi encontrado que, numa aproximação com três sub-redes, esta transição era de primeira ordem. Em estudos posteriores, baseados no grupo de renormalização no espaço real, esta transição foi encontrada como sendo de segunda ordem. Mais recentemente, Patrykiejew e colaboradores [86] investigaram, com simulações de Monte Carlo, uma versão modificada do modelo BL, ao qual foi adicionada uma interação repulsiva de três corpos. O principal 
resultado deste trabalho foi que a transição entre as fases líquidas ocorria através de uma descontinuidade no calor específico, que corresponde a uma transição de fase de segunda ordem, segundo a classificação de Ehrenfest [96]. Estas simulações incluíram o modelo BL original, com a interação $\zeta=\epsilon_{\mathrm{vdw}} / \epsilon_{\mathrm{hb}}=1 / 4$ (veja a fig. 4(a) na ref. [86]).

Apesar deste resultado, é possível que a transição LDL-HDL possa representar um exemplo de uma transição de primeira ordem fraca, como foi encontrado para o modelo de Potts de três estados antiferromagnético na rede triangular [97]. Para esclarecer esta questão, serão necessários estudos adicionais, tanto usando uma metodologia que permita distinguir entre transições de segunda ordem e transições de primeira ordem fracas [98], como a dinâmica de tempos curtos [99], ou investigando os histogramas de um parâmetro de ordem de quiralidade [97], que no modelo BL corresponde ao termo anisotrópico indicado na eq. (2.8).

\subsubsection{Propriedades anômalas do líquido de alta densidade}

A metaestabilidade da linha TMD parece ser a principal deficiência do modelo BL, como modelo para a água líquida. Entretanto, os resultados das simulações de Monte Carlo feitas por Patrykiejew e colaboradores [86], sugerem que a linha de máximos de densidade encontra a coexistência gás-HDL em uma região estável. Este trabalho [86] apresenta o diagrama de fases densidade vs. temperatura, para o modelo BL $\operatorname{com} \zeta=1 / 4$ (fig. 4.6), que pode ser comparado com o diagrama que obtivemos na rede de Husimi [fig. 4.2 (a)]. Nos dois casos, a densidade da fase HDL, sobre a linha de coexistência gásHDL, aumenta em uma certa temperatura. Nas simulações, este aumento ocorre numa região estável, ao passo que nossos resultados analíticos indicam que este aumento ocorre numa região metaestável.

Há uma relação interessante que interliga o encontro da linha TMD com a linha de coexistência e uma densidade crescente com a temperatura, nesta coexistência. A inclinação da função densidade no líquido, $\rho(T, P)$, ao longo da linha de coexistência, e na direção do ponto crítico, pode ser expressa como

$$
\begin{aligned}
\left(\frac{\partial \rho}{\partial T}\right)_{\operatorname{coex}} & =\left(\frac{\partial \rho}{\partial T}\right)_{P} \cos \theta+\left(\frac{\partial \rho}{\partial P}\right)_{T} \sin \theta \\
& =\rho \kappa_{T} \sin \theta-\rho \alpha \cos \theta
\end{aligned}
$$

onde $\theta \equiv \theta(T, P)$ é o ângulo entre a tangente à linha de coexistência $P_{\text {coex }}(T)$ e o eixo $T, \alpha$ e $\kappa_{T}$ são o coeficiente de expansão térmico e a compressibilidade isotérmica, dados 


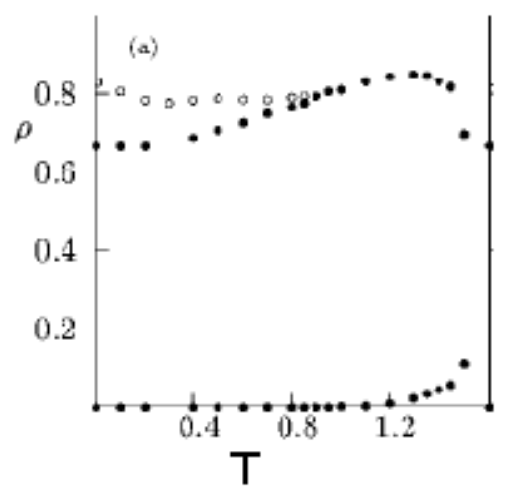

Figura 4.6: Diagrama de fases $\rho$ vs. $T$ do modelo BL, $\operatorname{com} \zeta=1 / 4$, de acordo com as simulações de Patrykiejew. Círculos preenchidos marcam os dois lados da coexistência gás-HDL e círculos vazios indicam a localização da transição de fase entre os líquidos HDL-LDL. Extraído da ref. [86].

pelas eqs. (3.41a) e (3.41b).

Considerando que o líquido é mais denso e menos entrópico que o gás (i.e., $0<\theta<\pi / 2$ ) podemos concluir da eq. $4.2 \mathrm{~b}$ que:

i) se a linha de máximos de densidade encontrar a linha de coexistência, a densidade do líquido, na coexistência, deve aumentar em função da temperatura no ponto de encontro;

ii) se a densidade do líquido aumentar com a temperatura será possível, mas não necessário, que a linha de máximos de densidade encontre a linha de coexistência;

iii) ao contrário, se a densidade do líquido decrescer com sua temperatura ao longo da coexistência, $(\partial \rho / \partial T)_{\text {coex }}<0$, teremos $\alpha>0$, i.e., a linha de coexistência não poderá cruzar a linha de anomalia na densidade.

Nossos resultados na rede de Bethe estão de acordo com este critério. Além disso, o encontro da linha TMD com a linha de coexistência parece coincidir com a máxima densidade na coexistência, no regime metaestável da fase HDL (veja a figura 4.2). Nas simulações feitas por Patrykiejew e colaboradores [86], não existe nenhum dado sobre a linha TMD, mas o diagrama de fases (estável) $\rho$ vs. $T$, mostrado na figura 4.6, apresenta um máximo para a densidade da fase líquida, indicando que é possível que uma linha TMD estável passe por aquela região.

Tanto no modelo BL, quanto no modelo BEG, o aumento anômalo na densidade, em baixas temperaturas, e para $p<1$, é acompanhado por uma diminuição rápida no 
número de pontes de hidrogênio por partícula (ou em $\Delta \rho_{\mathrm{f}}$, no modelo BEG), bem como por um aumento rápido na entropia por partícula, como pode ser visto na fig 4.4. Estas características são enfatizadas na fase HDL metaestável do modelo BL.

Considerando este comportamento, podemos distinguir duas estruturas diferentes na fase HDL: uma estrutura líquida ligada, cuja densidade aumenta com a temperatura, e uma estrutura líquida normal. A estrutura líquida ligada ocorre em baixas temperaturas e pressões e é limitada pela linha TMD, enquanto a estrutura líquida normal que ocorre em altas pressões, $p>1$, e em altas temperaturas, $t>t_{\mathrm{TMD}}$. Conforme dito anteriormente, a estrutura HDL ligada é muito similar ao LDL, no sentido de que é menos densa e faz mais pontes de hidrogênio que a estrutura HDL normal. Entretanto, a estrutura HDL ligada possui a mesma simetria da fase HDL (paramagnética) e não possui o ordenamento de sub-redes característico da fase LDL (antiferromagnética). Por este motivo, não é possível localizar a rede de pontes de hidrogênio na estrutura HDL ligada, ou mesmo especificar as sub-redes que estão cheias ou vazias, como ocorre na fase LDL.

As estruturas dos líquidos HDL, ligado e normal, possuem diferentes mecanismos para aumentar a entropia do sistema, com o aumento da temperatura. No HDL normal, ganha-se entropia com o aumento no número de arranjos espaciais das moléculas, ou seja, com o aumento no volume molecular. No HDL ligado, por outro lado, a entropia aumenta, mesmo com o decréscimo no volume molecular, devido ao aumento no número de configurações da rede de pontes de hidrogênio (ou na rede de acoplamentos de $\Delta \rho_{\mathrm{f}}$, no caso do modelo BEG) e a frustração exerce um papel importante neste caso. A frustração impede que novas pontes sejam criadas à medida que partículas são inseridas na rede, com o aumento da densidade. Assim, enquanto o número de pontes de hidrogênio por partícula diminui, o número de pontes por unidade de volume permanece constante, resultando em um aumento rápido no número de configurações permitidas e, conseqüentemente, na entropia. Mas as estruturas HDL ligada e normal possuem a mesma simetria, de forma que com o aumento da temperatura (e da densidade), a estrutura ligada eventualmente se torna igual à estrutura normal sem que ocorra uma transição de fase. Desta forma, a linha TMD pode ser considerada o ponto médio de uma mudança contínua entre duas estruturas na mesma fase termodinâmica.

O efeito da pressão na estrutura HDL ligada pode ser deduzido se notarmos que a pressão também contribui para a diminuição do volume molecular. Assim, em pressões 
mais altas (mas ainda abaixo de $p=1$ ) a mudança entre as estruturas HDL ligada e HDL normal é favorecida e ocorre em temperaturas mais baixas. Concomitantemente, a localização da linha TMD é deslocada para temperaturas mais baixas, tendendo a $t=0$ em $p=1$. Os parâmetros estruturais do líquido também são afetados e o valor absoluto das taxas de variação da densidade, da entropia e do número de pontes de hidrogênio por partícula aumentam significativamente quanto $p=1$ é aproximado pelo limite inferior, veja a fig. 4.4. No caso da estrutura HDL normal, o papel desempenhado pela pressão é o oposto do que acabamos de discutir, resultando em taxas de variação absolutas menores daquelas quantidades.

Comparando os modelos BL e BEG [fig. 4.4 (a) e (b)] vemos que este último apresenta uma variação mais suave na densidade, acompanhada por uma variação menos abrupta em $\Delta \rho_{\mathrm{f}}$, em relação a $\rho_{\mathrm{hb}}$ no modelo BL. A entropia, por outro lado, apresenta taxas maiores de variação no modelo BEG. Este fato está relacionado à existência de maior número de estados compatíveis com a formação de um acoplamento $\Delta \rho_{\mathrm{f}}$ do que com a formação de uma ponte de hidrogênio, em cada par de moléculas.

Devido à esta 'flexibilidade' do modelo BEG, uma menor variação na densidade é suficiente para maximizar a entropia da rede de acoplamentos $\Delta \rho_{\mathrm{f}}$. Pela mesma razão, $\Delta \rho_{\mathrm{f}}$ tende a um valor limite, em altas temperaturas, que é maior que o valor limite de $\rho_{\mathrm{hb}}$.

Nossos dados para as susceptibilidades dos modelos BL e BEG também podem ser discutidas em termos de uma competição entre duas estruturas na mesma fase líquida. As figs. 4.5 (a) e (b) mostram que a compressibilidade isotérmica satisfaz um critério descoberto por Sastry et al [38], que estabelece que a presença de uma linha TMD com inclinação negativa implica em uma compressibilidade isotérmica decrescente com a temperatura, na mesma pressão. Os máximos observados em $\kappa_{t}$ se deslocam para temperaturas mais baixas, e a altura do pico aumenta, quando se aproxima da vizinhança de $p=1$. O mesmo comportamento é observado em $c_{p}$. Os máximos observados nas duas funções estão relacionados às flutuações no volume molecular e na entropia, sendo consistentes com uma competição entre duas estruturas líquidas na mesma fase termodinâmica. A capacidade térmica a volume constante, não aumenta na mesma região, como mostrado nas figuras 4.5 (e) e (f). 


\subsubsection{Frustração}

A importância da frustração no modelo BL pode ser facilmente reconhecida quando o Hamiltoniano é escrito em uma representação de spin-1, como na eq. (2.7), já que o acoplamento bilinear de spin é antiferromagnético, eq. (2.10a).

O modelo de Ising antiferromagnético na rede triangular é considerado, na literatura, o protótipo de um modelo com frustração energética. Este modelo foi resolvido exatamente por Wannier a campo magnético nulo [84], e foi encontrada uma fase paramagnética, sem nenhuma transição de fase ocorrendo a temperatura finita. Além disso, a solução encontrada por Wannier prediz uma entropia residual por sítio igual a 0,323066 [85] em $T=0$. Tanto o modelo BL, quanto o modelo BEG, se reduzem ao modelo de Ising antiferromagnético, no limite de pressão infinita, quando a rede fica completamente preenchida. Isto pode ser observado na eq. 2.7: com exceção do termo de acoplamento bilinear de spin, todos os termos do Hamiltoniano tornam-se independentes da configuração quando o sistema está preenchido por moléculas, $\rho=1$. Nossos resultados são consistentes com a solução de Wannier pois os dois modelos possuem uma entropia residual na fase HDL para pressões maiores que $p=1$. Como pode ser visto nas figs. 4.4 (e) e (f), a entropia residual em $p \approx 1,2$ é $s \approx 0,40 \pm 0,01$, tanto no modelo BL quanto no BEG. Além disso, nenhuma transição de fase pode ser pode ser observada em temperaturas finitas e pressões altas nos dois modelos.

O que propomos neste trabalho é a aplicação do conceito de frustração energética, associado ao modelo de Ising antiferromagnético na rede triangular, para sistemas de spin-1 como os que estudamos. No modelo BL, o principal efeito da frustração é impor uma restrição natural à formação de uma rede completamente preenchida por pontes de hidrogênio. Analogamente, existe um impedimento à formação de uma rede completamente acoplada com interações antiferromagnéticas, no modelo BEG. Considerando que as interações frustradas são mais "fortes" que a interação não-frustrada de van der Waals, i.e., que a desigualdade (4.1) é satisfeita, é esperado o aparecimento de uma estrutura com menor densidade, $\rho<1$, e com um número maior de ligações, em baixas pressões. Assim, o aparecimento da anomalia na densidade, que está associado a uma competição entre as estruturas HDL ligada e normal, pode ser atribuído à frustração energética do modelo.

Para que possamos desenvolver melhor nossas idéias sobre o papel da frustração, vamos 
considerar outro modelo de gás de rede orientacional em duas dimensões (GRO2D) [4]. No modelo GRO2D as moléculas são dispostas nos sítios de uma rede triangular e possuem quatro braços que formam pontes e dois braços inertes. Os ingredientes energéticos do modelo incluem as pontes de hidrogênio e interações de van der Waals isotrópicas. Redes totalmente ligadas são possíveis tanto para o estado de baixa densidade quanto para o estado de alta densidade e, por este motivo, o modelo não é frustrado. Contudo, a fase líquida de baixa densidade só é estável se a interação de van der Waals for repulsiva. Apenas neste caso o modelo apresenta uma transição de fase entre dois líquidos e uma linha TMD. Note que o modelo proposto por Besseling e Lyklema [68], que pode ser visto como um versão tridimensional do GRO2D, também necessita de uma interação de van der Waals repulsiva para apresentar um comportamento similar à água.

É importante notar que o modelo GRO2D foi originalmente proposto como um candidato a descrever a fase líquida da água, apresentando uma transição entre dois líquidos em altas pressões e anomalia na densidade. Recentemente, entretanto, estudos por simulações de Monte Carlo [77] parecem indicar que este segundo ponto crítico é, na verdade, um ponto tricrítico, que separa a linha de coexistência de uma linha crítica entre as fases HDL e LDL. Também há indicações de resultado semelhante [72] para o modelo de gás de rede orientacional em três dimensões [70, 71].

Outra característica que diferencia os modelos BL e GRO2D é a localização da anomalia na densidade. Enquanto no modelo BL esta anomalia ocorre na fase HDL, que é desordenada, no modelo GRO2D a anomalia está presente na fase LDL, que apresenta distinção de sub-redes e está separada da fase HDL por uma transição de segunda ordem. Além disso, com estes resultados recentes [77], verificou-se que o modelo GRO2D não apresenta nenhum ponto crítico, para os parâmetros estudados.

Apesar das diferenças existentes entre os modelos BL e GRO2D, é possível estender a idéia de frustração para incluir este último. Se considerarmos que uma interação de van der Waals repulsiva introduz restrições para a formação de um estado denso com todas as moléculas satisfazendo todas as pontes de hidrogênio, podemos classificar todos estes modelos como frustrados: ou com a frustração imposta pela estrutura rede, como no caso dos modelos BL e BEG, ou com a frustração imposta por um termo energético, como no modelo GRO. Certamente uma classificação deste tipo precisa ser esclarecida com mais estudos sobre o modelo GRO2D e sobre outros modelos em duas e três dimensões. 


\section{Capítulo 5}

\section{Efeito Hidrofóbico}

Além das propriedades líquidas anômalas, como a existência de extremos na densidade e nas funções termodinâmicas de resposta em função da temperatura, a água também apresenta propriedades peculiares como solvente. Solutos apolares, como o metano e etano, são muito pouco solúveis em água em condições ambientes de temperatura e pressão [100, 101]. Além disso, a solubilidade nestes sistemas diminui com o aumento da temperatura, enquanto que em solventes simples a solubilidade destes solutos aumenta [100, 101].

Provavelmente, o exemplo mais conhecido de resistência à dissolução em água seja o da separação água-óleo, que ocorre em condições de temperatura e pressão ambiente. Essa falta de miscibilidade no meio aquoso, conhecida como efeito hidrofóbico, possui um papel fundamental na estabilidade de sistemas biomoleculares como proteínas e membranas [101, 102].

Neste capítulo iremos estudar o efeito hidrofóbico no modelo Bell-Lavis (e também no modelo antiferromagnético de Blume-Emery-Griffiths) através da hidratação hidrofóbica, obtendo expressões para quantidades como a solubilidade e a energia livre de solvatação [102], e da interação hidrofóbica [100], que surge como uma interação efetiva entre as partículas de soluto, criada pelo meio aquoso, e que também é conhecida como potencial de força médio. Como estas duas medidas, a energia livre de solvatação e o potencial de força médio, representam diferentes aspectos do mesmo fenômeno, esperamos que elas estejam ligadas entre si de alguma maneira.

Esta ligação foi estudada em um modelo simplificado [103, 104] do efeito hidrofóbico por Widom e colaboradores, sendo encontrada uma dependência linear entre essas duas quantidades, que independe da dimensionalidade do sistema [105]. Como neste modelo 
o efeito hidrofóbico surge apenas da hipótese de que a inserção de um soluto em meio aquoso é entropicamente desfavorecida e energeticamente favorecida, espera-se que esta relação entre solvatação e interação hidrofóbica também possa ser observada em modelos com uma representação mais detalhada do meio aquoso, e que também apresentam o efeito hidrofóbico.

\subsection{Termodinâmica de solvatação: conceitos básicos}

Vamos considerar dois sistemas moleculares nas fases $\alpha$ e $\beta$, mantidas constantes a temperatura e a pressão. Um processo no qual uma molécula A é transferida da fase $\alpha$ para a fase $\beta$ resulta na seguinte variação da energia livre de Gibbs total do sistema:

$$
\begin{aligned}
\Delta G_{A}(\alpha \rightarrow \beta) & =G^{\beta}\left(N_{A}^{\beta}+1\right)-G^{\beta}\left(N_{A}^{\beta}\right)+G^{\alpha}\left(N_{A}^{\alpha}-1\right)-G^{\alpha}\left(N_{A}^{\alpha}\right) \\
& =\mu_{A}^{\beta}-\mu_{A}^{\alpha},
\end{aligned}
$$

onde $\mu_{A}^{\beta}$ e $\mu_{A}^{\alpha}$ são os potenciais químicos da molécula A nas fases $\beta$ e $\alpha$. Esta variação na energia livre de Gibbs contém as contribuições da reestruturação do solvente que envolve a molécula A e da translação da molécula A, em ambas as fases. Como estamos interessados em estudar o efeito da inserção de uma molécula A na termodinâmica e na estrutura do solvente, será importante retirar as contribuições puramente translacionais do soluto para a variação de energia livre. Faremos isto introduzindo o conceito de potencial pseudoquímico e definindo quantidades padronizadas de solvatação [100].

Vamos considerar um sistema com $N_{A}$ partículas do tipo $A$ e $N_{B}$ partículas do tipo $B$ imersas em um banho térmico a temperatura $T$ e volume constante $V$. A transição do ensemble de Gibbs, utilizado na eq. (5.1), para o ensemble canônico, poderá ser feita $a$ posteriori [106], através de uma transformada de Legendre. A função de partição deste sistema, no ensemble canônico, será dada por:

$$
Z\left(T, V, N_{A}, N_{B}\right)=\frac{1}{N_{A} ! N_{B} !} \sum_{\left\{\vec{R}_{A}^{\left(N_{A}\right)}, \vec{R}_{B}^{\left(N_{B}\right)}\right\}} e^{-\beta H\left(\vec{R}_{A}^{\left(N_{A}\right)}, \vec{R}_{B}^{\left(N_{B}\right)}\right)}
$$

onde $\vec{R}_{k}^{\left(N_{k}\right)}$ representa o conjunto de $N_{k}$ vetores com as coordenadas das partículas do tipo $k$.

No limite termodinâmico, esta função de partição estará relacionada com a energia livre de Helmholtz pela expressão

$$
F\left(T, V, N_{A}, N_{B}\right)=-k_{B} T \ln Z\left(T, V, N_{A}, N_{B}\right) .
$$


Vamos reescrever o potencial químico das partículas do tipo A

$$
\begin{aligned}
\mu_{A} & =\left(\frac{\partial F}{\partial N_{A}}\right)_{T, V, N_{B}} \\
& =F\left(T, V, N_{A}+1, N_{B}\right)-F\left(T, V, N_{A}, N_{B}\right) \\
& =-k_{B} T \ln \left[\frac{Z\left(T, V, N_{A}+1, N_{B}\right)}{Z\left(T, V, N_{A}, N_{B}\right)}\right],
\end{aligned}
$$

e separar a interação da partícula $N_{A}+1$ com o resto do sistema, definindo a energia de ligação

$$
U_{L}\left(N_{A}, N_{B}\right)=U\left(N_{A}+1, N_{B}\right)-U\left(N_{A}, N_{B}\right) .
$$

Agora, deslocando o ponto de referência para o sistema de coordenadas da partícula $N_{A}+1$ e utilizando a eq. (5.2) poderemos reescrever o argumento no logaritmo da eq. (5.4) como:

$$
\begin{aligned}
\frac{Z\left(T, V, N_{A}+1, N_{B}\right)}{Z\left(T, V, N_{A}, N_{B}\right)} & =\frac{1}{N_{A}+1} \frac{\sum_{\left\{\vec{R}_{A}^{\left(N_{A}+1\right)}, \vec{R}_{B}^{\left(N_{B}\right)}\right\}} e^{-\beta\left[U\left(N_{A}, N_{B}\right)+U_{L}\left(N_{A}, N_{B}\right)\right]}}{\sum_{\left\{\vec{R}_{A}^{\left(N_{A}\right)}, \vec{R}_{B}^{\left(N_{B}\right)}\right\}} e^{-\beta U\left(N_{A}, N_{B}\right)}} \\
& =\frac{V}{N_{A}+1} \frac{\sum_{\left\{\vec{R}_{A}^{\left(N_{A}\right)}, \vec{R}_{B}^{\left(N_{B}\right)}\right\}} e^{-\beta\left[U\left(N_{A}, N_{B}\right)+U_{L}\left(N_{A}, N_{B}\right)\right]}}{\sum_{\left\{\vec{R}_{A}^{\left(N_{A}\right)}, \vec{R}_{B}^{\left(N_{B}\right)}\right\}} e^{-\beta U\left(N_{A}, N_{B}\right)}} \\
& =\frac{V}{N_{A}+1} \sum_{\left\{\vec{R}_{A}^{(N A)}, \vec{R}_{B}^{\left(N_{B}\right)}\right\}} e^{-\beta U_{L}\left(N_{A}, N_{B}\right)} P\left(\vec{R}_{A}^{\left(N_{A}\right)}, \vec{R}_{B}^{\left(N_{B}\right)}\right) .
\end{aligned}
$$

Por fim, notando que no limite termodinâmico $N_{A}+1 \approx N_{A}$, escrevemos o potencial químico na eq. (5.4) como

$$
\begin{aligned}
\mu_{A} & =-k_{B} T \ln \left[\frac{\left\langle e^{-\beta U_{L}}\right\rangle}{\rho_{A}}\right] \\
& =k_{B} T \ln \rho_{A}-k_{B} T \ln \left\langle e^{-\beta U_{L}}\right\rangle,
\end{aligned}
$$

Neste ponto convém notar que, se não existir interação entre as partículas, o argumento no segundo logaritmo do lado direito da eq. 5.7 torna-se igual à identidade, $\left\langle e^{-\beta U_{L}}\right\rangle=1$, e o potencial químico do composto $A$ fica simplesmente:

$$
\mu_{A}=k_{B} T \ln \rho_{A}
$$

Comparando esta expressão com eq. (5.7), podemos afirmar que o potencial químico de uma partícula é composto por um termo relacionado com a translação das partículas, em todo o volume do sistema, e uma contribuição devido à interação entre as partículas. Já que estamos interessados em estudar o efeito das interações moleculares sobre a termodinâmica, convém definir o termo de potencial químico sem contribuições translacionais, 
conhecido como potencial pseudo-químico

$$
\mu_{A}^{*}=\mu_{A}-k_{B} T \ln \rho_{A}=-k_{B} T \ln \left\langle e^{-\beta U_{L}}\right\rangle .
$$

Vamos agora incluir um índice de fase na definição (5.9), para reescrever a variação de energia livre na eq. (5.1) como:

$$
\Delta G_{A}(\alpha \rightarrow \beta)=\mu_{A}^{\beta *}-\mu_{A}^{\alpha *}+k_{B} T \ln \left(\frac{\rho_{A}^{\beta}}{\rho_{A}^{\alpha}}\right) .
$$

Note que novamente temos uma separação entre os termos relacionados à translação e à interação entre as partículas do sistema. Vamos chamar o termo ligado à interação entre as partículas de energia livre de solvatação padrão, $\Delta G_{A}^{*}(\alpha \rightarrow \beta)$, definindo

$$
\Delta G_{A}^{*}(\alpha \rightarrow \beta)=\mu_{A}^{\beta *}-\mu_{A}^{\alpha *}
$$

Quando $\alpha$ e $\beta$ são duas fases em equilíbrio termodinâmico temos $\mu_{A}^{\beta}=\mu_{A}^{\alpha}$ e a energia livre de solvatação padrão fica:

$$
\Delta G_{A}^{*}(\alpha \rightarrow \beta)=-k_{B} T \ln \Sigma
$$

onde $\Sigma$, que é conhecido como o coeficiente de partição de $A$ nas duas fases em equilíbrio, é dado por

$$
\Sigma=\frac{\rho_{A}^{\beta}}{\rho_{A}^{\alpha}} .
$$

Quando, na fase $\alpha$, a molécula $A$ é diluída em um gás, e, na fase $\beta, A$ é diluída em uma solução, $\Sigma$ torna-se o coeficiente de solubilidade de Ostwald [107]. De agora em diante iremos considerar o limite de diluição infinita de $A$ nas duas fases e, por este motivo, simplificaremos a notação da energia livre de solvatação padrão para $\Delta G^{*}$.

Outras quantidades padronizadas, como a entropia e a entalpia de solvatação, podem ser obtidas a partir da energia livre de solvatação padrão na eq. (5.12), da seguinte forma [107]:

$$
\begin{aligned}
\Delta S_{P}^{*} & =-\left(\frac{\partial \Delta G^{*}}{\partial T}\right)_{P}+k_{B} T\left(\epsilon^{\beta}-\epsilon^{\alpha}\right) \\
\Delta H_{P}^{*} & =\Delta H_{P}=\Delta G+T \Delta S_{P} \\
& =\Delta G_{P}^{*}+T \Delta S_{P}^{*}
\end{aligned}
$$

onde $\epsilon^{\alpha}$ e $\epsilon^{\beta}$ são os coeficientes de expansão térmica do solvente nas fases $\alpha$ e $\beta^{1}$.

\footnotetext{
${ }^{1}$ Aqui nós utilizamos o símbolo $\epsilon$ para o coeficiente de expansão térmica para distingüi-lo da fase $\alpha$.
} 
Em seguida iremos construir um Hamiltoniano efetivo para o modelo Bell-Lavis na presença de um soluto apolar no ensemble grande canônico. Na subseção 5.2.2 estudaremos este modelo no interior do cacto de Husimi e calcularemos o potencial pseudo-químico no limite de diluição infinita. Todas as propriedades relevantes para o processo de solvatação, listadas nas eqs. (5.14), podem ser obtidas a partir do potencial pseudo-químico juntamente com as propriedades do solvente.

\subsection{O modelo Bell-Lavis para solvente com soluto apolar}

\subsubsection{Hamiltoniano efetivo}

Para incluir um soluto apolar neste modelo vamos considerar que a atração de van der Waals entre solutos equivale a $-\epsilon_{s s}$ e que a interação entre uma molécula de água e um soluto contribui para a energia do sistema com $-\epsilon_{w s}$. Vamos generalizar o modelo incluindo uma variável $\eta_{i}$ para descrever a presença $\left(\eta_{i}=1\right)$ ou a ausência $\left(\eta_{i}=0\right)$ de um soluto no sítio $i$. Para evitar a superposição entre moléculas de água e soluto será necessário restringir os estados $q_{i}=\left\{\eta_{i}, S_{i}\right\}$ permitidos em cada sítio do sistema: estados de spin $S_{i}$ inteiros, correspondendo a diferentes orientações das moléculas de água, serão acessíveis em cada sítio $i$ apenas quanto $\eta_{i}=0$.

Com estas definições, o Hamiltoniano efetivo de uma mistura de água com soluto apolar, em cada triângulo, será dada por:

$$
h_{\mathrm{BLS}}=h_{\mathrm{BL}}+u_{\mathrm{ws}}+u_{\mathrm{ss}}-\frac{\mu_{s}}{3}\left(\eta_{a}+\eta_{b}+\eta_{c}\right),
$$

com os três primeiros termos do lado direto da equação correspondendo, respectivamente, à contribuição do Hamiltoniano efetivo do modelo BL original, da interação água-soluto e da interação soluto-soluto, e $\mu_{s}$ correspondendo ao potêncial químico do soluto. Na equação (5.15), os termos responsáveis pela interação água-soluto e soluto-soluto são

$$
u_{\mathrm{ws}}=-\epsilon_{\mathrm{ws}}\left(\eta_{a} S_{b}^{2}+S_{a}^{2} \eta_{b}+\eta_{b} S_{c}^{2}+S_{b}^{2} \eta_{c}+\eta_{c} S_{a}^{2}+S_{c}^{2} \eta_{a}\right)
$$

$\mathrm{e}$

$$
u_{\mathrm{ss}}=-\epsilon_{\mathrm{ss}}\left(\eta_{a} \eta_{b}+\eta_{b} \eta_{c}+\eta_{c} \eta_{a}\right)
$$

No que se segue, obtemos uma expressão para o potencial grande canônico deste modelo no cacto de Husimi. Como nós estamos interessados nas propriedades de solvatação 
na fase líquida de alta densidade, que apresenta um comportamento anômalo típico da água, podemos estudar o sistema no cacto de Husimi simétrico, sem distinção de subredes. Um cacto de Husimi mais complicado, seqüencial e com distinção de sub-redes, é necessário para descrever o líquido de baixa densidade, que é uma fase ordenada presente em baixas temperaturas e baixas pressões no diagrama de fases. Não estudaremos as propriedades de solvatação nesta fase, porque ela não apresenta o comportamento anômalo que nos interessa.

\subsubsection{Aproximação de Bethe}

Iremos estudar o modelo BL com soluto apolar no interior do cacto de Husimi usando a versão simétrica e sem sub-redes. A versão do cacto sem sub-redes será utilizada por ser suficiente para representar a fase HDL, que possui o comportamento anômalo característico da água líquida. Os cálculos desta seção são similares aos feitos no capítulo 3, mas com o uso das variáveis $q_{l}$. A fase HDL possui uma simetria paramagnética e não apresenta uma distinção de sub-redes, de forma que é possível substituir o mapeamento dinâmico descrito pelas equações (3.22a)-(3.22c) por um único polinômio. Este também será um resultado adicional de nossos cálculos quando tomarmos, mais adiante, o limite de diluição infinita do soluto apolar.

A função de partição de um sistema com o Hamiltoniano (5.15) em um cacto de Husimi simétrico com $M$ gerações, com um triângulo central indexado pela geração 0, é dada por:

$$
\Xi_{0}^{(M)}=\sum_{q_{a}, q_{b}, q_{c}}{ }^{\prime} e^{-\beta h\left(q_{a}, q_{b}, q_{c}\right)} \Lambda_{0}^{2}\left(q_{a}\right) \Lambda_{0}^{2}\left(q_{b}\right) \Lambda_{0}^{2}\left(q_{c}\right),
$$

onde a soma sobre $\left\{q_{a}, q_{b}, q_{c}\right\}$ é restrita aos estados em que não há superposição entre as moléculas de água e soluto. Nesta equação, $\Lambda_{k}\left(q_{l}\right)$ é a função de partição de um ramo do cacto começando na geração $k$, no estado $q_{l}$, cujos ramos subseqüentes crescem por $M-k$ gerações. Note que simplificamos a notação do Hamiltoniano, $h_{\mathrm{BLS}}\left(q_{a}, q_{b}, q_{c}\right) \equiv h\left(q_{a}, q_{b}, q_{c}\right)$.

É possível retirar a restrição na soma do lado direito da equação (5.18) definindo

$$
R_{l}=\left(\eta_{l}-S_{l}^{2}\right)^{\eta_{l}},
$$

já que

$$
\sum_{\eta_{l}, S_{l}}^{\prime} f\left(\eta_{l}, S_{l}\right)=\sum_{\eta_{l}, S_{l}} R_{l} f\left(\eta_{l}, S_{l}\right)
$$


Iremos introduzir uma simplificação adicional absorvendo o termo (5.19) no Hamiltoniano através da definição

$$
h^{\prime}\left(q_{a}, q_{b}, q_{c}\right)=h\left(q_{a}, q_{b}, q_{c}\right)-k_{B} T \sum_{l=a, b, c} \ln R_{l} .
$$

Com estas mudanças, a função de partição grande canônica do cacto pode ser escrita como:

$$
\Xi_{0}^{(M)}=\sum_{q_{a}, q_{b}, q_{c}} e^{-\beta h^{\prime}\left(q_{a}, q_{b}, q_{c}\right)} \Lambda_{0}^{2}\left(q_{a}\right) \Lambda_{0}^{2}\left(q_{b}\right) \Lambda_{0}^{2}\left(q_{c}\right) .
$$

Devido à auto-similaridade do cacto, obtemos relações de recorrência para a função de partição dos ramos em gerações sucessivas:

$$
\Lambda_{k}\left(q_{l}\right)=\sum_{q_{m}^{\prime}, q_{n}^{\prime}} e^{-\beta h^{\prime}\left(q_{l}, q_{m}^{\prime}, q_{n}^{\prime}\right)} \Lambda_{k+1}^{2}\left(q_{m}^{\prime}\right) \Lambda_{k+1}^{2}\left(q_{n}^{\prime}\right) .
$$

De forma similar à (3.21), vamos escrever a função de partição de um ramo do cacto como:

$$
\Lambda_{k}\left(q_{l}\right)=B_{k} x_{w, k}^{S_{l}^{2}} x_{s, k}^{\eta_{l}},
$$

onde $x_{w, k}$ e $x_{s, k}$ são as funções de partição parciais de geração $k$ em que o sítio da base do ramo contém uma molécula de água ou soluto, respectivamente. Com esta definição podemos reescrever a eq. (5.23) como um mapeamento dinâmico nas funções de partição parciais da seguinte forma:

$$
\begin{gathered}
x_{w, k}=\frac{\Lambda_{k+1}(0,1)}{\Lambda_{k+1}(0,0)}=\frac{f_{k+1}(0,1)}{f_{k+1}(0,0)} \\
x_{s, k}=\frac{\Lambda_{k+1}(1,0)}{\Lambda_{k+1}(0,0)}=\frac{f_{k+1}(1,0)}{f_{k+1}(0,0)}
\end{gathered}
$$

onde as funções $f_{k}(\eta, S)$ são

$$
f_{k}\left(q_{l}\right)=\sum_{q_{m}, q_{n}} e^{-\beta h^{\prime}\left(q_{l}, q_{m}, q_{n}\right)} x_{w, k}^{2\left(S_{m}^{2}+S_{n}^{2}\right)} x_{s, k}^{2\left(\eta_{m}+\eta_{n}\right)} .
$$

Note que $f_{k}(0,1)=f_{k}(0,-1)$ devido à invariância da função de partição de um ramo com uma inversão na orientação da molécula de água, que só ocorre quando não há distinção de sub-redes. A função $B_{k}=\Lambda_{k}(0,0)$ satisfaz a seguinte relação de recorrência

$$
B_{k}=B_{k+1}^{4} f_{k+1}(0,0),
$$

que é análoga à eq. (3.24) e que também será utilizada para obter o potencial grande canônico. 
As equações (5.25a) e (5.25b) podem ser iteradas partindo de uma geração grande, $k=M \gg 1$, até que um ponto fixo seja encontrado. Como foi discutido no capítulo 3, um caminho alternativo também pode ser adotado: as eqs. (5.25a)-(5.25b) podem ser transformadas em uma equação polinomial e resolvidas analiticamente, assumindo que as funções de partição parciais do mapeamento dinâmico se encontram no ponto fixo das relações de recorrência. A partir de agora, iremos assumir que $x_{w}$ e $x_{s}$ são calculados no ponto fixo e o subscrito $k$ não será mais utilizado. Como será mostrado posteriormente, no limite de diluição infinita $x_{s}$ dependerá unicamente das propriedades do solvente e da energia de interação entre as moléculas de soluto e água, $-\epsilon_{w s}$.

Para obter uma expressão para o potencial grande canônico do modelo BL com o solvente, vamos utilizar a equação (3.25) $\operatorname{com} \delta=3$ e $r=4$, que são os valores adequados para o cacto de Husimi. Uma expressão para $\phi$ em termos das funções de partição parcial, $x_{w}$ e $x_{s}$, pode ser obtida a partir da relação $\Xi=e^{-\beta \Phi}$ e com o uso das relações de recorrência (5.27). Após alguns cálculos, temos

$$
\phi=-\frac{k_{B} T}{a_{0}} \ln \left[\frac{f(0,0)}{2 x_{w}^{3}+x_{s}^{3}+1}\right] .
$$

\subsubsection{Solubilidade}

No limite de diluição infinita a fugacidade do soluto, $z_{s}=e^{-\beta \mu_{s}}$, tende a um valor nulo e as eqs. (5.25a) e (5.25b) são desacopladas. Usando a notação dos pesos de Boltzmann definida nas tabelas 2.2 e 5.1 estas equações são reescritas como:

$$
x_{w}=\frac{\left(3 a_{0}+a_{3}\right) x_{w}^{4}+\left(a_{1}^{b}+a_{1}^{u}+2 a_{4}\right) x_{w}^{2}+a_{2}}{\left(a_{1}^{b}+a_{1}^{u}+2 a_{4}\right) x_{w}^{4}+4 a_{2} x_{w}^{3}+1},
$$

e

$$
x_{s}=z_{s}^{1 / 3} y_{s}
$$

onde $y_{s}$ é uma função escrita como:

$$
y_{s}=\frac{1+4 a_{2} v x_{w}^{2}+\left(2 a_{4}+a_{1}^{b}+a_{1}^{u}\right) v^{2} x_{w}^{4}}{1+4 a_{2} x_{w}^{2}+\left(2 a_{4}+a_{1}^{b}+a_{1}^{u}\right) x_{w}^{4}},
$$

$\operatorname{com} v=e^{\beta \epsilon_{w s}}$. Será útil transformar a eq. (5.29) em um polinômio de grau 5:

$$
\left(a_{1}^{b}+a_{1}^{u}+2 a_{4}\right) x_{w}^{5}-\left(3 a_{0}+a_{3}\right) x_{w}^{4}+4 a_{2} x_{w}^{3}-\left(a_{1}^{b}+a_{1}^{u}+2 a_{4}\right) x_{w}^{2}+x_{w}-a_{2}=0
$$

para uso posterior. 
Note que quando o soluto está infinitamente diluído $y_{s}$ tende a um valor constante enquanto $x_{s}$ se anula. Logo abaixo utilizaremos $y_{s}$ para obter uma expressão para a energia livre de solvatação neste limite.

Vamos agora considerar o valor médio de algumas quantidades relevantes no interior do cacto. Usando as eqs. (5.22) e (5.25) pode-se mostrar que as densidades de moléculas de água e de soluto são escritas como:

$$
\rho_{w}=\left\langle S_{l}^{2}\right\rangle=\frac{2 x_{w}^{3}}{2 x_{w}^{3}+x_{s}^{3}+1}
$$

$\mathrm{e}$

$$
\rho_{s}=\left\langle\eta_{l}\right\rangle=\frac{x_{s}^{3}}{2 x_{w}^{3}+x_{s}^{3}+1} .
$$

Pode-se facilmente inverter $x_{w}$ e $x_{s}$ em termos de $\rho_{w}$ e $\rho_{s}$. Com este cálculo podemos obter a seguinte expressão ligando a fugacidade do soluto às densidades e à função $y_{s}$ :

$$
z_{s}=\frac{\rho_{s}}{1-\rho_{s}-\rho_{w}} y_{s}^{-3}
$$

Desta forma o potencial pseudo-químico do soluto, discutido na subseção 5.1, assume a seguinte expressão no limite de diluição infinita:

$$
\mu_{s}^{*}=-k_{B} T \ln \left[\left(1-\rho_{w}\right) y_{s}^{3}\right] .
$$

A parte relevante da energia livre de solvatação está relacionada ao potencial pseudoquímico através da eq. (5.10). A partir desta podemos obter uma expressão para o coeficiente de partição na eq. (5.13), que mede a solubilidade de um soluto apolar ao longo da coexistência gás-líquido, dada por

$$
\Sigma=e^{-\beta \Delta G^{*}}
$$

com $\Delta G^{*}=\left.\mu_{A}^{*}\right|_{\text {líq }}-\left.\mu_{A}^{*}\right|_{\text {gás }}$. Outras propriedades de solvatação podem ser obtidas através de $\Delta G^{*}$, com o uso das expressões (5.14). 
Tabela 5.1: Configurações com soluto apolar de uma célula unitária com o Hamiltoniano 5.15. Em cada linha os estados moleculares são mostrados em notação de fluido, com um quadrado, $\square$, indicando o número de solutos apolares em cada triângulo, acompanhados do Hamiltoniano (na notação de fluído), da densidade de moléculas de água, $\rho_{w}$, número de ligações de hidrogênio por partícula, $\rho_{h b}$, densidade de soluto apolar, $\rho_{s}$, configurações do estado na notação de spin e o peso de Boltzmann na última coluna. Na última coluna $z_{s}=e^{\beta \mu}, u=e^{\beta \epsilon_{s s}}$ e $v=e^{\beta \epsilon_{w s}}$. Esta tabela pode ser vista como uma continuação da tabela 2.2 (página 19).

\begin{tabular}{|c|c|c|c|c|c|c|}
\hline Fase & $h_{B L S}\left(q_{a}, q_{b}, q_{c}\right)$ & $\rho_{w}$ & $\rho_{h b}$ & $\rho_{s}$ & $\left(q_{a}, q_{b}, q_{c}\right)$ & $e^{-\beta h_{\mathrm{BLS}}\left(q_{a}, q_{b}, q_{c}\right)}$ \\
\hline$(\square)$ & $-\frac{1}{3} \mu_{s}$ & 0 & 0 & $1 / 3$ & $(\square, 0,0)$ & $z_{s}^{1 / 3}$ \\
\hline$(\square \square)$ & $-\epsilon_{w s}-\frac{2}{3} \mu_{s}$ & 0 & 0 & $2 / 3$ & $(\square, \square, 0)$ & $u z_{s}^{2 / 3}$ \\
\hline$(\square \square \square)$ & $-3 \epsilon_{w s}-\mu_{s}$ & 0 & 0 & 1 & $(\square, \square, \square)$ & $u^{3} z_{s}$ \\
\hline líquida de baixa densidade $(\square)$ & $-\epsilon_{h b}-\epsilon_{v d w}-2 \epsilon_{w s}-\frac{2}{3} \mu_{w}-\frac{1}{3} \mu_{s}$ & $2 / 3$ & $3 / 2$ & $1 / 3$ & $(+,-, \square)$ & $z_{s}^{1 / 3} v^{2} a_{1}^{b}$ \\
\hline líquida de baixa densidade não-ligada $(\square)$ & $-\epsilon_{v d w}-2 \epsilon_{w s}-\frac{2}{3} \mu_{w}-\frac{1}{3} \mu_{s}$ & $2 / 3$ & 0 & $1 / 3$ & $(-,+, \square)$ & $z_{s}^{1 / 3} v^{2} a_{1}^{u}$ \\
\hline intercalada $(\square)$ & $-\epsilon_{w s}-\frac{1}{3} \mu_{w}-\frac{1}{3} \mu_{s}$ & $1 / 3$ & 0 & $1 / 3$ & $(\square, \pm, 0)$ & $z_{s}^{1 / 3} v a_{2}$ \\
\hline intercalada $(\square \square)$ & $-2 \epsilon_{w s}-\epsilon_{s s}-\frac{1}{3} \mu_{w}-\frac{2}{3} \mu_{s}$ & $1 / 3$ & 0 & $2 / 3$ & $(\square, \pm, \square)$ & $z_{s}^{2 / 3} u v^{2} a_{2}$ \\
\hline leve orientada $(\square)$ & $-2 \epsilon_{w s}-\epsilon_{v d w}-\frac{2}{3} \mu_{w}-\frac{1}{3} \mu_{s}$ & $2 / 3$ & 0 & $1 / 3$ & $(+, \square,+)$ & $z_{s}^{1 / 3} v^{2} a_{4}$ \\
\hline
\end{tabular}




\subsubsection{Função de correlação de pares}

A função de correlação de pares $g_{l m}(r)$ entre moléculas dos tipos $l$ e $m$ é proporcional à probabilidade $\Pi_{l m}(r)$ de encontrarmos uma molécula $m$ a uma distância $r$ do centro de uma molécula $l$. Esta probabilidade é definida em relação ao centro da molécula $l$ e, devido ao volume excluído, temos $\Pi_{l m}(0)=0$. Quando a distância em relação a $l$ é muito grande a probabilidade de encontrar uma molécula $m$ dependerá apenas da densidade destas moléculas, $\rho_{m}$, e teremos $\lim _{r \rightarrow \infty} \Pi_{l m}(r) \propto \rho_{m}$. Como a função de correlação de pares deve tender ao valor unitário para distâncias muito longas, define-se $g_{l m}(r)$ como:

$$
g_{l m}(r)=\frac{\Pi_{l m}(r)}{\rho_{m}}
$$

Já que estamos utilizando uma notação em que os estados de cada sítio são representados por variáveis de spins, devemos reescrever a função de correlação entre as moléculas em termos das funções de correlação entre as variáveis de spin da rede. Vamos fazer isto considerando um sistema onde os estados do solvente são representados pelos valores de spin \pm 1 e os buracos correspondem ao spin nulo, como no modelo BL. Neste caso temos ${ }^{2}$ $g_{w w}(r)=\Pi_{w w}(r) / \rho_{w}$, onde $\rho_{w}$ é a densidade do solvente. A partir deste ponto iremos supor que o soluto encontra-se em diluição infinita e iremos simplificar nossa notação para $\rho_{w}=\rho$.

Considere que $P_{|j-i|}\left(S_{i}, S_{j}\right)$ seja a probabilidade de encontrarmos dois sítios $i$ e $j$ nos estados $S_{i}$ e $S_{j}$. Agora considere uma configuração do cacto de Husimi em que existe uma molécula no sítio $a$ do triângulo central. Sabendo que o sistema encontra-se nessa configuração, a probabilidade de encontrarmos uma molécula em uma sub-rede $a$, distante $r$ gerações, será dada por:

$$
\begin{aligned}
\Pi_{w w}(r) & =\frac{P_{r}(+,+)+P_{r}(+,-)+P_{r}(-,+)+P_{r}(-,-)}{P_{r}(+,+)+P_{r}(+,-)+P_{r}(+, 0)+P_{r}(-,+)+P_{r}(-,-)+P_{r}(-, 0)} \\
& =\frac{\sum_{S_{a, 0}, S_{a, r}} S_{a, 0}^{2} S_{a, r}^{2} P_{r}\left(S_{a, 0}, S_{a, r}\right)}{\sum_{S_{a, 0}, S_{a, r}} S_{a, 0}^{2} P_{r}\left(S_{a, 0}, S_{a, r}\right)} \\
& =\frac{\left\langle S_{a, 0}^{2} S_{a, r}^{2}\right\rangle}{\left\langle S_{a, 0}^{2}\right\rangle}=\frac{\left\langle S_{a, 0}^{2} S_{a, r}^{2}\right\rangle}{\rho} .
\end{aligned}
$$

Utilizando a definição (5.38) a função de correlação de pares entre as moléculas de água,

\footnotetext{
${ }^{2} \mathrm{O}$ subscrito $w$ refere-se a water, do inglês, e foi utilizado para não causar confusão com a sub-rede $a$.
} 
nos modelos BL e BEG ${ }^{3}$, passa a depender da função de correlação de spin biquadrática como:

$$
g_{w w}(r)=\frac{\left\langle S_{a, 0}^{2} S_{a, r}^{2}\right\rangle}{\rho^{2}}
$$

Também podemos obter uma expressão para a correlação de pares entre moléculas do soluto em termos das correlações entre os spins em cada sítio. No entanto, algum cuidado deve ser tomado neste cálculo, pois estamos considerando o limite de diluição infinita com soluto apolar inerte, com o sistema descrito apenas pelo Hamiltoniano (2.7). Uma generalização para o caso com solutos interagentes será feita posteriormente, na subseção 5.2.5.

Quando o limite de diluição infinita é utilizado, as correlações entre as moléculas de soluto ficam determinadas apenas pela estrutura da água. Nestas condições, uma molécula de soluto inerte é equivalente a um buraco na rede e, levando isto em conta, podemos associar a probabilidade de encontrar duas moléculas de soluto à probabilidade de encontrarmos dois buracos. A probabilidade $\Pi_{h h}(r)^{4}$ de encontrar dois buracos separados por $r$ sítios na rede é escrita como:

$$
\begin{aligned}
\Pi_{h h}(r) & =\frac{P_{r}(0,0)}{P_{r}(0,+)+P_{r}(0,0)+P_{r}(0,-)} \\
& =\frac{\sum_{S_{a, 0}, S_{a, r}}\left(1-S_{a, 0}^{2}\right)\left(1-S_{a, r}^{2}\right) P_{r}\left(S_{a, 0}, S_{a, r}\right)}{\sum_{S_{a, 0}, S_{a, r}}\left(1-S_{a, 0}^{2}\right) P_{r}\left(S_{a, 0}, S_{a, r}\right)} \\
& =\frac{\left\langle\left(1-S_{a, 0}^{2}\right)\left(1-S_{a, r}^{2}\right)\right\rangle}{\left\langle\left(1-S_{a, 0}^{2}\right)\right\rangle}=\frac{\left\langle\left(1-S_{a, 0}^{2}\right)\left(1-S_{a, r}^{2}\right)\right\rangle}{(1-\rho)}
\end{aligned}
$$

Utilizando a eq. (5.38) e lembrando que a densidade de buracos é $\rho_{h}=1-\rho$ podemos escrever a função de correlação de pares entre buracos como:

$$
g_{h h}(r)=\frac{\left\langle\left(1-S_{a, 0}^{2}\right)\left(1-S_{a, r}^{2}\right)\right\rangle}{(1-\rho)^{2}} .
$$

\subsubsection{Técnica da Matriz de Transferência - funções de correlação}

As expressões para as correlações de spin entre sítios em uma rede são complicadas, pois envolvem as contribuições de todos os sítios intermediários no percurso ligando os

\footnotetext{
${ }^{3}$ Aqui estamos nos referindo ao modelo BEG antiferromagnético, na rede triangular, enquanto modelo isotrópico que possui propriedades similares à da água.

${ }^{4} \mathrm{O}$ índice $h$ refere-se a hole, do inglês, e foi utilizado para não ocorrerem confusões quanto ao uso de $b$, que também é uma sub-rede no cacto.
} 
pontos de referência para o cálculo das correlações na rede. Entretanto, podemos transformar o cálculo algébrico das funções de correlação em um problema de diagonalização de matrizes utilizando a Técnica da Matriz de Transferência (TMT) [108, 109]. Esta técnica, que foi desenvolvida no contexto do modelo de Ising unidimensional [93], permite associar a função de partição de um dado sistema ao traço de um produto de matrizes de transferência, que intermediam a interação entre os sítios consecutivos do sistema.

Em nossos cálculos, tomamos como ponto de partida o trabalho de Chin-Kun Hu e N. Sh. Izmailian [108, 109], no qual a TMT foi utilizada para obter expressões analíticas das correlações entre spins em um sistema de spin-S qualquer, no interior de uma árvore de Cayley. Embora tenhamos considerado apenas sistemas com spin-1, duas generalizações foram necessárias: a realização do cálculo no cacto de Husimi e o uso de sub-redes.

Neste ponto é importante notar que a distância que será utilizada em nossos cálculos é apenas o número de passos que liga o menor caminho de um sítio a outro no cacto, que é conhecida como distância química. Para que as funções de correlação dependam de uma distância que corresponde a uma medida em um espaço físico, seria necessário considerar o cacto inserido em alguma rede, como foi feito na ref. [110] para sistemas poliméricos. Eventualmente, também deve ser considerado o fato de que existe mais de um caminho ligando dois sítios no cacto de Husimi. Contudo, essas duas correções ainda não foram implementadas neste trabalho e as funções de correlações serão calculadas apenas em função da distância química.

A presença de sub-redes introduz algumas complicações no cálculo das funções de correlação de pares, escritas nas eqs. (5.40) e (5.42), por exigir a escolha de um caminho ligando dois sítios. Para simplificar a notação, escolhemos este caminho entre as sub-redes $a$ e $c$, sempre começando $\operatorname{com} a$. Não existe nenhuma razão física para uma dependência com o caminho na função de correlação e pode ser demonstrado (veja o apêndice A) que esta escolha não causa nenhuma mudança nos cálculos. Em uma simplificação adicional, também consideramos um caminho com um número ímpar de passos, de forma que tanto o primeiro como o último sítio pertencem à sub-rede $a$. Esta última restrição não irá alterar os cálculos de forma essencial e a generalização para qualquer número de passos é imediata.

O primeiro passo a ser tomado, na obtenção de uma expressão algébrica de $\left\langle S_{a, 0}^{2} S_{a, r}^{2}\right\rangle$, é tornar explícito o somatório sobre os spins dos sítios ao longo do caminho acac $\cdots a$. 
Inicialmente os cálculos serão sem a presença do soluto e no interior de um cacto de Husimi infinito. Por este motivo, poderemos desconsiderar os índices que especificam o tipo molecular e a geração da função de partição parcial, utilizando a notação $x_{w, k}\left(S_{l, k}\right)=$ $x\left(S_{l, k}\right)=x^{S_{l, k}^{2}}$. Com esta simplificação este somatório resulta na seguinte expressão:

$$
\begin{array}{r}
\left\langle S_{a, 0}^{m} S_{a, r}^{n}\right\rangle=\frac{\sum_{S_{a, 0}, S_{c, 0}} S_{a, 0}^{m} x^{2}\left(S_{a, 0}\right) \sum_{S_{b, 0}} w\left(S_{a, 0}, S_{b, 0}, S_{c, 0}\right) x^{2}\left(S_{b, 0}\right) x\left(S_{c, 0}\right)}{\sum_{S_{a, 0}, S_{c, 0}} x^{2}\left(S_{a, 0}\right) \sum_{S_{b, 0}} w\left(S_{a, 0}, S_{b, 0}, S_{c, 0}\right) x^{2}\left(S_{b, 0}\right) x\left(S_{c, 0}\right)} \\
\times \frac{\sum_{S_{a, 1}} \sum_{S_{b, 1}} w\left(S_{a, 1}, S_{b, 1}, S_{c, 0}\right) x^{2}\left(S_{b, 1}\right) x\left(S_{a, 1}\right) \cdots}{\sum_{S_{a, 1}} \sum_{S_{b, 1}} w\left(S_{a, 1}, S_{b, 1}, S_{c, 0}\right) x^{2}\left(S_{b, 1}\right) x\left(S_{a, 1}\right) \cdots} \\
\times \frac{\sum_{S_{c, r-1}} \sum_{S_{b, r-1}} w\left(S_{a, r-2}, S_{b, r-1}, S_{c, r-1}\right) x^{2}\left(S_{b, r-1}\right) x\left(S_{c, r-1}\right)}{\sum_{S_{c, r-1}} \sum_{S_{b, r-1}} w\left(S_{a, r-2}, S_{b, r-1}, S_{c, r-1}\right) x^{2}\left(S_{b, r-1}\right) x\left(S_{c, r-1}\right)} \\
\times \frac{\sum_{S_{a, r}} \sum_{S_{b, r}} w\left(S_{a, r}, S_{b, r}, S_{c, r-1}\right) x^{2}\left(S_{b, r}\right) x^{2}\left(S_{a, r}\right) S_{a, r}^{n}}{\sum_{S_{a, r}} \sum_{S_{b, r}} w\left(S_{a, r}, S_{b, r}, S_{c, r-1}\right) x^{2}\left(S_{b, r}\right) x^{2}\left(S_{a, r}\right)},
\end{array}
$$

onde $w\left(S_{a_{k}}, S_{b_{k}}, S_{c_{k}}\right)=\exp \left(-\beta h\left[S_{a, k}, S_{b, k}, S_{c, k}\right]\right)$.

Nosso objetivo, nesta seção, é encontrar uma forma matricial para a expressão acima no caso em que $m=n=2$. Para tanto, iremos atribuir uma matriz de transferência a cada aresta que liga dois sítios ao longo do percurso escolhido. Neste ponto é necessário prosseguir com cautela: como o modelo de Bell-Lavis não é invariante sob a troca de duas sub-redes teremos matrizes diferentes para as conexões que ligam o sítio $a$ ao $c$ e o sítio $c$ ao sítio $a$. Isto não introduzirá nenhum problema significativo, visto que a operação de transposição é equivalente a uma troca de sub-redes, i.e., $V_{c a}^{T}=V_{a c}$.

Também será importante relembrar alguns detalhes do cacto de Husimi, que podem ser observados na figura 5.1. No cacto de Husimi cada sítio conecta três triângulos. No entanto, se considerarmos um sítio com sub-rede $l$ e índice $k$, num percurso ligando dois sítios separados por $r$ passos, veremos que apenas dois dos triângulos têm seus pesos de Boltzmann aparecendo explicitamente na eq. (5.43). A contribuição do terceiro triângulo conectado ao sítio $l$ aparece através da função de partição parcial $x\left(S_{l, k}\right)$. Seguindo a abordagem da ref. [109], esta função de partição parcial é 'dividida' entre as duas matrizes de transferência relacionadas às arestas adjacentes ao sítio $k$, sendo que cada uma delas 'fica' com uma contribuição $x^{1 / 2}\left(S_{l, k}\right)$.

Além disso, todas as matrizes de transferência contém uma soma sobre os estados de spin da sub-rede $b$, o peso de Boltzmann do triângulo no qual a aresta que liga os sítios $a$ e $c$ se encontra, além do quadrado da função de partição parcial, para incluir os dois ramos do cacto que se originam no sítio $b$. Assim, podemos escrever os elementos da matriz que 


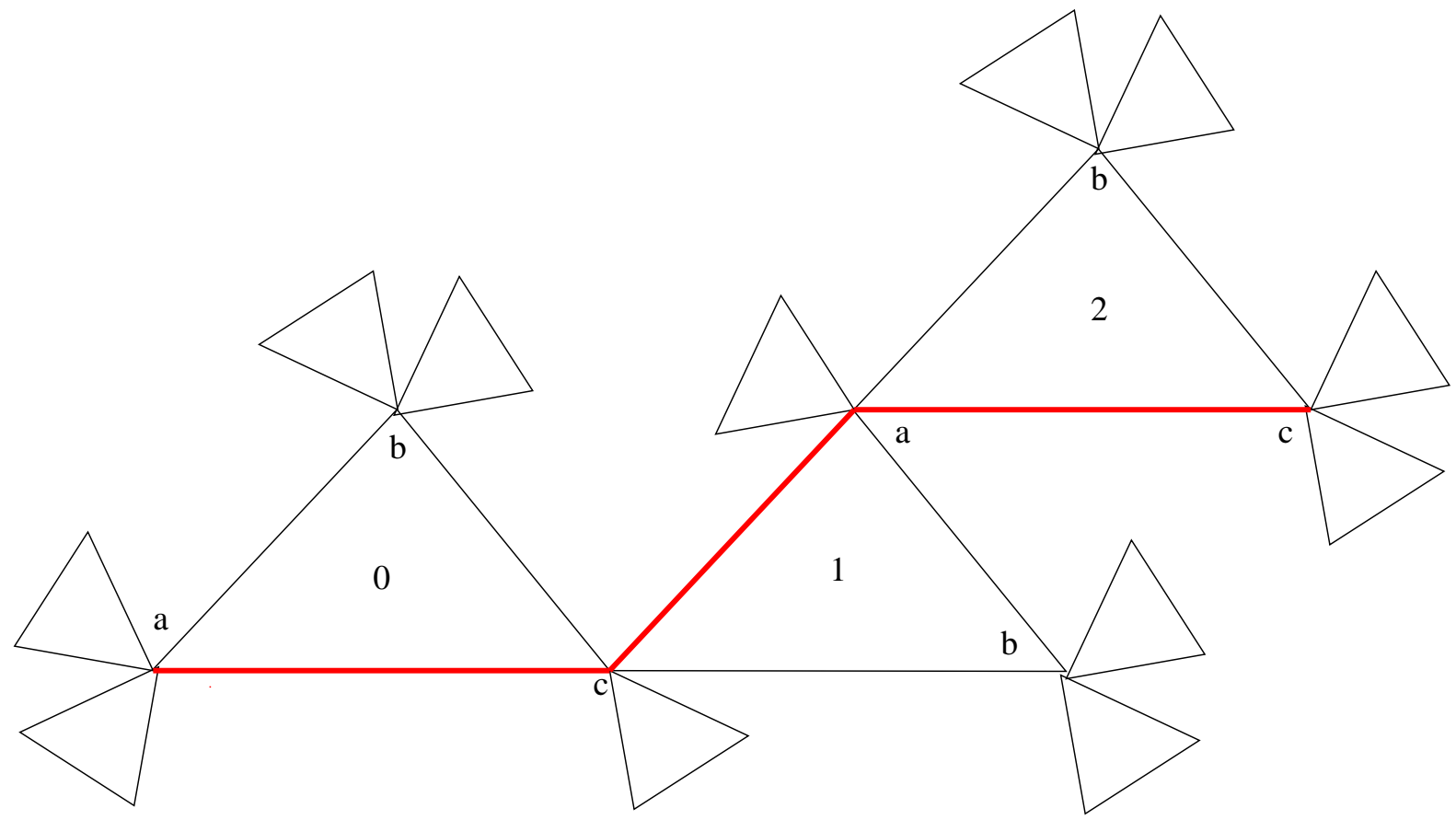

Figura 5.1: Construção da função de correlação de pares. Caminho mais curto ligando dois sítios distantes por três passos no interior do cacto de Husimi. Ao longo do percurso estão indicadas as gerações de cada triângulo e as sub-redes dos sítios.

conecta os sítios das sub-redes $a$ e $c$ da seguinte maneira:

$$
\left(V_{a c}\right)_{S S^{\prime}}=\sum_{S_{b}} w\left(S, S_{b}, S^{\prime}\right) x^{1 / 2}(S) x^{2}\left(S_{b}\right) x^{1 / 2}\left(S^{\prime}\right)
$$

Por construção temos $V_{c a}=V_{a c}^{T}$. Através das regras de formação das ligações de hidrogênio (veja a tabela 2.1) fica evidente que as matrizes que conectam as diferentes sub-redes satisfazem $V_{c a}=V_{a b}=V_{b c}$ e $V_{a c}=V_{c b}=V_{b a}$. Considerando estas condições, vamos simplificar a nossa notação usando apenas $V_{a c}=V$ e $V_{c a}=V^{T}$.

Neste ponto é importante notar que os sítios extremos, 0 e $r$, apresentam um termo diferenciado para a função de partição parcial na forma explícita da função de correlação (5.43). Retirando deste termo a parte referente à ligação que alcança cada extremo, sobra uma contribuição de $x^{3 / 2}\left(S_{a, l}\right)$, que tem a ver com os ramos adicionais que se ligam aos extremos. Além disso, no numerador da expressão (5.43) também aparecem as contribuições $S_{a, 0}^{m}$ e $S_{a, r}^{n}$.

Para escrever a expressão (5.43) como uma razão entre dois traços de matrizes, vamos transformar o percurso entre os sítios 0 e $r$ em um caminho fechado. Para isto, criamos uma ligação fictícia entre o primeiro e o último sítio do percurso e incluímos nesta ligação 
os termos adicionais dos extremos, citados no parágrafo anterior. Desta forma, os elementos das matrizes de transferência das ligações fictícias que irão aparecer no numerador e no denominador da forma matricial da eq. (5.43) são, respectivamente, escritos como:

$$
\begin{array}{r}
A_{S S^{\prime}}=x^{3 / 2}(S) x^{3 / 2}\left(S^{\prime}\right), \\
A_{S S^{\prime}}^{\prime}=S^{2} S^{\prime 2} x^{3 / 2}(S) x^{3 / 2}\left(S^{\prime}\right) .
\end{array}
$$

Com o auxílio destas matrizes, a forma matricial de $\left\langle S_{a, 0}^{2} S_{l, r}^{2}\right\rangle$ fica dada por:

$$
\left\langle S_{a, 0}^{2} S_{l, r}^{2}\right\rangle=\frac{\operatorname{Tr}\left\{A^{\prime} V V^{T} V V^{T} \cdots\right\}}{\operatorname{Tr}\left\{A V V^{T} V V^{T} \cdots\right\}}
$$

com o produto " $V V^{T} V V^{T} \ldots$ "tendo um número de matrizes igual a $r$.

A seqüência exata das matrizes " $V V^{T} V \ldots$ " que aparece nos dois traços da função (5.47) está ligada ao percurso escolhido entre as sub-redes. Esta seqüência poderia ser diferente caso outro percurso tivesse sido usado. No apêndice A mostramos que sempre temos

$$
\left\langle S_{a, 0}^{2} S_{l, r}^{2}\right\rangle=\frac{\operatorname{Tr}\left\{A^{\prime} V^{r}\right\}}{\operatorname{Tr}\left\{A V^{r}\right\}}
$$

para qualquer percurso escolhido. Contudo, a expressão (5.48) é válida apenas para as fases que não apresentam distinção de sub-redes, como no gás e no líquido de alta densidade do modelo BL. Não esperamos que uma passagem similar à feita entre as equações (5.47) e (5.48) exista para a fase LDL, devido ao ordenamento de sub-redes nesta fase.

Para ilustrar os problemas ligados ao cálculo da função de correlação (5.48), vamos listar explicitamente as matrizes incluídas nesta expressão. Notando que no líquido de alta densidade e no gás $x(s)=x^{s^{2}}, A$ e $A^{\prime}$ são escritos como:

$$
A=\left(\begin{array}{ccc}
x^{3} & x^{3 / 2} & x^{3} \\
x^{3 / 2} & 1 & x^{3 / 2} \\
x^{3} & x^{3 / 2} & x^{3}
\end{array}\right), \quad A^{\prime}=\left(\begin{array}{ccc}
x^{3} & 0 & x^{3} \\
0 & 0 & 0 \\
x^{3} & 0 & x^{3}
\end{array}\right) .
$$

Para simplificar a matriz $V$ vamos manter a notação usada para descrever o modelo BL na fase líquida de alta densidade, como na equação (5.29). Considerando os pesos de Boltzmann listados na tabela 2.2, a matriz $V$ fica dada por:

$$
V=\left(\begin{array}{ccc}
\left(a_{0}+a_{3}\right) x^{3}+a_{4} x & \left(a_{4}+a_{1}^{b}\right) x^{5 / 2}+a_{2} x^{1 / 2} & 2 a_{0} x^{3}+a_{1}^{b} x \\
\left(a_{4}+a_{1}^{u}\right) x^{5 / 2}+a_{2} x^{1 / 2} & 2 a_{2} x^{2}+1 & \left(a_{4}+a_{1}^{b}\right) x^{5 / 2}+a_{2} x^{1 / 2} \\
2 a_{0} x^{3}+a_{1}^{u} x & \left(a_{4}+a_{1}^{u}\right) x^{5 / 2}+a_{2} x^{1 / 2} & \left(a_{0}+a_{3}\right) x^{3}+a_{4} x
\end{array}\right) .
$$


Embora a equação (5.48) seja significativamente menos complicada que a equação (5.43), parece ser consideravelmente difícil diagonalizar a matriz $V$ para obter uma expressão simples e analítica de $g_{w w}(r)$. Mesmo assim, com um pouco de álgebra linear podemos simplificar esta expressão. Através da equação (5.29) podemos mostrar que as matrizes $A$ e $V$ comutam e que, por isso, podem ser escritas na mesma base. Como $A$ é consideravelmente mais simples do que $V$, vamos utilizar os autovetores ortonormalizados de $A$ como uma base para representar $V$. Estes autovetores podem ser escritos como:

$$
\Psi_{A, 0}=\frac{1}{\sqrt{2 x^{3}+1}}\left(\begin{array}{c}
x^{3 / 2} \\
1 \\
x^{3 / 2}
\end{array}\right), \quad \Psi_{A, 1}=\frac{1}{2}\left(\begin{array}{c}
-\sqrt{2} \\
0 \\
\sqrt{2}
\end{array}\right), \quad \Psi_{A, 2}=\frac{1}{\sqrt{x^{3}+1}}\left(\begin{array}{c}
-1 \\
x^{3 / 2} \\
0
\end{array}\right)
$$

Através destes autovetores, podemos encontrar a transformação unitária que diagonaliza $A, A_{D}=P^{-1} A P$. Usando novamente a eq. (5.29), vemos que a transformação unitária que diagonaliza $A$ nos dá um dos autovalores de $V$, por transformá-la em uma matriz bloco diagonal.

Os autovalores associados aos autovetores de $A$ podem ser facilmente encontrados e são $\lambda_{0}=2 x^{3}+1$ e $\lambda_{1}=\lambda_{2}=0$. Considerando que $A$ e $V$ comutam, podemos concluir que o autovetor associado ao autovalor $\lambda_{0}$ também será um autovetor de $V$. Não podemos fazer uma afirmação deste tipo para os autovetores associados ao autovalor nulo porque existe uma degenerescência neste autovalor. Devido à esta degenerescência, apenas podemos assegurar que os outros dois autovetores de $V$ estarão restritos ao subespaço dos autovetores $A$ com autovalor nulo.

Apesar destas dificuldades, usamos o fato de que os autovalores degenerados são nulos para obter $\operatorname{Tr}\left\{A V^{r}\right\}$, com os seguintes cálculos:

$$
\begin{aligned}
\operatorname{Tr}\left\{A V^{r}\right\} & =\operatorname{Tr}\left\{A_{D} V_{A}^{r}\right\} \\
& =\operatorname{Tr}\left\{\left(\begin{array}{ccc}
2 x^{3}+1 & 0 & 0 \\
0 & 0 & 0 \\
0 & 0 & 0
\end{array}\right)\left(\begin{array}{ccc}
\lambda_{0}^{r} & 0 & 0 \\
0 & \left(V_{A}^{r}\right)_{22} & \left(V_{A}^{r}\right)_{23} \\
0 & \left(V_{A}^{r}\right)_{32} & \left(V_{A}^{r}\right)_{33}
\end{array}\right)\right\} \\
& =\left(2 x^{3}+1\right) \lambda_{0}^{r},
\end{aligned}
$$

onde $V_{A}=P^{-1} V P$, e o autovalor $\lambda_{0}$ é dado por:

$$
\lambda_{0}=\frac{2\left(3 a_{0}+a_{3}\right) x^{6}+3\left(a_{1}^{b}+a_{1}^{u}+2 a_{4}\right) x^{4}+6 a_{2} x^{2}+1}{2 x^{3}+1} .
$$


Com estas mudanças podemos simplificar a equação (5.48) para:

$$
\left\langle S_{a, 0}^{2} S_{l, r}^{2}\right\rangle=\frac{\operatorname{Tr}\left\{A^{\prime} V^{r}\right\}}{\left(2 x^{3}+1\right) \lambda_{0}^{r}}
$$

\section{Função de correlação de pares entre solutos não interagentes}

Da mesma forma que construímos uma expressão matricial para a função de correlação de spins na eq. (5.48) também podemos obter uma equação para a função de correlação de buracos, $\left\langle\left(1-S_{a, 0}^{2}\right)\left(1-S_{a, r}^{2}\right)\right\rangle$. A passagem de uma expressão algébrica para uma expressão matricial se dará de forma semelhante ao desenvolvido no tópico acima, com a ressalva de que ao invés de aparecer uma matriz $A^{\prime}$ teremos, no denominador, uma matriz $A_{b}^{\prime}$ com elementos dados por:

$$
\left(A_{b}^{\prime}\right)_{S S^{\prime}}=\left(1-S^{2}\right)\left(1-S^{\prime 2}\right) x^{3 / 2}(S) x^{3 / 2}\left(S^{\prime}\right)
$$

Listando de forma explícita, esta matriz assume o seguinte formato

$$
A_{b}^{\prime}=\left(\begin{array}{lll}
0 & 0 & 0 \\
0 & 1 & 0 \\
0 & 0 & 0
\end{array}\right)
$$

Seguindo os mesmos passos de (5.45) a (5.48), com o auxílio dos resultados do apêndice A, obtemos:

$$
\left\langle\left(1-S_{a, 0}^{2}\right)\left(1-S_{a, r}^{2}\right)\right\rangle=\frac{\operatorname{Tr}\left\{A_{b}^{\prime} V^{r}\right\}}{\left(2 x^{3}+1\right) \lambda_{0}^{r}}
$$

\section{Função de correlação de pares entre solutos interagentes}

Para tratar o caso mais geral de um soluto interagente, vamos utilizar uma expressão alternativa para a função de correlação de pares, dada por

$$
g_{s s}(r)=e^{-\beta u_{s s} \delta_{1, r}} \frac{\left\langle\exp \left\{-\beta\left[U_{w s}^{(0)}+U_{w s}^{(r)}\right]\right\}\right\rangle}{\left\langle\exp \left[-\beta U_{w s}^{(0)}\right]\right\rangle^{2}}
$$

onde $u_{s s}$ é a energia de interação entre dois solutos, $\delta_{1, r}$ é o delta de Kronecker, $U_{w s}^{(k)}$ é a energia total de interação entre um soluto situado no sítio $k$ e o solvente nas suas vizinhanças, e as médias são tomadas sobre todos os estados do solvente no cacto. Uma demonstração desta relação pode ser encontrada na Ref. [111].

Todos os estados do solvente devem ser considerados nas médias que aparecem nesta definição de $g_{s s}(r)$, incluindo os estados com moléculas de solvente no mesmo sítio em que 
se encontram o soluto. Contudo, como a energia de interação entre o soluto e o solvente também deve incluir a interação de caroço duro $^{5}$, de forma que a contribuição destas configurações desaparece no final. Em uma sub-rede $a$ no triângulo central do cacto de Husimi, esta energia de interação com o solvente é

$$
U_{w s}^{(k)}=u_{w s}^{\prime}\left(S_{a, 0}, S_{b, 0}, S_{c, 0}\right)+u_{w s}^{\prime}\left(S_{a, 0}, S_{b,-1}, S_{c,-1}\right)+u_{w s}^{\prime}\left(S_{a, 0}, S_{b,-1}^{\prime}, S_{c,-1}^{\prime}\right)
$$

e possui três termos que estão ligados a cada um dos triângulos que partem deste sítio. A energia de interação entre soluto e solvente em um único triângulo é dada por

$$
u_{w s}^{\prime}\left(S_{a, 0}, S_{b, 0}, S_{c, 0}\right)=u_{w s}\left(S_{a, 0}, S_{b, 0}, S_{c, 0}\right)+u_{h c}\left(S_{a, 0}\right)
$$

onde $u_{w s}$ é dado pela eq. (5.16) e o termo de caroço duro, $u_{h c}$, é dado por

$$
u_{h c}(S)=-k_{B} T \ln \left(1+S^{2}\right) .
$$

Vamos agora considerar o termo $\left\langle\exp \left[-\beta U_{w s}^{(0)}\right]\right\rangle^{2}$, que aparece no denominador da eq. (5.58). Como estamos fixando a presença de um soluto no sítio 0, as médias sobre os triângulos que partem deste sítio se tornam independentes e, por isto, temos

$$
\left\langle\exp \left[-\beta U_{w s}^{(0)}\right]\right\rangle^{2}=\left\langle\exp \left(-\beta u_{w s}^{\prime}\right)\right\rangle^{6}
$$

com a média no lado direito desta equação obtida através da (3.30). Após alguma álgebra podemos mostrar que

$$
\left\langle\exp \left(-\beta u_{w s}^{\prime}\right)\right\rangle=(1-\rho) y_{s}
$$

com $y_{s}$ determinado pela eq. (5.31), lembrando que anteriormente consideramos o limite de diluição infinita e definimos $x_{w}\left(l, S_{l}\right)=x^{S_{l}^{2}}$.

Vamos considerar o termo que aparece no numerador de $g_{s s}(r)$ na eq. (5.58). Devido à presença do soluto nos sítios 0 e $r$ teremos uma independência entre os termos ligados aos triângulos que não estão no percurso entre os dois solutos. Por este motivo, teremos

$$
\begin{gathered}
\left\langle\exp \left\{-\beta\left[U_{w s}^{(0)}+U_{w s}^{(r)}\right]\right\}\right\rangle= \\
\left\langle\exp \left(-\beta u_{w s}^{\prime}\right)\right\rangle^{4}\left\langle\exp \left[-\beta u_{w s}^{\prime}\left(S_{a, 0}, S_{b, 0}, S_{c, 0}\right)-\beta u_{w s}^{\prime}\left(S_{a, r}, S_{b, r-1}, S_{c, r-1}\right)\right]\right\rangle .
\end{gathered}
$$

Neste ponto falta apenas calcular a média no lado direito da última equação. Para fazer isto vamos notar que a interação de caroço duro pode ser utilizada mais de uma

\footnotetext{
${ }^{5}$ do inglês hard-core.
} 
vez, já que $\left(1-S^{2}\right)=\left(1-S^{2}\right)^{2}$. Assim, podemos utilizá-la duas vezes para reescrever o último termo que resta para ser calculado em um formato similar ao da correlação entre buracos, como

$$
\begin{gathered}
\left\langle\exp \left[-\beta u_{w s}^{\prime}\left(S_{a, 0}, S_{b, 0}, S_{c, 0}\right)-\beta u_{w s}^{\prime}\left(S_{a, r}, S_{b, r-1}, S_{c, r-1}\right)\right]\right\rangle= \\
\left\langle\left(1-S_{a, 0}^{2}\right)\left(1-S_{a, r}^{2}\right) \exp \left[-\beta u_{w s}^{\prime}\left(S_{a, 0}, S_{b, 0}, S_{c, 0}\right)-\beta u_{w s}^{\prime}\left(S_{a, r}, S_{b, r-1}, S_{c, r-1}\right)\right]\right\rangle .
\end{gathered}
$$

Notando que a média acima está no mesmo formato da correlação entre buracos, dada pela eq. (5.57), podemos estender aqueles cálculos para incluir a interação entre soluto e solvente. No caso em que $r>1$, estes cálculos resultam em

$$
g_{s s}(r)=\frac{1}{(1-\rho) y_{s}^{2}} \frac{\operatorname{Tr}\left\{A_{b}^{\prime} V^{(h w)} V^{r-2} V^{(w h)}\right\}}{\lambda_{0}^{r}},
$$

onde as matrizes $V^{(h w)}=\left[V^{(w h)}\right]^{T}$ são responsáveis pela interação entre o soluto e o solvente, e são dadas por

$$
\left(V^{(h w)}\right)_{S S^{\prime}}=\sum_{S_{b}} w\left(S, S_{b}, S^{\prime}\right) x^{1 / 2}(S) x^{2}\left(S_{b}\right) x^{1 / 2}\left(S^{\prime}\right) e^{-\beta u_{w s}^{\prime}\left(S, S_{b}, S^{\prime}\right)}
$$

Listando explicitamente seus elementos, esta matriz assume o seguinte formato:

$$
V^{(h w)}=\left(\begin{array}{ccc}
0 & 0 & 0 \\
\left(a_{4}+a_{1}^{u}\right) v^{2} x^{5 / 2}+a_{2} v x^{1 / 2} & 2 a_{2} v x^{2}+1 & \left(a_{4}+a_{1}^{b}\right) v^{2} x^{5 / 2}+a_{2} v x^{1 / 2} \\
0 & 0 & 0
\end{array}\right) .
$$

\section{Modelo Blume-Emery-Griffiths}

Para calcular $g_{w w}(r)$ do modelo BEG lembramos que neste caso o potencial grande canônico do estado líquido de alta densidade não ligado torna-se igual ao do líquido de alta densidade ligado, em $T=0$. Por este motivo os pesos de Boltzmann destes estados tornam-se idênticos, $a_{1}^{b}=a_{1}^{u}=a_{1}$, e a matriz $V$ torna-se supersimétrica, i.e., simétrica em relação às diagonais principal e secundária. Esta propriedade irá nos auxiliar a obter uma expressão analítica para a função de correlação, no caso do modelo BEG, já que toda matriz supersimétrica comuta com a matriz de inversão $J$, dada por:

$$
J=\left(\begin{array}{lll}
0 & 0 & 1 \\
0 & 1 & 0 \\
1 & 0 & 0
\end{array}\right)
$$


A transformação unitária que diagonaliza $J$ é $J_{D}=U^{-1} J U$, onde $U$ é um operador Hermitiano escrito como:

$$
U=\left(\begin{array}{ccc}
\sqrt{2} / 2 & 0 & \sqrt{2} / 2 \\
0 & 1 & 0 \\
\sqrt{2} / 2 & 0 & -\sqrt{2} / 2
\end{array}\right) .
$$

Felizmente, quando representamos a matriz $V$ na base de $U$, surge um autovalor que é diferente daquele obtido na eq. (5.52). Desta forma, após a mudança de base a matriz $V_{U}$ torna-se bloco diagonal, mas com outra região em formato de bloco.

A esta altura não é difícil imaginar que uma dupla transformação unitária pode ser utilizada para diagonalizar completamente $V$, no caso em que $a_{1}^{u}=a_{1}^{b}$. Vamos fazer isto primeiro representando as matrizes $A, A^{\prime}$ e $V$ na base $U$ que diagonaliza $J$ :

$$
\begin{aligned}
& A_{U}=U A U, \\
& A_{U}^{\prime}=U A U, \\
& V_{U}=U V U .
\end{aligned}
$$

Em seguida vamos encontrar a transformação que diagonaliza $A_{U}, A_{D}=P^{\prime-1} A_{U} P^{\prime}$, para que possamos representar $A_{U}^{\prime}$ e $V_{U}$ na base desta transformação. Aplicando estas duas mudanças de representação sobre $V$ verificamos que obtemos uma matriz diagonal, $V_{D}=P^{\prime-1} U V U P^{\prime}$, com os seguintes autovalores:

$$
\begin{aligned}
& \lambda_{0}=\frac{2\left(3 a_{0}+a_{3}\right) x^{6}+6\left(a_{1}+a_{4}\right) x^{4}+6 a_{2} x^{2}+1}{2 x^{3}+1} \\
& \lambda_{1}=\frac{4 a_{2} x^{5}-4\left(a_{1}+a_{4}\right) x^{4}+\left(3 a_{0}+a_{3}\right) x^{3}+2 x^{3}-4 a_{2} x^{2}+\left(a_{1}+a_{4}\right) x}{2 x^{3}+1} \\
& \lambda_{2}=\left(a_{3}-a_{0}\right) x^{3}+\left(a_{4}-a_{1}\right) x
\end{aligned}
$$

Podemos utilizar as eqs. (5.29) ou (5.32) para simplificar estes autovalores para

$$
\begin{aligned}
& \lambda_{0}=2\left(a_{1}+a_{4}\right) x^{4}+4 a_{2} x^{2}+1, \\
& \lambda_{1}=\frac{1}{x}\left[2 a_{2} x^{3}-\left(a_{1}+a_{4}\right) x^{2}+x-a_{2}\right], \\
& \lambda_{2}=\left(a_{3}-a_{0}\right) x^{3}+\left(a_{4}-a_{1}\right) x .
\end{aligned}
$$

Também podemos calcular o denominador da eq. (5.48) com este procedimento, obtendo o mesmo resultado da eq. (5.52). Tornando explícita a representação da matriz $A_{U}$ 
na eq. (5.71a) podemos calcular, para o caso do modelo BEG, o numerador da eq. (5.54) como:

$$
\operatorname{Tr} A^{\prime} V^{r}=\frac{4 x^{6} \lambda_{0}^{r}+2 x^{3} \lambda_{1}^{r}}{2 x^{3}+1}
$$

Utilizando as expressões para a densidade dadas nas eqs. (3.31) e (3.32) do capítulo 3, juntamente com as funções de correlação de spin e correlação de pares, dadas pelas expressões (5.54) e (5.40), obtemos:

$$
\begin{aligned}
g_{w w}(r) & =1+1 /\left(2 x^{3}\right)\left(\frac{\lambda_{1}}{\lambda_{0}}\right)^{r} \\
& =1+\frac{1-\rho}{\rho} e^{-r / \zeta},
\end{aligned}
$$

onde $\zeta$ é o comprimento de correlação do sistema, que pode ser escrito como:

$$
\zeta=\left[\ln \left(\lambda_{0} / \lambda_{1}\right)\right]^{-1}
$$

Também podemos obter uma expressão analítica para a função de correlação entre buracos no modelo BEG, aplicando as transformações utilizadas acima à matriz $A_{b}^{\prime}$, que aparece no traço da eq. (5.57). Como resultado destes cálculos, temos:

$$
\begin{aligned}
g_{h h}(r) & =1+\left(2 x^{3}\right)\left(\frac{\lambda_{1}}{\lambda_{0}}\right)^{r} \\
& =1+\frac{\rho}{1-\rho} e^{-r / \zeta}
\end{aligned}
$$

onde $\zeta$ novamente é o comprimento de correlação do solvente, definido acima.

No caso do soluto interagente, é conveniente utilizar $\operatorname{Tr}\{A B C D\}=\operatorname{Tr}\{D A B C\}$ para reescrever

$$
\operatorname{Tr}\left\{A_{b}^{\prime} V^{(h w)} V^{r-2} V^{(w h)}\right\}=\operatorname{Tr}\left\{V^{(w h)} A_{b}^{\prime} V^{(h w)} V^{r-2}\right\}=\operatorname{Tr}\left\{K V^{r-2}\right\} .
$$

Aplicando as mesmas transformações utilizadas acima sobre as matrizes $V$ e $K$ obtemos, após alguma álgebra,

$$
g_{s s}(r)=1+\frac{\rho}{1-\rho}\left(\frac{\lambda_{1}^{(s)} / \lambda_{0}^{(s)}}{\lambda_{1} / \lambda_{0}}\right)^{2} e^{-r / \zeta},
$$

para $r>1, \operatorname{com} \lambda_{0}^{(s)}$ e $\lambda_{1}^{(s)}$ sendo dados por

$$
\lambda_{0}^{(s)}=2\left(a_{1}+a_{4}\right) x^{4} v^{2}+4 a_{2} x^{2} v+1,
$$

e

$$
\lambda_{1}^{(s)}=\frac{1}{x}\left[2 a_{2} x^{3}-\left(a_{1}+a_{4}\right) x^{2} v^{2}+x-a_{2} v\right] .
$$


Note que quando o soluto deixa de ser interagente, $\epsilon_{s s}=\epsilon_{w s}=0$, temos $v=1$ e a função de correlação entre os solutos passa a ser idêntica à função de correlação entre buracos.

Para $r=1$, a função de correlação de pares pode ser calculada diretamente, sendo igual a

$$
g_{s s}(1)=\frac{e^{\beta \epsilon_{s s}}}{1-\rho} \frac{2 a_{2} x^{2} v^{2}+1}{2\left(a_{1}+a_{4}\right) x^{4} v^{2}+4 a_{2} x^{2} v+1} .
$$

Novamente iremos lembrar que as funções de correlação obtidas acima foram expressas da distância química, sendo necessário representar o cacto em alguma rede para representar uma medida de distância em um espaço físico [110]. 


\section{Capítulo 6}

\section{Modelos de Água: Conclusões}

O modelo Bell-Lavis de água líquida foi comparado à sua versão isotrópica, o modelo de Blume-Emery-Griffiths antiferromagnético na rede triangular. Mostramos que o estado fundamental dos dois modelos é topologicamente idêntico, com as fases fluidas (gás, líquido de baixa densidade e líquido de alta densidade) equivalentes às fases magnéticas (paramagneto, antiferromagneto e paramagneto frustrado). Os efeitos de temperatura finita foram considerados com um estudo do sistema no interior do cactus de Husimi seqüencial. Os diagramas de fases e as linhas de máximo de densidade na fase HDL, dos dois modelos, foram comparados com valores equivalentes de interação reduzida.

Foi mostrado que as características anômalas da fase líquida de alta densidade nos dois modelos são muito similares, com linhas de máximo de densidade ocorrendo em pressões e temperaturas equivalentes. A estabilidade da fase LDL é substancialmente aumentada no modelo BL, em comparação com o modelo BEG. Este incremento na estabilidade da fase LDL faz com que a linha de máximos de densidade ocorra em uma região metaestável da fase HDL. Para o modelo BEG isotrópico, tanto a linha de máximos de densidade quanto as anomalias nas funções termodinâmicas de resposta ocorrem em um regime estável.

A existência destas características no modelo BEG mostra que o caráter orientacional da ligação de hidrogênio não é relevante para o comportamento anômalo do modelo BL, da mesma forma como foi observado em estudos anteriores com modelos contínuos de núcleo amaciado $[46,112,113]$.

Nos dois modelos, a anomalia na densidade é acompanhada por uma alta taxa de variação na entropia e no número de ligações de hidrogênio (generalizadas) por partícula, e por um comportamento anômalo nas funções termodinâmicas de resposta.

Nesta tese, propomos uma explicação para o comportamento anômalo nos dois modelos através de uma competição entre duas estruturas líquidas. Sugerimos que esta 
competição surge devido à frustração energética, i.e., à impossibilidade de formação de ligações de hidrogênio (generalizadas) em todas as ligações da rede. A frustração possibilita o aparecimento da fase líquida de baixa densidade que, por sua vez, 'cede' algumas de suas características ao líquido de alta densidade ligado. O comportamento anômalo da estrutura líquida HDL ligada pode ser entendido se notarmos que existe uma entropia associada à rede de ligaçõess de hidrogênio (generalizada) no líquido, e que a entropia desta rede aumenta rapidamente com a densidade quando novas partículas são inseridas. Da competição entre as estruturas HDL ligada e normal surgem as temperaturas de máximo de densidade, em cada pressão fixa. Por este motivo, a frustração energética é responsável pelo aparecimento da linha de máximos de densidade tanto no modelo BL quanto no modelo BEG.

O efeito hidrofóbico também está sendo estudado no modelo BL e em sua versão isotrópica, sendo que os resultados já obtidos foram apresentados no capítulo 5 .

Simulações de Monte Carlo estão sendo realizadas com o modelo BL, para obter o seu diagrama de fases e checar a ligação entre frustração, anomalia na densidade e transições de fase entre dois líquidos. 


\section{Capítulo 7}

\section{Enovelamento de Proteínas}

\subsection{Introdução}

Os mecanismos que levam uma seqüência de aminoácidos de uma proteína a determinar sua estrutura tridimensional é um dos maiores problemas da biologia molecular na atualidade. Podemos afirmar isto porque as proteínas são entidades biomoleculares básicas que desempenham um número muito grande de funções biológicas. Algumas delas são responsáveis pelo transporte de íons em membranas celulares, pela integridade estrutural de algumas células, e pelas ações enzimáticas que regulam e catalisam diversas reações químicas importantes no organismo [114]. Como a função biológica de uma proteína está intimamente relacionada à sua estrutura [115], o conhecimento desta é vital para entender as cadeias de eventos que resultam em atividades biológicas ou o efeito da interação de compostos químicos sobre a proteína.

Em condições ambientes de temperatura e pressão, proteínas globulares pequenas enovelam-se espontaneamente para uma conformação tridimensional única, comumente chamada de estado nativo, em detrimento de um número muito grande de estados possíveis para uma cadeia polimérica (neste caso, polipeptídica) $[114,116,117]$. De fato, as proteínas possuem propriedades típicas que estão ligada à evolução biológica de sua seqüência de aminoácidos [118], já que a maioria das cadeias polipeptídicas que poderiam ser formadas com uma combinação aleatória de aminoácidos não possui um estado nativo estável tanto do ponto de vista termodinâmico, quanto em relação à mutabilidade da seqüência [118].

Algumas proteínas podem apresentar estados diferentes do nativo em condições biológicas. Certas doenças, como a doença da vaca-louca e do mal de Alzheimer [119, 120], estão relacionadas à proteínas mal dobradas que possivelmente atuam cataliticamente induzindo 
outras proteínas semelhantes a também assumirem uma conformação errada [120]. Nestes exemplos, as proteínas mal dobradas formam agregados moleculares que levam ao aparecimento da doença.

A estrutura tridimensional de uma proteína pode ser obtida por métodos cristalográficos, como a difração de Raios-X [116], desde que seja possível obter o seu cristal com altíssimo grau de pureza, e também por Ressonância Magnética Nuclear [121]. Contudo, este tipo de procedimento nem sempre é possível e, mesmo quando viável, é extremamente dispendioso e demorado. Por outro lado, o seqüenciamento genético de todo o DNA de uma espécie está se tornando rotineiro, desde que foi realizado o mapeamento do DNA humano pelo Consórcio Internacional de Seqüenciamento do Genoma Humano e pela empresa privada Celera Genomics. No Brasil, já foram seqüenciados o DNA de algumas bactérias ligadas à doenças de plantas com alta importância econômica, incluindo a Xylella fastidiosa [122] (causadora da praga do amarelinho em plantações de laranja) e a Leifsonia xyli (que ataca a cana-de-açucar) [123]. Em todo o mundo, novos genomas de espécies animais e vegetais são obtidos a cada ano, resultando numa grande quantidade de informação que, apesar de relevante, não resulta no conhecimento das estruturas protéicas relacionadas aos genes seqüenciados.

Dentro deste contexto, entender os mecanismos que levam ao enovelamento de uma proteína torna-se crucial para o desenvolvimento pleno da biotecnologia. Apesar disto, esta área de pesquisa tem se mostrado extremamente complexa e a obtenção da estrutura tridimensional de uma proteína a partir de sua seqüência é um problema que vem resistindo a várias décadas de estudo, assim como a um aumento exponencial no poder de processamento dos computadores. Isto ocorre porque existe uma lacuna de conhecimento muito grande entre a escala de tamanho onde ocorrem as interações entre moléculas pequenas e a escala mesoscópica na qual se encontram as proteínas, que possuem algumas dezenas de milhares de átomos. Uma outra fonte de complexidade no enovelamento de proteínas é o fato dele ocorrer imerso em meio aquoso. A presença da água torna muito difícil a simulações de modelos realísticos de proteínas na escala de tempo em que ocorre o enovelamento, que é da ordem de milisegundos.

Devido a estas dificuldades, o estudo do enovelamento tem ocorrido de forma complementar. Ao mesmo tempo em que são investigados métodos computacionais e potenciais mais eficazes para a simulação de modelos com detalhe atômico [124], visando o enove- 
lamento in silico, também busca-se um entendimento mais aprofundado das interações que resultam no processo de enovelamento através de modelos teóricos simplificados de polipeptídeos [125]. Neste trabalho adotamos a segunda abordagem, tendo em vista o uso de ferramentas analíticas e computacionais da mecânica estatística.

Em uma abordagem em rede [125], um aminoácido (ou um grupo de poucos aminoácidos) de uma proteína é representado por um monômero em um sítio de uma rede quadrada (2D) ou cúbica (3D), que é conectado por uma ligação covalente com outros monômeros. A cadeia polipeptídica assume estados em que são consideradas a restrição de volume excluído e onde as interações ocorrem apenas entre os primeiros vizinhos na rede. Como o número de estados acessíveis ao sistema fica muito reduzido, em comparação com representações mais realísticas, é possível realizar simulações de Monte Carlo e observar os processos de enovelamento e desenovelamento ocorrerem inúmeras vezes em modelos de proteínas com várias dezenas de aminoácidos, a um custo computacional pequeno. No caso dos modelos bidimensionais torna-se acessível a enumeração completa do espaço conformacional de modelos de proteínas pequenas (o tamanho do polímero pode chegar a $N=26$ monômeros em alguns modelos) e, conseqüentemente, a função de partição do modelo. A vantagem desta simplificação é que ela possibilita uma comparação extensiva dos aspectos termodinâmicos e dinâmicos do enovelamento com os ingredientes energéticos (interações hidrofóbicas, hidrofílicas, ligações de hidrogênio, propensões a formação de estruturas secundárias, etc.) e topológicas (tamanho do polímero, presença de cadeias laterais, tipo de rede, etc.) dos modelos estudados.

Em nosso trabalho, estamos particularmente interessados em entender como as interações intramoleculares contribuem para um processo de enovelamento cooperativo, essencialmente de dois estados, que ocorre em proteínas globulares pequenas [126]. Diferentes medidas da organização de uma proteína, como a quantidade de estrutura secundária, o raio de giro e o enterramento de resíduos de triptofano [114], mostram a presença dominante do estado nativo em baixas temperaturas, e um estado desnaturado em altas temperaturas $[127,128]$. A transição entre estes dois estados ocorre de forma abrupta e consome uma grande quantidade de calor [127, 128]. Como discutiremos mais à frente, este processo é comparável a uma transição de fase de primeira ordem [129], onde existem dois estados com populações distintas e igualmente prováveis no ponto da transição, em oposição a uma transição de segunda ordem (não cooperativa), que possui 


\subsection{Introdução}

um único estado se deslocando à medida que a transição se aproxima.

A cooperatividade de proteínas globulares pequenas é um fato conhecido mas, até o momento, nenhum modelo simplificado foi capaz de reproduzir este resultado. Alguns modelos teleológicos, como o modelo Gō tridimensional e os modelos de capilaridade, apresentam uma cooperatividade apreciável [127, 128]. Contudo estes modelos têm ingredientes que direcionam o estado fundamental para a estrutura nativa e, por isso, não esclarecem como as interações intramoleculares contribuem para a cooperatividade. Várias tentativas de modelagem foram feitas neste sentido e nenhuma delas resultou em modelos com interações fisicamente plausíveis e realmente cooperativos [130, 126, 127, 128, 131, 132]. No entanto, podemos tentar abstrair destes estudos alguns elementos que podem ser responsáveis por tornar as proteínas cooperativas. De forma genérica, podemos afirmar que é necessário um balanço entre interações locais e não-locais e que, além disso, os efeitos de muitos corpos são relevantes [126, 129]. Neste contexto, tem sido verificado que a interação hidrofóbica é mais complicada do que originalmente imaginado, com contribuições importantes ocorrendo nas interações de muitos corpos [133], na solvatação e na de-solvatação [134]. Além disso, percebe-se que as ligações de hidrogênio da cadeia polipeptídica contribuem significativamente para a determinação da estrutura e da termodinâmica das proteínas.

Nossa opinião é que as ligações de hidrogênio possam ser o elemento energético responsável pela cooperatividade no enovelamento de proteínas globulares pequenas. Contudo, a inclusão da ligação de hidrogênio precisa ser feita com cuidado, considerando as diferentes hipóteses sobre a sua formação no interior das proteínas e no meio aquoso. Neste capítulo vamos discutir como as ligações de hidrogênio podem aumentar significativamente a cooperatividade de modelos de proteínas e homopolipeptídeos. Ao invés de considerarmos as ligações de hidrogênio como um fenômeno puramente entálpico, adotamos uma visão em que a ligação de hidrogênio induz uma restrição no conjunto de estruturas compatíveis com o estado nativo e que, por isso, também se apresenta como um fenômeno entrópico. Esta restrição é observada experimentalmente: os grupos polares da cadeia principal das proteínas fazem ligações de hidrogênio ao serem enterrados no estado nativo. Para representar este processo, ao invés de favorecermos os estados que apresentam as ligações de hidrogênio com uma interação atrativa, desfavorecemos os estados em que monômeros se enterram sem estar formando ligações de hidrogênio, 
através de uma penalização energética. Esta penalização corresponde à energia resultante da quebra das ligações de hidrogênio que aqueles monômeros faziam com a água, quando não estavam enterrados. Os resultados serão apresentados brevemente e estão discutidos em maior detalhe nas referências [135] e [136].

Nas próximas subseções faremos uma introdução ao conceito de cooperatividade calorimétrica e iremos comparar uma transição de enovelamento cooperativa a uma transição de fase de primeira ordem, seguindo os trabalhos de Chan [127] e Pereira de Araujo [137]. Em seguida apresentamos nossa tentativa de tornar cooperativos modelos de proteínas e homopolipeptídeos $[135,136]$.

\subsection{Cooperatividade calorimétrica: conceitos básicos}

Antes de iniciarmos, é importante lembrar que o conceito de cooperatividade é utilizado em várias áreas da biologia molecular, sendo sempre definido de forma comparativa com um determinado processo que não é cooperativo. No caso de uma proteína a cooperatividade refere-se a quanto a transição de enovelamento é consistente com a existência de dois estados, i.e., ao quanto a separação entre os estados nativo e desnaturado mantémse inalterada ao longo do processo de enovelamento. Nesta transição o referencial pode ser uma transição de descompactação, com o aumento da temperatura, tendo um único estado cujo raio de giro médio aumenta à medida que o sistema se aquece.

Vários parâmetros foram propostos, no contexto dos modelos simplificados de proteínas, para medir o caráter proteico de um heteropolipeptídeo. Alguns deles tentam capturar o comportamento abrupto da transição de enovelamento e outros, como o Z-Score, visam quantificar a estabilidade da estrutura nativa da proteína. Por exemplo, a cooperatividade de Thirumalai, $\Omega_{c}$, que é um parâmetro adimensional que mede o quão rápido ocorre uma transição entre dois estados, é definida como

$$
\Omega_{c}=\frac{T_{\max }^{2}}{\Delta T} \max \left[\frac{d\langle\chi\rangle}{d T}\right]
$$

onde $T_{\max }$ refere-se à temperatura em que ocorre a máxima taxa de variação de uma variável de controle de dois estados $\chi$, e $\Delta T$ à meia largura do pico da taxa de variação de $\chi$. Utilizando a entalpia como uma medida de controle, uma transição de fase de primeira ordem apresentaria uma cooperatividade $\Omega_{c}$ infinita, devido à descontinuidade da capacidade térmica no ponto da transição. No entanto, convém observar que alguns sistemas pouco cooperativos podem ter um valor alto de $\Omega_{c}$. 
Um critério mais exigente, e que tem sido utilizado experimentalmente para determinar se proteínas apresentam ou não dois estados é a cooperatividade calorimétrica. Esta cooperatividade tem sido utilizada pelo grupo de Hue S. Chan para investigar a origem da cooperatividade no processo de enovelamento de proteínas globulares pequenas. No que se segue iremos introduzir a cooperatividade calorimétrica seguindo a abordagem adotada por Chan. Para uma discussão mais detalhada sobre o assunto, recomendamos o texto original [127].

Segundo o critério calorimétrico, para que uma proteína seja cooperativa, a entalpia $\Delta H_{\text {cal }}$ absorvida durante o processo de desenovelamento deve ser comparável à entalpia de van't Hoff, que mede a diferença de entalpia entre os estados nativo e desnaturado, no ponto médio da transição. No que se segue, apresentaremos este critério de cooperatividade e mostraremos como ele se relaciona com dados experimentais de proteínas.

Experimentalmente, a cooperatividade de uma proteína é verificada assumindo-se que alguma propriedade, como o raio de giro, se comporta como uma coordenada de reação em um sistema de dois estados, sendo esta hipótese validada a posteriori. No caso de modelos minimalistas, onde temos acesso a toda informação microscópica do sistema, podemos definir exatamente os estados nativo e desnaturado e acompanhar a população do estado nativo em função da temperatura. Se assumirmos que o estado nativo de uma proteína é constituído por uma única estrutura numa entalpia $H_{N}$ bem definida, a diferença entre a entalpia do sistema em uma temperatura $T$ e o estado nativo será:

$$
\Delta H_{c a l}(T)=\langle H(T)\rangle-H_{N}
$$

Vamos desconsiderar a possibilidade de desenovelamento a frio nos modelos simplificados de proteínas que iremos estudar. Neste caso, $H_{N}$ independe de $T$ e no limite $T \rightarrow 0$ temos $\Delta H_{\text {cal }}(0)=0$. Por outro lado, no limite $T \rightarrow \infty$ o processo de desenovelamento da proteína está completo e $\Delta H_{\text {cal }}=\lim _{T \rightarrow \infty} \Delta H_{\text {cal }}(T)$ corresponde ao calor absorvido pelo sistema para passar do estado nativo para o estado desnaturado. Experimentalmente, esta quantidade pode ser obtida integrando-se a curva de capacidade térmica partindo de uma temperatura baixa, em que a proteína esteja no estado nativo, até uma temperatura muito maior que aquela do pico da transição de enovelamento.

Para definir a entalpia de van't Hoff, vamos usar a constante de equilíbrio entre as 
populações dos estados nativo e desnaturado, dada por:

$$
K_{e q}(T)=\frac{P_{N}}{P_{D}}=\frac{e^{-\beta H_{N}}}{\sum_{D} g\left(H_{i}\right) e^{-\beta H_{i}}}
$$

onde $P_{N}$ e $P_{D}$ são as probabilidades de acharmos o sistema nos estados nativo e desnaturado; a soma no denominador é realizada sobre todos os níveis de energia dos estados desnaturado e $g\left(H_{i}\right)$ é o número de estados em cada nível. A entalpia de van’t Hoff é calculada como a diferença de entalpia entre os estados nativo e desnaturado na temperatura média da transição, $T_{1 / 2}$, onde as populações destes estados são igualmente prováveis. Usando a constante de equilíbrio definida na eq. (7.3), $\Delta H_{v H}$ fica definida como:

$$
\Delta H_{v H}=-\left.k_{B} T_{1 / 2}^{2} \frac{\partial \ln K_{e q}(T)}{\partial T}\right|_{T=T_{1 / 2}}=\left\langle H\left(T_{1 / 2}\right)\right\rangle_{D}-H_{N}
$$

onde $\langle\cdots\rangle_{D}$ indica uma média com pesos de Boltzmann sobre o espaço formado apenas pelas estruturas do estado desnaturado. Comparando a expressão (7.4) com $\Delta H_{\text {cal }}$ vemos que estas quantidades serão iguais apenas se a entalpia do estado desnaturado não se alterar desde o ponto médio do processo de desenovelamento até o ponto em que a proteína se encontra totalmente desnaturada, em altas temperaturas. Caso isto ocorra, o sistema pode ser considerado de dois estados.

O parâmetro de cooperatividade é, então, definido através da razão entre as entalpias de van't Hoff e calorimétrica, $\kappa=\Delta H_{v h}\left(T_{1 / 2}\right) / \Delta H_{\text {cal }}$. Assim, quando a transição de enovelamento/desenovelamento ocorre de forma cooperativa, i.e., como um processo de dois estados, temos $\kappa=1$.

Agora iremos fazer uso de uma expressão para o parâmetro $\kappa$ envolvendo a capacidade térmica, discutida anteriormente por Chan [127]. Em termos da entalpia, a capacidade térmica a pressão constante é dada por:

$$
C_{P}(T)=\frac{\left\langle H^{2}(T)\right\rangle-\left\langle H^{2}(T)\right\rangle}{k_{B} T^{2}}
$$

Em qualquer sistema podemos separar os estados acessíveis (mesmo que de forma arbitrária) para transformar a função de partição numa soma de dois termos, $Z(T)=$ $Z_{N}(T)+Z_{D}(T)$, onde o primeiro termo refere-se ao estado 'nativo' e o segundo ao estado 'desnaturado'. Assumindo uma separação deste tipo, pode-se definir uma capacidade térmica do estado desnaturado como

$$
C_{P}^{(D)}(T)=\frac{\partial\langle H\rangle_{D}}{\partial T}
$$


onde o subscrito $D$ indica que a média é feita apenas sobre o estado desnaturado, como na eq. 7.4. Neste ponto é importante notar que $C_{P}^{(D)}(T)$ caracteriza as flutuações que ocorrem na entalpia do estado desnaturado, desconsiderando-se a existência do estado nativo. Em um sistema de dois estados ideal, onde existem apenas transições de um estado para outro, esta capacidade térmica é nula. Logo, para um sistema com cooperatividade calorimétrica próxima de dois estados, $\kappa \approx 1$, devemos observar $C_{P}^{(D)}(T) \ll C_{P}(T)$ para $T>T_{1 / 2}$.

Usando (7.4), (7.5) e (7.6), é possível mostrar que a entalpia de van’t Hoff pode ser reescrita como

$$
\Delta H_{v H}=2 T_{1 / 2} \sqrt{k_{B}\left[C_{P}\left(T_{1 / 2}\right)-C_{P}^{(D)}\left(T_{1 / 2}\right)\right]}
$$

Desta forma, um sistema de dois estados satisfaz

$$
\Delta H_{v H}^{(2)}=2 T_{1 / 2} \sqrt{k_{B} C_{P}\left(T_{1 / 2}\right)}=\Delta H_{c a l}
$$

Este resultado é relevante porque $C_{P}^{(D)}(T)$ não é acessível experimentalmente (pela impossibilidade física de se restringir o espaço conformacional de uma proteína), mas $C_{P}(T)$ pode ser facilmente obtido. Além disso, a equação (7.8) permite distinguir sistemas calorimetricamente cooperativos dos não-cooperativos já que, enquanto para sistemas de dois estados esta relação é exata, para os outros sistemas ela resulta num limite superior para a cooperatividade. Isto ocorre porque $\delta H=T \sqrt{k_{B} C_{P}(T)}$ também é a flutuação na entalpia do sistema. Considerando que a maior flutuação possível é $\delta H=\Delta H_{\text {cal }} / 2$, que ocorre quando dois estados são igualmente populados e separados por $\Delta H_{\text {cal }}$, sempre teremos $\Delta H_{v H}<\Delta H_{v H}^{(2)}<\Delta H_{c a l}$. Assim, podemos definir um parâmetro

$$
\kappa_{2}=\Delta H_{v H}^{(2)} / \Delta H_{c a l}
$$

que pode ser calculado a partir de dados experimentais e que também indica o grau de cooperatividade de uma proteína.

Um problema que surge, tanto do ponto de vista experimental quanto em modelos de proteínas, é a determinação da temperatura média da transição, $T_{1 / 2}$. Este valor é estimado experimentalmente através do máximo de capacidade térmica, mas ele também pode ser obtido com o ponto médio de algum parâmetro de controle de dois estados, como a quantidade de estrutura secundária. Em proteínas cooperativas as diferentes medidas do ponto médio da transição são sempre muito próximas e a escolha do parâmetro de controle não altera o resultado significativamente. Por outro lado, em proteínas pouco 
cooperativas e em modelos de proteínas, esta escolha pode alterar significativamente o valor obtido para $\kappa_{2}$.

No caso dos modelos minimalistas, várias alternativas podem ser consideradas, incluindo o cálculo de $\Delta H_{v H}$ com uma constante de equilíbrio obtida através de uma definição do estado nativo. Este cálculo geralmente leva a cooperatividades menores do que as obtidas com a eq. (7.8), e pode ser questionado pelo uso de uma definição arbitrária do estado nativo. Embora todos os modelos de proteínas tenham em comum a existência de um único mínimo de energia livre, o estado nativo nem sempre é representado apenas por esta estrutura. Em vários modelos uma população com um número grande de contatos nativos também pode ser incluída no estado nativo. Levando em conta estes problemas, o procedimento mais utilizado, e que também é adotado aqui, é o cálculo da cooperatividade através da capacidade térmica do sistema com a expressão (7.8), utilizando os valores obtidos no máximo da capacidade térmica. Os valores de cooperatividade obtidos desta forma podem ser diretamente comparados com dados experimentais e não apresentam problemas relacionados à escolha de um estado nativo.

Um outro problema que surge na comparação dos modelos de proteínas com os dados experimentais é o uso da capacidade térmica em "excesso" no cálculo da entalpia de van't Hoff experimental. A capacidade térmica em "excesso" é obtida do calor específico experimental após a subtração das linhas de base empíricas, cujo intuito é retirar o efeito do reordenamento do solvente em torno da cadeia polimérica após o desenovelamento. Existe a possibilidade de que a subtração de linhas de base empíricas também retire contribuições de transições conformacionais para a capacidade térmica. Por este motivo, vários modelos tem sido comparados aos dados experimentais com o uso desta subtração. No entanto, em sistemas com $\kappa_{2} \approx 1$ a subtração das linhas de base não muda significativamente a cooperatividade do sistema. Em nosso trabalho optamos por uma abordagem mais próxima aos argumentos experimentais e não utilizamos a subtração de linha de base pela ausência do solvente ${ }^{1}$ nos modelos simplificados que estudamos.

Fazer com que os modelos minimalistas de proteínas satisfaçam o critério calorimétrico não tem se mostrado uma tarefa fácil. Modelos com interações fisicamente plausíveis, como o HP e os modelos de 3 e 20 letras, não são calorimetricamente de dois estados $[127,128]$. Algumas estruturas nativas do modelo Gō, apresentaram cooperatividade

\footnotetext{
${ }^{1} \mathrm{O}$ efeito do solvente está incluído no modelo de forma implícita através da interação hidrofóbica e do tipo de ligação de hidrogênio.
} 
calorimétrica $\kappa_{2}>0,96$, contudo, este modelo é extremamente teleológico [127, 128].

Um dos modelos mais cooperativos em três dimensões, com $\kappa_{2} \approx 0,96$, utiliza um alfabeto de 5 letras, interações locais desfavorecendo geometrias inexistentes em proteínas, ligações de hidrogênio dependendo do ambiente e um termo que força a propagação de $\alpha$ hélices [131]. Contudo, este modelo também é teleológico, pois a formação de ligações de hidrogênio e de $\alpha$-hélices é favorecida apenas quando estas são compatíveis com o estado nativo!

A dificuldade em se modelar um sistema cooperativo ocorre porque o critério calorimétrico exige que as estruturas com entalpia intermediária entre os estados nativo e desnaturado estejam pouco populadas no ponto médio da transição. Segundo um estudo feito com o modelo de energias aleatórias [127], em que uma delta de Dirac e uma gaussiana são utilizadas para representar os estados nativo e desnaturarado, o sistema só se torna cooperativo quando $\sigma_{H} \ll H_{D} \sqrt{2 \ln g_{D}}$, com $\sigma_{H}$ e $g_{D}$ sendo a dispersão na energia e a densidade de estados do estado desnaturado, e $H_{D}$ a diferença de energia do estado desnaturado para o nativo. No entanto, para que isto ocorra é necessário que o estado desnaturado esteja concentrado em uma região muito pequena, e que não exista nenhuma estrutura com entalpia intermediária. Considerando a enorme quantidade de estados que um polipeptídio pode assumir, é extremamente difícil imaginar um cenário que satisfaça os requerimentos sugeridos pelo modelo de energias aleatórias. De fato, não acreditamos que este seja um cenário razoável no contexto de polímeros e, também, que seja possível obter modelos minimalistas de proteínas que sejam cooperativos sem eliminar as estruturas com entalpias intermediárias. Como veremos a seguir, é possível que um sistema mesoscópico seja cooperativo, desde que ele apresente uma região côncava na entropia, em função da energia, entre os estados nativo e desnaturado.

\subsection{Paralelo com a transição de fase de primeira ordem}

O enovelamento de proteína globular pequena é geralmente comparado a uma transição de fase de primeira ordem, porque durante a transição os estados nativo e desnaturado mantêm-se separados [129]. Este processo é oposto ao que ocorre em uma transição contínua, quando uma única população se desloca de um estado A para um estado B passando por vários estados intermediários.

Como uma proteína é um sistema mesoscópico, esperamos que alguns fenômenos 


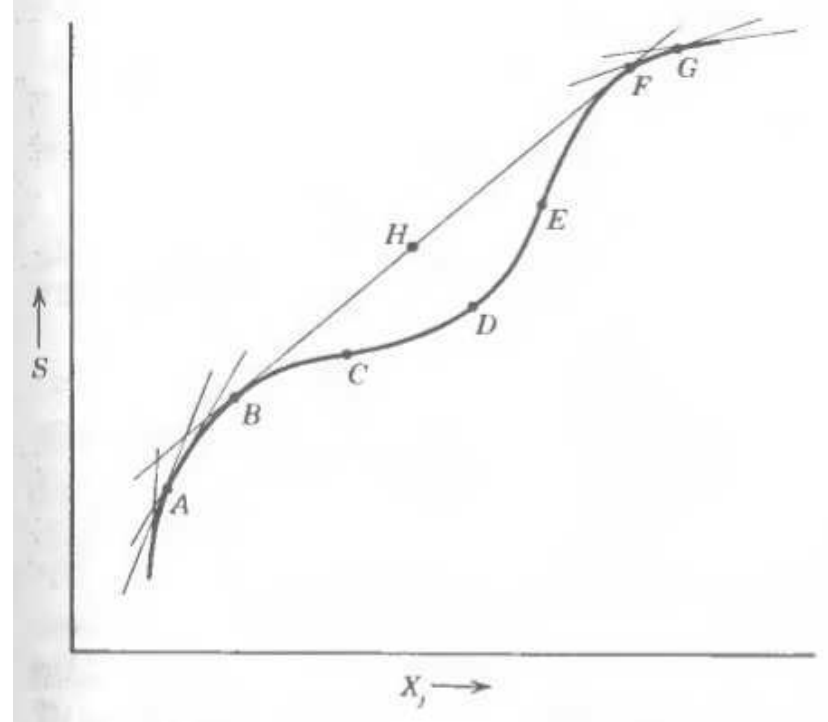

Figura 7.1: Entropia em função da energia numa região em que ocorre uma transição de fase de primeira ordem. Figura extraída da Ref. [106].

típicos de sistemas macroscópicos apareçam em sua termodinâmica, mas de forma menos acentuada. Por exemplo, embora algumas proteínas cooperativas apresentem uma transição que é muito similar a uma transição de fase de primeira ordem, esta não ocorre de forma abrupta, mas num intervalo pequeno de temperaturas.

Para compreender melhor os elementos que fazem com que um modelo de proteínas seja cooperativo, ou pouco cooperativo, vamos discutir brevemente a termodinâmica das transições de fase de primeira ordem. Maiores detalhes podem ser encontrados em livros texto de termodinâmica e mecânica estatística [93, 106]. Para uma discussão mais detalhada sobre este paralelo entre a transição de enovelamento e uma transição de fase de primeira ordem, recomendamos a leitura da ref. [129].

Um sistema fechado pode ser descrito pela relação entre entropia e energia, dada por:

$$
S(E)=k_{B} \ln g(E)
$$

onde $g(E)$ é a densidade de estados do sistema, com $g(E) \Delta E$ sendo o número de microestados entre $E$ e $E+\Delta E$. A estabilidade termodinâmica exige que esta entropia seja côncava, i.e., $\partial S^{2} / \partial^{2} E<0$. Quando a função (7.10) possui uma região convexa, indicando a existência de uma instabilidade, é necessário construir um envelope de tangentes à entropia e substituir a região contendo a convexidade por uma tangente como a da figura 7.1, que toca um ponto $\mathrm{B}$ anterior e um ponto $\mathrm{F}$ posterior à instabilidade. Desta forma, quando a temperatura do sistema, $1 / T=\partial S / \partial E$ aumenta atingindo o ponto $\mathrm{B}$ 
ocorre uma transição de fase, onde os estados B e F, coexistem evitando que o sistema acesse os estados intermediários entre B e F. Embora os estados entre os pontos C e E sejam instáveis e inacessíveis, nada impede que o sistema acesse os estados localizados entre B e C, no entanto, na temperatura em que estes estados podem ser encontrados, eles apresentam uma entropia menor que a dos estados acessíveis após a transição de fase, e por esse motivo, são estados metaestáveis. É possível obter materiais em fases metaestáveis desde que se "impeça" a transição de fase. Além disso, os trechos BC e EF podem ser obtidos em soluções analíticas aproximadas, como em cálculos de campo médio. Contudo, em muitos sistemas, como no caso dos líquidos, pequenas flutuações são suficientes para levar o sistema para o estado termodinamicamente estável.

Pelo fato de uma proteína ser um sistema mesoscópico, ela não satisfaz os requisitos de um sistema no limite termodinâmico (no sentido de que o tamanho do polipeptídio tende ao infinito). Mesmo assim, podemos introduzir uma entropia microscópica usando a definição (7.10) e utilizá-la para fazer uma analogia entre transição de fase de primeira ordem num sistema macroscópico e a transição de dois estados num sistema mesoscópico. Neste caso, se houver uma convexidade na entropia microscópica de um sistema mesoscópico, esperamos que uma transição de dois estados apareça ligando um ponto $N$ anterior à convexidade a um ponto posterior $D$. A temperatura em que esta transição ocorre será aproximadamente $T_{f}=\left(E_{D}-E_{N}\right) /\left(S_{D}-S_{N}\right)$. Entretanto, os estados localizados na região "instável" devem estar presentes com uma pequena população no ponto médio da transição que, embora seja acessível em simulações Monte Carlo, não é relevante para a termodinâmica quando se trata de um sistema cooperativo. Por outro lado, quando o sistema não é cooperativo, os estados intermediários dão uma contribuição relevante para a termodinâmica de enovelamento.

Desta forma, procuraremos criar uma "instabilidade" na região intermediária entre os estados nativo e desnaturado, introduzindo um ingrediente energético que desfavoreça os estados intermediários. Este ingrediente é a ligação de hidrogênio, que será utilizada em uma abordagem diferente da comumente adotada na literatura. Ao invés de assumirmos que a ligação de hidrogênio na proteína é mais favorável que no solvente (que implica em uma diminuição na energia para cada ligação formada), assumimos que as energias da ligação de hidrogênio na proteína e no solvente são idênticas, mas que existe um custo energético para que um monômero se enterre no interior da proteína sem uma ligação. 
a

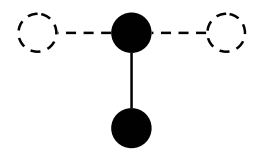

b

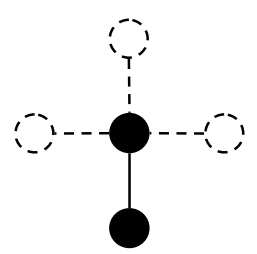

C

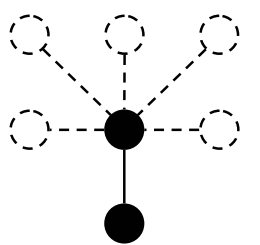

d

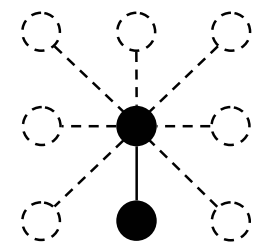

Figura 7.2: Passos possíveis entre monômeros vizinhos. Além dos quatro vetores $( \pm 1,0)$ e $(0, \pm 1)$ da rede quadrada usual, os quatro vetores ligando aos segundos vizinhos $( \pm 1, \pm 1)$ também são permitidos, resultando em um número variável de conformações locais por monômero, ou coordenação $z$, assim como em duas distâncias possíveis para as ligações, i.e., 1 e $\sqrt{2}$ unidades de rede. A figura representa com linhas pontilhadas as posições possíveis para a inserção de um terceiro monômero, após dois monômeros terem sido posicionados, em uma cadeia polimérica com os diferentes valores de $z$ utilizados neste trabalho. (a) Rede com coodenação $z=2$, sem passos entre os segundos vizinhos e apenas com todas ligações formando um ângulo de $90^{\circ}$. (b) Rede quadrada usual, com coordenação $z=3$. (c) Rede estendida com $z=5$, com passos entre os primeiros vizinhos, mas com nenhuma ligação cujos ângulos são menores do que $90^{\circ}$. (d) Rede estendida com $z=7$, onde todas as ligações com os primeiros vizinhos podem ser feitas, sem nenhuma restrição no ângulo entre ligações subseqüentes. Para uma determinada combinação $z / z_{h}, z$ define o conjunto de conformações permitidas para cada monômero enquanto $z_{h}<z$ define o subconjunto de conformações locais assumidas como compatíveis para a formação da ligação de hidrogênio.

Este custo energético é, na verdade, uma penalização para cada ligação quebrada devido ao enterramento de um monômero (ou um par de monômeros) em uma conformação que não permite a realização da ligação, que existia enquanto o monômero estava exposto ao solvente.

Dois estudos diferentes foram realizados visando incluir a ligação de hidrogênio em modelos de polipeptídios em rede para entender a contribuição desta interação na cooperatividade. Em um primeiro momento, estudamos modelos de heteropolímeros bidimensionais e tridimensionais, considerando que a ligação hidrofóbica só contribui para a energia quando os dois monômeros se encontram em conformações compatíveis com a formação de ligações de hidrogênio [135]. Posteriormente, fizemos um estudo mais detalhado sobre as diferentes definições de ligações de hidrogênio, considerando tanto as hipóteses energéticas quanto as restrições geométricas possíveis, e estudamos a cooperatividade de um modelo de homopolipeptídio em rede [136]. Na próxima seção discutiremos estes dois estudos. 


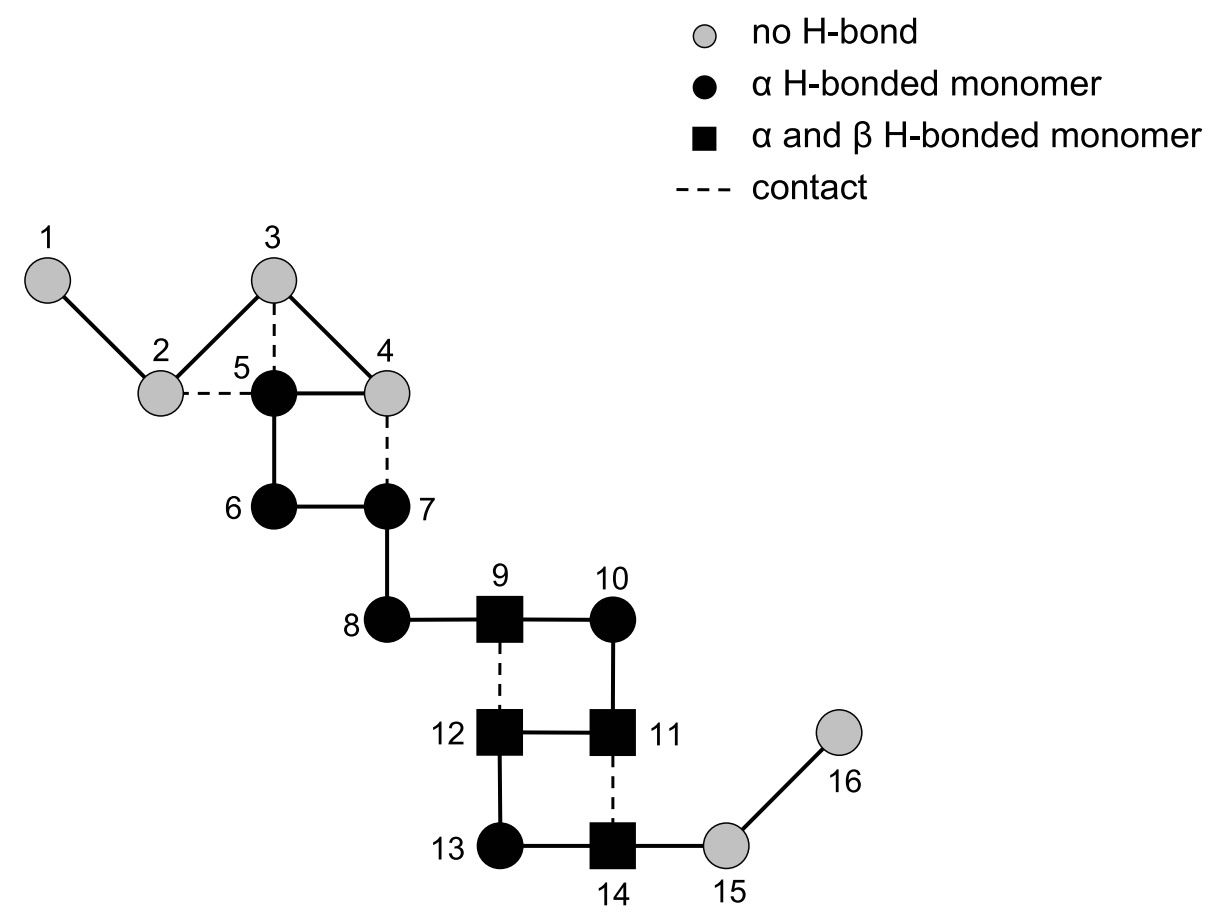

Figura 7.3: Ilustração das ligações de hidrogênio do tipo $\alpha$ e $\beta$, acopladas e desacopladas, para $z / z_{h}=7 / 3$ em uma conformação com 16 monômeros. Passos diagonais são permitidos, já que $z=7$, mas como $z_{h}=3$, apenas os monômeros de 5 a 14 , que estão conectados aos monômeros vizinhos com passos não diagonais, são compatíveis com a formação de ligações de hidrogênio. De acordo com a definição de ligações de hidrogênio $\alpha$, uma ligação de hidrogênio é contada para cada um destes monômeros, que estão pintados de preto. Destes monômeros apenas aqueles com número 9, 11, 12 e 14, mostrados com quadrados, também são compatíveis com a definição de uma ligação de hidrogênio $\beta$. Figura extraída da Ref. [136]. 


\subsection{O modelo de polímero estendido em rede}

Uma cadeia polipeptídica é representada na rede quadrada, com cada monômero disposto em um sítio da rede e a ligação com o monômero subseqüente ocorrendo com passos que podem ser dados entre os primeiros e os segundos sítios vizinhos da rede. Desta forma, são permitivos os tamanhos 1 ou $\sqrt{2}$ (em unidades de rede) em cada ligação covalente entre dois monômeros consecutivos na cadeia polimérica. Na figura 7.2 ilustramos os passos permitidos para a inserção de um terceiro monômero em um polipeptídio, após a inserção de dois monômeros, para cada coordenação local z utilizada neste trabalho.

Consideramos um monômero compatível com a formação de uma ligação de hidrogênio sempre que ele se encontra em uma coordenação local $z_{h}<z$. Além disso, duas definições diferentes foram utilizadas para as ligações de hidrogênio: $\alpha$ e $\beta$. Nas de tipo $\alpha$, que dependem apenas da configuração local, uma ligação é formada sempre que um monômero está numa coordenação local $z_{h}$. Nas ligações de tipo $\beta$, é necessário que dois monômeros (distantes por mais de dois passos na cadeia) façam contato e estejam ambos em conformações locais compatíveis com a coordenação $z_{h}$. Na figura 7.3 mostramos uma estrutura com $N=16$, indicando a ocorrência de contatos e de cada tipo de ligação de hidrogênio.

\subsubsection{Pontes de hidrogênio em um modelo de proteínas}

Neste estudo, relativo ao artigo no anexo II, estudamos a introdução da ligação de hidrogênio em modelos de heteropolímeros em duas e três dimensões. Consideramos que apenas os contatos entre monômeros cujas conformações locais satisfazem a restrição da ligação de hidrogênio tipo $\beta$ contribuem para a energia do sistema, sendo chamados de contatos viáveis. Neste trabalho não implementamos as ligações do tipo $\alpha$. Com esta restrição, a energia do sistema, dada pela função hidrofóbica $[12,14]$, ficou escrita como:

$$
E\left(\vec{h}, \overrightarrow{c^{\prime}}\right)=-\sum_{i} h_{i} c_{i}^{\prime}=-\vec{h} \cdot \overrightarrow{c^{\prime}}
$$

onde $\overrightarrow{c^{\prime}}=\left\{c_{1}^{\prime}, \cdots, c_{N}^{\prime}\right\}$ representa o número de contatos viáveis feitos por cada monômero em uma dada estrutura, onde a viabilidade de um contato corresponde à exigência de formação de uma ligação do tipo $\beta$, e $\vec{h}=\left\{h_{1}, \cdots, h_{N}\right\}$ é a seqüência com a hidrofobicidade de cada monômero. Note que a restrição para a formação de ligações de hidrogênio é imposta sobre todos os pares de monômeros fazendo contato, incluindo em que um ou mais monômeros não são hidrofóbicos. 


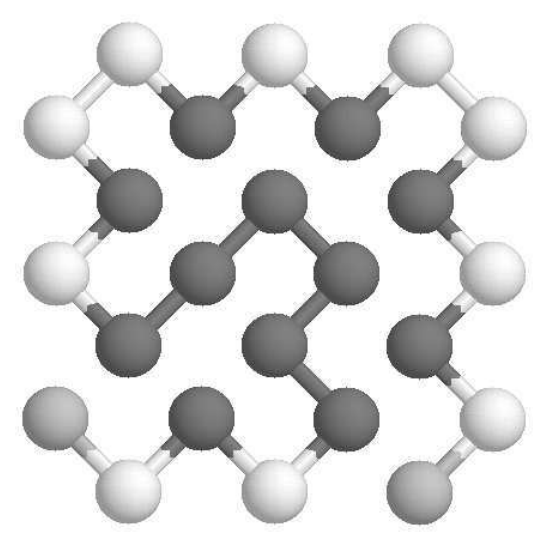

(a)

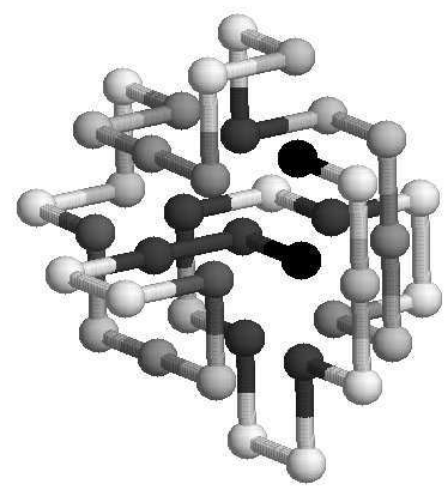

(b)

Figura 7.4: (a) Conformação bidimensional com 24 monômeros utilizada como estrutura nativa nas simulações. Monômeros enterrados (cinza escuro) são hidrofóbicos, expostos (branco) são hidrofílicos e as duas extremidades (cinza claro) são neutras. Os valores de hidrofobicidade são $1,-1$ e 0 , para monômeros hidrofóbicos, hidrofílicos e neutros, respectivamente, resultam na mesma energia nativa $E^{*}=-24$. A conformação de 40 monômeros mostrada em (b) foi utilizada em todas as simulações em três dimensões. As hidrofobicidades dos monômeros, representadas por diferentes tons de cinza, foram obtidas com a diferença entre o número de contatos nativos e o valor médio de contatos da estrutura nativa, resultando em $E^{*}=-105$. Todos os 33 contatos nativos do potencial Gō possuem energia -1, enquanto os contatos não nativos são neutros. A energia total da estrutura nativa com este potencial é $E^{*}=-33$.

Estudamos uma estrutura bidimensional de 24 monômeros, mostrada na fig. 7.4 (a), e uma estrutura tridimensional com 40 monômeros, mostrada na fig. 7.4 (b). Embora tenhamos estudado três estruturas em duas dimensões, iremos discutir apenas os resultados obtidos com a estrutura n24D2a analisada em [138]. Para a estrutura tridimensional foi utilizada um valor $z / z_{h}=5 / 4$, que corresponde à restrição de que apenas os estados com conformação local com as ligações covalentes formando um ângulo de $90^{\circ}$ são compatíveis com a formação da ligação de hidrogênio. As estruturas mostradas na figura 7.4 foram estudadas em trabalhos anteriores [139, 14, 140], tendo sido escolhidas por serem segregadas, com boa parte de seus monômeros ou totalmente expostos ou totalmente enterrados. Em estudos anteriores, mostrou-se que a segregação é importante para que a estrutura tenha caráter proteico $[12,139,14]$. Simulações de Monte Carlo foram feitas para cada uma destas estruturas e a densidade de estados, $g(E)$, foi obtida através de técnicas de histograma padrão $[141,142]$. Checamos a validade de nossas simulações comparando os resultados obtidos para cadeias de tamanho pequeno, $N=12$, com os resultados de uma enumeração completa de microestados. 


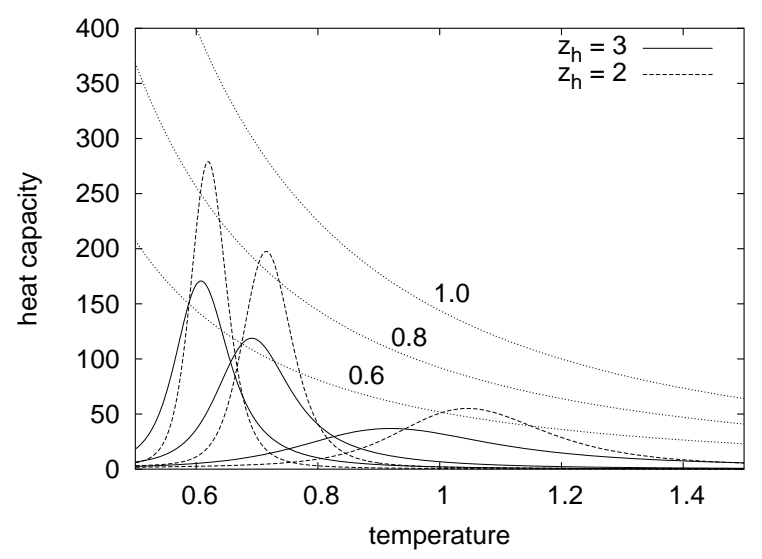

Figura 7.5: Curvas de capacidade térmica da conformação nativa n24D2a, obtidas através da técnica do histograma a partir de trajetórias de Monte Carlo com $10^{8}$ ou $10^{9}$ passos (cada passo corresponde a $N=24$ tentativas de movimento), gravadas a cada $10^{4}$ passos, em temperaturas próximas ao pico de capacidade térmica, $T_{f}$. A amostragem conformacional foi checada através de simulações de controle em diferentes temperaturas. As curvas de capacidade térmica são mostradas com dois tipos de linha, dependendo do valor de $z_{h}$. Para cada $z_{h}$, $z$ aumenta de 3 para 5 e depois para 7 , na medida em que o pico de capacidade térmica se desloca para temperaturas mais baixas. Curvas monotônicas decrescentes indicam os valores que o pico de capacidade térmica deveria assumir, em cada temperatura, para que $\kappa_{2}$ assuma os valores 0,6 , 0, 8 e 1,0, de acordo com a eq. (7.12). Figura extraída da Ref. [135].

A densidade de estados foi utilizada para calcular curvas de capacidade térmica, das quais extraímos o índice de cooperatividade de Klimov e Thirumalai $\Omega_{c}$ e a cooperatividade calorimétrica $\kappa_{2}$, definidos nas equações (7.1) e (7.9). Nos dois casos, a variação entre a energia nativa e o estado desnaturado pode ser calculado pela própria energia nativa, $\Delta E \approx E^{*}$, já que a energia média do estado desnaturado é aproximadamente nula.

\section{Resultados e discussão}

Na figura 7.5 mostramos as curvas de capacidade térmica da estrutura bidimensional com as seis combinações de $z_{h}$ e $z$ investigadas. Além disso, incluímos a posição esperada para o pico de capacidade térmica $T_{f}$, numa dada temperatura, para que o sistema apresente cooperatividade $\kappa_{2}=$ const., dada por

$$
C_{V}\left(T_{f}\right)=\frac{E^{* 2}\left(\kappa_{2}\right)^{2}}{4 T_{f}^{2}} .
$$

Estas curvas permitem uma comparação entre a cooperatividade de sistemas com um número de estados muito diferentes, como quando temos $z=3$ ou $z=7$. Com o aumento da coordenação do sistema a posição do pico de capacidade térmica se desloca para baixas temperaturas e a altura do pico aumenta, como pode ser observado nestas curvas. 
Tabela 7.1: A tabela mostra, para cada combinação de $z$ e $z_{h}$, o valor de $T_{f}$ obtido diretamente das curvas de capacidade térmica mostradas na figura 7.5, e os parâmetros de cooperatividade $\kappa_{2}$ e $\Omega_{c}$ da conformação nativa bidimensional n24D2a, considerada nesta tese.

\begin{tabular}{lcrrrrr}
\hline$z / z_{h}$ & $3 / 3$ & $5 / 3$ & $7 / 3$ & $3 / 2$ & $5 / 2$ & $7 / 2$ \\
\hline$T_{f}$ & 0,92 & 0,69 & 0,61 & 1,05 & 0,72 & 0,62 \\
$\kappa_{2}$ & 0,47 & 0,63 & 0,66 & 0,65 & 0,84 & 0,86 \\
$\Omega_{c}$ & 3,3 & 16,3 & 25,2 & 8,5 & 44,0 & 64,6 \\
\hline
\end{tabular}

Na tabela 7.1, que descreve algumas propriedades termodinâmicas do modelo bidimensional, podemos observar que o parâmetro $\Omega_{c}$, que varia de 10 a 100 em proteínas reais [143], aumenta de 3,3 para 64,6 quando passamos do modelo sem ligação de hidrogênio $\left(z / z_{h}=3 / 3\right)$ para um modelo com ligações do tipo $\beta$ com $z / z_{h}=7 / 2$. A cooperatividade da transição de enovelamento, segundo o critério de Klimov e Thirumalai, aumenta com a coordenação local z e com o grau de restrição na definição da ligação de hidrogênio. O mesmo comportamento foi observado em outras duas estruturas bidimensionais [138]. Um comportamento similar também pode ser deduzido da cooperatividade calorimétrica $\kappa_{2}$. Para um valor de $z_{h}$ fixo, a cooperatividade aumenta com a coordenação local $z$, enquanto que, com a coordenação local fixa, a cooperatividade aumenta com a diminuição de $z_{h}$, i.e., com o aumento na restrição imposta para que haja a ligação de hidrogênio.

Como foi discutido em [138], entretanto, a cooperatividade não se correlaciona muito bem com a razão $z / z_{h}$ : em uma das estruturas investigadas nesta referência obtivemos $\kappa_{2}\left(z / z_{h}=5 / 2\right)=\kappa_{2}(7 / 2)=0,83$ e $\kappa_{2}(=5 / 3)=0,63>\kappa_{2}(7 / 3)=0,62$. Assim, parece existir um valor ótimo para a razão $z / z_{h}$ em cada caso, que pode ser ligeiramente dependente da estrutura nativa.

O efeito da ligação de hidrogênio sobre a entropia microscópica do sistema, obtida a partir das densidades de estados do modelo bidimensional pode ser observado na figura 7.6. A entropia do sistema aumenta consideravelmente com o aumento em $z$, como esperado, o que está relacionado à diminuição da temperatura de enovelamento e da cooperatividade. Outro efeito observado é que o número de estados com energia intermediária entre os estados nativo e desnaturado diminui, com a introdução da ligação de hidrogênio, tornando a curva de entropia mais convexa à medida que a restrição no critério da ligação aumenta. Como discutimos anteriormente, uma relação entre esta convexidade e a cooperatividade já era esperada devido à comparação entre a transição de enovelamento e uma transição 

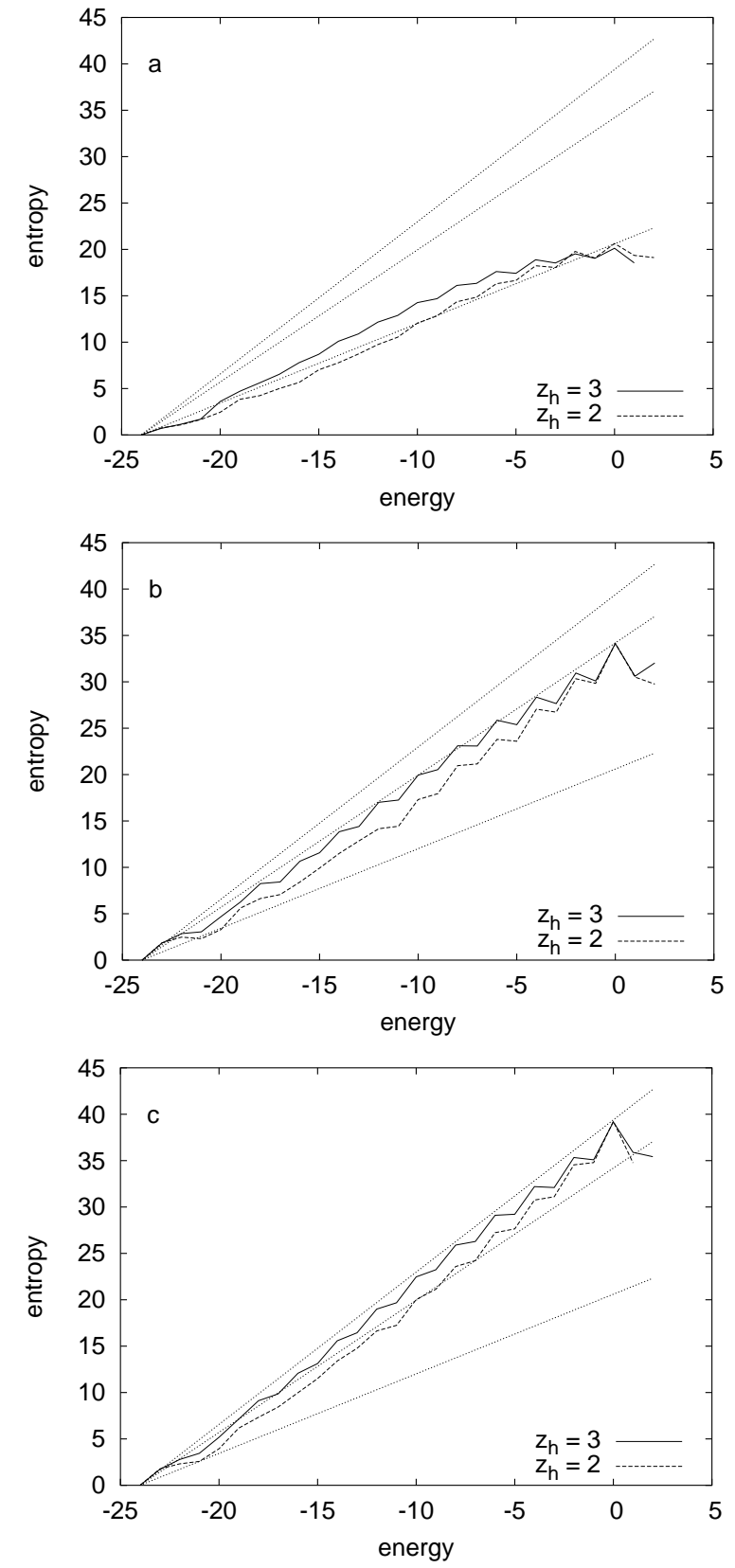

Figura 7.6: A entropia microscópica, $S(E)=k_{B} \ln g(E)$, do modelo com a estrutura bidimensional como estado nativo foi obtida através de técnicas de histograma. Cada painel contém duas curvas correspondendo a $z_{h}=3$ e $z_{h}=2$, e um único valor de $z=3$ (a), $z=5$ (b) e $z=7$ (c). As linhas retas conectando os pontos $\left(E^{*}=-24,0\right)$ e $(E=0, S(0))$ para $z_{h}=2$, que é essencialmente idêntica para $z_{h}=3$, facilitam a visualização do aumento na concavidade quando $z_{h}$ diminui. A repetição das três linhas retas em todos os diagramas facilita a comparação entre diferentes valores de coordenação $z$. Figura extraída da Ref. [135]. 
(a)
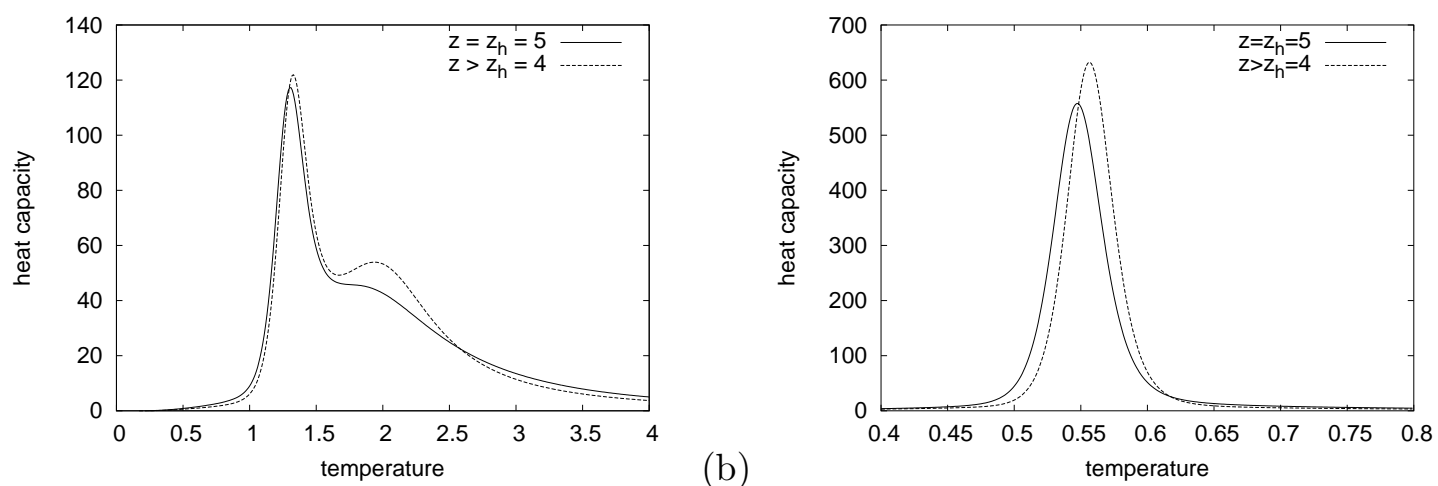

Figura 7.7: Curva de capacidade térmica para o modelo tridimensional estudado com os potenciais (a) hidrofóbico e (b) Gō. Estas curvas foram obtidas através de simulações de Monte Carlo de até $4 \times 10^{9}$ passos ( 1 passo é igual a $N=40$ tentativas de movimento) em diferentes temperaturas, e com o uso de técnicas padrões de histograma para extrapolar os cálculos para outras temperaturas. Cada painel mostra duas curvas correspondendo aos casos em que as ligações de hidrogênio estão implementadas ou não. Figura extraída da Ref. [135].

de fase de primeira ordem. Outro resultado desta mudança na convexidade é o deslocamento do pico de capacidade térmica para temperaturas mais altas, com a diminuição de $z_{h}$ numa coordenação fixa, já que o estado nativo não é alterado com a introdução das ligações de hidrogênio.

Uma forte dependência de $\Omega_{c}$ com $z$ está relacionada à existência de uma ligação entre a entropia do estado desnaturado e a largura do pico de enovelamento [127]. Por outro lado, o comportamento de $\kappa_{2}$ parece depender mais da convexidade na entropia do que da coordenação z. Linhas retas, ligando o máximo de entropia do estado desnaturado ao estado nativo, foram utilizadas na figura 7.6 para facilitar a observação das convexidades nas entropias, em cada caso.

Note que é desnecessário eliminar as conformações intermediárias para que o sistema se torne cooperativo, como sugere um modelo de energias aleatórias [127]. Este conjunto de estruturas é praticamente inevitável. Entretanto, com o procedimento proposto neste trabalho podemos fazer com que os estados intermediários se tornem praticamente instáveis, em relação aos nativo e desnaturado, ao longo da transição.

Na figura 7.7 mostramos as curvas de capacidade térmica obtidas do modelo com a estrutura tridimensional como estado nativo, utilizando a função de energia hidrofóbica (a) e Gō (b). Como discutido em outros trabalhos [139, 140], uma transição de compactação é observada no modelo tridimensional com a função de energia hidrofóbica e está associado ao ombro na curva de capacidade térmica do modelo sem ligações de hidrogênio na 
figura 7.7 (a). Com a introdução da ligação de hidrogênio a transição de enovelamento desta curva praticamente não se modifica, e o parâmetro de cooperatividade varia de $\kappa_{2}\left(z / z_{h}=5 / 5\right)=0,27$ para $\kappa_{2}\left(z / z_{h}=5 / 4\right)=0,28$, quando a ligação é incluída. Provavelmente esta pequena mudança está relacionada ao fato de não termos aumentado a coordenação local da cadeia polimérica tridimensional, o que faz com que a razão $z / z_{h}$ seja pequena.

Entretanto, podemos notar que a transição de compactação é significantemente mais afetada, tornando-se mais cooperativa. Este resultado é muito interessante pois indica que o procedimento que implementamos afeta mais a transição de compactação do que o enovelamento em si, já que a ligação de hidrogênio é implementada com os mesmos princípios para todos os monômeros. Este realmente é o caso, pois o uso de uma ligação de hidrogênio similar à implementada nesta seção pode elevar significativamente a cooperatividade da transição de compactação em homopolímeros hidrofóbicos, como veremos na próxima subseção.

No caso dos modelos bidimensionais, a compactação e o enovelamento da proteína ocorrem ao mesmo tempo e, por este motivo, a inclusão da ligação de hidrogênio aumenta a cooperatividade do enovelamento. Este não é o caso do modelo tridimensional com a função de energia hidrofóbica. Também investigamos o modelo tridimensional com uma função de energia mais específica, conhecida como Gō, onde apenas contatos existentes na estrutura nativa contribuem para a energia do sistema. Com esta função de energia as transições de enovelamento e compactação ocorrem ao mesmo tempo [140] e a cooperatividade tem um aumento mais significativo, passando de $\kappa_{2} \approx 0,79$, sem ligações de hidrogênio, para $\kappa_{2} \approx 0,85$, com $z / z_{h}=5 / 4$. Este resultado corrobora nossa hipótese de que o efeito das ligações de hidrogênio é tornar mais cooperativa a transição de compactação da proteína.

\subsubsection{Pontes de hidrogênio e cooperatividade em um homopolipeptídio hi- drofóbico em rede}

Neste trabalho consideramos um modelo de homopolipeptídio hidrofóbico cujas ligações entre os monômeros na rede quadrada podem ser feitas com diferentes coordenações, ilustradas na figura 7.2. Consideramos tanto ligações de hidrogênio do tipo $\alpha$ quanto ligações do tipo $\beta$. Além disso, duas formas de contribuição energética da ligação de hidrogênio 
foram utilizadas para investigar hipóteses distintas sobre o efeito da entalpia das ligações de hidrogênio no sistema composto por meio aquoso e homopolipolímero. Note que a presença do meio aquoso é representada de forma implícita nos modelos que temos discutido.

Na implementação mais simples, que chamamos de $E_{1}$, para cada ligação de hidrogênio realizada no homopolipeptídio a energia é diminuída por uma quantidade fixa, $\epsilon_{1}$. Esta implementação corresponde a assumir que uma ligação de hidrogênio feita por um monômero no interior do polipeptídio compacto é mais favorável do que uma ligação realizada entre este mesmo monômero e uma molécula de água, por uma quantidade que é independente da configuração local no interior do polipeptídio. Nesta implementação, o decréscimo no número total de ligações de hidrogênio, que ocorre quando os monômeros se enterram sem a formação de ligações, é desconsiderado.

Na segunda implementação, chamada de $E_{2}$, assumimos que a formação de ligações de hidrogênio no interior e no exterior da proteína são equivalentes, mas que o enterramento de resíduos sem a formação de ligações é desfavorável, por reduzir o número de ligações. Desta forma, para cada contato formado sem a presença de ligações de hidrogênio a energia é aumentada por uma quantidade $\epsilon_{2}$, que corresponde à energia necessária para quebrar as ligações de hidrogênio que poderiam ser formadas com o solvente, caso aquele monômero estivesse exposto ao meio aquoso.

Nas duas implementações, as energias do sistema ficam dadas por:

$$
\begin{aligned}
E_{1} & =\sum_{i=1}^{N}\left(-h c_{i}-\epsilon_{1} b_{i}\right) \\
& =-h C-\epsilon_{1} B
\end{aligned}
$$

e

$$
\begin{aligned}
E_{2} & =\sum_{i=1}^{N}\left(-h c_{i}+\epsilon_{2} c_{i}^{\prime \prime}\right) \\
& =-h C+\epsilon_{2} C^{\prime \prime},
\end{aligned}
$$

onde as somas são feitas sobre todos os monômeros $i, c_{i}$ é o número total de contatos em que cada monômero $i$ está envolvido, com $\sum_{i} c_{i}=C$ sendo duas vezes o número de contatos, $b_{i}$ é o número de ligações de hidrogênio em que o monômero $i$ está envolvido, $\operatorname{com} \sum_{i} b_{i}=B$ sendo o número total de ligações de hidrogênio $\alpha$ ou duas vezes o número de ligações de hidrogênio $\beta$, e $c_{i}^{\prime \prime} \leq c_{i}$ sendo o número de contatos em $c_{i}$ nos quais a ligação de hidrogênio não é satisfeita, $\operatorname{com} \sum_{i} c_{i}^{\prime \prime}=C^{\prime \prime}$. 
Combinando as duas definições de ligação de hidrogênio com as duas implementações energéticas possíveis obtemos quatro tipos de modelos, para cada valor de $z$ e $z_{h}$ : $\alpha_{1}$, $\alpha_{2}, \beta_{1}$ e $\beta_{2}$. Na definição $\alpha$ a presença ou ausência de uma ligação de hidrogênio no monômero $i$ depende apenas da conformação local deste monômero. Assim, é possível obter um estado em que não há nenhum contato na cadeia e o número de ligações é igual ao número de monômeros. Isto acontece, por exemplo, nos modelos $\alpha_{1}$ com coordenação $z>3$ e restrição na conformação local dada por $z_{h} \leq 3$. Estes casos são representativos de uma $\alpha$-hélice, daí a designação ligações do tipo $\alpha$.

Na definição $\beta$, as ligações de hidrogênio somente ocorrem quando os dois monômeros de um determinado contato se encontram em uma das $z_{h}$ conformações locais compatíveis com a formação da ligação de hidrogênio. Neste caso, o número de ligações de hidrogênio $b_{i}$, formadas pelo monômero $i$, está limitada ao número de contatos feitos por este monômero. Já o número de contatos inviáveis, i.e., daqueles contatos não compatíveis com a formação da ligação, é dado por $c_{i}^{\prime \prime}=c_{i}-b_{i}$.

Note que na eq. (7.14), no esquema de interação $E_{2}$, a hidrofobicidade dos monômeros pode ser interpretada como estando acoplada à formação de ligações de hidrogênio, já que a formação de um contato sem a ligação de hidrogênio possui uma energia maior do que um contato com a ligação. Por outro lado, no esquema de interação dado pela energia (7.13), $E_{1}$, a hidrofobicidade dos monômeros pode ser visto como estando desacoplada da formação de ligações, já que tanto as ligações de hidrogênio quanto os contato atuam diminuindo a energia do sistema, ocorrendo concomitantemente apenas nas ligações do tipo $\beta$.

\section{Resultados}

Neste trabalho nós fixamos o valor da interação hidrofóbica como unidade de energia e investigamos o comportamento da cooperatividade de um homopolipeptídio hidrofóbico com as quatro implementações propostas para a ligação de hidrogênio, em função da energia de interação da ligação de hidrogênio e do tamanho da cadeia. Realizamos a enumeração completa das cadeias homopolipeptídicas para todos os tamanhos com até $N=26(z=3$ e 2$), N=18(z=5)$ e $N=16(z=7)$. A cooperatividade calorimétrica foi investigada através do parâmetro $\kappa_{2}$, definido na eq. (7.9) e discutido na seção 7.2.

Nas figuras 7.8 (a) e (b) investigamos a cooperatividade, em função do tamanho, e 

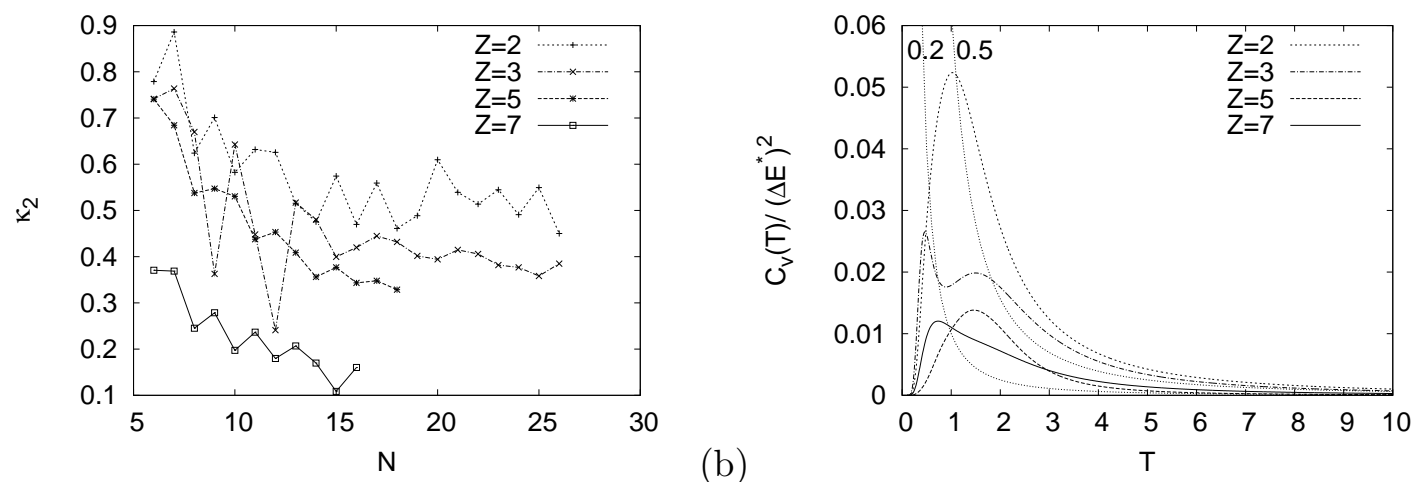

(a)

Figura 7.8: Caracterização termodinâmica do colapso de homopolipeptídios hidrofóbicos sem ligações de hidrogênio, com diferentes coordenações $z$. (a) A dependência de $\kappa_{2}$ com o tamanho da cadeia é mostrada para diferentes coordenações $z$ e (b) a capacidade térmica normalizada como função da temperatura, $C_{V}(T) /\left(\Delta E^{*}\right)^{2}$, é mostrada para diferentes valores de $z$ e tamanho fixo $N=16$. Linhas decrescentes em (b) indicam o tamanho do pico da capacidade térmica normalizada que corresponderia aos valores de cooperatividade indicados no gráfico, de acordo com a eq. (7.12). Figura extraída da Ref. [136].

a curva de capacidade térmica, em função da temperatura, de um homopolipeptídio hidrofóbico sem ligações de hidrogênio, com diferentes coordenações e $N=16$. Note que no caso $z=3$ a curva de capacidade térmica apresenta mais de um máximo. Este máximo extra, que ocorre em baixas temperaturas, aparece apenas em alguns tamanhos da coordenação $z=3$ e está relacionado a uma reacomodação na compactação do polímero em temperaturas muito baixas. Além disso, ele está associado às oscilações na cooperatividade em função do tamanho do polímero, sendo que a magnitude deste pico adicional de capacidade térmica diminui com o tamanho da cadeia. Por este motivo, estes picos adicionais serão desconsiderados em nossa análise daqui para frente.

Vamos agora analisar a cooperatividade no caso $z / z_{h}=7 / 3$, na figura 7.9. Um comportamento similar também foi observado para os casos $z / z_{h}=7 / 2,5 / 3$ (veja o anexo III) e 5/2. A cooperatividade em função do tamanho foi calculada com as quatro definições de ligações de hidrogênio, usando uma interação de hidrogênio escolhida com o valor 'arbitrário' $\epsilon_{1}=\epsilon_{2}=1,0$, veja fig. 7.9 (a). O valor de $\kappa_{2}$ tende a decrescer com o tamanho e, com esta combinação de $z$ e $z_{h}$, existe uma ordem entre as cooperatividades de diferentes modelos que acompanha o grau de restrição da ligação, dada por $\kappa_{2}\left(\beta_{2}\right)>\kappa_{2}\left(\alpha_{2}\right)>$ $\kappa_{2}\left(\beta_{1}\right)>\kappa_{2}\left(\alpha_{1}\right)$. Embora em outras combinações de $z$ e $z_{h}$ as cooperatividades não estejam sempre ordenadas desta forma, para todos os tamanhos e todas as combinações $z / z_{h}$, de uma maneira geral, temos os homopolipeptídios com ligações do tipo $\beta$ mais 


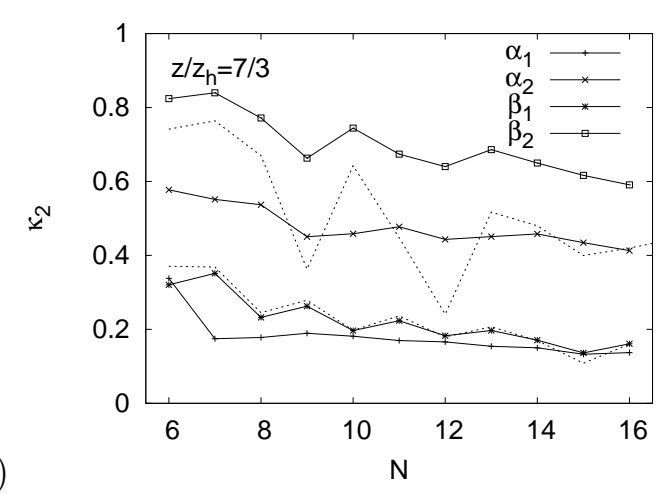

(a)

Figura 7.9: Dependência de $\kappa_{2}$ com o tamanho da cadeia, $N$, e a magnitude da ligação de hidrogênio, $\epsilon_{1}$ ou $\epsilon_{2}$, para diferentes implementações da ligação de hidrogênio $\left(\alpha_{1}, \alpha_{2}, \beta_{1}\right.$ e $\left.\beta_{2}\right)$ com a coordenação $z=7$ e com $z_{h}=3$. A magnitude da ligação de hidrogênio no painel (a) é igual, em módulo, à interação hidrofóbica, $\epsilon_{1}=1$ ou $\epsilon_{2}=1$. O tamanho da cadeia utilizada no painel (b) é $N=16$. Curvas correspondendo à cooperatividade do colapso do homopolipeptídio sem ligações de hidrogênio também são mostradas, com linhas pontilhadas em (a), no caso das redes com coordenação $z$ (inferior) e $z_{h}$ (superior). Os símbolos no painel (b) indicam os pontos que foram utilizados para calcular as distribuições de energia na fig. 7.10 e as densidades de estados na fig. 7.11. Figura extraída da Ref. [136].

cooperativos do que os com ligações do tipo $\alpha$, e os homopolipeptídios com ligações acopladas (energia $E_{2}$ ) mais cooperativos do que os com ligações desacopladas (energia $\left.E_{1}\right)$.

O comportamento da cooperatividade em função da energia de interação é mostrada na figura 7.9 (b), para cadeias com uma redução na coordenação local $z / z_{h}=7 / 3$ e tamanho $N=16$. Com a interação desacoplada a cooperatividade tende a aumentar monotonicamente com a interação atrativa para $\epsilon_{1}>2,0$. Com a interação acoplada a cooperatividade apresenta um crescimento rápido, que atinge um máximo próximo de $\epsilon_{2} \approx 1$, e decresce logo em seguida. Este resultado está qualitativamente em acordo com um resultado anterior, que mostrou que o uso de ligações de hidrogênio desacopladas não induzia um aumento significativo na cooperatividade de um homopolímero [144, 130], com interações de magnitude similar à do efeito hidrofóbico. Considerando estes resultados, o uso do esquema de interações acopladas parece ser mais fisicamente plausível, visto que ligações de hidrogênio muito fortes, em relação à interação hidrofóbica, impediriam o colapso do polímero e levariam à formação de longos segmentos de estrutura secundária $[144,145]$.

A cooperatividade tem uma dependência qualitativa muito maior com o esquema de interação, acoplado ou desacoplado, do que com o tipo de ligação de hidrogênio imple- 
mentado, $\alpha$ ou $\beta$. Também podemos notar que, no esquema de interação acoplado, as ligações do tipo $\alpha$ se tornam mais cooperativas quando a ligação de hidrogênio se torna duas vezes maior que a interação hidrofóbica. Já no esquema de interação desacoplado, as ligações do tipo $\beta$ são sempre mais cooperativas do que as ligações do tipo $\alpha$.

Na figura 7.10 mostramos as distribuições de energia de seis casos diferentes, contemplando os 4 tipos de modelos investigados neste trabalho. No caso em que as interações são desacopladas (gráficos à esquerda), o sistema é pouco cooperativo e apresenta uma distribuição com um único estado, que se desloca para a esquerda à medida que a temperatura abaixa. Neste esquema de interação, quando a energia da ligação de hidrogênio do tipo $\beta$ aumenta para $-\epsilon_{1}=-3,0$, observamos o aparecimento de uma distribuição bimodal no pico de capacidade térmica, associada a uma cooperatividade $\kappa_{2} \approx 0,49$. No caso em que as interações são acopladas (gráficos à direita), mesmo com a ligação do tipo $\alpha$, mostrada na fig. 7.10 (b), podemos notar o princípio de uma transição de dois estados à medida que a temperatura abaixa (veja a legenda da figura). Para as ligações do tipo $\beta$, o sistema é mais cooperativo e a distribuição de estados no pico de capacidade térmica é ligeiramente de dois estados, correspondendo a uma cooperatividade $\kappa_{2}=0,59$. Quando a interação repulsiva entre os contatos que não formam ligações fica muito forte, como na figura 7.10 (f), com $\epsilon_{2}=3,0$, surge um conjunto de estruturas com entalpias positivas que faz com que uma grande quantidade de calor tenha que ser absorvida para que o sistema se desenovele completamente. Embora neste caso o sistema apresente uma distribuição tipicamente de dois estados no pico de enovelamento, o valor de $\kappa_{2}$ é baixo porque ele é dividido pela entalpia $\Delta H_{\text {cal }}$ necessária para desenovelar completamente o sistema.

O comportamento observado nas figuras 7.9 (b) e 7.10 pode ser entendido se analisarmos as densidades de estados do sistema, i.e., o número de estruturas para cada energia, e as subdensidades de estados com um número fixo de ligações de hidrogênio, no esquema desacoplado, ou com um número fixo de contatos sem ligações de hidrogênio, no esquema acoplado, como é mostrado na fig. 7.11. Fizemos esta análise para as ligações do tipo $\beta$, com os mesmos parâmetros das figs. 7.10 (c)-(f), e também para o caso em que não há ligação de hidrogênio.

Como verificamos anteriormente [135], a cooperatividade do sistema, quando medida pelo parâmetro $\kappa_{2}$, se correlaciona com uma convexidade na entropia microcanônica do sistema. No caso dos modelos com interações desacopladas do tipo $\beta_{1}$, mostrados nas 

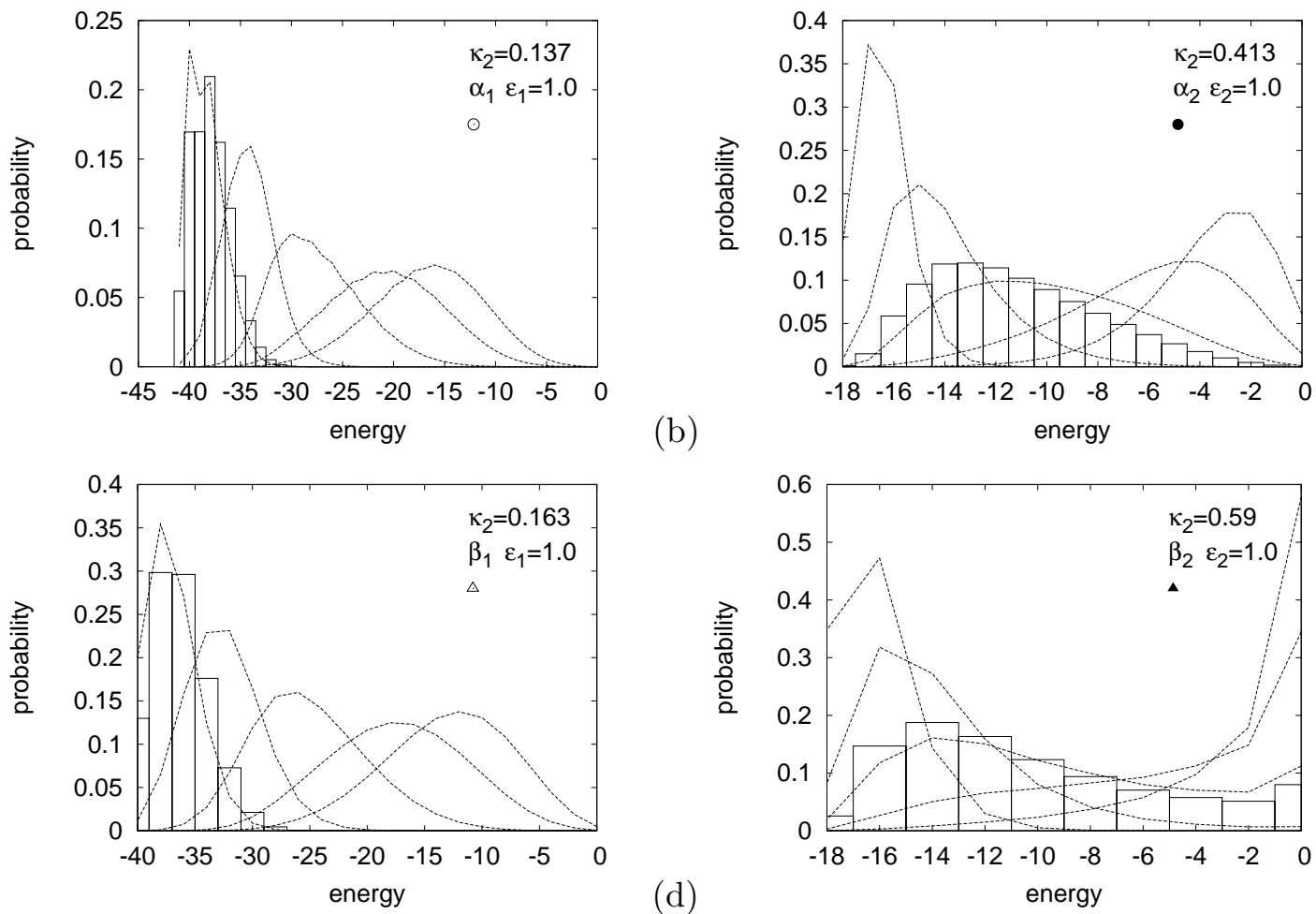

(c)
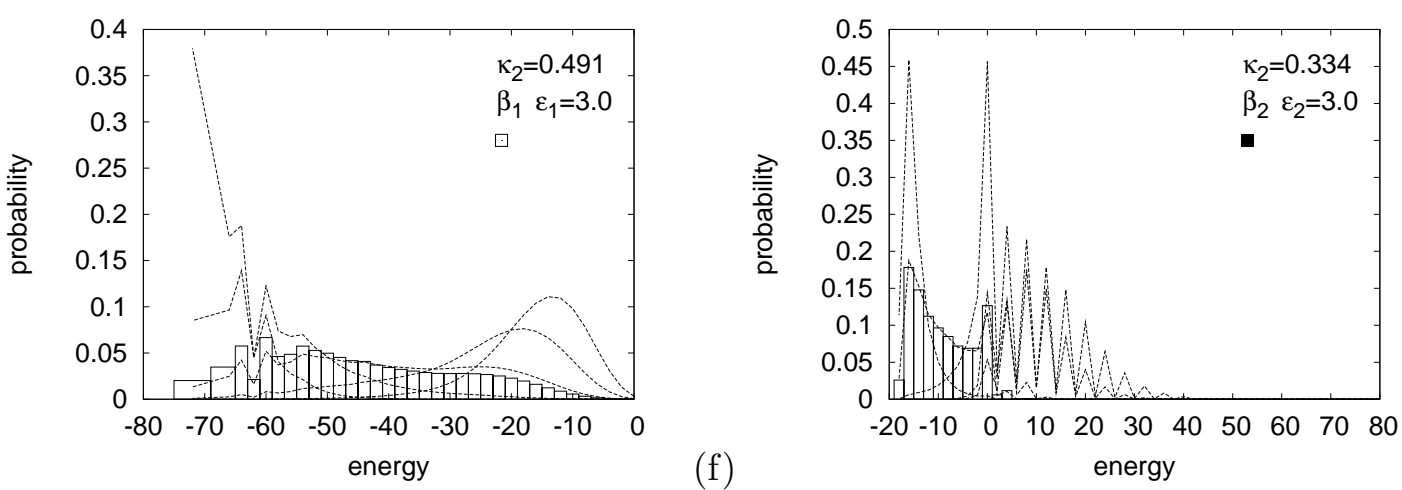

Figura 7.10: Distribuições de energia ao longo da transição de compactação para diferentes implementações da ligação de hidrogênio, com uma redução na coordenação da rede $z / z_{h}=7 / 3$ fixa e para uma cadeia com tamanho $N=16$. Em cada painel a distribuição de energia em $T_{m a x}$, a temperatura do máximo de capacidade térmica, é mostrada com caixas enquanto cinco curvas pontilhadas (da esquerda para a direita) correspondem às temperaturas em que $10 \%$, $25 \%, 50 \%, 75 \%$ e $90 \%$ do calor transferido na transição. Os diferentes painéis correspondem às seguintes implementações da ligação de hidrogênio: (a) $\alpha_{1} \operatorname{com} \epsilon_{1}=1,0$, (b) $\alpha_{2} \operatorname{com} \epsilon_{2}=1,0$, (c) $\beta_{1}$ com $\epsilon_{1}=1,0$, (d) $\beta_{2}$ com $\epsilon_{2}=1,0$, (e) $\beta_{1}$ com $\epsilon_{1}=3.0$, e (f) $\beta_{2}$ com $\epsilon_{2}=3,0$. Os valores da cooperatividade, $\kappa_{2}$, também são indicados em cada caso. Cada painel contém um símbolo que está indicando a localização daquela distribuição na figura 7.9 (b). Figura extraída da Ref. [136]. 
(a)

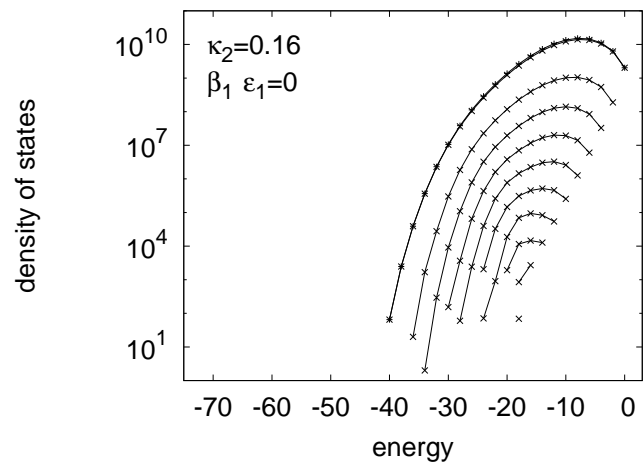

(c)

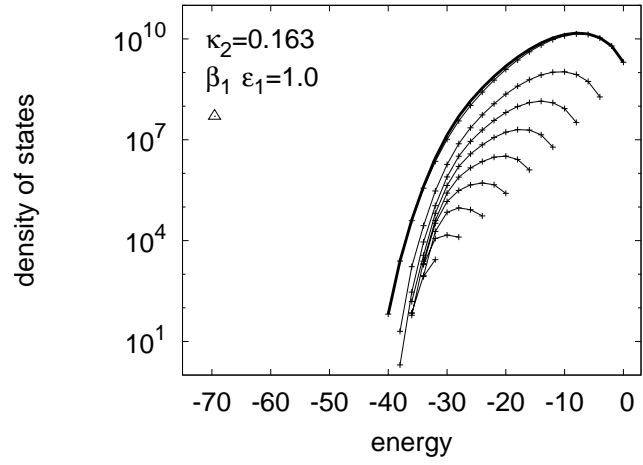

(e)

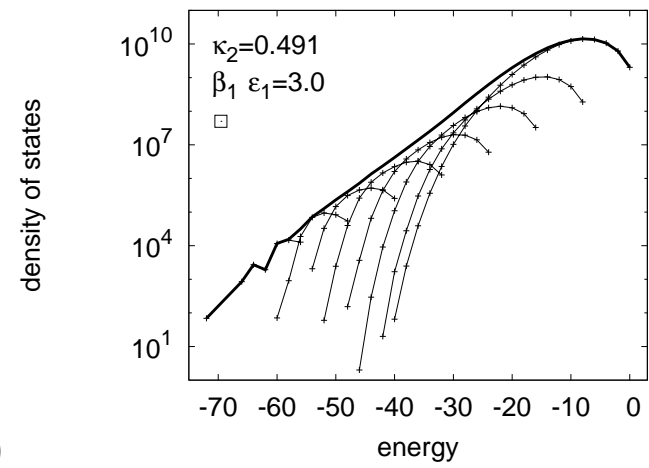

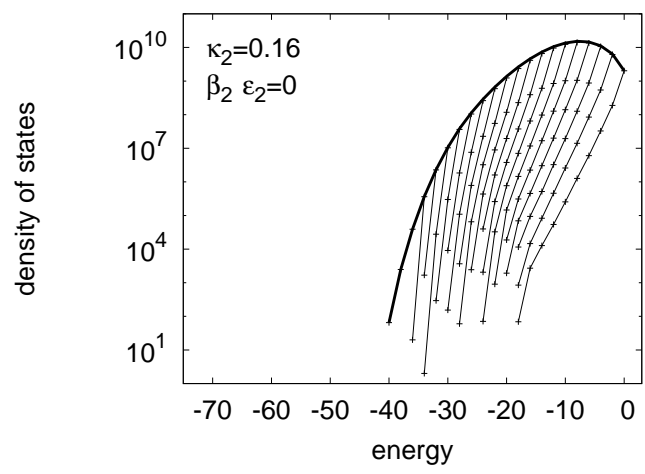

(d)
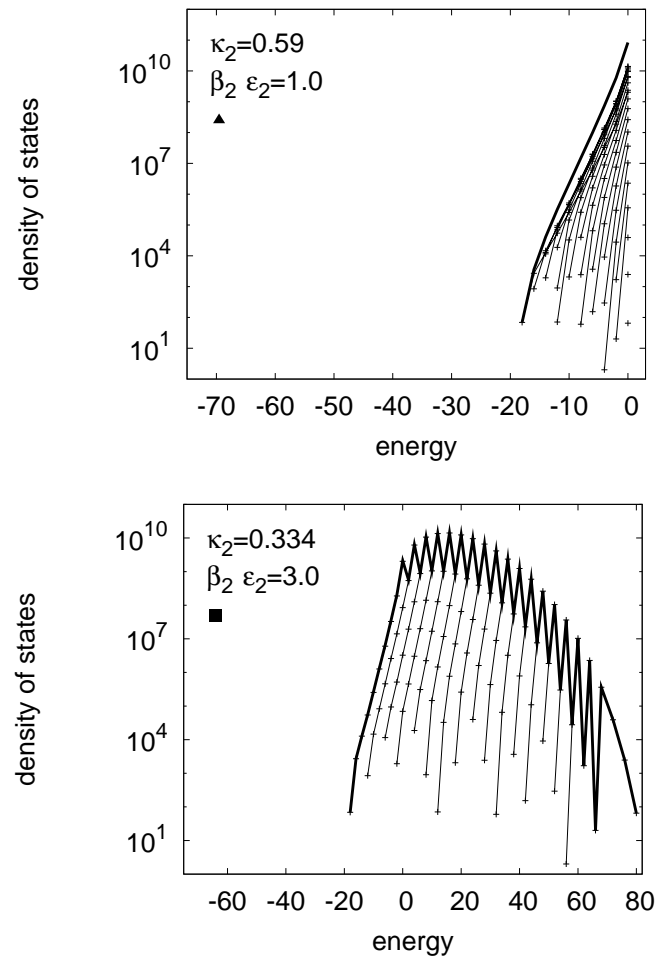

Figura 7.11: Densidade de estados (linhas espessas) e subdensidades de estados (linhas finas com pontos), em escala logarítmica, são mostradas para homopolipeptídios hidrofóbicos com as implementações desacoplada (esquerda) e acoplada (direita) da ligação de hidrogênio, com a redução da coordenação na rede fixa em $z / z_{h}=7 / 3$ e o tamanho da rede fixo em $N=16$. As subdensidades em (a), (c) e (e) correspondem ao número de conformações com um determinado número de ligações de hidrogênio, $B$, que são gradualmente deslocadas para a esquerda à medida que a energia da ligação de hidrogênio, $-\epsilon_{1}$, diminui. As subdensidades em (b), (d) e (f) correspondem ao número de conformações com um determinado número de contatos que não satisfazem as restrições da ligação de hidrogênio, $C^{\prime \prime}$, que são gradualmente deslocadas para a direita à medida que a energia necessária para quebrar uma ligação de hidrogênio, $\epsilon_{2}$, aumenta. Em cada painel está indicado o valor absoluto da energia da ligação de hidrogênio, e um símbolo que pode ser utilizado para localizar o ponto que corresponde a cada distribuição na figura 7.9 (b). Figura extraída da Ref. [136]. 
figs. 7.11 (a), (c) e (e), percebemos que o aumento na intensidade da ligação de hidrogênio leva a uma diminuição na energia das subdensidades de estados com maior número de ligações de hidrogênio. Quando a energia da ligação passa para $\epsilon_{1}=1,0$, partindo do caso sem ligação, o deslocamento das subdensidades com mais ligações de hidrogênio faz com que ocorra um ligeiro aumento na concavidade da entropia microcanônica, que induz uma pequena diminuição da cooperatividade. Aumentos subseqüentes em $\epsilon_{1}$ diminuem a concavidade da entropia, aumentando $\kappa_{2}$. No caso $\beta_{2}$, em que as interações estão acopladas, quando aumentamos $\epsilon_{2}$ estamos penalizando o conjunto de estruturas que faz contatos em conformações incompatíveis com a ligação de hidrogênio. Por este motivo, as subdensidades de estados são deslocadas para a direita quando $\epsilon_{2}=1,0$, em relação ao caso em que não há ligação, veja a figura 7.11 (b). Neste exemplo, a cooperatividade aumenta de $\kappa_{2} \approx 0,16$ para $\kappa_{2} \approx 0,59$, porque a entropia deixou de ser côncava em toda a sua extensão e passou a se convexa em grande parte dos estados intermediários entre os estados de menor energia e os estados de maior energia. Conforme discutido acima, quando aumentamos ainda mais o parâmetro $\epsilon_{2}$, como na figura 7.11 (f), criamos estados com entalpias positivas que aumentam a variação de entalpia necessária para desenovelar completamente o sistema. No entanto, estes estados de maior entalpia só são acessíveis em temperaturas muito altas e não estão presentes no máximo da transição de compactação, que apresenta uma distribuição típica de dois estados.

\subsection{Conclusões}

Estudamos implementações alternativas da ligação de hidrogênio em modelos de polipeptídios em rede e mostramos que a ligação de hidrogênio é um ingrediente importante para o seu comportamento cooperativo. O uso de ligações de hidrogênio em modelos bidimensionais e tridimensionais de proteínas mostrou que a cooperatividade está relacionada à convexidade da entropia microcanônica do sistema, sendo desnecessário eliminar as estruturas intermediárias entre os estados nativo e desnaturado. Com as simulações de Monte Carlo de um modelo de proteína tridimensional descobrimos que a ligação de hidrogênio atua, principalmente, sobre o processo de compactação da proteína, tornandoo mais cooperativo. Esta hipótese foi corroborada com o estudo de homopolipeptídios hidrofóbicos em rede através da enumeração completa de microestados.

O conjunto de todos os nossos resultados sugere que a escolha de uma definição de 
ligação de hidrogênio pode ter conseqüências importantes sobre a termodinâmica de polipeptídios. Além disso, nossos resultados sugerem que as transições contínuas, não cooperativas, que foram observadas em outros modelos podem estar relacionadas ao tipo de ligação de hidrogênio, que é energeticamente favorecida e desacoplada das interações hidrofóbicas, utilizada nestes estudos.

Como foi mostrado em nossos trabalhos, o uso de uma ligação de hidrogênio acoplada ao efeito hidrofóbico pode aumentar significativamente a cooperatividade do sistema, sendo mais consistente com observações experimentais que sugerem uma transição de dois estados para proteínas e mesmo polipeptídios sem uma estrutura nativa definida. 


\section{Apêndice A}

\section{Independência da Escolha do}

\section{Percurso na Função de Correlação de}

\section{Pares}

Na seção 5.2.5 utilizamos o fato de que as matrizes $A$ e $V$ comutam para obter uma expressão analítica para o traço do produto de matrizes $A V^{r}$. Neste apêndice iremos utilizar a comutatividade entre estas duas matrizes para mostrar que as funções de correlação de spin, nas fases com simetria paramagnética, independem do percurso escolhido entre as sub-redes.

Sabendo que $\left[A, V^{T}\right]=0$ e que $A$ é simétrica, vamos notar que também temos $[A, V]=$ 0. Agora indicamos que a eq. (5.29) pode ser usada para checar que o produto de matrizes $A V$ também é uma matriz simétrica. Por fim, usando estas duas propriedades, podemos concluir que:

$$
\begin{aligned}
A V & =(A V)^{T}=V^{T} A^{T} \\
& =V^{T} A \\
& =A V^{T} .
\end{aligned}
$$

Com este resultado é possível 'transladar' a matriz $A$ ao longo de qualquer seqüência arbitrária de matrizes $V$ e $V^{T}$, trocando todas as matrizes $V^{T}$ por $V$, ou vice-versa. Desta forma fica demonstrado que

$$
A V V^{T} V V^{T} \cdots=A V^{n}
$$

onde $n$ é o número de matrizes que aparecem no produto " $V V^{T} V V^{T} \ldots$ ". 


\section{APÊNDICE A. INDEPENDÊNCIA DA ESCOLHA DO PERCURSO NA FUNÇÃO DE CORRELAÇÃO DE PARES}

Para simplificar o numerador da equação (5.47) lembramos que $A$ é inversível e inserimos $A^{-1} A=1$ no produto de matrizes que aparece naquele numerador, para obtermos uma relação similar à obtida na eq. (A.1). Realizando explicitamente estes cálculos, o numerador da equação (5.47) fica:

$$
\begin{aligned}
\operatorname{Tr}\left\{A^{\prime} V V^{T} V V^{T} \cdots\right\} & =\operatorname{Tr}\left\{A^{\prime} A^{-1} A V V^{T} V V^{T} \cdots\right\} \\
& =\operatorname{Tr}\left\{A^{\prime} A^{-1} A V^{n}\right\} \\
& =\operatorname{Tr}\left\{A^{\prime} V^{n}\right\} .
\end{aligned}
$$

Como foi dito logo acima, este processo pode ser utilizado com qualquer combinação de $V$ e de sua transposta, mostrando que a expressão da função de correlação de pares, $g_{w w}(r)$, é independente da escolha do caminho ao longo das sub-redes nas fases que não apresentam distinção de sub-redes. A independência com o percurso também pode ser demonstrada em outras funções de correlação, como a função de correlação entre buracos, com o mesmo procedimento utilizado para obter a eq. (A.2). 


\section{Referências Bibliográficas}

[1] N. Guisoni and V. B. Henriques, "Square water as a solvent: Monte carlo simulations," Braz. J. Phys., vol. 30, p. 736, 2000.

[2] N. Guisoni, Polimorfismo Líquido e Efeito Hidrofóbico através de Modelos Simplificados. PhD thesis, Instituto de Física, Universidade de São Paulo., São Paulo, 2000 .

[3] E. H. Lieb, "Exact solution of the problem of the entropy of the two-dimensional ice," Phys. Rev. Lett., vol. 18, no. 692, 1967.

[4] V. B. Henriques and M. C. Barbosa, "Liquid polymorphism and density anomaly in a lattice gas model," Phys. Rev. E, vol. 71, p. 031504, 2005.

[5] G. M. Bell and D. A. Lavis, "2-dimensional bonded lattice fluids .1. interstitial model," J. Phys. A, vol. 3, p. 427, 1970.

[6] G. M. Bell and D. A. Lavis, "2-dimensional bonded lattice fluids .2. orientable molecule model," J. Phys. A, vol. 3, p. 568, 1970.

[7] D. A. Lavis, "The steam-water-ice system: a two-dimensional bonded lattice model. the first-order approximation," J. Phys. C, vol. 6, p. 1530, 1973.

[8] D. A. Lavis, "Symmetry properties and 2-phase coexistence curve of a 2-dimensional bonded lattice fluid," J. Phys A, vol. 8, p. 1933, 1975.

[9] D. A. Lavis, "Exact matrix calculation for a 2-dimensional model of steam-water-ice system - bulk and boundary properties," J. Phys A, vol. 9, p. 2077, 1976.

[10] A. P. Young and D. A. Lavis, "Critical behavior of a 2-dimensional bonded lattice model," J. Phys. A, vol. 12, p. 229, 1979.

[11] B. W. Southern and D. A. Lavis, "Renormalization group-study of a twodimensional lattice model with directional bonding," J. Phys. A., vol. 13, p. 251, 1980 .

[12] A. F. Pereira de Araújo, "Folding protein models with a simple hydrophobic energy function: The fundamental importance of monomer inside/outside segregation," Proc. Natl. Acad. Sci. USA, vol. 96, pp. 12482-12487, Oct 1999.

[13] W. L. Treptow, M. A. A. Barbosa, L. G. Garcia, and A. F. Pereira de Araújo, "Non-native interactions, effective contact order and protein folding: A mutational investigation with the hydrophobic model," Proteins: Struct., Funct. and Genet., vol. 49, p. 167, 2002. 


\section{REFERÊNCIAS BIBLIOGRÁFICAS}

[14] M. A. A. Barbosa and A. F. Pereira de Araújo, "Relevance of structural segregation and chain compaction for the thermodynamics of folding of a hydrophobic exact protein model," Phys. Rev. E, vol. 67, p. 051919, 2003.

[15] F. Franks, Water: a Matrix for life (second edition). Royal Society of Chemistry, 2000 .

[16] D. Eisenberg and W. Kauzmann, The Structure and Properties of Water. Clarendon Press, 1969.

[17] P. G. Debenedetti, "Supercooled and glassy water," J. Phys.: Cond. Matter, vol. 15, p. 1669, 2003.

[18] P. G. Debenedetti, Metastable Liquids: Concepts and principles. Princeton University Press, 1996.

[19] C. A. Angell and H. Kanno, "Density maxima in high-pressure supercooled water and liquid silicon dioxide," Science, vol. 193, p. 1121, 1976.

[20] R. J. Speedy, "Stability-limit conjecture. an interpretation of the properties of water," J. Phys. Chem., vol. 86, p. 982, 1982.

[21] R. J. Speedy, "Comment on 'supercooled and glassy water'," J. Phys.: Cond. Matter, vol. 16, p. 6811, 2004.

[22] P. G. Debenedetti, "Reply to comment on 'supercooled and glassy water'," J. Phys.: Cond. Matter, vol. 15, p. 6815, 2004.

[23] M. Pretti and C. Buzano, "Thermodynamic anomalies in a lattice model of water," J. Chem. Phys., vol. 121, p. 11856, 2004.

[24] P. H. Poole, F. Sciortino, T. Grande, H. Stanley, and C. A. Angell, "Effect of hydrogen bonds on the thermodynamic behavior of liquid water," Phys. Rev. Lett., vol. 73, p. 1632, 1994.

[25] P. H. Poole, F. Sciortino, U. Essmann, and H. E. Stanley, "Phase behavior of metastable water," Nature, vol. 360, p. 324, 1992.

[26] S. Harrington, R. Zhang, P. H. Poole, F. Sciortino, and H. E. Stanley, "Liquid-liquid phase transition: Evidence from simulations," Phys. Rev. Lett., vol. 78, p. 2409, 1997.

[27] A. M. Saitta and F. Datchi, "Structure and phase diagram of high-density water: The role of interstitial molecules," Phys. Rev. E, vol. 67, p. 020201, 2003.

[28] M. Yamada, S. Mossa, H. E. Stanley, and F. Sciorti, "Interplay between timetemperature transformation and the liquid-liquid phase transition in water," Phys. Rev. Lett., vol. 88, p. 195701, 2002.

[29] D. J. Lacks, "polyamorphism in silica," Phys. Rev. Lett., vol. 84, p. 4629, 2000.

[30] C. A. Angell, S. Borick, and M. Grabow, "Glass transitions and first order liquidmetal-to-semiconductor transitions in 4-5-6 covalent systems," J. Non-Cryst. Solids, vol. 207, no. 463, 1996. 
[31] P. H. Poole, M. Hemmati, and F. Sciotino, "Fragile-to-strong transition and polyamorphism in the energy landscape of liquid silica," Nature, vol. 412, no. 514, 2001.

[32] S. Sastry and C. A. Angell, "Liquid-liquid phase transition in supercooled silicon," Nature Materials, vol. 2, no. 739, 2003.

[33] Y. Katayama, T. Mizutani, W. Utsumi, O. Shimomura, M. Yamakata, and K. Funakoshi, "A first-order liquid-liquid phase transition in phosphorus," Nature, vol. 403, p. $170,2000$.

[34] G. Monaco, S. Falconi, W. A. Crichton, and M. Mezouar, "nature of first-order pt in phosphorus," Phys. Rev. Lett., vol. 90, p. 255701, 2003.

[35] R. Kurita and H. Tanaka, "On the abundance and general nature of the liquid-liquid phase transition in molecular systems," J. Phys.: Cond. Matter, vol. 17, p. L293, 2005.

[36] O. Mishima and H. E. Stanley, "Decompression-induced melting of ice iv and the liquid-liquid transition in water," Nature, vol. 392, p. 164, 1998.

[37] O. Mishima and H. E. Stanley, "The relationship between liquid supercooled and glassy water," Nature, vol. 396, p. 329, 1998.

[38] S. Sastry, P. G. Debenedetti, F. Sciortino, and H. E. Stanley, "Singularity-free interpretation of the thermodynamics of supercooled water," Phys. Rev. E, vol. 53, p. $6144,1996$.

[39] L. P. N. Rebelo, P. G. Debenedetti, and S. Sastry, "Singularity-free interpretation of the thermodynamics of supercooled water. ii. thermal and volumetric behavior," J. Chem. Phys., vol. 109, p. 629, 1998.

[40] G. Franzese and H. E. Stanley, "A theory for discriminating the mechanism responsible for the water density anomaly," Physica A, vol. 314, p. 508, 2002.

[41] G. Franzese and H. E. Stanley, "The widom line of supercooled water," J. Phys.: Cond. Matter, vol. 19, no. 205126, 2007.

[42] G. Franzese, M. I. Marques, and H. E. Stanley, "Intramolecular coupling as a mechanism for a liquid-liquid phase transition," Phys. Rev. E, vol. 67, no. 011103, 2003.

[43] C. Buzano, E. D. Stefanis, A. Pelizzola, and M. Pretti, "Two-dimensional lattice?uid model with waterlike anomalies," Phys. Rev. E, vol. 69, no. 061502, 2004.

[44] E. A. Jagla, "The interpretation of water anomalies in terms of core-softened models," Braz. J. Phys., vol. 34, no. 17, 2004.

[45] H. Tanaka, "Simple physical explanation of the unusual thermodynamic behavior of liquid water," Phys. Rev. Lett., vol. 80, p. 5750, 1998.

[46] E. A. Jagla, "Core-softened potentials and the anomalous properties of water," J. Chem. Phys., vol. 111, p. 8980, 1999.

[47] E. A. Jagla, "Phase behavior of a system of particles with core collapse," Phys. Rev. E, vol. 58, p. 1478, 1998. 
[48] I. Saika-Voivod, F. Sciortino, T.Grande, and P. Poole, "Simulated silica," Phil. Trans. R. Soc., vol. A 363, p. 525, 2005.

[49] M. R. Sadr-Lahijany, A. Scala, S. V. Buldyrev, and H. E. Stanley, "Waterlike anomalies for core-softened models of fluids: One dimension," Phys. Rev. E, vol. 60, p. 6714, 1999.

[50] A. Scala, M. R. Sadr-Lahijany, N. Giovambattista, S. V. Buldyrev, and H. E. Stanley, "Waterlike anomalies for core-softened models of fluids: Two-dimensional systems," Phys. Rev. E, vol. 63, p. 041202, 2001.

[51] G. Franzese, G. Malescio, S. V. B. Anna Skibinsky, and H. E. Stanley, "Generic mechanism for generating a liquid-liquid phase transition," Nature, vol. 409, p. 692, 2001.

[52] G. Franzese, "Differences between discontinuous and continuous soft-core attractive potentials: the appearance of density anomaly," J. Mol. Liq., vol. 136, p. 267, 2007.

[53] A. B. Oliveira, G. Franzese, P. A. Netz, and M. C. Barbosa, "Water-like hierarchy of anomalies in a continuous spherical shouldered potential," J. Chem. Phys., vol. 128, p. 064901, 2008.

[54] H. M. Gibson and N. B. Wilding, "Metastable liquid-liquid coexistence and density anomalies in a core-softened ?uid," Phys. Rev. E, vol. 73, p. 061507, 2006.

[55] E. Lomba, N. G. Almarza, C. Martin, and C. McBride, "Phase behavior of attractive and repulsive ramp ?uids: Integral equation and computer simulation studies," $J$. Chem. Phys., vol. 126, p. 244510, 2007.

[56] E. A. Jagla, "The interpretation of water anomalies in terms of core-softened models," Braz. J. Phys., vol. 34, p. 17, 2004.

[57] G. M. Bell, "One dimensional bonded fluids," J. Math. Phys., vol. 10, p. 1753, 1969.

[58] A. B. de Oliveira and M. C. Barbosa, "Density anomaly in a competing interactions lattice gas model," J. Phys.: Cond. Matter, vol. 17, p. 399, 2005.

[59] K. A. T. Silverstein, A. D. J. Haymet, and K. A. Dill, "A simple model of water and the hydrophobic effect," J. Am. Chem. Soc., vol. 120, p. 3166, 1998.

[60] T. M. Truskett and K. A. Dill, "Predicting water's phase diagram and liquid-state anomalies," J. Chem. Phys., vol. 117, p. 5101, 2002.

[61] T. M. Truskett and K. A. Dill, "A simple statistical mechanical model of water," J. Phys. Chem. B, vol. 106, p. 11829, 2002.

[62] F. L. Somer and J. Kovac, "Variable-structure cell model of two-dimensional liquids and glasses," J. Chem. Phys., vol. 102, no. 8995, 1995.

[63] K. A. T. Silverstein, A. D. J. Haymet, and K. A. Dill, "Molecular model of hydrophobic solvation," J. Chem. Phys., vol. 111, p. 8000, 1999.

[64] G. M. Bell, "Statistical mechanics of water: lattice with directed bonding," J. Phys. $C$, vol. 5, p. 889, 1972. 
[65] G. M. Bell and D. W. Salt, "Three dimensional lattice model for the water-ice system," J. Chem. Soc., Faraday Trans. II, vol. 72, p. 76, 1976.

[66] J. S. Whitehouse, N. I. Christou, D. Nicholson, and N. G. Parsonage, "A grand ensemble monte carlo investigation of the bell lattice model for water," J. Phys. A: Math. Gen., vol. 17, p. 1671, 1984.

[67] D. A. Lavis and B. W. Southern, "Renormalization-group study of a 3-dimensional lattice model with directional bonding," J. Stat. Phys., vol. 35, p. 489, 1984.

[68] N. A. M. Besseling and J. Lyklema, "Equilibrium properties of water and its liquidvapor interface," J. Phys. Chem., vol. 98, p. 11610, 1994.

[69] N. A. M. Besseling and J. Lyklema, "Molecular thermodynamics of hydrophobic hydration," J. Phys. Chem. B, vol. 101, p. 7604, 1997.

[70] M. Girardi, A. L. Balladares, V. B. Henriques, and M. Barbosa, "Liquid polymorphism and density anomaly in a three-dimensional associating lattice gas," $J$. Chem. Phys., vol. 126, p. 064503, 2007.

[71] M. Girardi, M. Szortyka, and M. Barbosa, "Diffusion anomaly in a three dimensional lattice gas," Physica A, vol. 386, p. 692, 2007.

[72] C. Buzano, E. de Stephanis e M. Pretti. Trabalho submetido para publicação.

[73] C. J. Roberts and P. G. Debenedetti, "Polyamorphism and density anomalies in network-forming fluids: Zeroth- and first-order approximations," J. Chem. Phys., vol. 105, p. 658, 1996.

[74] C. J. Roberts, A. Z. Panagiotopoulos, and P. G. Debenedetti, "Liquid-liquid immiscibility in pure fluids: Polyamorphism in simulations of a network-forming fluid," Phys. Rev. Lett., vol. 77, p. 4386, 1996.

[75] A. L. Balladares, M. Girardi, V. Henriques, and M. C. Barbosa, "Liquid polymorphism, density anomaly and h-bond disruption in an associating lattice gases," J.Phys.: Cond. Matter, vol. 19, p. 116105, 2007.

[76] M. Szortyka and M. C. Barbosa, "Diffusion anomaly in an associating lattice gas model," Physica A, vol. 380, p. 27, 2007.

[77] Márcia Barbosa e colaboradores, trabalho em andamento. Comunicação pessoal.

[78] S. Sastry, F. Sciortino, and H. E. Stanley, "Limits of stability of the liquid phase in a lattice model with water-like properties," J. Chem. Phys., vol. 98, p. 9863, 1993.

[79] M. Blume, V. J. Emery, and R. B. Griffiths, "Ising model for the $\lambda$ transition and phase separation in $h e^{3}-h e^{4}$ mixtures," Phys. Rev. A, vol. 4, p. 1071, 1971.

[80] G. Grigelionis and A. Rosengren, "Study of the blume-emery-griffiths model on the triangular lattice by the cluster-variation method," Physica A, vol. 208, p. 287, 1994.

[81] P. D. Gujrati, "Bethe or bethe-like lattice calculations are more reliable than conventional mean-field calculations," Phys. Rev. Lett., vol. 74, p. 809, 1995. 
[82] J. L. Monroe, "Frustrated ising systems on husimi trees," Physica A, vol. 256, p. 217, 1998.

[83] M. Pretti, "A note on cactus trees: Variational vs. recursive approach," J. Stat. Phys., vol. 111, p. 993, 2003.

[84] G. H. Wannier, "Antiferromagnetism. the triangular ising net.," Phys. Rev., vol. 79, p. $357,1950$.

[85] G. H. Wannier, "Errata. antiferromagnetism. the triangular ising net.," Phys. Rev. $B$, vol. 7, p. 5017, 1973.

[86] A. Patrykiejew, O. Pizio, and S. Sokolowski, "Novel phase behavior in a twodimensional network-forming lattice fluid," Phys. Rev. Lett., vol. 83, p. 3442, 1999.

[87] C. Buzano, E. D. Stefanis, and M. Pretti, "Hydration of an apolar solute in a two-dimensional waterlike lattice fluid," Phys. Rev. E, vol. 71, no. 051502, 2005.

[88] J. L. Monroe, "Phase-diagrams of ising-models on husimi trees .1. pure multisite interaction systems," J. Stat. Phys., vol. 65, p. 255, 1991.

[89] J. L. Monroe, "Phase-diagrams of ising-models on husimi trees .2. pair and multisite interaction systems," J. Stat. Phys., vol. 67, p. 1185, 1992.

[90] A. Pelizzola and M. Pretti, "Properties of some mean-field-like approximations for the triangular ising antiferromagnet," Phys. Rev. B, vol. 60, p. 10134, 1999.

[91] M. N. Tamashiro and S. R. Salinas, "Bethe-peierls approximation for the triangular ising antiferromagnet in a ?eld," Phys. Rev. B, vol. 56, p. 8241, 1997.

[92] R. J. Baxter, Exactly Solved Models in Statistical Mechanics. Academic Press, 1982.

[93] S. R. A. Salinas, Introdução à Física Estatística. Editora Universidade de São Paulo, 2005.

[94] J. C. Wheeler, "The $180^{\circ}$ rule at class of higher-order triple points," Phys. Rev. A, vol. 12, p. 267, 1975.

[95] J. C. Wheeler, "Geometric constraints at triple points," J. Chem. Phys., vol. 61, p. $4474,1974$.

[96] P. Ehrenfest, "Phasenumwandlungen im ueblichen und erweiterten sinn, classifiziert nach dem entsprechenden singularitaeten des thermodynamischen potentiales.," Communications from the Physical Laboratory of the University of Leiden, vol. 75b, p. 153, 1933.

[97] Z. F. Wang, B. W. Southern, and D. A. Lavis, "Monte carlo study of an extended three-state potts model on the triangular lattice," Phys. Rev. B, vol. 67, no. 054415, 2003.

[98] B. W. Southern e D. A. Lavis. Comunicação pessoal.

[99] S. Bekhechi, B. W. Southern, A. Peles, and D. Mouhanna, "Short-time dynamics of a family of xy noncollinear magnets," Phys. Rev. E, vol. 74, no. 016109, 2006. 
[100] A. Ben-Naim, Hydrophobic Interactions. Plenum Press, 1980.

[101] C. Tanford, The Hydrophobic Effect: Formation of Micelles and Biological Membranes, 2nd ed. New York: Wiley, 1980.

[102] N. T. Southall, K. A. Dill, and A. D. J. Haymet, "A view of the hydrophobic effect," J. Phys. Chem. B, vol. 106, p. 521, 2002.

[103] A. B. Kolomeisky and B. Widom, "Model of the hydrophobic interaction," Faraday Discuss., vol. 112, p. 81, 1999.

[104] G. T. Barkema and B. Widom, "Model of hydrophobic attraction in two and three dimensions," J. Chem. Phys., vol. 113, p. 2349, 2000.

[105] K. Koga, P. Bhimalapuram, and B. Widom, "Correlation between hydrophobic attraction and the free energy of hydrophobic hydration," Molecular Physics, vol. 100, p. 24, 2002.

[106] H. B. Callen, Thermodynamics and an Introduction to Thermostatistics, 2nd Edition. New York: John Wiley, 1985.

[107] K. Koga, P. Bhimalapuram, and B. Widom, "The hydrophobic effect," Phys. Chem. Chem. Phys., vol. 5, p. 3085, 2003.

[108] N. S. Izmailian and C.-K. Hu, "Exact spin-spin correlation functions of bethe lattice ising and beg models in external fields," Phys. A, vol. 254, p. 198, 1998.

[109] C.-K. Hu and N. S. Izmailian, "Exact spin-spin correlation functions of bethe lattice ising and beg models in external fields," Phys. Rev. E, vol. 58, p. 1644, 1998.

[110] J. F. Stilck, C. E. Cordeiro, and R. L. P. G. do Amaral, "Semiflexible polymer an anisotropic bethe lattice," Phys. Rev. E, vol. 61, p. 5520, 2000.

[111] A. Ben-Naim, Water and Aqueous Solutions: Introduction to a Molecular Theory. Plenum Press, 1974.

[112] A. B. Oliveira, P. A. Netz, T. Colla, and M. C. Barbosa, "Thermodynamic and dynamic anomalies for a three dimensional isotropic core-softened potential," $J$. Chem. Phys., vol. 124, p. 084505, 2006.

[113] A. B. Oliveira, P. A. Netz, T. Colla, and M. C. Barbosa, "Structural anomalies for a three dimensional isotropic core-softened potential," J. Chem. Phys., vol. 125, p. $124503,2006$.

[114] A. A. Lehninger, D. L. Nelson, and M. M. Cox, Lehninger Princípios de Bioquímica. São Paulo: Sarvier, 2006.

[115] M. S. Cheunga, L. L. Chavez, and J. N. Onuchic, "The energy landscape for protein folding and possible connections to function," Polymer, vol. 45, p. 547, 2004.

[116] G. E. Schulz and R. H. Schirmer, Principles of protein structure. Nova York: Springer, 1979.

[117] K. A. Dill and H. S. Chan, "From levinthal to pathways to funnels," Nat. Struct. Biol., vol. 4, pp. 10-19, 1997. 
[118] E. Bornberg-Bauer and H. S. Chan, "Modeling evolutionary landscapes: Mutational stability, topology, and superfunnels in sequence space," Proc. Natl. Acad. Sci. USA, vol. 96, pp. 10689-10694, 1999.

[119] P. M. Harrison, H. S. C. S. B. Prusiner, and F. E. Cohen, "Thermodynamics of model prions and its implications for the problem of prion protein folding," J. Mol. Biol., vol. 286, p. 593, 1998.

[120] C. King and R. Diaz-Avalos, "Protein-only transmission of three yeast prion strains," Nature, vol. 428, p. 319, 2004.

[121] G. Wider, "Structure determination of biological macromolecules in solution using nmr spectroscopy," BioTech., vol. 29, p. 1278, 2000.

[122] A. J. G. S. et al, "The genome sequence of the plant pathogen xylella fastidiosa," Nature, vol. 406, p. 151, 2000.

[123] Página na internet, http://www.fapesp.br/materia/56/genoma/genoma.htm. Acessado em 8/2008.

[124] F. Robert, "Problem solved - a sort of," Science, vol. 321, p. 784, 2008.

[125] A. Kolinskia and J. Skolnick, "Reduced models of proteins and their applications," Polymer, vol. 45, p. 511, 2004.

[126] H. S. Chan, S. Shimizu, and H. Kaya, "Cooperativity principles in protein folding," Methods in Enzymology, vol. 380, pp. 350-379, 2004.

[127] H. S. Chan, "Modeling protein density of states: Additive hydrophobic effects are insufficient for calorimetric two-state cooperativity," Proteins, vol. 40, p. 543, 2000.

[128] H. Kaya and H. S. Chan, "Polymer principles of protein calorimetric two-state cooperativity," Proteins, vol. 40, pp. 637-661, 2000.

[129] A. F. Pereira de Araújo, "Protein folding cooperativity: Basic insights from minimalist protein models," Prot. Pept. Lett., vol. 12, pp. 223-228, 2005.

[130] M. Knott and H. S. Chan, "Exploring the effects of hydrogen bonding and hydrophobic interactions on the foldability and cooperativity of helical proteins using a simplified atomic model," Chem. Phys., vol. 307, p. 187, 2004.

[131] H. Kaya and H. S. Chan, "Energetic components of cooperative protein folding," Phys. Rev. Lett., vol. 85, pp. 4823-4826, 2000.

[132] H. Kaya and H. S. Chan, "Simple two-state protein foldin kinetics requires nearLevinthal thermodynamic cooperativity," Proteins, vol. 52, pp. 510-523, 2003.

[133] S. Shimizu and H. S. Chan, "Anti-cooperativity and cooperativity in hydrophobic interactions: Three-body free energy landscapes and comparison with implicit-solvent potential functions for proteins," Proteins, vol. 48, p. 15, 2002.

[134] H. Kaya and H. S. Chan, "Solvation effects and driving forces for protein thermodynamic and kinetic cooperativity: How adequate is native-centric topological modeling?," J. Mol. Biol., vol. 326, p. 911, 2003. 
[135] M. A. A. Barbosa, L. G. Garcia, and A. F. P. de Araujo, "Entropy reduction effect imposed by hydrogen bond formation on protein folding cooperativity: Evidence from a hydrophobic minimalist model," Phys. Rev. E, vol. 72, p. 051903, 2005.

[136] G. M. N. Fleury, M. A. A. Barbosa, and A. F. P. de Araujo, "Alternative hydrogen bond implementations produce opposite effects on collapse cooperativity of lattice homopolypeptide models," Phys. Rev. E, vol. 76, p. 051914, 2007.

[137] A. F. P. de Araujo, "Protein folding cooperativity: basic insights from minimalist models," Prot. Pept. Lett., vol. 12, p. 223, 2005.

[138] M. A. A. Barbosa, L. G. Garcia, and A. F. Pereira de Araújo, "Entropy reduction effect imposed by hydrogen bond formation on protein folding cooperativity: Evidence from a hydrophobic minimalist model," Phys. Rev. E, vol. 72, p. 051903, 2005.

[139] L. G. Garcia, W. L. Treptow, and A. F. Pereira de Araújo, "Folding simulations of a three-dimensional protein model with a non-specific hydrophobic energy function," Phys. Rev. E, vol. 64, p. 011912, 2001.

[140] L. G. Garcia and A. F. Pereira de Araújo, "Folding pathway dependence on energetic frustration and interaction heterogeneity for a three dimensional hydrophobic protein model," Proteins: Struct., Funct. and Bioinf., vol. 62, p. 46, 2006.

[141] N. D. Socci and J. N. Onuchic, "Kinetic and thermodynamic analysis of proteinlike heteropolymers: Monte Carlo histogram technique," J. Chem. Phys., vol. 103, no. 11, pp. 4732-4744, 1995.

[142] A. M. Ferrenberg and R. H. Swendsen, "Optimized Monte Carlo data analysis," Phys. Rev. Lett., vol. 63, pp. 1195-1198, 1989.

[143] D. K. Klimov and D. Thirumalai, "Cooperativity in protein folding: from lattice models with sidechains to real proteins," Folding 83 Design, vol. 3, pp. 127-139, 1998.

[144] J. J. Chou and E. I. Shakhnovich, "A study on local-global cooperativity in protein collapse," J. Phys. Chem. B, vol. 103, p. 2535, 1999.

[145] T. X. Hoang, A. Trovato, F. Seno, J. R. Banavar, and A. Maritan, "Geometry and symmetry presculpt the free-energy landscape of proteins," Proc. Natl. Acad. Sci. USA, vol. 101, p. 7960, 2004. 


\section{Lista de Figuras}

1.1 Anomalias termodinâmicas da água. . . . . . . . . . . . . . . 2

1.2 Cenários termodinâmicos da água. . . . . . . . . . . . . . . . . . 3

1.3 Estrutura da água. . . . . . . . . . . . . . . . . 5

2.1 Interações no modelo Bell-Lavis e Estados da molécula de água. . . . . . . 12

2.2 Estado fundamental dos modelos Bell-Lavis e Blume-Emery-Griffiths antiferromagnético. . . . . . . . . . . . . . . . . 16

3.1 Exemplos de árvores hierárquicas . . . . . . . . . . . . . . 25

3.2 Ramo simétrico e seqüencial do cacto de Husimi . . . . . . . . . . . . 26

3.3 Diagrama de fases do modelo de Ising antiferromagnético na rede triangular 28

3.4 Variação da magnetização, no modelo de Ising antiferromagnético, em função da geração no interior dos cacto de Husimi simétrico e seqüencial 32

3.5 Magnetização do modelo de Ising antiferromagnético nos cacto de Husimi simétrico e seqüencial . . . . . . . . . . . . . . . . . . . . . 32

3.6 Visualização da prescrição de Gujrati para o cacto de Husimi seqüencial. 37

4.1 Diagramas de fase temperatura vs. pressão dos modelos Bell-Lavis e BlumeEmery-Griffiths antiferromagnético . . . . . . . . . . . . . . . 45

4.2 Diagramas de fase temperatura vs. densidade dos modelos Bell-Lavis e Blume-Emery-Griffiths . . . . . . . . . . . . . . . . . . . 47

4.3 Detalhe do diagrama de fase temperatura vs. densidade do modelo de Blume-Emery-Griffiths antiferromagnético. . . . . . . . . . . . . . 48

4.4 Densidade, ligações de hidrogênio e entropia nos modelos Bell-Lavis e Blume-Emery-Griffiths antiferromagnético. . . . . . . . . . . . . . . . 50 
4.5 Compressibilidade isotérmica e capacidade térmica a volume e pressão constantes nos modelos Bell-Lavis e Blume-Emery-Griffiths antiferromagnético. 51

4.6 Diagrama de fases do modelo BL, de acordo com as simulações de Patry-

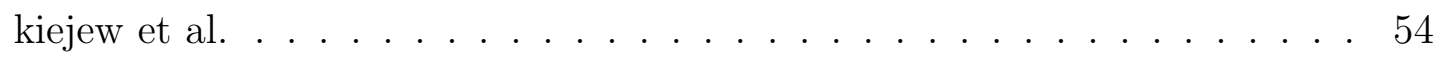

5.1 Construção da função de correlação de pares. . . . . . . . . . . . . . . . . . 73

7.1 Entropia em função da energia numa transição de fase de primeira ordem. 95

7.2 Passos entre monômeros vizinhos na rede. . . . . . . . . . . . . . . . 97

7.3 Estrutura ilustratando das ligações de hidrogênio do tipo $\alpha$ e $\beta$. . . . . . 98

7.4 Conformações utilizadas como estruturas nativas. . . . . . . . . . . . . 100

7.5 Curvas de capacidade térmica de uma conformação bidimensional. . . . . . 101

7.6 Entropia microscópica da conformação bidimensional. . . . . . . . . . . . . 103

7.7 Curva de capacidade térmica do modelo tridimensional. . . . . . . . . . . . 104

7.8 Cooperatividade e capacidade térmica de homopolímeros na rede extendida, sem ligação de hidrogênio. . . . . . . . . . . . . . . . . . . 108

7.9 Cooperatividade em função do tamanho e da interação de hidrogênio. . . 109

7.10 Distribuições de energia ao longo da transição de compactação . . . . . . . 111

7.11 Densidade de estados e subdensidades de estados de modelos com diferentes implementações de ligações de hidrogênio. . . . . . . . . . . . . . . . . . . 112 


\section{Lista de Tabelas}

2.1 Ligações de hidrogênio em um triângulo. . . . . . . . . . . . . . . . . . 13

2.2 Configurações de um triângulo com o Hamiltoniano que interpola entre modelo Bell-Lavis e Blume-Emery-Griffiths antiferromagnético. . . . . . . . 19

4.1 Variáveis reduzidas. . . . . . . . . . . . . . . . . . . . . . . 43

5.1 Configurações com soluto apolar. . . . . . . . . . . . . . . . . . 68

7.1 Parâmetros termodinâmicos de uma conformação bidimensional . . . . . . 102 



\section{Anexo I: Frustration and anomalous behavior in the Bell-Lavis model of liquid water}





\title{
Frustration and anomalous behavior in the Bell-Lavis model of liquid water
}

\author{
Marco Aurélio Alves Barbosa and Vera Bohomoletz Henriques* \\ Instituto de Física, Universidade de São Paulo, Caixa Postal 66318, 05315970 São Paulo, São Paulo, Brazil
}

(Received 18 January 2008; published 19 May 2008)

\begin{abstract}
We have reconsidered the Bell-Lavis model of liquid water and investigated its relation to its isotropic version, the antiferromagnetic Blume-Emery-Griffiths model on the triangular lattice. Our study was carried out by means of an exact solution on the sequential Husimi cactus. We show that the ground states of both models share the same topology and that fluid phases (gas and low- and high-density liquids) can be mapped onto magnetic phases (paramagnetic, antiferromagnetic, and dense paramagnetic, respectively). Both models present liquid-liquid coexistence and several thermodynamic anomalies. This result suggests that anisotropy introduced through orientational variables play no specific role in producing the density anomaly, in agreement with a similar conclusion discussed previously following results for continuous soft core models. We propose that the presence of liquid anomalies may be related to energetic frustration, a feature common to both models.
\end{abstract}

DOI: 10.1103/PhysRevE.77.051204

PACS number(s): $61.20 . \mathrm{Gy}, 65.20 .-\mathrm{w}$

\section{INTRODUCTION}

Water is one of the most intriguing fluids in nature due to its peculiar properties, relative abundance, and relevance for life. In the liquid phase, several of its properties are recognized as anomalous, since they are unusual in liquids with the same molecular size as $\mathrm{H}_{2} \mathrm{O}$. Among its anomalous features, the best known is probably the increase in density with temperature that happens from the melting point up to $4{ }^{\circ} \mathrm{C}$, at atmospheric pressures. The density anomaly exists in a large region of the pressure-temperature phase diagram and forms a line of temperatures of maximum density (TMD), which has negative inclination and enters the supercooled metastable regime above $40 \mathrm{MPa}$ [1]. Other important anomalous quantities are the basic thermodynamic derivatives: heat capacity $C_{P}$, thermal expansion $\alpha_{P}$, and isothermal compressibility $k_{T}$, whose magnitudes increase as the temperature is lowered toward the supercooled regime, at lower pressures [2-4].

Different thermodynamic scenarios have competed to describe the presence of anomalies in liquid water. Two of them, the stability limit conjecture [5] and the secondcritical-point hypothesis [6], assign the origin of these phenomena to thermodynamic instabilities in the supercooled regime. These would be due to the retracing of the gas-liquid spinodal to positive temperature, in the former case, or to a second critical point, related to the end of a liquid-liquid phase transition at high pressures, in the latter case. The second-critical-point hypothesis has received a lot of attention lately because liquid-liquid phase transitions, which were originally found in simulations of realistic models of water [6], were also found in simulations of $\mathrm{SiO}_{2}[7]$ and in high-temperature $\mathrm{x}$-ray diffraction experiments of phosphorus $[8,9]$. In addition to these results, there is some experimental evidence of a phase transition between two amorphous phases of water $[10,11]$ as well as for other substances [12], which might possibly be related to the low-temperature continuation of the liquid-liquid phase transition. The third

\footnotetext{
*vera@if.usp.br
}

possibility is the singularity-free scenario $[13,14]$, which is based on a set of thermodynamical equations connecting the increase in magnitude of $k_{T}, C_{P}$, and $\alpha_{P}$ to the presence of a TMD line of a negative slope in the pressure vs temperature plane.

Despite the lack of consensus on the thermodynamic description behind liquid anomalies, it is widely accepted that the hydrogen bond is responsible for them in water. At ambient pressure, hydrogen bonds create a fully bonded, tetrahedral structure in ice Ih, which is less dense than the liquid phase. Since the latent heat of fusion is not enough to break all bonds, these structures are partially preserved in the liquid. At the same time, the existence of a "normal liquid" structure, which is less bonded and more dense than the former structure, creates a free energy competition between different liquids that results in a density anomaly [15].

Different kinds of interactions have been used to implement the above description in statistical fluid models. Many reproduce the density anomaly and other waterlike properties. Models could be grouped into two main categories: isotropic and orientational. In both groups, continuous as well as lattice models, more tractable in analytical calculations, and easier to simulate, have been presented.

Core-softened continuous and lattice models, and latticevolume-dependent Potts state models belong in the first group. In the so-called core-softened models it is considered that the relevant feature is the presence of two characteristic lengths: the range of the usual attractive interaction and the range of a soft repulsive interaction, in addition to the hard core [16-25]. This additional interaction would be responsible for the competition between fluids of different densities. A few lattice versions of the core-softened models were implemented with nearest-neighbor and next-nearestneighbor interactions in one (1D) [26] and two dimensions (2D) [27]. The core-softened models may present density and other anomalies and/or liquid-liquid coexistence, depending on the form of the repulsive soft core and on the presence of an attractive interaction. A different lattice statistical model was presented by Sastry and collaborators: particle states were represented by Potts variables with isotropic bonding, coupled to an ad hoc variation of molecular volume 
$[13,14]$. The latter was used as an example of the singularityfree scenario.

A second group of models emphasizes the orientational character of the hydrogen bond interactions, which for a long time have been accepted as responsible for water anomalies. In the 2D Mercedez-Benz model [28] water molecules are represented by particles with three bonding arms, with no distinction of donors or acceptors, in order to mimic hydrogen bonds. Water thermodynamic and solvation anomalies and also liquid-liquid transitions may be present, under different approaches [29-32]. A lattice version of the MercedezBenz model was an early proposal of Bell and Lavis [33], which was investigated in several papers [34-36]. An orientational 3D lattice gas model which allowed for a distinction between donor and acceptor hydrogen bond states was investigated by Roberts and Debenedetti [37,38]. A simpler 2D orientational lattice gas was proposed more recently [39-41]. All these models were shown to exhibit a density anomaly and liquid polymorphism.

In the case of the lattice models, isotropic or orientational, several ad hoc features were added, in order to mimic different physical microscopic aspects. In some cases, the denser liquid states are energetically destabilized with a weakening factor that lowers bond strength whenever another molecule comes closer to bonding molecules [37,42-45] or, equivalently, a slightly repulsive van der Waals interaction $[39,41,46]$. In other cases, an additional number of $q$ nonbonding states is assigned to each water molecule, in order to force an entropy increase in the unbonded and disordered liquid $[13,14,37,44,45,47]$. As mentioned previously, there are also cases in which particle states typical of low temperatures are associated with lower local density $[13,14]$. In some studies, several of the above structural and energetic elements are present simultaneously.

Despite the fact that most of the mentioned models display some features of liquid water, it is still not possible to ascertain the relevant microscopic aspects that lead to a density anomaly.

In the present study we give a further step in the direction of looking for minimum requirements for a water model. We give a detailed analysis of the properties of the Bell-Lavis model, the simplest known lattice model for a bonding fluid, and compare them to those of its isotropic version, a frustrated antiferromagnet.

The Bell-Lavis (BL) model was proposed almost 40 years ago. It can be interpreted as a triangular lattice version of the Mercedez-Benz model [29]. In the original paper [33], the properties of the BL model were calculated on a triangle, named by the authors as an approximation with short-range order, and it was shown to present a density anomaly. Later, the first approach was improved with the use of three sublattices, named as an approximation with long-range order. Under this approximation, a new phase emerged: a bonded, low-density phase, which the authors identified as solid [34]. The discovery of the new phase led to the conclusion that the liquid density anomaly was in a metastable region, where the solid was stable. Subsequently, an explicit form for the gasliquid coexistence line, in stable and metastable regimes, was calculated using a symmetry transformation, in the context of the first-order approximation with short-range order. It was then possible to derive analytical expressions for the thermodynamic response functions, which presented behavior similar to that of water [48], with numerically reasonable ratios, for both the temperatures of minimum isothermal compressibility and of maximum density, to the gas-liquid critical temperature [48]. These findings represented interesting features of the model, despite the metastability of the liquid phase. A real space renormalization group $[35,36]$ study was also undertaken, and indicated that the solid-liquid transition was critical, as well as that the TMD occurred in the solid phase, in contradiction with the previous results.

In this paper we reconsider the BL model, through an analysis of the model's ground state and phase diagrams, and try to understand which features are relevant for the appearance of a density anomaly, by considering a simpler version of its Hamiltonian. To achieve this goal, we have chosen to study the isotropic version of the BL Hamiltonian, which is equivalent to the antiferromagnet Blume-Emery-Griffiths (BEG) model on the triangular lattice [49], and to compare the properties of both models using equivalent parameters. We found similarities between the two models' properties, particularly concerning the ground state and the density anomaly.

The thermodynamic properties have been obtained on the Bethe lattice [50], using the recursive approach in a sequentially constructed Husimi cactus [51]. This methodology is appropriate for the study of systems with energetic frustration, as has been discussed elsewhere [51,52], and becomes equivalent to Bell's long-range order approximation [34], in which three sublattices are considered.

We have abandoned the interpretation of the less dense and bonded phase as solid. Such an interpretation requires that the system remain liquid at very high pressures, at low temperatures, which does not seem physically reasonable. We have therefore chosen to name the two phases as liquid, denoting the less dense and bonded phase as low-density liquid (LDL), and the disordered liquid as high-density liquid (HDL). The liquid-liquid transition could become a transition between two amorphous states, at low temperatures. However, the distinction between the amorphous solid and liquid states is based on viscosity [53] and, so far, there are no studies on diffusion for the BL model.

This paper is organized as follows. In Sec. II the BellLavis model is presented, its Hamiltonian is built using Potts and spin representations, and a comparison is made with the antiferromagnetic Blume-Emery-Griffiths model. In Sec. III the recursive approach to the Husimi cactus is introduced and the description of a frustrated spin-1 system is given [51]. An expression for the grand potential and the mean value of some relevant quantities in the interior of the $\mathrm{Hu}-$ simi cactus are presented, in the same section. The thermodynamics and the liquid structure of both models are analyzed in Sec. IV and concluding remarks are left for the last section.

\section{THE BELL-LAVIS MODEL: AN ANISOTROPIC ANTIFERROMAGNETIC BEG MODEL}

The Bell-Lavis model is defined on a triangular lattice whose vertices can be either occupied by a molecule, or 


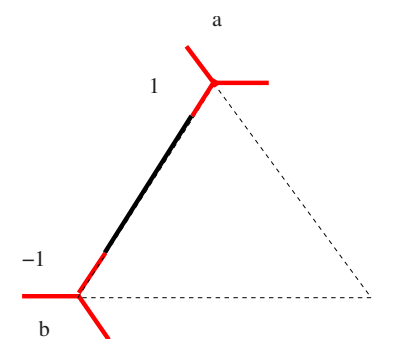

(a)

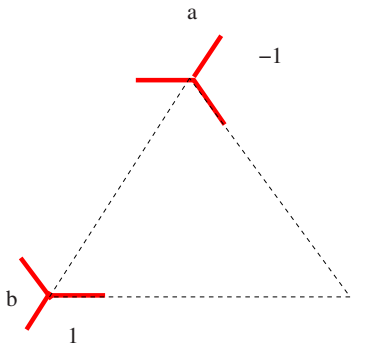

(b)

FIG. 1. (Color online) Interactions on the Bell-Lavis water model. (a) Water molecules forming a hydrogen bond with a pair interaction energy of $-\left(\epsilon_{\mathrm{vdW}}+\epsilon_{\mathrm{hb}}\right)$ and (b) molecules interacting only through van der Waals attraction with a pair interaction energy of $-\epsilon_{\mathrm{vdW}}$.

empty. Each molecule has three bonding arms separated by $120^{\circ}$ and two different orientations. The energetics of the model is simple and includes van der Waals interaction and hydrogen bonds between neighboring molecules. Hydrogen bonding depends on specific molecular orientations and happens when the bonding arms of neighboring molecules point to each other. Figure 1 shows examples of (a) bonded and (b) unbonded molecules. The states of a particle are represented through occupational, $\eta_{i}$, and orientational, $\tau_{i}^{i j}$, variables. $\eta_{i}$ indicates the presence or absence of a particle at site $i\left(\eta_{i}\right.$ $=1$ or 0 , respectively) and $\tau_{i}^{i j}$ stands for the presence or absence of a bonding arm pointing from site $i$ to site $j\left(\tau_{i}^{i j}\right.$ $=1$ or 0 , respectively). With these definitions, the effective Hamiltonian of the system, in the grand canonical ensemble, can be written as

$$
\mathcal{H}_{\mathrm{BL}}=-\sum_{(i, j)} \eta_{i} \eta_{j}\left(\epsilon_{\mathrm{vdW}}+\epsilon_{\mathrm{hb}} \tau_{i}^{i j} \tau_{j}^{j i}\right)-\mu \sum_{i} \eta_{i}
$$

where $\epsilon_{\mathrm{vdW}}$ refers to the strength of the van der Waals interaction, $\epsilon_{\mathrm{hb}}>0$ to the strength of the hydrogen bond interaction, which is attractive by definition, and $\mu$ to the chemical potential. The first sum is performed over all pairs $(i, j)$ of nearest neighbors, and the second over all sites $i$.

Alternatively, this effective Hamiltonian can be written in a spin-1 representation [35]. This will be useful, since it permits one to relate the BL and BEG models naturally. To simplify the calculations, the effective Hamiltonian can be split between the lattice triangles as

$$
\mathcal{H}_{\mathrm{BL}}=\frac{1}{2} \sum h_{\mathrm{BL}}=\frac{1}{2} \sum\left(h_{\mathrm{vdW}}+h_{\mathrm{hb}}+h_{\mu}\right),
$$

where the summation is over all triangles in the lattice and the factor $1 / 2$ avoids double counting of links on adjacent triangles. In Eq. (2) we separate the contributions coming from van der Waals interactions, hydrogen bonds and chemical potential, by defining the terms $h_{\mathrm{vdW}}, h_{\mathrm{hb}}$, and $h_{\mu}$. Now, let us assume that the state of each site $k$ in a triangle is represented by a spin $S_{k}$ which assumes integer values for different particle orientations (see Fig. 1), and 0 for a hole. As will be seen later, it is necessary to use three sublattices- $a, b$, and $c$ - to distinguish the possible ordered states. With these definitions the van der Waals term $h_{\mathrm{vdW}}$ becomes

$$
h_{\mathrm{vdW}}=-\epsilon_{\mathrm{vdW}}\left(S_{a}^{2} S_{b}^{2}+S_{b}^{2} S_{c}^{2}+S_{c}^{2} S_{a}^{2}\right) .
$$

In order to obtain $h_{\mathrm{hb}}$ it is useful to define the spin projectors

$$
P_{ \pm}\left(S_{k}\right)=\frac{1}{2}\left(S_{k}^{2} \pm S_{k}\right)
$$

which give 1 , if the spin $S_{k}$ is equal to the projector's subscript, or 0 , if different. Using the labels of sublattices and the spin values of particle orientations as in Fig. $1, h_{\mathrm{hb}}$ and $h_{\mu}$ of Eq. (2) become

$$
h_{\mathrm{hb}}=-\epsilon_{\mathrm{hb}}\left[P_{-}\left(S_{a}\right) P_{+}\left(S_{b}\right)+P_{-}\left(S_{b}\right) P_{+}\left(S_{c}\right)+P_{-}\left(S_{c}\right) P_{+}\left(S_{a}\right)\right]
$$

and

$$
h_{\mu}=-\frac{\mu}{3}\left(S_{a}^{2}+S_{b}^{2}+S_{c}^{2}\right) .
$$

Note that every site is shared by six triangles, and the factor of $1 / 3$ has been used here to absorb the contribution of the chemical potential in a single triangle in Eq. (2). Using Eqs. (3)-(6), and grouping the terms by the order of spin coupling, we get

$$
\begin{aligned}
h_{\mathrm{BL}}= & \frac{\epsilon_{\mathrm{hb}}}{4}\left(S_{a} S_{b}+S_{b} S_{c}+S_{c} S_{a}\right)-\left(\epsilon_{\mathrm{vdW}}+\frac{\epsilon_{\mathrm{hb}}}{4}\right) \\
& \times\left(S_{a}^{2} S_{b}^{2}+S_{b}^{2} S_{c}^{2}+S_{c}^{2} S_{a}^{2}\right)-\frac{\mu}{3}\left(S_{a}^{2}+S_{b}^{2}+S_{c}^{2}\right) \\
& -\frac{\epsilon_{\mathrm{hb}}}{4}\left(S_{a}-S_{b}\right)\left(S_{b}-S_{c}\right)\left(S_{c}-S_{a}\right) .
\end{aligned}
$$

As noted previously by Young and Lavis [35], the Hamiltonian of Eq. (7) is obtained by adding an anisotropic interaction given by

$$
h_{\mathrm{ani}}=\frac{\epsilon_{\mathrm{hb}}}{4}\left(S_{a}-S_{b}\right)\left(S_{b}-S_{c}\right)\left(S_{c}-S_{a}\right) .
$$

to the BEG Hamiltonian

$$
\begin{aligned}
h_{\mathrm{BEG}}= & -J\left(S_{a} S_{b}+S_{b} S_{c}+S_{c} S_{a}\right)-K\left(S_{a}^{2} S_{b}^{2}+S_{b}^{2} S_{c}^{2}+S_{c}^{2} S_{a}^{2}\right) \\
& +\frac{\Delta}{3}\left(S_{a}^{2}+S_{b}^{2}+S_{c}^{2}\right) .
\end{aligned}
$$

The parameters of the BEG Hamiltonian are related to the fluid parameters of the BL model through

$$
J=-\frac{\epsilon_{\mathrm{hb}}}{4}<0
$$




$$
\begin{gathered}
K=\epsilon_{\mathrm{vdW}}+\frac{\epsilon_{\mathrm{hb}}}{4}, \\
\Delta=-\mu .
\end{gathered}
$$

From Eq. (10a)-(10c) it follows that hydrogen bonds in the BL model are in some way connected to antiferromagnetism, since $J=-\epsilon_{\mathrm{hb}}<0$. This relation will be discussed further in Sec. V.

To allow the comparison with the equivalent isotropic model we define an interpolating Hamiltonian

$$
h_{I}(\lambda)=h_{\mathrm{BEG}}+\lambda h_{\mathrm{ani}},
$$

which reproduces the BEG or the BL Hamiltonian on the triangular lattice, by setting $\lambda$ equal to 0 or 1 , respectively [54].

In addition, it will be convenient to define two interpolating parameters: the reduced interaction strength

$$
\zeta(\lambda)=\frac{K-\lambda|J|}{(1+3 \lambda)|J|}
$$

and the reduced chemical potential

$$
\mu^{*}(\lambda)=-\frac{\Delta}{(1+3 \lambda)|J|}
$$

with $J$ and $K$ defined as in Eqs. (9). Thus, for the BL model we have $\zeta(1)=\epsilon_{\mathrm{vdW}} / \epsilon_{\mathrm{hb}}$ and $\mu^{*}(1)=\mu / \epsilon_{\mathrm{hb}}$, while for the BEG model Eqs. (12) and (13) yield $\zeta(0)=K /|J|$ and $\mu^{*}(0)$ $=-\Delta /|J|$. Since these parameters have been chosen to univocally describe the corresponding ground states of the two models, the $\lambda$ dependence of $\zeta(\lambda)$ and $\mu^{*}(\lambda)$ will be left implicit. From now on, reference to $\zeta$ and $\mu^{*}$ implies use of Eqs. (12) and (13), with $\lambda=1$ for analysis of the BL model, and $\lambda=0$ for analysis of the BEG model.

A first insight into the similarities of the models can be obtained by inspecting possible spin states on a single triangle. Assuming that null temperature microstates are composed of the ordered repetition of triangle configurations (with the allowed degeneracies), one may calculate the corresponding ground state grand potentials. This assumption leads to four possible stable fluid phases for the BL model, at null temperature [gas $(G)$, high-density liquid (HDL), lowdensity liquid (LDL), and intercalated $(I)]$, which may be mapped onto magnetic phases displayed by the BEG model [paramagnetic $(P)$, frustrated paramagnetic (FP), antiferromagnetic (AF), and antiquadrupolar (AQ)]. Possible configurations for the different phases we propose are illustrated in Fig. 2. The high-density liquid phase is in fact highly degenerate. The free-energies per particle of the two HDL configurations represented in the figure are easily shown to be equal. These two and every configuration derived from the LDL structure by filling up some fraction $\theta$ of the empty sites coexist at $\zeta=-\mu^{*} / 6$. From now on we will take advantage of the relation between the two models, and all the references to thermodynamic phases of the BEG model will use the fluid notation.

The spectra of the interpolating Hamiltonian $H_{I}$ are shown in Table I, with fluid nomenclature indicated in the first col-

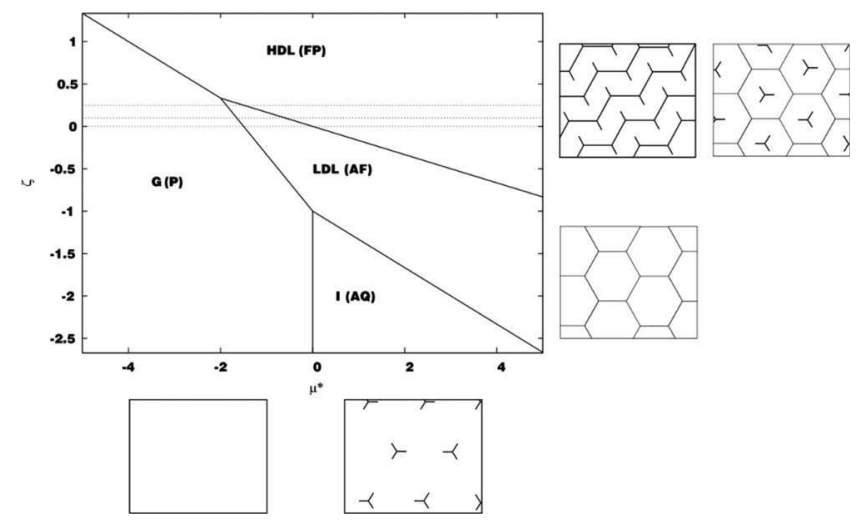

FIG. 2. Ground state of the Bell-Lavis and the antiferromagnetic Blume-Emery-Griffiths models (with a single triangle taken as a unitary cell) in terms of reduced interaction strengh $\zeta$ and reduced chemical potential $\mu^{*}$. Representative configurations of the BellLavis model are shown on the sides of the diagram, with straight lines representing hydrogen bonds. The degenerate HDL (FP) phase is represented by two of the many possible configurations (see text for phase names). Dotted lines indicate the parameters $(\zeta=1 / 4$, $1 / 10$, and 0 ) studied in this work.

umn. Ground state phase transition lines can be obtained from comparison of the grand potentials of Table I and it can be noted that the $T=0$ phase diagrams of the two models present the same topology, as shown in Fig. 2. The HDL and gas phases exist at some region of $\mu^{*}$, for all values of $\zeta$. There is a triple point at $\left(\mu^{*}=2, \zeta=1 / 3\right)$ indicating the appearance of a low-density liquid phase. This phase will be stable at some interval of $\mu^{*}$ for $\zeta<1 / 3$ and will coexist with the gas phase for interaction strengths in the range -1 $<\zeta<1 / 3$, until the appearance of another triple point at $\left(\mu^{*}=0, \zeta=-1\right)$. This triple point is related to the stability of the intercalated phase, and occurs only when the van der Waals interaction is repulsive and stronger than the hydrogen bond interaction in the BL model, i.e., when the overall interaction between molecules is repulsive.

Despite the topological equivalence between the ground states of the BL and BEG models, there is an important difference between the LDL phase and the antiferromagnetic phase which is caused by the anisotropic interaction term in Eq. (8). As can be seen in Table I, the only states that have been changed by this term were the low-density liquid and the unbonded low-density liquid (both antiferromagnetic states), whose "microscopic" grand potentials per triangle differ by $\Delta H=-4 \lambda J=\lambda \epsilon_{\mathrm{hb}}$. By making $\lambda=0$ these states merge into the antiferromagnetic state, indicating that the major effect of the anisotropy is to distinguish between lowdensity bonding and nonbonding states, thus breaking the degeneracy of the antiferromagnetic states. This is illustrated in Fig. 1, in which all states represented are antiferromagnetic, whereas for the liquid, only (a) represents bonded states, of lower energy, while (b) represents nonbonding states, of higher energy.

\section{EXACT SOLUTION ON THE BETHE LATTICE}

The BL and BEG models are studied here using a recursive approach [52] to the Bethe lattice [50]. The Bethe lattice 
TABLE I. Ground state of the effective Hamiltonian in Eq. (11), under the hypothesis discussed in the text. Stable and unstable configurations are shown with fluid names, microscopic grand potentials (using fluid and magnetic parameters in different columns), degeneracy $\Omega$, density $\rho$, the number of hydrogen bonds per particle $\rho_{\mathrm{hb}}$, the equivalent quantity for the BEG model $\Delta \rho_{f}$, and illustrative spin representations. The unbonded $L D L$ is emphasized because it is unstable in the BL model but is stable, and equal to the LDL, in the antiferromagnetic BEG model.

\begin{tabular}{|c|c|c|c|c|c|c|c|}
\hline \multirow[b]{2}{*}{ Fluid phase } & \multicolumn{2}{|c|}{$H_{I}\left(S_{a}, S_{b}, S_{c}\right)$} & \multirow[b]{2}{*}{$\Omega$} & \multirow[b]{2}{*}{$\rho$} & \multirow[b]{2}{*}{$\rho_{\mathrm{hb}}$} & \multirow[b]{2}{*}{$\Delta \rho_{f}$} & \multirow[b]{2}{*}{$\left(S_{a}, S_{b}, S_{c}\right)$} \\
\hline & Fluid & Magnetic & & & & & \\
\hline \multicolumn{8}{|l|}{ Stable phases } \\
\hline Gas & 0 & 0 & 1 & 0 & 0 & 0 & $(0,0,0)$ \\
\hline HDL & $-\epsilon_{\mathrm{hb}}-3 \epsilon_{\mathrm{vdW}}-\mu$ & $J-3 K+\Delta$ & 6 & 1 & 1 & 1 & $(+,-, \pm)$ \\
\hline LDL & $-\frac{(1+\lambda)}{2} \epsilon_{\mathrm{hb}}-\epsilon_{\mathrm{vdW}}-\frac{2}{3} \mu$ & $(1+2 \lambda) J-K+\frac{2}{3} \Delta$ & 3 & $2 / 3$ & $3 / 2$ & $3 / 2$ & $(+,-, 0)$ \\
\hline Intercalated & $-\frac{1}{3} \mu$ & $\frac{1}{3} \Delta$ & 6 & $1 / 3$ & 0 & 0 & $(0, \pm, 0)$ \\
\hline $\begin{array}{l}\text { Unbonded } L D L \\
\text { Unstable phases }\end{array}$ & $-\frac{(1-\lambda)}{2} \epsilon_{\mathrm{hb}}-\epsilon_{\mathrm{vdW}}-\frac{2}{3} \mu$ & $(1-2 \lambda) J-K+\frac{2}{3} \Delta$ & 3 & $2 / 3$ & 0 & $3 / 2$ & $(-,+, 0)$ \\
\hline Densely ordered & $-3 \epsilon_{\mathrm{vdW}}-\mu$ & $-3 J-3 K+\Delta$ & 2 & $2 / 3$ & 0 & $-3 / 2$ & $(+,+,+)$ \\
\hline Lightly ordered & $-\epsilon_{\mathrm{vdW}}-\frac{2}{3} \mu$ & $-J-K+\frac{2}{3} \Delta$ & 6 & 1 & 0 & -1 & $(+, 0,+)$ \\
\hline
\end{tabular}

is known to capture the essential features of different models, particularly when the usual mean field treatment fails [50]. On the recursive approach, the system is studied in an infinite hierarchical tree, which here is the sequential Husimi cactus, and the thermodynamical properties are calculated on the interior of this tree by iterating a set of recursion relations until a fixed point is reached.

A triangular lattice may be represented by a Husimi cactus of coordination $q=6$. This is achieved by letting the branches of the cactus grow indefinitely, and attaching the base sites of two branches to each vertex of the central triangle. Figure 3 shows two branches of the Husimi cactus that were grown for three generations: one constructed with the usual symmetrical procedure and the other through a sequential procedure [51]. While in the symmetrical procedure all generations grow simultaneously from the central triangle, in the sequential procedure generations starting on different sublattices are grown in a sequence which specifies the order in which sublattices are added in the growth process. Here we adopt this order as $a \rightarrow b \rightarrow c \rightarrow a$.

In the next section we present a set of recursion relations that describe a general spin-1 Hamiltonian on the sequential Husimi cactus and give an expression for the grand potential of this system in the interior of the cactus.

\section{A. Recursive approach to a general spin-1 Hamiltonian on the sequential Husimi cactus}

Let us consider the general Hamiltonian $h\left(S_{a}, S_{b}, S_{c}\right)$ on a single triangle. The partition function of a sequential Husimi cactus with $M$ generations, and growth starting in generation 0 on sublattice $a$ of a central triangle, is given by

$$
\Xi_{0,1,2}^{(M)}=\sum_{S_{a}, S_{b}, S_{c}} e^{-\beta h\left(S_{a}, S_{b}, S_{c}\right)} \Lambda_{0}^{2}\left(a, S_{a}\right) \Lambda_{1}^{2}\left(b, S_{b}\right) \Lambda_{2}^{2}\left(c, S_{c}\right),
$$

where $\beta=1 / k_{B} T . \Lambda_{k}\left(l, S_{l}\right)$ is the partition function of a branch of the cactus starting at a site of sublattice $l$ on gen- eration $k$, in state spin $s_{l}$, whose child branches will grow sequentially for $m-k$ generations. Due to the cactus's selfsimilarity, the partition functions of branches on sucessive generations satisfy the following equations:
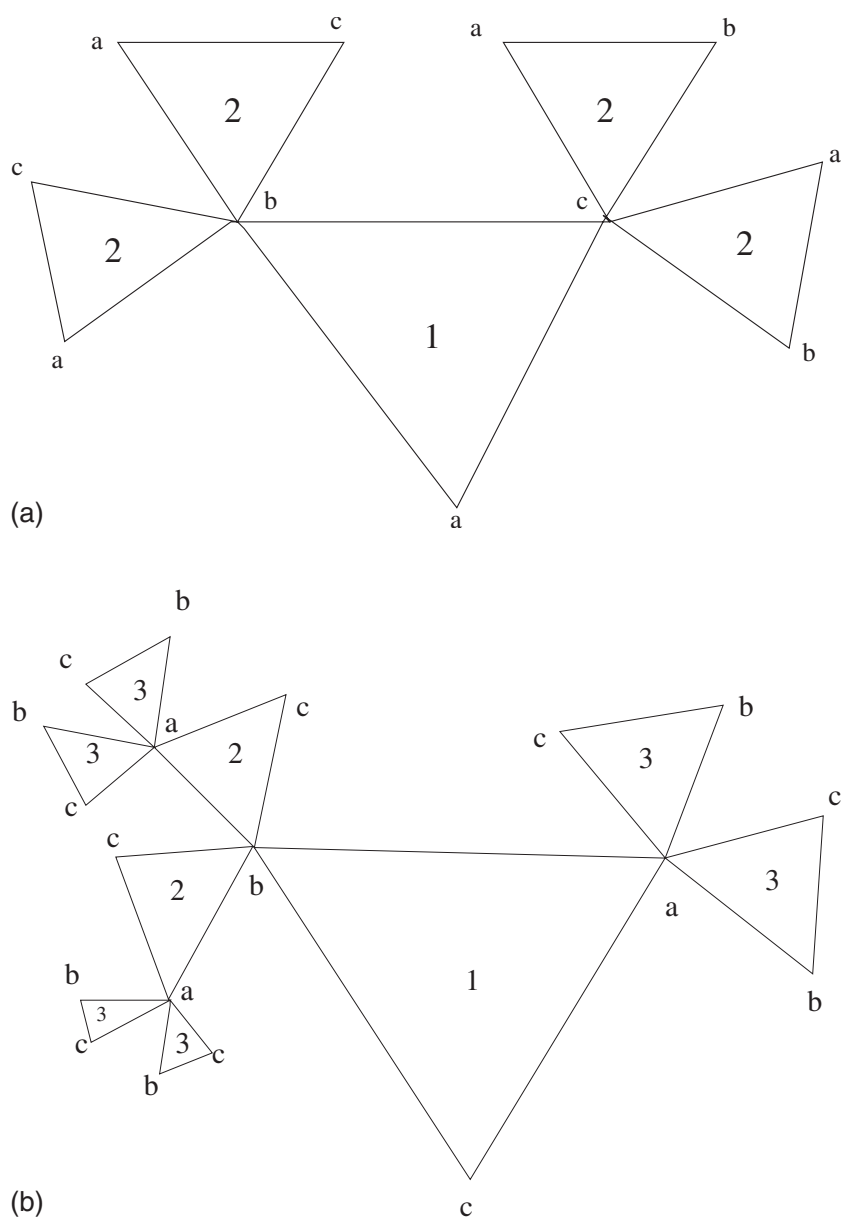

FIG. 3. (a) Symmetrical and (b) sequential constructions of the branches of the Husimi cactus. 


$$
\begin{aligned}
& \Lambda_{k}\left(a, S_{a}\right)=\sum_{S_{b}^{\prime}, S_{c}^{\prime}} e^{-\beta h\left(S_{a}, S_{b}^{\prime}, S_{c}^{\prime}\right)} \Lambda_{k+1}^{2}\left(b, S_{b}^{\prime}\right) \Lambda_{k+2}^{2}\left(c, S_{c}^{\prime}\right), \\
& \Lambda_{k}\left(b, S_{b}\right)=\sum_{S_{c}^{\prime}, S_{a}^{\prime}} e^{-\beta h\left(S_{a}^{\prime}, S_{b}, S_{c}^{\prime}\right)} \Lambda_{k+1}^{2}\left(c, S_{c}^{\prime}\right) \Lambda_{k+2}^{2}\left(a, S_{a}^{\prime}\right), \\
& \Lambda_{k}\left(c, S_{c}\right)=\sum_{S_{a}^{\prime}, S_{b}^{\prime}} e^{-\beta h\left(S_{a}^{\prime}, S_{b}^{\prime}, S_{c}\right)} \Lambda_{k+1}^{2}\left(a, S_{a}^{\prime}\right) \Lambda_{k+2}^{2}\left(b, S_{b}^{\prime}\right) .
\end{aligned}
$$

Normalization of the probabilities on each sublattice reduces the initial nine equations, resulting from the three possible states for $S_{l}$, to six equations. The definition

$$
\Lambda_{k}\left(l, S_{l}\right)=B_{k}(l) x_{k}\left(l, S_{l}\right)^{S_{l}^{2}}
$$

may be used to rewrite Eqs. (15a)-(15c) as a dynamical mapping on the partial partition functions $x_{k}\left(l, S_{l}\right)$, given by

$$
\begin{aligned}
& x_{k}\left(a, S_{a}\right)=\frac{f_{(k+1, k+2)}\left(a, S_{a}\right)}{f_{(k+1, k+2)}(a, 0)}, \\
& x_{k}\left(b, S_{b}\right)=\frac{f_{(k+1, k+2)}\left(b, S_{b}\right)}{f_{(k+1, k+2)}(b, 0)}, \\
& x_{k}\left(c, S_{c}\right)=\frac{f_{(k+1, k+2)}\left(c, S_{c}\right)}{f_{(k+1, k+2)}(c, 0)} .
\end{aligned}
$$

The functions $f_{(m, n)}\left(l, S_{l}\right)$ are

$$
\begin{aligned}
& f_{(m, n)}\left(a, S_{a}\right)=\sum_{S_{b}^{\prime}, S_{c}^{\prime}} e^{-\beta h\left(S_{a}, S_{b}^{\prime}, S_{c}^{\prime}\right)} x_{m}^{2 S_{b}^{\prime 2}}\left(b, S_{b}^{\prime}\right) x_{n}^{2 S_{c}^{\prime 2}}\left(c, S_{c}^{\prime}\right), \\
& f_{(m, n)}\left(b, S_{b}\right)=\sum_{S_{c}^{\prime}, S_{a}^{\prime}} e^{-\beta h\left(S_{a}^{\prime}, S_{b}, S_{c}^{\prime}\right)} x_{m}^{2 S_{c}^{\prime 2}}\left(c, S_{c}^{\prime}\right) x_{n}^{2 S_{a}^{\prime 2}}\left(a, S_{a}^{\prime}\right), \\
& f_{(m, n)}\left(c, S_{c}\right)=\sum_{S_{a}^{\prime}, S_{b}^{\prime}} e^{-\beta h\left(S_{a}^{\prime}, S_{b}^{\prime}, S_{c}\right)} x_{m}^{2 S_{c}^{\prime 2}}\left(a, S_{a}^{\prime}\right) x_{n}^{2 S_{b}^{\prime 2}}\left(b, S_{b}^{\prime}\right) .
\end{aligned}
$$

Note that $x_{k}(l, 0)$ and $B_{k}(l)$ do not appear in Eqs. (18) due to definition (16). The functions $B_{k}(l)=\Lambda_{k}(l, 0)$ satisfy some recursion relations which will be used later to obtain the grand potential. For $l=a$ this relation is

$$
B_{k}(a)=B_{k+1}^{2}(b) B_{k+2}^{2}(c) f_{(k+1, k+2)}(a, 0) .
$$

The set of Eqs. (16) are iterated sequentially, starting from large $M$ values, until a fixed point is found. The existence of more than one fixed point, which can be obtained using different initial values in Eqs. (16), indicates the presence of various phases. The region of stability of each phase is es- tablished by comparing grand potentials. In the neighborhood of any fixed point we will have, for $k \ll M, x_{k}\left(l, S_{l}\right)$ $=x_{k-1}\left(l, S_{l}\right)=x\left(l, S_{l}\right)$. From now on the subscript $k$ will be avoided on the partial partition functions $x\left(l, S_{l}\right)$ and it will be assumed that their values are obtained on the interior of the cactus tree.

An analytical expression for the grand potential may be obtained by following Gujrati's proposal [50], in which it is assumed that the grand potential of the cactus is additive in the contributions from surface and bulk sites. Moreover, it is also assumed [50] that the surface grand potential of a cactus with $M$ generations is equal to the grand potential of a certain number $r$ of cactus with $M-1$ generations, with $r$ being the ratio of the numbers of surface sites on trees with successive $M$. For the $q=r+1=6$ symmetrical Husimi cactus, the bulk grand potential per unit area, $\phi$, is given by

$$
\phi=\frac{\Phi}{A}=\frac{\Phi_{0}^{(M)}-r \Phi_{0}^{(M-1)}}{\delta a_{0}},
$$

where $\delta=3$ is the difference, in site number, between one cactus with $M$ generations and the $r=4$ cactus with $M-1$ generations, and $A=\delta a_{0}$ with $a_{0}$ being the area of a single site. For the sequential Husimi cactus this quantity will be slightly different because each branch starts in different generation. Using the growth definition adopted here, $\phi$ for the sequential Husimi cactus is written as

$$
\phi=\frac{\Phi}{A}=\frac{\Phi_{0,1,2}^{(M)}-2 \Phi_{3,1,2}^{(M-1)}-2 \Phi_{3,4,2}^{(M-2)}}{3 a_{0}} .
$$

To obtain an expression for $\phi$ in terms of the partial partition functions $x_{k}\left(a, S_{a}\right)$, it is convenient to write

$$
\Xi_{0,1,2}^{(M)}=B_{0}^{2}(a) B_{1}^{2}(b) B_{2}^{2}(c) \sum_{S_{a}} x^{2 S_{a}^{2}}\left(a, S_{a}\right) f\left(a, S_{a}\right),
$$

where the subscript $k$ may be omitted in $f\left(a, S_{a}\right)$ because $k$ $\ll M$.

The grand potential per unit of area is obtained using the relation $\Xi=e^{-\beta \Phi}$ and applying Eqs. (19) and (22) on Eq. (21). After some algebra, this procedure leads to

$$
\phi=-\frac{k_{B} T}{3 a_{0}} \ln \left(\prod_{l=a, b, c} \frac{f(l, 0)}{\sum_{S_{l}} x\left(l, S_{l}\right)^{3 S_{l}^{2}}}\right) .
$$

Finally, the pressure at given temperature $T$ and chemical potential $\mu$ is simply $P=-\phi$. In what follows we introduce the mean value of some quantities necessary for the analysis of Sec. IV.

\section{B. Mean values In the interior of the cactus}

To obtain the mean value of some properties it will be useful to write the probability of finding a molecular configuration with given spin values $S_{a}, S_{b}$, and $S_{c}$ in the interior of the cactus: 


$$
\begin{aligned}
& P\left(S_{a}, S_{b}, S_{c}\right) \\
& \quad=\frac{e^{-\beta H_{I}\left(S_{a}, S_{b}, S_{c}\right)} x^{2 S_{a}^{2}}\left(a, S_{a}\right) x^{2 S_{b}^{2}}\left(b, S_{b}\right) x^{2 S_{c}^{2}}\left(c, S_{c}\right)}{\sum_{S_{a}^{\prime}, S_{b}^{\prime}, S_{c}^{\prime}} e^{-\beta H_{I}\left(S_{a}^{\prime}, S_{b}^{\prime}, S_{c}^{\prime}\right)} x^{2 S_{a}^{\prime 2}}\left(a, S_{a}^{\prime}\right) x^{2 S_{b}^{\prime 2}}\left(b, S_{b}^{\prime}\right) x^{2 S_{c}^{\prime 2}\left(c, S_{c}^{\prime}\right)}} .
\end{aligned}
$$

This definition implies that the mean value of any function $g\left(S_{a}, S_{b}, S_{c}\right)$ will be simply

$$
\left\langle g\left(S_{a}, S_{b}, S_{c}\right)\right\rangle=\sum_{S_{a}, S_{b}, S_{c}} g\left(S_{a}, S_{b}, S_{c}\right) P\left(S_{a}, S_{b}, S_{c}\right) .
$$

Thus, the density on the central triangle is given by

$$
\rho=\frac{1}{3} \sum_{l=a, b, c}\left\langle S_{l}^{2}\right\rangle
$$

and the mean energy per particle of the interpolating Hamiltonian [Eq. (11)] is

$$
u(\lambda)=\frac{1}{\rho}\left\langle h_{I}(\lambda)-h_{\mu}\right\rangle
$$

with $h_{I}(\lambda)$ and $h_{\mu}$ from Eqs. (11) and (6), respectively.

A quantity that is relevant for the particular case of the $\mathrm{BL}$ model is the number of hydrogen bonds per particle:

$$
\rho_{\mathrm{hb}}=-\frac{1}{\epsilon_{\mathrm{hb}} \rho}\left\langle H_{\mathrm{hb}}\right\rangle .
$$

At this point it is interesting to define a quantity similar to $\rho_{\mathrm{hb}}$, in the context of the BEG model. Before doing this, let us note that the mean number of nearest neighbors per particle is

$$
\rho_{\mathrm{NN}}=\frac{1}{\rho}\left\langle S_{a}^{2} S_{b}^{2}+S_{b}^{2} S_{c}^{2}+S_{c}^{2} S_{a}^{2}\right\rangle,
$$

and that using this definition Eq. (27) becomes

$$
u(\lambda=1)=u_{\mathrm{BL}}=-\epsilon_{\mathrm{hb}} \rho_{\mathrm{hb}}-\epsilon_{\mathrm{vdW}} \rho_{\mathrm{NN}}
$$

for the BL model, with $\lambda=1$, and

$$
u(\lambda=0)=u_{\mathrm{BEG}}=-|J|\left(-\frac{1}{\rho}\left\langle S_{a} S_{b}+S_{b} S_{c}+S_{c} S_{a}\right\rangle\right)-K \rho_{\mathrm{NN}}
$$

for the antiferromagnetic BEG model, with $\lambda=0$.

By comparing Eqs. (30) and (31) one realizes that the quantity

$$
\Delta \rho_{f}=-\frac{1}{\rho}\left\langle S_{a} S_{b}+S_{b} S_{c}+S_{c} S_{a}\right\rangle
$$

has an energetic meaning in the BEG model that is equivalent to the density of hydrogen bonds in the BL model. It is worth mentioning that $\Delta \rho_{f}$ presents the desired behavior at $T=0$, i.e., $\rho_{\mathrm{hb}}=\Delta \rho_{f}$ for all stable states of Table I, and that the unbonded low-density liquid becomes equal to the LDL phase in the BEG model. Nevertheless, the definitions $\rho_{\mathrm{hb}}$ and $\Delta \rho_{f}$ are not equal for unstable configurations at $T=0$, e.g., for the densely oriented and lightly oriented states in
Table I $\rho_{\mathrm{hb}}=0$ but $\Delta \rho_{f}=-1$ in the latter and $\Delta \rho_{f}=-3 / 2$ in the former.

Another relevant extensive property is the entropy per particle, which can be calculated numerically from the expression of the grand potential in Eq. (21) and is written as

$$
s=-\frac{1}{N} \frac{\partial \Phi}{\partial T}=-\frac{1}{\rho} \frac{\partial \phi}{\partial T},
$$

where $N$ is the number of particles in a system with fixed area $A$.

\section{PHASE DIAGRAMS AND THERMODYNAMIC PROPERTIES}

To begin our analysis we compare the finite-temperature pressure-temperature phase diagrams of the two models for three values of reduced interaction strength $\zeta=1 / 4,1 / 10$, and 0 , as shown in Fig. 4. These values were chosen in the interval $0 \leq \zeta<1 / 3$, which satisfies the stability condition for the LDL phase and the restriction of an attractive van der Waals interaction (or biquadratic spin coupling, in the BEG model). The reduced units defined in Table II are used. Phase transitions, temperatures of maximum and minimum density, and the locus of null entropy are shown with different lines and symbols in this figure.

In spite of the perfect mapping of the $t=0$ phase diagram topologies, temperature introduces some distinctions between the thermodynamic behavior of the two models. The first difference we note is that the anisotropic interaction in the BL model favors the LDL, since this phase is stable at larger temperatures and pressures, in comparison to the antiferromagnetic phase of the BEG model. This may be related to the behavior of the entropy. The latter can be inferred by applying the Clausius-Clapeyron equation to the liquidliquid coexistence line. At higher temperatures, both models present a more entropic HDL phase, as compared to the LDL phase. At lower temperatures, however, the BL model presents a more entropic LDL, as compared to HDL, which may explain the improvement of the stability of the LDL. This result is somewhat unexpected because in the ground state analysis of Sec. II it was found that the number of states of the LDL phase, in the BL model, was half the degeneracy of the BEG model.

Both models exhibit a coexistence line between the gas and HDL phases, ending in a critical point. The position of this point, $\left(t_{c}, p_{c}\right)$, goes to lower temperature and pressure as the intensity of the van der Waals interaction (biquadratic spin coupling) is lowered. In the BL model this shift produces noticeable changes in the phase diagram, since the critical point concerned crosses the gas-LDL transition, becoming metastable at some $\zeta^{\prime}$ in the interval $1 / 4<\zeta^{\prime}$ $<1 / 10$.

A density anomaly was searched for in the HDL phase. Lines of maximum density are shown in Fig. 4 and display similar behavior for equal $\zeta$, in both models. The TMD line meets the LDL-HDL coexistence, at null temperature and at pressure $p=1$. An important point to note is that, in the BL model, the lines of maximum densities are always in the metastable HDL phase. As to the BEG model, the TMD oc 

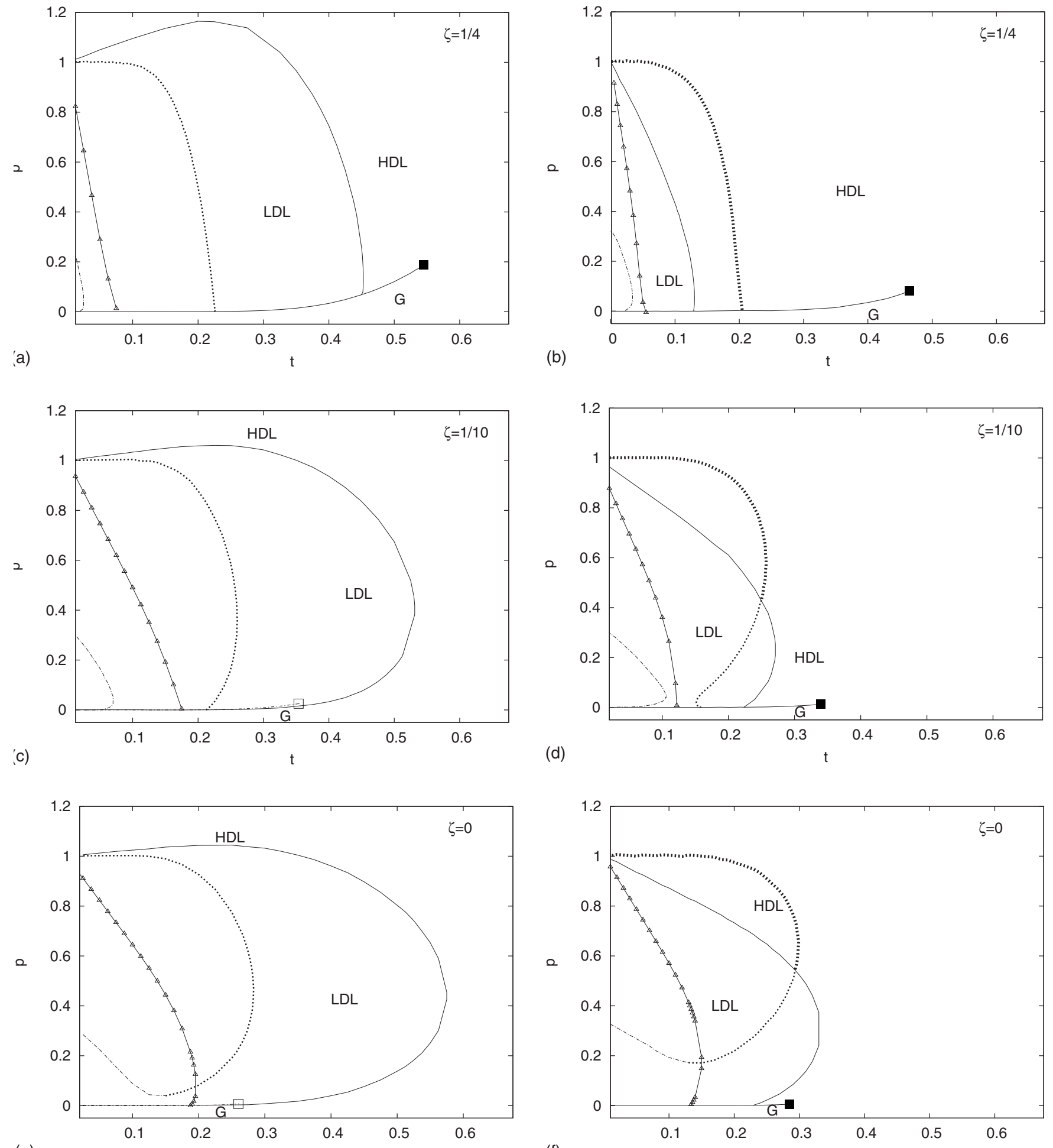

(e)

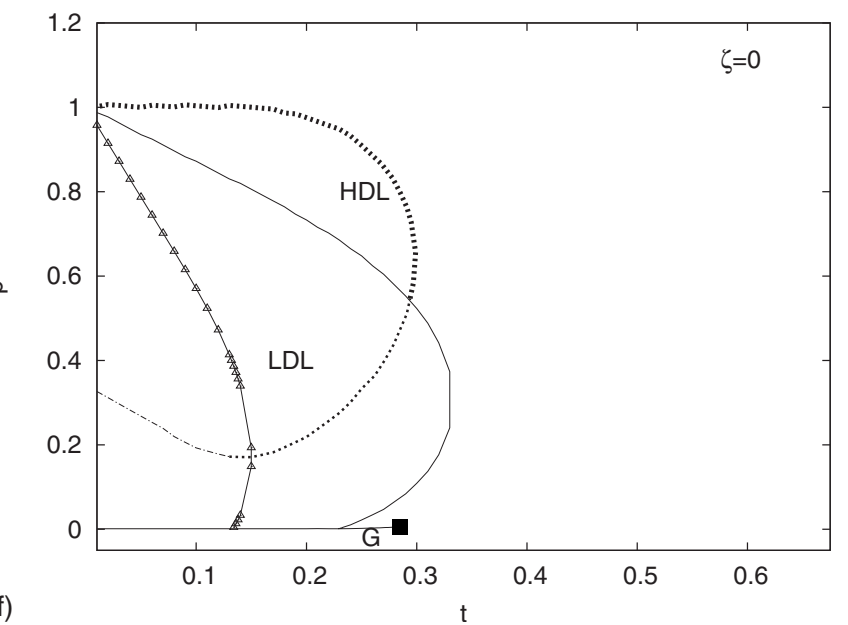

FIG. 4. Reduced temperature vs pressure phase diagrams of the Bell-Lavis (left) and antiferromagnetic Blume-Emery-Griffiths (right) models compared with reduced interaction strength $\zeta$ values $1 / 4,1 / 10$, and 0 . Phases are indicated in fluid notation as G (gas), HDL (high-density liquid), and LDL (low-density liquid). Phase coexistences are represented by a line and the critical point of the coexistence between gas and HDL is marked with a square. Note that an unfilled square has been used to indicate the metastability of this point in (c) and (e). The loci of stable maximum, metastable maximum, and metastable minimum density in the HDL phase are shown with thick dotted, thin dotted, and dash-dotted lines, respectively. A line connected with triangles indicates the temperatures, on each graphic, below which the entropy in the HDL phase is negative. 
TABLE II. Definition of the reduced variables used for the BellLavis and antiferromagnetic Blume-Emery-Griffiths models.

\begin{tabular}{ccc}
\hline \hline & $\mathrm{BL}$ & $\mathrm{BEG}$ \\
\hline$t$ & $k_{B} T / \epsilon_{\mathrm{hb}}$ & $k_{B} T /|J|$ \\
$p$ & $P a_{0} /\left(\epsilon_{\mathrm{hb}}-3 \epsilon_{\mathrm{vdW}}\right)$ & $P a_{0} /(|J|-3 K)$ \\
$k_{t}$ & $\left(\epsilon_{\mathrm{hb}}-3 \epsilon_{\mathrm{vdW}}\right) k_{T} / a_{0}$ & $(|J|-3 K) k_{T} / a_{0}$ \\
$c_{v}$ & $c_{V} / k_{B}$ & $c_{V} / k_{B}$ \\
$c_{p}$ & $c_{P} / k_{B}$ & $c_{P} / k_{B}$ \\
\hline \hline
\end{tabular}

curs in a stable HDL phase, for $\zeta=1 / 4$, and partly in stable and partly in metastable regions of the HDL phase, for $\zeta$ $=1 / 10$ and 0 .

Lines of minimum density were also found for both models, at lower temperatures, in the metastable HDL phase (see Fig. 4).

For $\zeta=1 / 4$, the BL metastable TMD line has a negative inclination when it meets the gas phase, at low pressures. This result is in accordance with a previous study by Bell and Lavis (Ref. [33]), in which a few curves of density, as functions of temperature, at fixed pressure, are shown.

For $\zeta=1 / 10$, the line of minimum density is shifted to higher temperatures and the TMD line returns to lower temperatures, at low pressures. In the case of the BEG model, the derivative of the TMD line changes its sign twice, retracing toward higher temperatures, just before meeting the gas phase.

For $\zeta=0$, the lines of maximum and minimum density merge into a single curve, at a minimum of that line. A similar behavior has been observed with differerent orientational models (see Fig. 4 of Ref. [37] and Fig. 5 of Ref. [44]). In both BEG and BL models, a single locus of extremum densities appears at some value of $\zeta$ between $1 / 10$ and 0 , probably at a higher value of $\zeta$ for the BEG model, due to the proximity of the two lines shown in Fig. 4(d). Under the $\zeta=0$ condition the BEG model corresponds to the antiferromagnetic Blume-Capel model.

Analogously to other cases, the analytical solutions from Bethe-like approaches [55] may present a region in the phase diagram with unphysical solutions of negative entropy. We observe such a region in the metastable HDL, for all the investigated values of $\zeta$, as shown in Fig. 4. By inspecting these regions of negative entropy, it can be concluded that the observed minimum in density is unphysical in both models, at least within the approximation used in this work.

\section{A. The $\zeta=1 / 4$ case}

From now on let us consider the case $\zeta=1 / 4$ in detail. Figure 5 displays the density vs temperature phase diagrams. Only phase coexistence lines, both stable and metastable, TMD lines, and the triple point have been shown, for clarity.

In the BL model, the density anomaly occurs in a metastable regime and a reentrance can be noted in the metastable continuation of the gas-HDL coexistence, when the TMD line encounters it. The null temperature limit of the metastable TMD line is at density $\rho_{0}^{\prime}=0.976 \pm 0.016$, which is
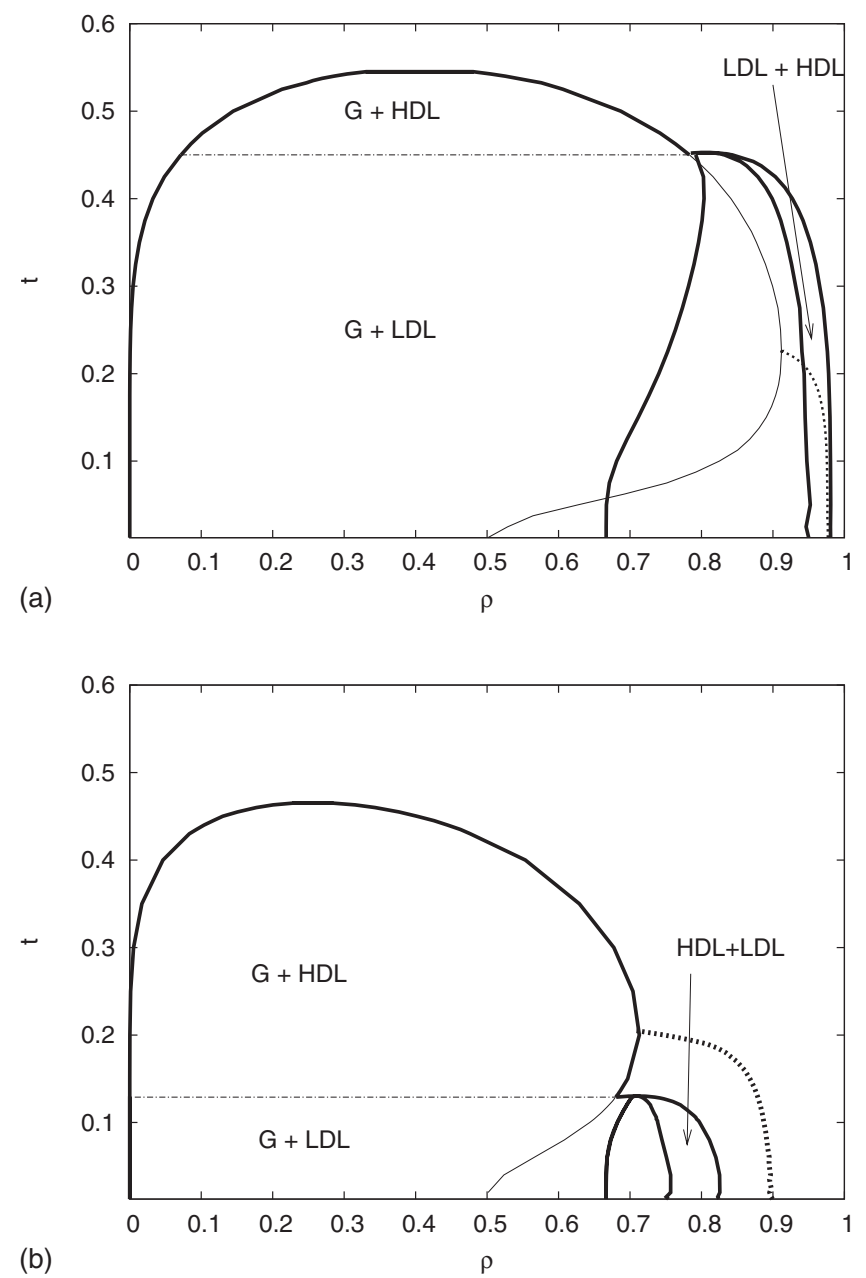

FIG. 5. Reduced temperature vs density phase diagram of the (a) Bell-Lavis and (b) antiferromagnetic Blume-Emery-Griffiths models with the reduced interaction strength value $\zeta=1 / 4$. Labels are the same used in Fig. 4. Phase transitions and the metastable continuation of the coexistence between gas and HDL are shown with thick and thin lines, respectively. The temperature of maximum densities and the triple point are shown with dotted and dash-dotted line, respectively.

compatible with the value $\rho_{0}=0.9763$, found by Lavis for the $t=0$ and $p=1$ limits [33]. The coexistence between LDL and HDL is very thin and occurs mostly at densities larger than 0.7. Near to the triple point there is an azeotropic point, at which two regions of coexistence meet. This point is related to the existence of a region with reversed relative densities, in the liquid phases, and corresponds to a very small region in which the derivative of the coexistence line $d p_{\text {coex }} / d t$, is positive.

In the BEG model the TMD line meets the gas-HDL phase coexistence in a stable regime and a reentrance can be noted in this coexistence too, as shown in Fig. 5(b). The null temperature limit of the TMD line happens at a density $\rho_{0}^{\prime \prime}$ $=0.89 \pm 0.025$. The LDL-HDL coexistence lies at lower temperatures and lower densities, when compared to the equivalent liquid-liquid coexistence, in the BL model. Again, near to the triple point there is an azeotropic point that can be visualized in Fig. 6. In the BEG model, the region of re- 


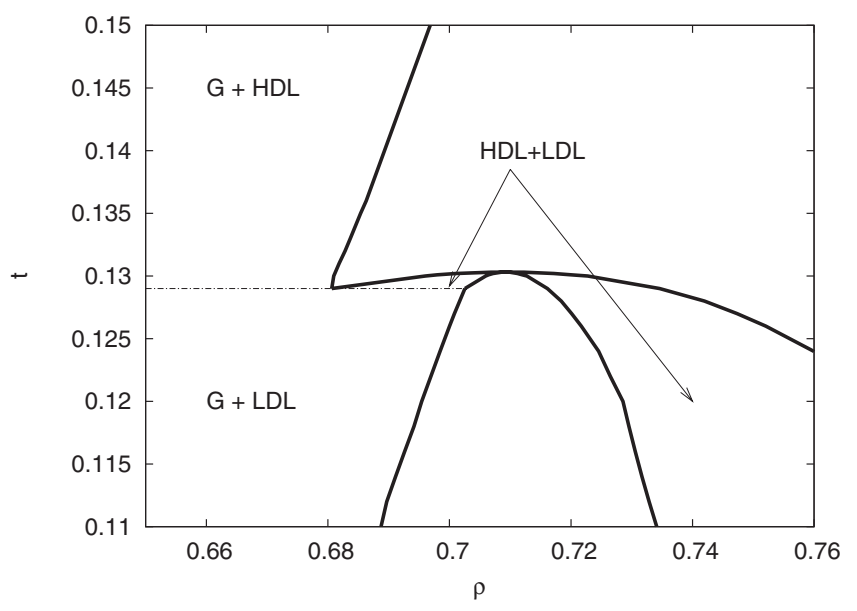

FIG. 6. Reduced temperature vs density phase diagram of the antiferromagnetic Blume-Emery-Griffiths model shown in Fig. 5 in the neighborhood of the triple point. Labels are the same used in Figs. 4 and 5.

versed densities in the LDL-HDL coexistence is larger, corresponding to $d p_{\text {coex }} / d t>0$ in a wider pressure interval.

At the $t=0$ limit, the LDL density at gas-LDL coexistence goes to $2 / 3$, for both models, whereas the metastable continuation of the gas-HDL coexistence line yields density $1 / 2$. The density $2 / 3$ was used in the ground state analysis of Sec. II, in order to predict the existence of the LDL phase. This analysis provided the values $p=0$ and 1 for the gas-LDL and the LDL-HDL transitions, respectively, which are the same values found in the phase diagrams of Fig. 4. However, from the Husimi cactus calculations, the $t=0$ limit for the LDL density at the LDL-HDL coexistence line is $\rho_{\mathrm{LDL}}$ $=0.95 \pm 0.005$. On the HDL side we have found $\rho_{\mathrm{HDL}}$ $=0.98 \pm 0.0005$. These densities are somewhat different from the values $\rho_{\mathrm{LDL}}^{\prime}=0.8963$ and $\rho_{\mathrm{HDL}}^{\prime}=0.9763$, found at $t=0$ in the approximation used by Lavis [34]. For the BEG model, the corresponding densities are $\rho_{\mathrm{LDL}}^{\prime \prime}=0.75 \pm 0.03$ and $\rho_{\mathrm{HDL}}^{\prime \prime}$ $=0.83 \pm 0.02$.

In Fig. 7 structural properties in the HDL phase of the models are compared at equivalent pressures as functions of temperature. At null temperature, the quantities of both models converge to the same values, except for the entropy at small pressures. A density anomaly is present for all pressures $p<1$, but the temperature of maximum density reaches denser states in the BL model. Concomitant with the density increase, there is a steep decrease in the density of hydrogen bonds $\rho_{\mathrm{hb}}$ and the corresponding quantity in the BEG model, $\Delta \rho_{f}$. This decrease is less steep in the BEG case, accompanying a smaller density increase. The entropy per particle is higher for the BEG model, generally, but at higher pressures $(p>1)$ and at the null temperature limit, it converges to a finite value that is identical in both BL and BEG models. This residual entropy is associated with the degeneracy of the ground state, which allows for several configurations to present the same free energy in this region.

The behavior of thermodynamic response functions in the HDL phase are compared for both models in Fig. 8. Isothermal compressibilities, shown in Figs. 8(a) and 8(b), present maxima at pressures $p<1$, which increase in magnitude as pressure $p=1$ is approached. The isobaric heat capacities also present peaks whose positions are dislocated to lower temperatures, accordingly. The isovolumetric heat capacities display maxima at low pressures, with peak size decreasing as pressure is increased, and eventually disappearing on approaching $p=1$.

\section{DISCUSSION}

We have shown that a line of maximum densities exist in a wide region of pressures and temperatures for both the BL and the BEG models (see Fig. 4), with reduced interaction strengths in the range

$$
0 \leq \zeta \leq 1 / 4
$$

We emphasize the meaning of the above inequality. The 0 $\leq \zeta$ condition reflects the requirement of a physically relevant attractive van der Waals interaction. At the other end, the condition $\zeta \leq 1 / 4$ guarantees the stability of the LDL phase at $t=0(\zeta<1 / 3$; see Fig. 2$)$.

The existence of the LDL phase seems to be a necessary condition for the presence of a density anomaly in the BL and BEG models, because it indirectly creates a free energy competition between two liquid structures: a normal and a bonded HDL structure. The normal HDL structure occurs at higher pressures, while the bonded HDL arises as a metastable liquid, in the region of stability of the LDL and at low pressures $(p<1)$. The "new" bonded HDL structure appears to "borrow" some properties of the LDL phase. This idea is further discussed in what follows.

\section{A. Liquid-liquid coexistence}

The stability of the LDL phase is easily established if one looks at the ground state Gibbs free energy. At null pressure and $t=0$, the free energy per particle is given by $g(p=0, t$ $=0)=u$ and the gas will coexist with the liquid phase of lower energy. Inspection of Table I shows that the LDL phase has lower energy than the HDL phase if the energy of each hydrogen bond is at least three times the energy of the van der Waals interaction. For systems under this condition, as the pressure increases, there will be a point at which work performed by the compression suppresses the free energy difference between the different liquids. At this point, i.e., at $p=1$, the system passes through coexistence, and enters the HDL liquid phase.

For finite temperatures, both models present a narrow liquid-liquid phase transition as shown in the density vs temperature phase diagrams of Figs. 5 and 6 . In the case of the BL model, this transition has been a matter of controversy. It was found in an early study by Lavis to be of first order, in an approximation scheme with three sublattices [33], but subsequent studies [36] based on the real space renormalization group yielded a second-order phase transition. More recently, Patrykiejew et al. [56] investigated, through Monte Carlo simulations, a modified version of the BL model, to which a repulsive three-body interaction was added. The main result of this work was that the transition between liquid phases occurred through a discontinuity in the specific 

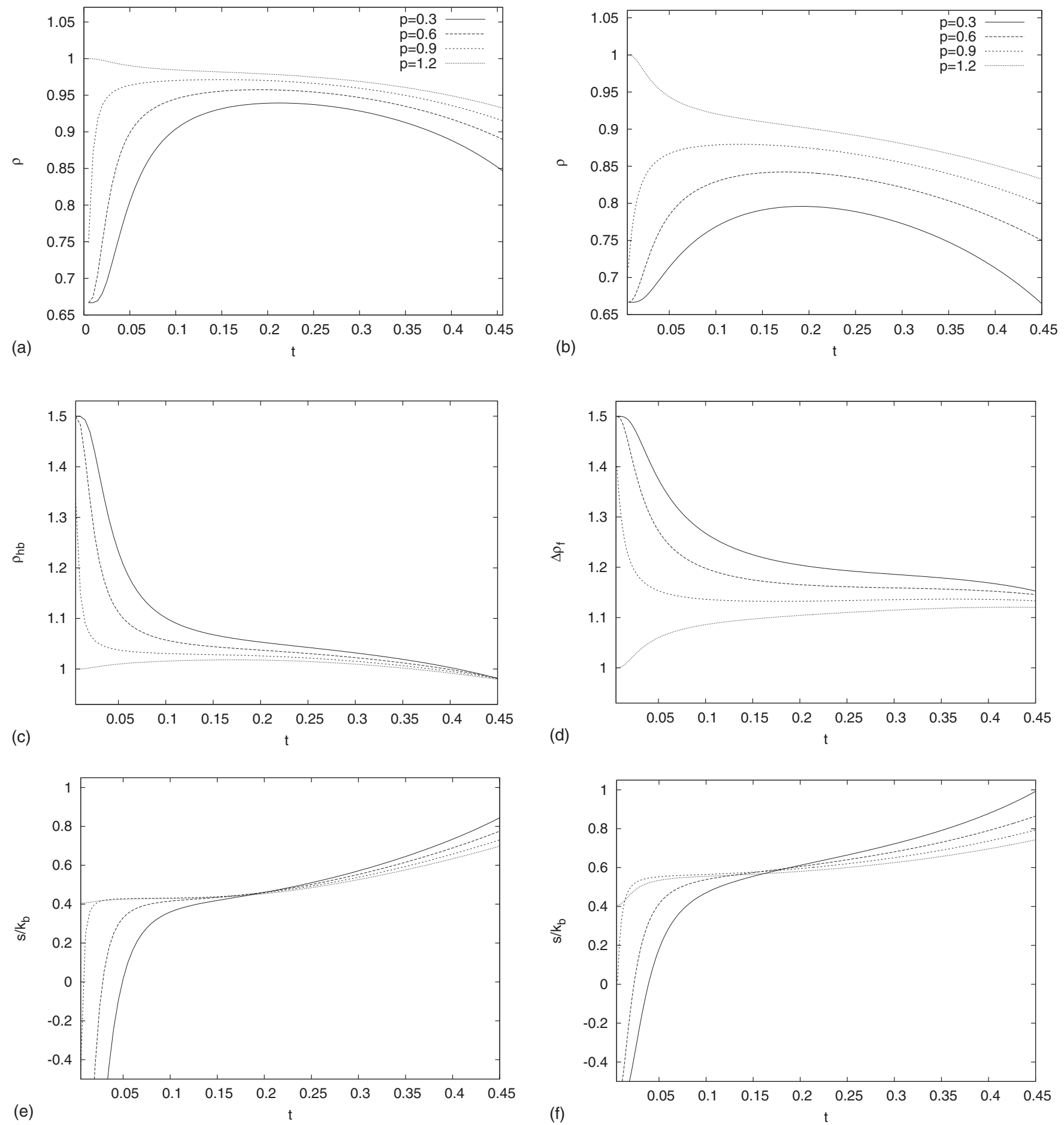

FIG. 7. Values of structural quantities, at the molecular level, of the Bell-Lavis (right) and the antiferromagnetic Blume-Emery-Griffiths models compared for the reduced interaction strength $\zeta=1 / 4$. From top to bottom we show (a) and (b) the density, (c) the number of hydrogen bonds per particle, (d) the quantity $\Delta \rho_{f}$, and (e) and (f) the entropy per particle.

heat, which would correspond to a second-order phase transition according to Ehrenfest's classification [57]. Those simulations included the original BL model, with $\epsilon_{\mathrm{vdW}} / \epsilon_{\mathrm{hb}}$ $=1 / 4$, discussed in this study [see Fig. 4(a) in Ref. [56]].

In spite of this result, it is possible that the HDL-LDL transition of the BL model may represent another example of a weakly first-order phase transition, as in the antiferromagnetic three-state Potts model on the triangular lattice [58], or may even not exist. In order to clarify this question, additional studies are necessary, either use of a methodology that allows one to distinguish between second- and weakly firstorder transitions [59], such as short-time dynamics [60], or 

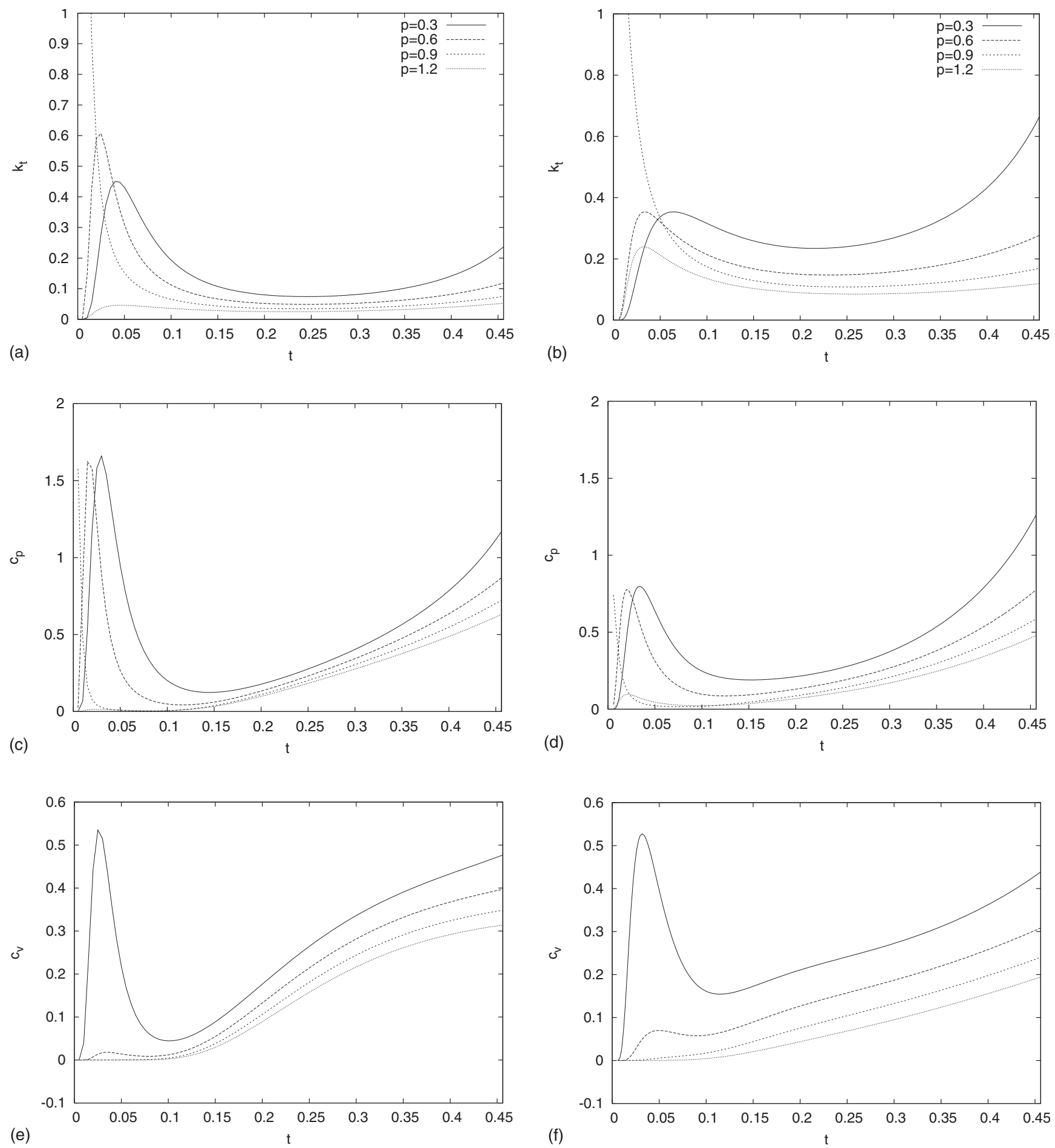

FIG. 8. Thermodynamic response functions of the Bell-Lavis (left) and the antiferromagnetic Blume-Emery-Griffiths (right) models compared for the interaction strength value $\zeta=1 / 4$, at constant pressure. The isothermal compressibility $k_{t}$ and the constant pressure $c_{p}$ and constant volume heat capacities $c_{v}$ are shown from top to bottom.

investigation of the histograms of a chirality order parameter [58], which in the BL model corresponds to the anisotropic term in Eq. (8).

\section{B. Anomalous behavior in the HDL phase}

The metastability of the TMD line seems to be a major deficiency of the BL model as a model for liquid water. Nev- ertheless, some of the results coming from Patrykiejew's [56] Monte Carlo simulations suggest that the line of density anomalies meets the gas-HDL coexistence line in a stable region. Figure 4(a) of that work [56], the density vs temperature phase diagram for the BL model, at $\zeta=1 / 4$, can be compared to our results; see Fig. 5(a). In both cases, the HDL density along the gas-HDL coexistence line presents an in- 
version of its slope, which represents one of the boundaries of the reentrant region.

The condition of a density increase with temperature along the coexistence curve is equivalent to an upper bound for the thermal expansion coefficient. The slope of the liquid density function $\rho(T, P)$ along the $P_{\text {coex }}(T)$ coexistence line, in the direction of increasing temperature toward the critical point can be expressed as $\partial_{\text {coex }} \rho=\sin (\theta) \rho k_{T}-\cos (\theta) \rho \alpha$. Where $\theta \equiv \theta(T, P)$ is the angle between the $P_{\text {coex }}(T)$ coexistence line and the $T$ axis, $k_{T}$ is the isothermal compressibility and $\alpha$ the isobaric expansion coefficient. Taking the liquid as denser and less entropic than the gas (i.e., $0<\theta<\pi / 2$ ) it follows that (i) if a TMD line touches the $P_{\text {coex }}(T)$ coexistence line, the liquid density, at coexistence, must be an increasing function of temperature, at the crossing point; (ii) if the liquid density increases with temperature along the coexistence line, it is possible, but not necessary, that the coexistence line encounters the line of maximum densities; and (iii) inversely, if the liquid density decreases with temperature along the coexistence line, $\partial_{\text {coex }} \rho<0$ and $\alpha>0$, i.e., the coexistence line cannot cross any region of anomalous density behavior.

Our Bethe lattice results are in accordance with these criteria, and the meeting of the TMD line with the liquid density at coexistence (see Fig. 5) seems to coincide with the maximum liquid density, in the metastable regime (for the HDL). In Patrykiejew's Monte Carlo simulations, there are no data on the TMD, but the (stable) $\rho$ vs $T$ phase diagram displays a maximum for the liquid density, indicating that there might, in fact, exist a stable TMD line crossing that region.

In both the BL and the BEG models, the anomalous increase in density, at lower temperatures and for $p<1$, is accompanied by a steep decrease in the number of hydrogen bonds (or $\Delta \rho_{f}$, in the BEG model) as well as by a large increase in the entropy per particle, as can be seen in Fig. 7. These features are emphasized in the metastable HDL phase of the BL model. Thus the anomalous liquid in the region limited by the TMD line may be called a bonded HDL, to distinguish it from the normal HDL, which occurs at higher pressures $(p>1)$ and temperatures $\left(t>t_{\mathrm{TMD}}\right)$. As stated before, the bonded HDL structure is similar to the LDL, in the sense that it is less dense and more bonded than the normal HDL structure. Nevertheless, the bonded structured liquid has the same symmetry as the HDL phase (paramagnetic) and does not have the sublattice distinction that is characteristic of the LDL (antiferromagnetic) phase. For this reason, one cannot localize the network of bonds in the bonded structure, or specify the sublattices that are filled or empty, as in the LDL.

The bonded and normal HDL structures present different mechanisms for increasing the system's entropy, as temperature rises. In the normal HDL structure, entropy is gained with an increase in the number of spatial arrangements of molecules, i.e., by increasing the molecular volume. As for the bonded HDL structure, entropy is gained, in spite of the decreasing molecular volume, due to the increase in the number of configurations for the hydrogen bond network (or in the $\Delta \rho_{f}$ coupling network, in the case of the BEG model) and frustration plays an important role. Frustration prevents new bonds from being created as particles are inserted to increase the density. Thus, while the number of hydrogen bonds $\left(\Delta \rho_{f}\right)$ per particle decreases, the number of bonds per unit "volume" is almost constant (results not shown), yielding a sharp rise in the number of bond configurations and thus of entropy. But bonded and normal HDL structures have the same symmetry, so that the density of the bonded structure eventually becomes equal to that of the normal structure, as temperature rises, and the TMD line may be considered as the midpoint of a continuous change between the two structures, in the same liquid phase.

The effect of pressure on the bonded HDL structure can be deduced by noting that pressure itself contributes to decrease the molecular volume. Thus, at higher pressures (but still below $p=1$ ) the change from the bonded to the normal structure is more favorable, and the position of the TMD line is shifted to lower temperatures, tending toward $t=0$ at $p$ $=1$. The structural parameters of the liquid are also affected, and the absolute rates of variation in density, entropy, and number of hydrogen bonds are significantly increased as $p$ $=1$ is approached from below (see Fig. 7). In the case of the normal HDL liquid, the role of pressure is the opposite of the former, yielding smaller absolute rates of variation of those quantities.

Comparison of the BEG and BL models [Fig. 7(a) and 7(b)] shows that the BEG model presents a smoother density variation, accompanied by less abrupt variations in $\Delta \rho_{f}$, as compared to $\rho_{\mathrm{hb}}$ of the BL model. Entropy, on the other hand, presents higher rates of variation for the BEG model. These features are related to the fact that, for a pair of neighboring molecules, there are more states compatible with a $\Delta \rho_{f}$ coupling than with a hydrogen bond. Because of this "flexibility" of the BEG model, a lower density increase is enough to maximize the entropy on the network of $\Delta \rho_{f}$ couplings. For the same reason, $\Delta \rho_{f}$ tends to a limiting value, at higher temperatures, which is larger than the limiting value for $\rho_{\mathrm{hb}}$.

Our data for the model susceptibilities can also be discussed in terms of the competition between two structures. Figures 8(a) and 8(b) display isothermal compressibilities in accordance with the criterion put forward by Sastry et al. [13], which states that the presence of a negatively inclined TMD line implies decreasing isothermal compressibility, at the same pressure. The maxima in $k_{t}$ are displaced toward smaller temperatures with increasing heights in the neighborhood of $p=1$. The same behavior is observed in $c_{p}$. The maxima observed on these two functions are related to large fluctuations in the molecular volume and in entropy, and are consistent with the competition between two structured liquids in the same thermodynamic phase. Although these fluctuations in volume and entropy are increasing while approaching $p=1$ at $t=0$, they are not related to a second critical point because the isovolumetric specific heat, which is proportional to fluctuations in energy, does not increase in the same region, as shown in Figs. 8(e) and 8(f)

\section{Frustration}

The importance of frustration in the BL model is easily recognizable when the Hamiltonian is written in a spin-1 
representation, as in Eq. (7), since the linear spin coupling is seen to be antiferromagnetic.

It is usually accepted that the prototype of an energetically frustrated system is the antiferromagnetic Ising model on the triangular lattice. This model has been studied at zero magnetic field by Wannier [61], who found a paramagnetic phase at all temperatures, without any phase transition at finite temperatures. In addition, Wannier's solution predicts a residual entropy at null temperature. Both the BL and the antiferromagnetic BEG models are reduced to the antiferromagnetic Ising model in the infinite-pressure limit, when the lattice becomes completely filled. This is readly seen from Eq. (7): except for the linear spin coupling, the other terms of the Hamiltonian become configuration independent for density $\rho=1$. Our results are consistent with Wannier's predictions, since at very high pressures both models presents a residual entropy in the ground state of the HDL phase [see Figs. 7(e) and 7(f)], and no phase transition at finite temperature.

We propose an extension of the application of the concept of frustration associated with the antiferromagnetic spin- $1 / 2$ Ising model on the triangular lattice to spin- 1 systems such as the ones treated in this study. For the BL model, the main effect of frustration is that it provides a natural restriction for the formation of a complete hydrogen-bonded network of molecules on the full lattice (or, analogously, of an antiferromagnetically coupled net of integer spins, in the BEG model). Considering the frustrated interactions to be "stronger" than the unfrustrated van der Waals interactions [i.e., that inequality (34) is satisfied], the appearance of a bonded structure of lower density $\rho<1$ at lower pressures is to be expected. The density anomaly which arises from the competition between the bonded and normal liquids may thus be assigned to frustration.

In order to further develop our ideas on the possible role of frustration, let us consider a different orientational lattice gas model (OLG) analyzed previously by one of us [39]. In the OLG model, molecules with four bonding and two inert arms sit on a triangular lattice. Energetic ingredients include hydrogen bonds and isotropic van der Waals interactions. Fully bonded nets are possible for a low-density state, as well as for the high-density state, and the model may thus be considered unfrustrated. However, the LDL phase is stable only if the "van der Waals" interaction is repulsive. Only in this case does the model present a liquid-liquid phase transition and a TMD line. It must be noted, however, that, unlike the BL model, the OLG model presents HDL and LDL phases of the same symmetry, with a liquid-liquid line ending in a critical point. The BL model presents two liquids with different symmetries and no critical point.

Despite the differences between the BL and the OLG models, it is possible to extend the idea of frustration to include the latter, by considering that repulsive van der Waals interactions introduce restrictions on the formation of a fully hydrogen-bonded network of molecules on the filled lattice. It would then be possible to classify all such systems as frustrated: either lattice frustrated, as would be the case of the BL and BEG models, or energetically frustrated, as in the case of the OLG model. Such a classification scheme for frustrated lattice models requires further clarification.

\section{CONCLUDING REMARKS}

The Bell-Lavis model for liquid water has been compared to its isotropic version: the antiferromagnetic Blume-EmeryGriffiths model on the triangular lattice. The ground state phase diagrams of the two models were shown to be topologically identical, with fluid phases (gas and low- and highdensity liquids) being equivalent to magnetic phases (paramagnet, antiferromagnet, and frustrated paramagnet). Finitetemperature effects have been considered by studying the system in the interior of the sequential Husimi cactus. Phase diagrams and maximum density lines in the high-density liquid phase were compared for equivalent values of the reduced interaction strength in both models. The anomalous features of the high-density liquid were shown to be very similar, with lines of maximum density occurring at equivalent pressures and temperatures. The stability of the LDL is substantially enhanced in the BL model, as compared to the BEG model. The larger LDL phase drives the anomalous behavior into a metastable regime of the HDL phase. For the isotropic BEG model, the line of maximum density, followed by anomalous response functions, occurs in the stable regime. The presence of these features in the BEG model shows that the orientational character of the hydrogen bond is unimportant for the anomalous behavior presented by the BL model, as observed in previous studies of continuous core-softened models $[19,62,63]$.

In both models, the density anomaly is accompanied by a large rate of variation in entropy and number of (generalized) hydrogen bonds per particle, and by anomalous behavior of the thermodynamical response functions.

We propose to explain the anomalous behavior presented by both models through a competition between two structured liquids. We suggest that this competition would arise due to energetic frustration related to restrictions imposed on the maximum number of bonds per triangle. We also propose that energetic frustration, as a natural restriction for the formation of favorable interactions, may be responsible for anomalous liquid properties on lattices. Further studies on different models and lattices (specially in three dimensions) are being planned to test the possible relation between frustration, density anomaly, and liquid-liquid phase transitions.

\section{ACKNOWLEDGMENTS}

We would like to thank S. Salinas, M. J. de Oliveira, J. Stilck, B. Widom, B. W. Southern, and D. A. Lavis for useful discussions and suggestions. M.A.A.B. acknowledges hospitality from R. Gargano and A. F. Pereira de Araujo, and the computational support from LCCC, during a visit to Universidade de Brasília. This work has been supported by FAPESP. 
[1] C. A. Angell and H. Kanno, Science 193, 1121 (1976).

[2] D. Eisenberg and W. Kauzmann, The Structure and Properties of Water (Clarendon Press, Oxford, 1969).

[3] P. G. Debenedetti, Metastable Liquids: Concepts and Principles (Princeton University Press, Princeton, NJ, 1996).

[4] P. G. Debenedetti, J. Phys.: Condens. Matter 15, R1669 (2003).

[5] R. J. Speedy, J. Phys. Chem. 86, 982 (1982).

[6] P. H. Poole, F. Sciortino, U. Essmann, and H. E. Stanley, Nature (London) 360, 324 (1992).

[7] D. J. Lacks, Phys. Rev. Lett. 84, 4629 (2000).

[8] Y. Katayama, T. Mizutani, W. Utsumi, O. Shimomura, M. Yamakata, and K. Funakoshi, Nature (London) 403, 170 (2000).

[9] G. Monaco, S. Falconi, W. A. Crichton, and M. Mezouar, Phys. Rev. Lett. 90, 255701 (2003).

[10] O. Mishima and H. E. Stanley, Nature (London) 392, 164 (1998).

[11] O. Mishima and H. E. Stanley, Nature (London) 396, 329 (1998).

[12] T. Loerting and N. Giovambattista, J. Phys.: Condens. Matter 18, R919 (2006).

[13] S. Sastry, P. G. Debenedetti, F. Sciortino, and H. E. Stanley, Phys. Rev. E 53, 6144 (1996).

[14] L. P. N. Rebelo, P. G. Debenedetti, and S. Sastry, J. Chem. Phys. 109, 626 (1998).

[15] I. Saika-Voivod, F. Sciortino, T. Grande, and P. Poole, Philos. Trans. R. Soc. London, Ser. A 363, 525 (2005).

[16] M. R. Sadr-Lahijany, A. Scala, S. V. Buldyrev, and H. E. Stanley, Phys. Rev. E 60, 6714 (1999).

[17] A. Scala, M. R. Sadr-Lahijany, N. Giovambattista, S. V. Buldyrev, and H. E. Stanley, Phys. Rev. E 63, 041202 (2001).

[18] E. A. Jagla, Phys. Rev. E 58, 1478 (1998).

[19] E. A. Jagla, J. Chem. Phys. 111, 8980 (1999).

[20] E. A. Jagla, Braz. J. Phys. 34, 17 (2004).

[21] G. Franzese, G. Malescio, S. V. B. Anna Skibinsky, and H. E. Stanley, Nature (London) 409, 692 (2001).

[22] G. Franzese, J. Mol. Liq. 136, 267 (2007).

[23] A. B. Oliveira, G. Franzese, P. A. Netz, and M. C. Barbosa, J. Chem. Phys. 128, 064901 (2008).

[24] H. M. Gibson and N. B. Wilding, Phys. Rev. E 73, 061507 (2006).

[25] E. Lomba, N. G. Almarza, C. Martin, and C. McBride, J. Chem. Phys. 126, 244510 (2007).

[26] G. M. Bell, J. Math. Phys. 10, 1753 (1969).

[27] A. B. de Oliveira and M. C. Barbosa, J. Phys.: Condens. Matter 17, 399 (2005).

[28] K. A. T. Silverstein, A. D. J. Haymet, and K. A. Dill, J. Am. Chem. Soc. 120, 3166 (1998).

[29] T. M. Truskett and K. A. Dill, J. Chem. Phys. 117, 5101 (2002).

[30] T. M. Truskett and K. A. Dill, J. Phys. Chem. B 106, 11829 (2002).

[31] F. L. Somer and J. Kovac, J. Chem. Phys. 102, 8995 (1995).

[32] K. A. T. Silverstein, A. D. J. Haymet, and K. A. Dill, J. Chem.
Phys. 111, 8000 (1999).

[33] G. M. Bell and D. A. Lavis, J. Phys. A 3, 568 (1970).

[34] D. A. Lavis, J. Phys. C 6, 1530 (1973).

[35] A. P. Young and D. A. Lavis, J. Phys. A 12, 229 (1979).

[36] B. W. Southern and D. A. Lavis, J. Phys. A 13, 251 (1980).

[37] C. J. Roberts and P. G. Debenedetti, J. Chem. Phys. 105, 658 (1996).

[38] C. J. Roberts, A. Z. Panagiotopoulos, and P. G. Debenedetti, Phys. Rev. Lett. 77, 4386 (1996).

[39] V. B. Henriques and M. C. Barbosa, Phys. Rev. E 71, 031504 (2005).

[40] V. B. Henriques, N. Guisoni, M. A. Barbosa, M. Thielo, and M. Barbosa, Mol. Phys. 103, 3001 (2005).

[41] M. Girardi, A. L. Balladares, V. B. Henriques, and M. Barbosa, J. Chem. Phys. 126, 064503 (2007).

[42] G. M. Bell, J. Phys. C 5, 889 (1972).

[43] G. M. Bell and D. W. Salt, J. Chem. Soc., Faraday Trans. 2 72, 76 (1976).

[44] M. Pretti and C. Buzano, J. Chem. Phys. 121, 11856 (2004).

[45] C. Buzano, E. D. Stefanis, A. Pelizzola, and M. Pretti, Phys. Rev. E 69, 061502 (2004).

[46] N. A. M. Besseling and J. Lyklema, J. Phys. Chem. 98, 11610 (1994).

[47] S. Sastry, F. Sciortino, and H. E. Stanley, J. Chem. Phys. 98, 9863 (1993).

[48] D. A. Lavis, J. Phys. A 8, 1933 (1975).

[49] G. Grigelionis and A. Rosengren, Physica A 208, 287 (1994).

[50] P. D. Gujrati, Phys. Rev. Lett. 74, 809 (1995).

[51] J. L. Monroe, Physica A 256, 217 (1998).

[52] M. Pretti, J. Stat. Phys. 111, 993 (2003).

[53] D. Tabor, Gases, Liquids and Solids (Cambridge University Press, Cambridge, U.K., 1991).

[54] It must be remembered that the interpolating Hamiltonian used in this work is a matter of choice. It would be possible, for instance, to interpolate between the BEG and BL Hamiltonians by considering an extended hydrogen bond interaction of the kind $g_{\mathrm{hb}}=-\epsilon_{\mathrm{hb}}\left[P_{\mathrm{LDL}}\left(S_{a}, S_{b}, S_{c}\right)+(1-\lambda) P_{\mathrm{ULDL}}\left(S_{a}, S_{b}, S_{c}\right)\right]$, with $P_{\mathrm{LDL}}$ and $P_{\mathrm{ULDL}}$ being the probability of finding the triangle's configuration in a low-density liquid state and in an unbonded low-density liquid state, described in Table I.

[55] A. Pelizzola and M. Pretti, Phys. Rev. B 60, 10134 (1999).

[56] A. Patrykiejew, O. Pizio, and S. Sokolowski, Phys. Rev. Lett. 83, 3442 (1999).

[57] G. Jaeger, Arch. Hist. Exact Sci. 53, 51 (1998).

[58] Z. F. Wang, B. W. Southern, and D. A. Lavis, Phys. Rev. B 67, 054415 (2003).

[59] B. W. Southern and D. A. Lavis (private communication).

[60] S. Bekhechi, B. W. Southern, A. Peles, and D. Mouhanna, Phys. Rev. E 74, 016109 (2006).

[61] G. H. Wannier, Phys. Rev. 79, 357 (1950).

[62] A. B. Oliveira, P. A. Netz, T. Colla, and M. C. Barbosa, J. Chem. Phys. 124, 084505 (2006).

[63] A. B. Oliveira, P. A. Netz, T. Colla, and M. C. Barbosa, J. Chem. Phys. 125, 124503 (2006). 



\section{Anexo II: Alternative hydrogen bond implementations produce opposite effects on collapse cooperativity of lattice homopolypeptide models}





\title{
Alternative hydrogen bond implementations produce opposite effects on collapse cooperativity of lattice homopolypeptide models
}

\author{
Gustavo M. N. Fleury \\ Instituto de Física, Universidade de Brasília, Brasília-DF 70910-900, Brazil \\ and Laboratório de Biologia Teórica, Departamento de Biologia Celular, Universidade de Brasília, Brasília-DF 70910-900, Brazil \\ Marco A. A. Barbosa \\ Instituto de Física Departamento de Física Geral, Universidade de São Paulo, São Paulo-SP 05508-900, Brazil \\ and Laboratório de Biologia Teórica, Departamento de Biologia Celular, Universidade de Brasília, Brasília-DF 70910-900, Brazil \\ Antônio F. Pereira de Araújo* \\ Laboratório de Biologia Teórica, Departamento de Biologia Celular, Universidade de Brasília, Brasília-DF 70910-900, Brazil
}

(Received 1 June 2007; published 20 November 2007)

\begin{abstract}
We use complete enumeration of self-avoiding chains of up to $N=26$ monomers in two-dimensional lattices to investigate the effect of alternative implementations of backbone hydrogen bonds on the cooperativity of homopolypeptide collapse. Following a recent study on protein folding models, we use the square lattice with $z=3$ local conformations per monomer and lattice extensions containing diagonal steps which result in $z=5$ or $z=7$ and assume that only a subset of $z_{h}<z$ local conformations is compatible with hydrogen bond formation. As previously observed in heteropolymeric folding, a significant increase in cooperativity, as measured by $\kappa_{2}$ values, results from the coupling between hydrogen bonds and hydrophobic interactions, in such a way that hydrophobic contacts are favorable only when contacting monomers are involved in hydrogen bond formation. For some $z / z_{h}$ combinations the energy distribution is bimodal at the collapse transition temperature. The situation can be regarded as if all hydrophobic contacts actually decrease the energy by the same amount, $2 h$, with the addition of an energetic increase, $\epsilon_{2}=h$, as a penalty for each contacting monomer not satisfying the hydrogen bond condition. Cooperativity is little affected and might even decrease, however, when hydrogen bonds produce a decrease in energy by the same amount, $\epsilon_{1}=h$, for each bonding monomer. For the more general situation when the hydrogen bond effect is not equal, in modulus, to the hydrophobic interaction, i.e., $\epsilon_{2} \neq h$ or $\epsilon_{1} \neq h$, we observe a pronounced increase in $\kappa_{2}$ for small $\epsilon_{2}$, with a maximum around $\epsilon_{2} / h \approx 1.5$, followed by a gradual decrease to a limiting value at large $\epsilon_{2}$. The opposite behavior is observed when $\epsilon_{1}$ is varied. The observed qualitative difference is shown to arise from opposite effects on the convexity of the total density of states of the system when subdensities corresponding to different numbers of hydrogen bonds are differently favored as opposed to the case when subdensities corresponding to different numbers of contacting monomers not forming hydrogen bonds are differently unfavored. Potential implications for the cooperativity of protein folding and protein unspecific collapse are discussed.
\end{abstract}

DOI: 10.1103/PhysRevE.76.051914

PACS number(s): 87.15.Cc, 87.10.+e

\section{INTRODUCTION}

We have recently observed that a significant increase in folding cooperativity can arise in protein lattice models when the formation of favorable hydrophobic interactions is coupled to an effective reduction in lattice coordination [1]. This scheme was intended to mimic the reduction in local conformational entropy resulting from the requirement that backbone polar groups must form hydrogen bonds upon insertion into the apolar protein core during the folding process. It was suggested, therefore, that hydrogen bonds might contribute significantly to protein folding two-state behavior. Since the underlying entropic effect is independent of sequence, a similar result could be expected to arise even for homopolymeric collapse or for the rapid unspecific contraction observed for some proteins upon a sudden environmental change from denaturing to folding conditions. Accordingly, the increase in cooperativity was actually more pronounced for collapse than for folding itself in one of the models for which the two transitions were not concomitant [1].
For several simple models investigated during the last decades, with no explicit consideration of hydrogen bonds or secondary structure, homopolymeric coil to globule transitions were found to be continuous, e.g., [2], as well as the initial unspecific collapse observed in some folding heteropolymeric models, e.g., [3-5], which is consistent with the theoretical prediction of a not cooperative, one-state, second-order collapse transition for flexible homopolymers [6-8]. It has also been known, both from theory and simulations, that collapse becomes a cooperative, two-state, firstorder transition for "stiff" polymers [6-10] and it is unclear how stiff a more realistic polypeptide model could be. Simulations with the " 210 " (or "knight") lattice, which is intended to be geometrically consistent with protein secondary structure [11], have also indicated, however, that the homopolypeptide collapse transition, when induced by a combination of uniformly attractive hydrophobic interactions with hydrogen bonds favoring $\alpha$-helix formation, could be reasonably sharp for some choices of parameters but not two state [12]. Langevin dynamic simulations of off-lattice, fold- 
ing heteropolypeptide models, with explicit consideration of favorable hydrogen bonds, have also found the transition from denatured to compact non-native conformations to be not cooperative [13]. It can be considered somewhat surprising, therefore, that experimentally observed time courses of rapid collapse for real proteins [14], and even some nonfolding heteropolypeptides [15], which only became technically possible during the last decade, were found to be consistent with a cooperative, barrier-crossing process, slower than expected for the continuous collapse of flexible polymers.

In the present study we perform an extensive investigation of the effect of alternative hydrogen bond implementations on collapse cooperativity of two-dimensional, exact, lattice homopolypeptide models. We are particularly interested in eventual qualitative thermodynamic differences resulting from distinct assumptions about the dominant net enthalpic contribution of hydrogen bond formation for the stability protein structures. An interesting debate on this issue has taken place in the literature for many years, as reviewed in [16]. Easily implementable, energetically favorable models of hydrogen bonds $[12,13]$ implicitly assume that internal bonds in proteins, between backbone polar groups, are enthalpically more favorable than external bonds, between these groups and water, and do not account for the cost of burying unpaired polar groups. Alternatively, as in the implementation used in our previous study [1], it might be assumed that internal and external bonds are enthalpically similar but the burial of unpaired polar groups is significantly unfavorable [17-19]. Note that both assumptions, although disagreeing about the stability of hydrogen bonds in an aqueous environment, are consistent with enthalpically favorable hydrogen bonds inside the apolar core of protein globules [20] and, therefore, with the plausible hypothesis of a significant reduction in the number of compact relevant conformations imposed by hydrogen bond formation, as corroborated by recent lattice [21,22] and off-lattice simulations [23-25].

We presently observe, however, that very simple models intended to capture these two alternative assumptions might actually display opposite effects regarding the thermodynamic cooperativity of collapse, as measured by the $\kappa_{2}$ parameter proposed by Chan and collaborators [26,27], indicating that this apparently subtle difference might be even more relevant for cooperativity than the geometric details of the polymer chain. The observed qualitative difference is shown to arise from opposite effects on the convexity of the total density of states of the system when subdensities corresponding to different numbers of hydrogen bonds are differently favored as opposed to the case when subdensities corresponding to different numbers of contacting monomers not forming hydrogen bonds are differently unfavored.

\section{EXTENDED LATTICE POLYMER MODEL}

As in our previous study [1], we use the square lattice with $z=3$ local conformations per monomer and lattice extensions containing diagonal steps which result in $z=5$ and $z=7$ and assume that only a subset of $z_{h}<z$ local conformations is compatible with hydrogen bond formation (Fig. 1). We use the term "coordination" for this number of possible

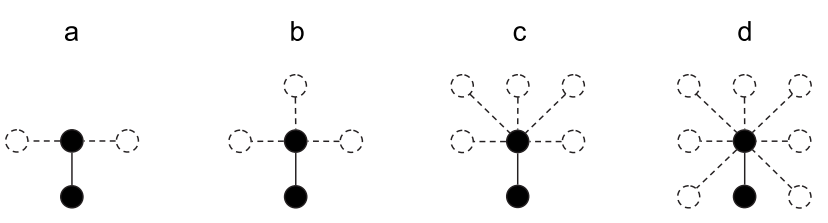

FIG. 1. Possible steps between adjacent beads. In addition to the four vectors $( \pm 1,0)$ and $(0, \pm 1)$ of the usual square lattice, four diagonal vectors $( \pm 1, \pm 1)$ might also be allowed, resulting in variable numbers of local conformations per monomer, or coordination $z$, as well as two possible distances between adjacent monomers, i.e., 1 and $\sqrt{2}$ lattice units. The figure represents with dotted lines the possible positions for the insertion of a third monomer in a polymer chain, for different values of $z$ used in the present study, after the two previous monomers, represented as filled circles, have already been placed. (a) The lattice with very low coordination $z$ $=2$, with no diagonal steps and adjacent bonds always forming an angle of $90^{\circ}$. (b) The usual square lattice with coordination $z=3$, with no diagonal steps. (c) The extended lattice with coordination $z=5$, with diagonal steps but with no angles between adjacent bonds smaller than $90^{\circ}$. (d) The extended lattice with coordination $z=7$, in which all diagonal steps are allowed with no angle restriction. For a given $z / z_{h}$ combination, $z$ defines the set of allowed local conformations for each monomer while $z_{h}<z$ defines the subset of local conformations assumed to be compatible with hydrogen bond formation.

local conformations, $z$ or $z_{h}$. For each $z / z_{h}$ combination, we now consider two alternative definitions of hydrogen bond ( $\alpha$ and $\beta$ ) and, for each of them, two alternative forms of energetic contribution to be added to the uniformly attractive hydrophobic interactions. According to definition $\alpha$, a hydrogen bond is simply counted for each monomer adopting one of the $z_{h}$ local conformations, independently of the local conformation of any eventual contact partner. It can be imagined that in this case the hydrogen bond interaction is satisfied locally, as in $\alpha$ helices. According to definition $\beta$ which, in this sense, loosely resembles $\beta$ sheets, a hydrogen bond is counted only when both monomers forming a contact adopt one of the $z_{h}$ local conformations. $\alpha$ and $\beta$ definitions do not differ in the specific $z_{h}$ local conformations assumed to be compatible with hydrogen bond formation, as would be the case in a more realistic consideration of protein secondary structures. Note that since possible step vectors for the extended lattices are not all equal in length, the distance between two given adjacent beads "fluctuates" between 1 and $\sqrt{2}$ lattice units, resembling therefore other "fluctuating bond" polymer models previously used in protein folding studies, e.g., [28]. The use of variable distances to model a polypeptide system, in which virtual bonds between adjacent $C_{\alpha}$ atoms are known to be constant, might be considered as a small price to be paid in order to overcome intrinsic limitations of the lattice to otherwise reproduce other properties of real polypeptides expected to be relevant for the problem under investigation, such as geometrically realistic protein backbone conformations [28] or, as in the present study, a large reduction in local conformational entropy upon hydrogen bond formation [1].

The two forms for the energetic contribution from hydrogen bonds are intended to reflect alternative assumptions re- 
garding the net enthalpic effect of these interactions in protein structures. In the simplest implementation, which is called $E_{1}$ in the present study, the energy of the model is decreased by a fixed amount, $\epsilon_{1}$, for each monomer involved in a hydrogen bond. It is implicitly assumed, therefore, that internal bonds, between protein backbone polar groups, are enthalpically more favorable than external bonds, between these groups and water, by a fixed amount which is independent of their local environment. The unavoidable decrease in the number of available water molecules resulting from monomer burial or, equivalently, the cost of burying unpaired polar groups, is therefore neglected. In the second implementation, which is called $E_{2}$, it is assumed that internal and external bonds are enthalpically equivalent but the burial of unpaired polar groups is unfavorable. Accordingly, the energy of the model is increased by an amount $\epsilon_{2}$ for each monomer involved in a contact for which a hydrogen bond is not satisfied. Hydrophobic interactions for each monomer $i$ are always implemented simply as a decrease in energy by the fixed amount $h$ for each contact in which it is involved, independently of hydrogen bond formation.

More specifically, the two energy functions are

$$
E_{1}=\sum_{i=1}^{N}\left(-h c_{i}-\epsilon_{1} b_{i}\right)=-h C-\epsilon_{1} B
$$

and

$$
E_{2}=\sum_{i=1}^{N}\left(-h c_{i}+\epsilon_{2} c_{i}^{\prime \prime}\right)=-h C+\epsilon_{2} C^{\prime \prime}
$$

where the sum is over all monomers, labeled by $i, c_{i}$ is the total number of contacts in which monomer $i$ is involved, with $\Sigma_{i} c_{i}=C$ being 2 times the total number of contacts, $b_{i}$ is the number of hydrogen bonds in which it is involved, with $\Sigma_{i} b_{i}=B$ being the total number of $\alpha$ hydrogen bonds or 2 times the total number of $\beta$ hydrogen bonds, and $c_{i}^{\prime \prime} \leq c_{i}$ is the number of contacts counted in $c_{i}$ for which a hydrogen bond is not satisfied, with $\sum_{i} c_{i}^{\prime \prime}=C^{\prime \prime}$. The two energy forms can be considered as particular examples of the more general expression

$$
E=\sum_{i=1}^{N}\left(-h c_{i}-\epsilon_{1} b_{i}+\epsilon_{2} c_{i}^{\prime \prime}\right)
$$

but we have not investigated the general situation in which both $\epsilon_{1} \neq 0$ and $\epsilon_{2} \neq 0$. When $\epsilon_{1}=\epsilon_{2}=0$ the situation is trivially reduced to the original hydrophobic function $E=-\vec{h} \cdot \vec{c}$ $[29,30]$ which becomes $E=-h C$ for the present homopolymer case.

Combining the two definitions of hydrogen bond with Eqs. (1) and (2) we obtain four model possibilities for each $z / z_{h}$ combination: $\alpha_{1}, \alpha_{2}, \beta_{1}$, and $\beta_{2}$. According to definition $\alpha$ the presence or absence of a hydrogen bond depends only on the local conformation of a single monomer and is independent of any contact formation. There are, therefore, only two possible numbers of hydrogen bonds for each monomer $i, b_{i}=0$, and $b_{i}=1$. Even for the extended lattices, we only consider monomer $j$ to form a contact with monomer $i, 1$
$<i<N$, if $|j-i|>1$ and if monomer $j$ occupies one of the four nearest-neighbor sites of the site occupied by monomer $i$. While for $z=2$ and $z=3$ only two of these sites might be occupied by other monomers than neighboring $i-1$ and $i$ +1 , which implies $0 \leq c_{i} \leq 2$, for the extended lattices with $z=5$ and $z=7$ all these four sites might be occupied by nonneighboring monomers, or $0 \leq c_{i} \leq 4$. The number of contacts for which a hydrogen bond is not satisfied for the $\alpha$ definition is either $c_{i}^{\prime \prime}=c_{i}$, when $b_{i}=0$, or $c_{i}^{\prime \prime}=0$, when $b_{i}=1$. Note that only for $\alpha_{1}$ there are energetically favorable conformations with no contacts, i.e., when $C=0$ and $B>0$. This situation would be analogous to stable $\alpha$ helices in the absence of long-range interactions. For $\alpha_{2}$, on the other hand, $C=0$ implies $E=0$, since $C^{\prime \prime} \leq C$.

According to definition $\beta$ the presence or absence of a hydrogen bond depends on the local conformation of both monomers involved in a contact. In this case $b_{i}$ is counted as the number of contacts satisfying the hydrogen bond condition in which monomer $i$ is involved and $c_{i}^{\prime \prime}=c_{i}-b_{i} . b_{i} \leq c_{i}$ can, in particular, be larger than 1 . Note that if $\epsilon_{2}=h$ in Eq. (2) the energy reduces to

$$
E_{2}=\sum_{i=1}^{N}-h\left(c_{i}-c_{i}^{\prime \prime}\right)=\sum_{i=1}^{N}-h c_{i}^{\prime}=-h C^{\prime},
$$

where $c_{i}^{\prime} \equiv c_{i}-c_{i}^{\prime \prime}$ is the number of "viable" contacts, with $\Sigma_{i} c_{i}^{\prime}=C^{\prime}$, which corresponds to the expression used in our previous study [1]. It might also be convenient to call the contacts counted in $c_{i}^{\prime \prime}$ as "not viable." Note that only for the $\beta$ definition the number of viable contacts coincides with the number of hydrogen bonds, i.e., $c_{i}^{\prime}=b_{i}$. For the $\alpha$ definition we have either $c_{i}^{\prime}=0$, when $b_{i}=0$, or $c_{i}^{\prime}=c_{i}$, when $b_{i}=1$. Also note from Eqs. (1), (2), and (4) that hydrophobic interactions for $E_{2}$, but not for $E_{1}$, are effectively "coupled" to hydrogen bond formation, in the sense that the hydrophobicity of each monomer effectively depends on whether or not it is forming a hydrogen bond. For this reason we also refer to energy schemes $E_{1}$ and $E_{2}$ as corresponding to "uncoupled" and "coupled" hydrogen bonds, respectively. $\alpha$ and $\beta$ hydrogen bonds, both coupled and uncoupled, are illustrated in Fig. 2 for a particular structure of 16 monomers with $z / z_{h}=7 / 3$. An assumed dependence of effective hydrophobicity on hydrogen bond formation has been recently investigated in the context of a geometrically realistic off-lattice protein model [31].

\section{RESULTS}

In the present study we fix the value of the hydrophobic interaction, $h$, as the unit of energy and investigate the thermodynamic behavior of the models as a function of the hydrogen bond strength, $\epsilon_{1}$ or $\epsilon_{2}$, and chain length, $N$. Complete enumeration of the conformational space of the four models $\left(\alpha_{1}, \alpha_{2}, \beta_{1}\right.$, and $\left.\beta_{2}\right)$ was performed for all combinations of $z / z_{h}$, for chain lengths of sizes up to $N=26(z=3$ and $z=2), N=18(z=5)$ and $N=16(z=7)$. Cooperativity is quantified by $\kappa_{2}$, as proposed by Chan and co-workers [26,27], which is intended to be analogous to the ratio between experimental van't Hoff and calorimetric unfolding enthalpies 


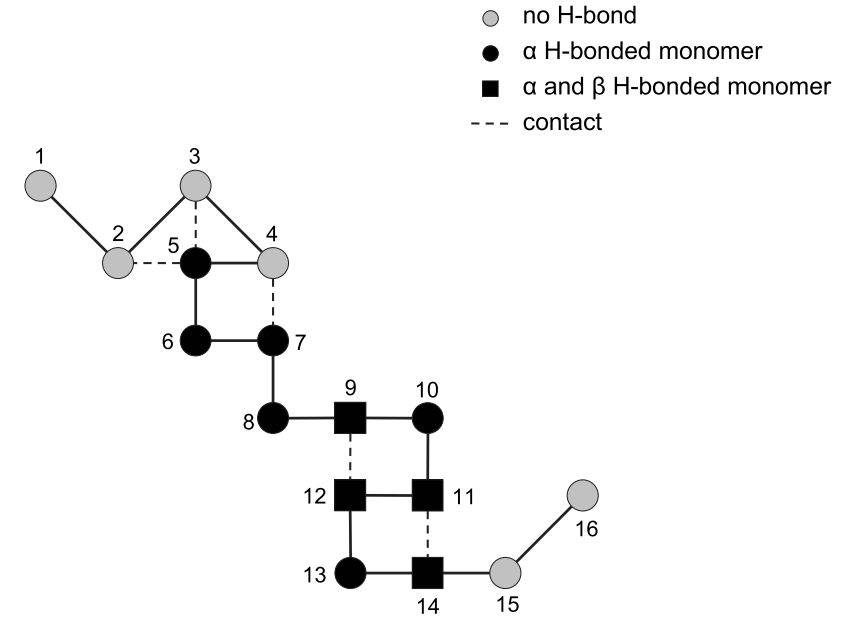

FIG. 2. Illustration of $\alpha$ and $\beta$ hydrogen bonds, both coupled and uncoupled, for $z / z_{h}=7 / 3$ in a conformation of 16 monomers. Diagonal steps are allowed, because $z=7$, but, since $z_{h}=3$, only monomers 5 to 14 , which are connected to both neighbors by nondiagonal steps, are assumed to be compatible with hydrogen bond formation. According to the $\alpha$ definition of hydrogen bond, therefore, one hydrogen bond is counted for each of these monomers, which are colored black. From these 10 compatible monomers only monomers $9,11,12$, and 14, shown as squares, are also contacting compatible monomers and, therefore, are the only monomers involved in hydrogen bond formation according to the $\beta$ definition. For this structure, $C=10$ is 2 times the total number of contacts. In order to use Eqs. (1) and (2) to compute the energy of this conformation for $\epsilon_{1}=h=1$ or $\epsilon_{2}=h=1$ we note that, for the $\alpha$ definition, $B=10$ and $C^{\prime \prime}=c_{2}^{\prime \prime}+c_{3}^{\prime \prime}+c_{4}^{\prime \prime}=1+1+1=3$, resulting in $E_{1}^{\alpha}=-20$, for uncoupled hydrogen bonds, and $E_{2}^{\alpha}=-7$, for coupled hydrogen bonds. For the $\beta$ definition $B=4$ and $C^{\prime \prime}=c_{2}^{\prime \prime}+c_{3}^{\prime \prime}+c_{4}^{\prime \prime}+c_{5}^{\prime \prime}+c_{7}^{\prime \prime}=1+1$ $+1+2+1=6$, resulting in $E_{1}^{\beta}=-14$ and $E_{2}^{\beta}=-4$ for coupled and uncoupled hydrogen bonds, respectively.

[32]. In our notation, with model energies assumed to correspond to experimental enthalpies, the expression for $\kappa_{2}$ is $[1,30]$,

$$
\kappa_{2}=\frac{\Delta H_{\mathrm{vH}}}{\Delta H_{\mathrm{cal}}}=\frac{2 T_{\max } \sqrt{C_{V}\left(T_{\max }\right)}}{\Delta E^{*}},
$$

where $C_{V}\left(T_{\max }\right)$ is the heat capacity at temperature $T_{\max }$, where its peak is located, and the calorimetric enthalpy $\Delta H_{\text {cal }}=\Delta E^{*}$ is now the difference between the average energy at infinite temperature, which must be computed for each model, and the minimal energy. The heat capacity for some models displays two peaks and in this case two $\kappa_{2}$ values are computed although only the larger value is usually considered for analysis. Note that $\kappa_{2}$ values close to 1 , which are considered to resemble proteinlike cooperativity, imply a bimodal energy distribution at the transition temperature. The reverse is not necessarily true, however, when the positions of the energy peaks happen to be significantly dependent on temperature $[27,33]$. Cooperativity measured by $\kappa_{2}$, as in the present study, has also been called "calorimetric cooperativity" $[26,27,30,33]$ in order to be distinguished from previously used, less restrictive criteria based on the "abruptness" of the transition, e.g., [34].

Figure 3(a) shows collapse cooperativity as a function of chain length for the four lattice variations used in the present study, with no hydrogen bonds. For each coordination value, $z, \kappa_{2}$ tends to decrease with chain length at small $N$ but no clear dependence is observed for $N \gtrsim 15$ for $z=3$ and $z=2$ while for $z=5$ and $z=7$ large conformational spaces have prevented enumeration for $N>18$ and $N>16$, respectively. Cooperativity also tends to increase as $z$ decreases, being as high as 0.6 for $z=2$, with $N=20$. The average number of contacts as a function of temperature for different values of $z$ and fixed chain size, $N=16$, is shown in Fig. 3(b). Heat capacity curves for these four models, normalized through the division by $\left(\Delta E^{*}\right)^{2}$, are shown in Fig. 3(c). Note, from Eq. (5), that the normalization procedure permits direct comparison between cooperativity values for the different curves. Decreasing lines in the same plot indicate the height of a normalized heat capacity peak that would correspond to specific $\kappa_{2}$ values at different temperatures. Energy distributions, which in the present case are identical in shape to contact distributions, at the temperature of the major heat capacity peak are shown for the same models in Fig. 3(d).

Some oscillations along $N$ are apparent in Fig. 3(a) and they can be partly attributed to the existence of a second peak in the heat capacity curve interfering with the relevant collapse peak at specific chain sizes, an extreme example of which is illustrated by the normalized heat capacity curves for $z=3$ shown in Fig. 4(a). Note that in addition to the primary peak corresponding to chain collapse a secondary peak might appear at a small temperature for some values of $N$, as illustrated by the curve for $N=20$. When this is the case, a corresponding second cooperativity value, smaller than the collapse cooperativity from the major peak, can also be computed. For $N=9$ and $N=12$, however, the primary peak is masked by this secondary peak, virtually disappearing in the first case and becoming a shoulder in the second, and only the cooperativity of the secondary peak can be computed. As seen in Fig. 4(b), $\kappa_{2}$ values observed for these chain sizes are unexpectedly low when compared to the rest of the curve shown in Fig. 3(a), which displays only the largest cooperativity value for each $N$, but are consistent with values for the secondary peak.

In order to investigate the effect of hydrogen bond implementations, $\alpha_{1}, \alpha_{2}, \beta_{1}$, and $\beta_{2}$, for different $z / z_{h}$ combinations, on collapse cooperativity we computed $\kappa_{2}$ values for these models with varying $N$ and fixed $\epsilon_{1}=1$ or $\epsilon_{2}=1$ and also with varying hydrogen bond strength and fixed $N$. On the left-hand side of Fig. 5 we observe the behavior of $\kappa_{2}$ as a function of $N$ for (a) $z / z_{h}=7 / 3$ and (c) $z / z_{h}=5 / 3$, with different lines corresponding to different hydrogen bond implementations. In order to facilitate the comparison between different curves, cooperativity for simple collapse, with no hydrogen bonds, in lattices corresponding to $z$ (lower dotted line) and $z_{h}$ (upper dotted line), reproduced from Fig. $3(\mathrm{a})$, are also plotted in these two panels. For this somewhat arbitrary choice of hydrogen bond "strength" the $\beta_{2}$ implementation is consistently the most cooperative, followed by $\alpha_{2}, \beta_{1}$, and $\alpha_{1}$. For $z / z_{h}=7 / 3$, as seen in Fig. 5(a), $\kappa_{2}$ is around 0.6 for the $\beta_{2}$ implementation and $N=16$, which rep- 

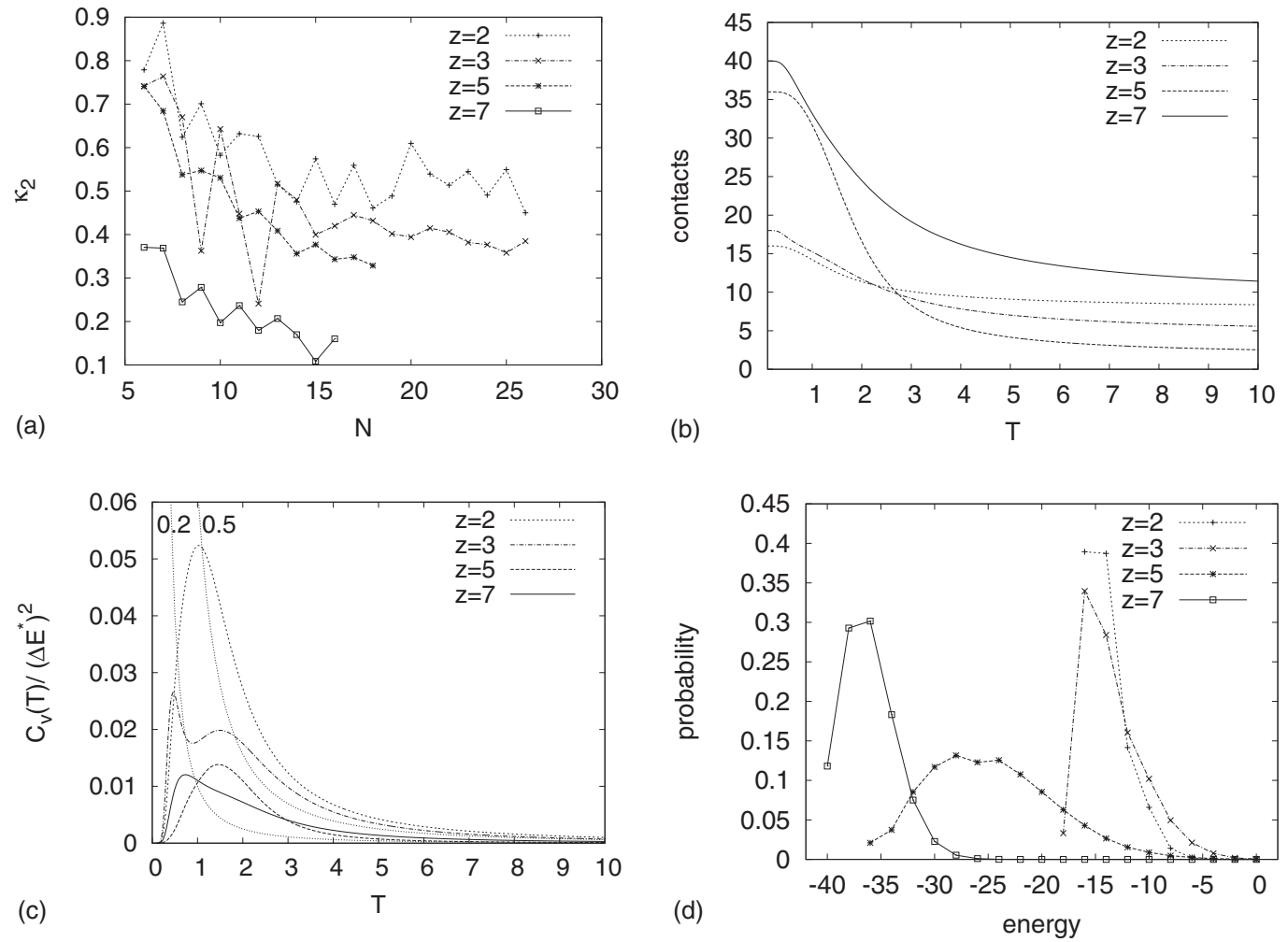

FIG. 3. Thermodynamic characterization of collapse for simple homopolymers, without hydrogen bonds, for different coordination's $z$. (a) $\kappa_{2}$ dependence on chain size with different lines corresponding to different coordination's $z$. (b) The average number of contacts as a function of temperature, (c) the normalized heat capacity, $C_{V}(T) /\left(\Delta E^{*}\right)^{2}$, as a function of temperature, and the equilibrium energy distribution at $T_{\max }$, the temperature of the primary heat capacity maximum is shown for different values of $z$ and fixed $N=16$. Decreasing lines in (c) indicate the height of a normalized heat capacity corresponding to the indicated cooperativity values.

resents a significant increase when compared to values lower than 0.2 observed in the simple collapse for $z=7$ and the same chain size, or to values around 0.4 observed for the square lattice with $z=3$. $\kappa_{2}$ values around 0.4 for $N=16$ are also observed for the $\alpha_{2}$ implementation. For the $\beta_{1}$ implementation the whole curve is very similar to the dotted line corresponding to the simple collapse for $z=7$ while $\kappa_{2}$ values tend to be even smaller than this low reference line for the $\alpha_{1}$ implementation. As seen in Fig. 5(c), $\kappa_{2}$ values for large $N$ are also around 0.6 for the $\beta_{2}$ implementation when $z / z_{h}$ $=5 / 3$. The general behavior observed for $z / z_{h}=7 / 3$ and $z / z_{h}=5 / 3$ is also very similar to what was found for lattice reductions $z / z_{h}=7 / 2$ and $z / z_{h}=5 / 2$, respectively (not shown). Cooperativity for small effective reductions in lattice coordination, either $z / z_{h}=7 / 5$ or $z / z_{h}=3 / 2$, is always lower than for the original square lattice (not shown).

The effect of hydrogen bond strength on cooperativity for different models is shown on the right-hand side of Fig. 5 for (b) $z / z_{h}=7 / 3$ and (d) $z / z_{h}=5 / 3$, with different lines in each panel corresponding to different hydrogen bond implementations. The value of $N$ in these two panels corresponds to the maximal chain size for which enumeration was performed for the particular lattice reduction, i.e., (b) $N=16$ and (d) $N$ $=18$. The common initial cooperativity value for all curves, at $\epsilon=0$, corresponds to the lattice with coordination $z$ and no hydrogen bonds. It is apparent that the general behavior of the curves in these two panels is more strongly determined by the energy definitions, $E_{1}$ or $E_{2}$, corresponding to the absence or presence, respectively, of coupling between hydrogen bonds and hydrophobic interactions, than on the particular definition of hydrogen bond, $\alpha$ or $\beta$. For all models with coupled interactions, there is a peak of cooperativity somewhere in the range $1 \lesssim \epsilon_{2} \lesssim 3$ followed by a monotonic decrease for large $\epsilon_{2} . \alpha_{2}$ hydrogen bonds tend to result in slightly broader and right-shifted peaks when compared to $\beta_{2}$ hydrogen bonds. In the case of uncoupled interactions, on the other hand, maximal cooperativity appears to be approached asymptotically as $\epsilon_{1}$ increases. The contrasting behavior of coupled versus uncoupled interactions is clearly visualized for (b) $z / z_{h}=7 / 3$, in which case sharp cooperativity peaks are observed for $\beta_{2}$ and $\alpha_{2}$ hydrogen bonds, reaching values of $\kappa_{2} \approx 0.6$ at $\epsilon_{2} \approx 1$ and $\kappa_{2} \approx 0.45$ at $\epsilon_{2} \approx 1.5$, respectively, while no peaks are observed for uncoupled interactions. $\kappa_{2}$ maximal values for large $\epsilon_{1}$ are around 0.6 and 0.3 for $\beta_{1}$ and $\alpha_{1}$ hydrogen bonds, respectively. Similar behavior is observed for (d) $z / z_{h}=5 / 3$, but in this case not only $\beta_{2}$ and $\beta_{1}$, but also $\alpha_{2}$ shows cooperativity as high as $\kappa_{2} \approx 0.6$. Note that cooperativity tends to decrease, or remain constant, in an initial model-dependent range of small hydrogen bond strengths.

Since the highest values of $\kappa_{2}$ observed for these models are never higher than 0.6 and, therefore, still low when compared to proteinlike folding cooperativity of $\kappa_{2} \approx 1$, it is important to verify if the large variations in $\kappa_{2}$ values shown in 

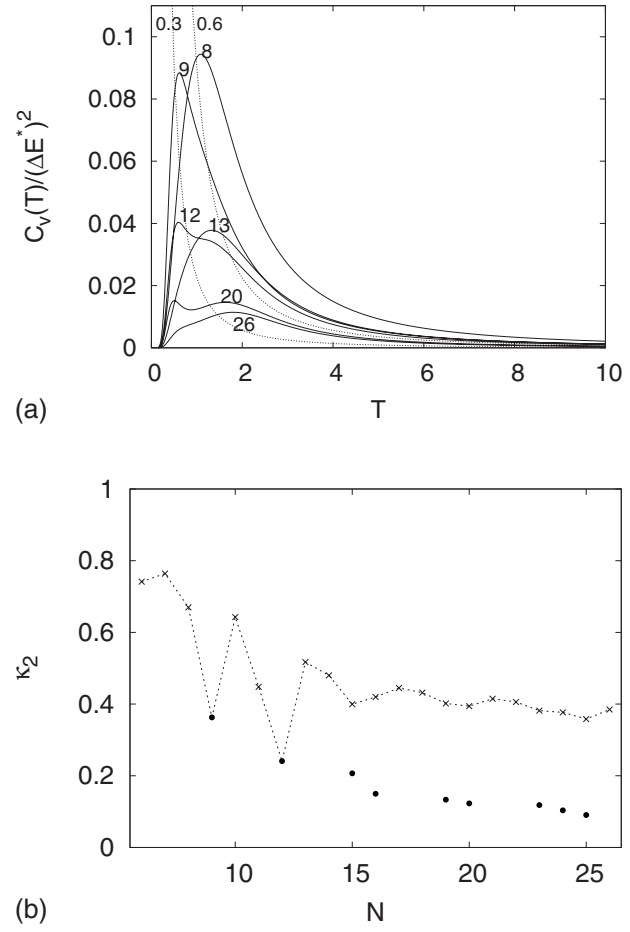

FIG. 4. Cooperativity dependence on chain size for the simple homopolymer, without hydrogen bonds, in the square lattice, corresponding to $z=3$. (a) Normalized heat capacity curves are shown for selected chain lengths, $N$, as indicated near each curve, with decreasing dotted lines corresponding to the height of normalized heat capacity peaks that would correspond to $\kappa_{2}=0.3$ and $\kappa_{2}=0.6$. (b) Calorimetric cooperativity, $\kappa_{2}$, for primary (crosses) and secondary (filled dots) heat capacity peaks as a function of the polymer size. The dashed line connecting the largest values for each $N$ is the line shown in Fig. 3(a) for $z=3$.

Fig. 5 do indeed reflect qualitatively different thermodynamic behaviors, from continuous, one-state, collapse transitions for small $\kappa_{2}$ values, to cooperative, two-state, transitions for large $\kappa_{2} \approx 0.6$. Equilibrium energy distributions at increasing temperatures might be used to verify this hypothesis, since one-state transitions, characterized by a continuous shift of a unimodal energy distribution, will be distinguishable from redistribution between modes of a bimodal distribution, which characterizes two-state transitions. In Fig. 6 we show the temperature dependence of the energy equilibrium distributions for the four hydrogen bond implementations, with (a)-(d) $z / z_{h}=7 / 3$ and $\epsilon_{1}=1$ or $\epsilon_{2}=1$, as well as (e) and (f) $\beta_{1}$ and $\beta_{2}$ with $\epsilon_{1}=3$ or $\epsilon_{2}=3$. Note that each panel, therefore, corresponds to a single point in the curves shown in Fig. 5(b), as indicated by matching symbols in both figures. Each panel in Fig. 6 shows the energy distribution at the temperature of maximal heat capacity, $T_{\max }$, as a histogram and five other distributions, from left to right, corresponding to the temperatures at which 10\%, 25\%, 50\%, 75\%, and $90 \%$ of the total heat of the transition has already been absorbed. The $\kappa_{2}$ value for the corresponding model is also indicated, as well as the matching symbol referring to Fig. 5 (b). Consistently with their very low $\kappa_{2}<0.2$ values, it is clear that distributions for (a) $\alpha_{1}$ and (c) $\beta_{1}$, for $\epsilon_{1}=1$, con- tinuously shift to higher energies as temperature increases, as expected for a not cooperative, one-state transition. For (d) $\beta_{2}$, with high $\kappa_{2} \approx 0.6$, a two-state transition is apparent from the redistribution among modes of a bimodal distribution. Also note that for (d) $\beta_{2}$, but not for (a) $\alpha_{1}$ or (c) $\beta_{1}$, the distribution at $T_{\max }$ is almost coincident with the distribution corresponding to $50 \%$ of the heat already absorbed and it is bimodal. This coincidence between these two distributions is also observed for (b) $\alpha_{2}$, with $\kappa_{2} \approx 0.4$, but in this case it is not bimodal. The increase in $\kappa_{2}$ for $\beta_{1}$ when hydrogen bonds become strong, when compared to hydrophobic interactions, is indeed related to a qualitative change to a two-state transition, as illustrated for (e) $\epsilon_{2}=3$. The decrease in $\kappa_{2}$ for $\beta_{2}$ in this regime, on the other hand, appears to result primarily from a significant amount of heat still absorbed after the transition has taken place and not from a change to a onestate transition, as illustrated for (f) $\epsilon_{2}=3$. Low $\kappa_{2}$ values associated to a strong temperature dependence of the highenergy mode in bimodal energy distributions have already been described for protein models $[33,35]$.

\section{DISCUSSION}

The effect of alternative implementations of hydrogen bonds on the collapse cooperativity of homopolypeptides was investigated by complete enumeration of twodimensional self-avoiding chains restricted to different lattices. Despite obvious limitations such as short chain lengths, lack of geometric detail, and space dimensionality, these models are consistent with a significant reduction in local conformational entropy upon hydrogen bond formation, which is an expected property of real hydrogen bonds between different groups of a single polypeptide chain. Additionally, their simplicity permits an extensive investigation of two alternative basic assumptions about the net enthalpic contribution from hydrogen bonds to the stability of protein structures. Interestingly, it is shown that collapse cooperativity might be strongly dependent on these assumptions.

The dependence of collapse cooperativity on lattice coordination $z$ for the simple homopolymer models, with no hydrogen bonds, is likely to be related to chain stiffness, since for a given chain length cooperativity increases as $z$ decreases, as seen in Fig. 3(a), while stiffness might be expected to increase. Other more specific lattice details which, in addition to $z$, might also contribute to chain stiffness are not able, therefore, to affect the expected order of cooperativity for the models under investigation. The somewhat unexpected order, if based on $z$ alone, of average number of contacts at high temperatures for the four lattices, on the other hand, like the apparently small number for $z=5$ and high number for $z=2$ shown in Fig. 3(b), are likely to reflect more specific details of the lattice, such as the values of possible angles between adjacent bonds.

The level of cooperativity obtained with different hydrogen bond implementations for a given value of lattice coordination reduction, $z / z_{h}$, and $\epsilon_{1}=1$ or $\epsilon_{2}=1$, does not appear to be trivially related to the cooperativity obtained for the simple homopolymers in lattices with coordination's $z$ or $z_{h}$, as shown on the left-hand side of Fig. 5. For models with a 

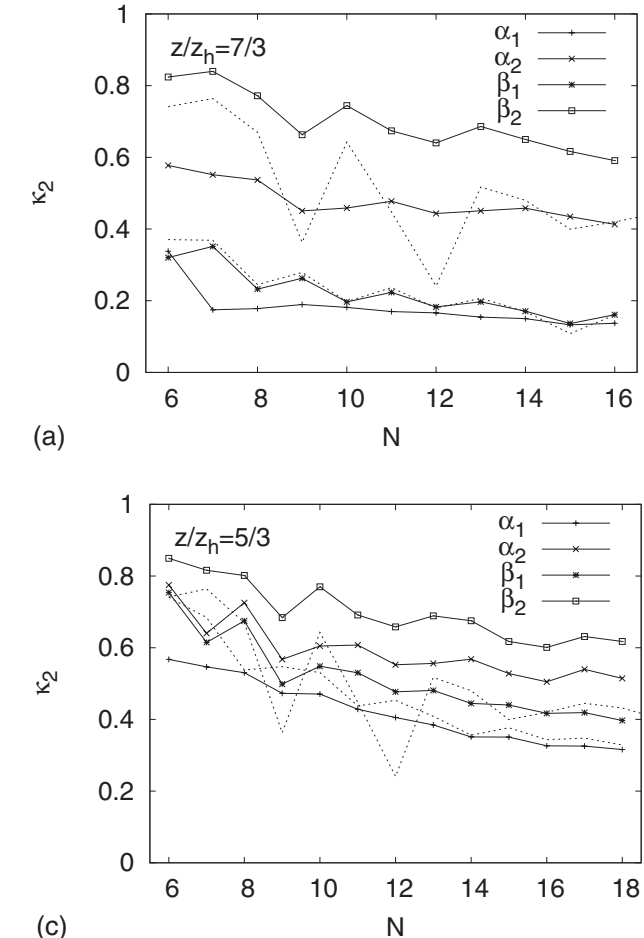
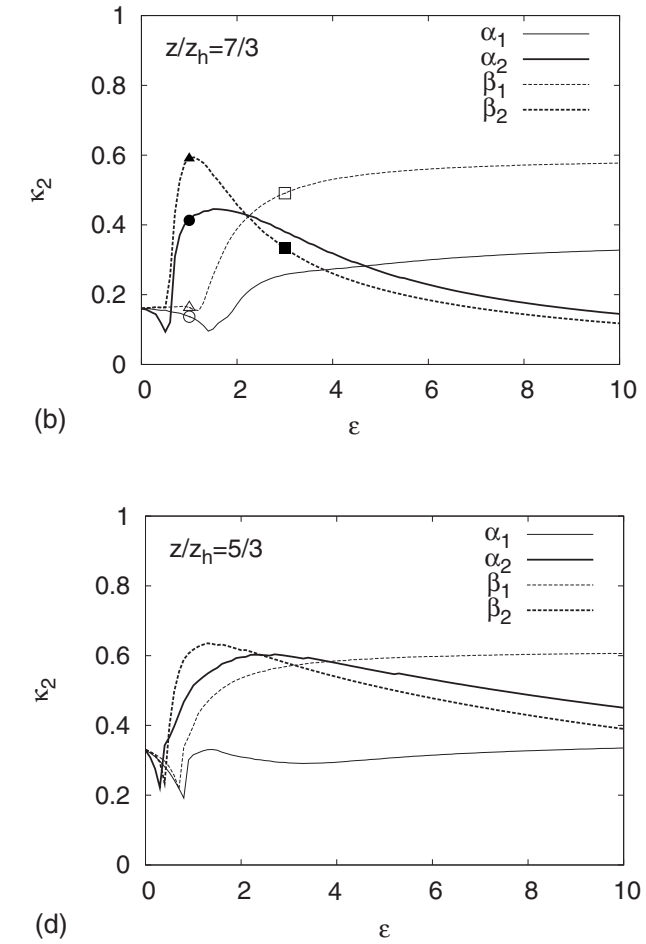

FIG. 5. $\kappa_{2}$ dependence on chain size, $N$ [left-hand side (a) and (c)], and hydrogen bond strength, $\epsilon_{1}$ or $\epsilon_{2}$ [right-hand side (b) and (d)], for different hydrogen bond implementations $\left(\alpha_{1}, \alpha_{2}, \beta_{1}\right.$, and $\left.\beta_{2}\right)$. Hydrogen bond strength in (a) and (c) is equal, in modulus, to the hydrophobic interaction, $\epsilon_{1}=1$ or $\epsilon_{2}=1$. Chain length is $N=16$ in (b) and $N=18$ in (d). Each panel corresponds to a given lattice reduction: $z / z_{h}=7 / 3$ [first row (a) and (b)] and $z / z_{h}=5 / 3$ [second row (c) and (d)]. For comparison, curves corresponding to simple homopolymer collapse, without hydrogen bonds, are also shown with dotted lines in (a) and (c) for lattices with coordination $z$ (lower) and $z_{h}$ (upper). Symbols in (b) indicate the points that were used to calculate energy distributions in Fig. 6 and densities of states in Fig. 7.

large reduction $\left(z / z_{h}=7 / 3, z / z_{h}=7 / 2, z / z_{h}=5 / 3\right.$, and $z / z_{h}$ $=5 / 2) \beta_{2}$ hydrogen bonds result in higher cooperativity than for the simple homopolymer in the lattice with coordination $z=3$ or $z=2$, while for $\alpha_{2}$ hydrogen bonds cooperativity tends to be similar or slightly higher than for the lattice with coordination $z=3$ although lower than for the lattice with small coordination $z=2$. Coupled hydrogen bonds, therefore, when $\epsilon_{2}=1$, clearly tend to increase cooperativity with respect to the collapse of simple homopolymers in the original square lattice. The situation is reversed for uncoupled hydrogen bonds, with $\epsilon_{1}=1$, since in this case cooperativity tends to be similar or even smaller than for simple flexible homopolymers in high coordination lattices $z=5$ or $z=7$.

The stronger dependence of the qualitative behavior of the system on the energy function definition, coupled versus uncoupled, than on the hydrogen bond definition, $\alpha$ versus $\beta$, is even more evident on the effect of hydrogen bond strength on collapse cooperativity shown on the right-hand side of Fig. 5. Also note that in geometrically realistic protein models only the energy definition is likely to be open to choice, since both $\alpha$ and $\beta$ hydrogen bonds should naturally arise in the same simulation depending on the distance along the sequence between hydrogen bond donor and acceptor. For the situation in which the hydrogen bond effect, $\epsilon_{1}$ or $\epsilon_{2}$, is comparable in magnitude to the hydrophobic interaction, coupled hydrogen bonds increase cooperativity while uncoupled hydrogen bonds have little effect or even decrease it, as discussed above. This result is consistent with previous observations of the not-cooperative collapse for polypeptide models with energetically favorable hydrogen bond interactions $[12,13]$. When the hydrogen bond effect becomes stronger, the situation is reversed, since $\kappa_{2}$ values for coupled hydrogen bonds decrease while they increase for uncoupled hydrogen bonds and, specifically for $\beta_{1}$, reach values as high as the highest values observed for coupled bonds. It is apparent, however, that this situation is likely to be less relevant for realistic models since very strong hydrogen bonds, when compared to hydrophobic interactions, would be likely to prevent collapse, resulting in long single segments of secondary structure, e.g., [12,24].

The connection between $\kappa_{2}$ values, shown in Fig. 5, and the shape of the energy distribution at $T_{\max }$, shown in Fig. 6, can be better understood when it is considered that

$$
C_{V}\left(T_{\max }\right)=\left.\left(\frac{\partial E}{\partial T}\right)_{V}\right|_{T=T_{\max }}=\frac{\sigma_{E}^{2}\left(T_{\max }\right)}{T_{\max }^{2}}
$$

or, from Eq. (5),

$$
\kappa_{2}=\frac{2 \sigma_{E}\left(T_{\max }\right)}{\Delta E^{*}}
$$

where $\sigma_{E}\left(T_{\max }\right)$ is the energy standard deviation at $T_{\max }$ $[27,35]$. It is clear, therefore, that the maximal possible value of $\kappa_{2}=1$ corresponds to $\sigma_{E}\left(T_{\max }\right)=\Delta E^{*} / 2$, or a perfectly bimodal energy distribution at $T_{\max }$, equally divided between 

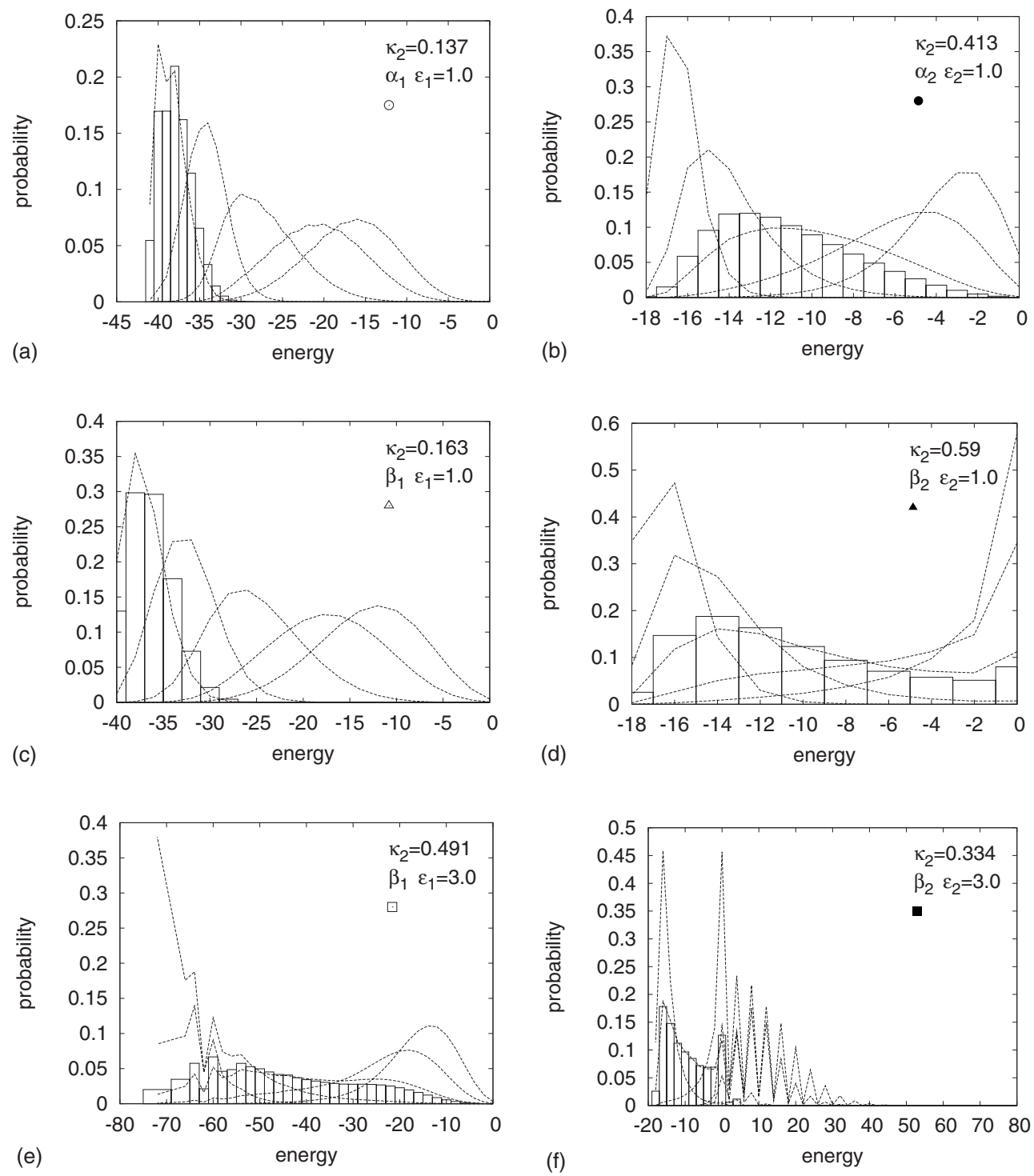

FIG. 6. Equilibrium energy distributions for different hydrogen bond implementations with fixed lattice coordination reduction $z / z_{h}$ $=7 / 3$ and chain length $N=16$. In each panel, the energy distribution at $T_{\max }$, the temperature of maximal heat capacity, is shown in boxes while five dashed curves, from left to right, correspond to temperatures at which $10 \%, 25 \%, 50 \%, 75 \%$, and $90 \%$ of the total heat of the transition has already been absorbed. The different panels correspond to $\alpha_{1}$ with (a) $\epsilon_{1}=1.0, \alpha_{2}$ with (b) $\epsilon_{2}=1.0, \beta_{1}$ with (c) $\epsilon_{1}=1.0, \beta_{2}$ with (d) $\epsilon_{2}=1.0, \beta_{1}$ with (e) $\epsilon_{1}=3.0$, and $\beta_{2}$ with (f) $\epsilon_{2}=3.0 . \kappa_{2}$ values for each model are also indicated. Each panel has a symbol matching the corresponding point in the curves shown in Fig. 5(b).

minimal and maximal possible energies, with no conformations with intermediate energy values. The minimal value $\kappa_{2}=0$, on the other hand, corresponds to all conformations having the same energy, or $\sigma_{E}=0$. Since the distinction between one-state and two-state transitions is based on the distribution being bimodal or unimodal, it is useful to consider the special value of $\kappa_{2}$ corresponding to a flat energy distribution with all energy levels equally populated at $T_{\max }$, which happens to be, if energy is considered to be a continuous variable, $\kappa_{2}^{\#}=2 \sqrt{\left(\int_{0}^{1} x^{2} d x\right)-\left(\int_{0}^{1} x d x\right)^{2}}$, or $\kappa_{2}^{\#}=2 \sqrt{1 / 3-1 / 4}$ $=0.577$. If $\kappa_{2}>\kappa_{2}^{\#}$ then the distribution at $T_{\max }$ must be bimodal, as in Fig. 6(d). The reverse is not necessarily true, however, because heat absorption above $T_{\max }$ might increase $\Delta E^{*}$ and result in $\kappa_{2}<\kappa_{2}^{\#}$ even if the distribution is clearly bimodal at $T_{\max }$, as in Fig. 6(f) and, to some extent, Fig. 6(e).

The intrinsic qualitative difference between coupled and uncoupled hydrogen bonds must result from their different effects on the logarithm of the density of states of the system, or microcanonical entropy, whose convexity or concavity is intimately connected to the existence or not, respectively, of a cooperative, two-state transition $[33,36,37]$. Since the number of conformations at any given energy results from the sum of conformations with different numbers of either hydrogen bonds, $B$, or unviable contacts, $C^{\prime \prime}$, the whole density of states can also be considered as the sum of "subdensities," each of them characterized either by the same $B$ or $C^{\prime \prime}$. Complete enumeration, for $z / z_{h}=7 / 3$, of all conformations for all possible numbers of contacts, $C$, as well as for the numbers 

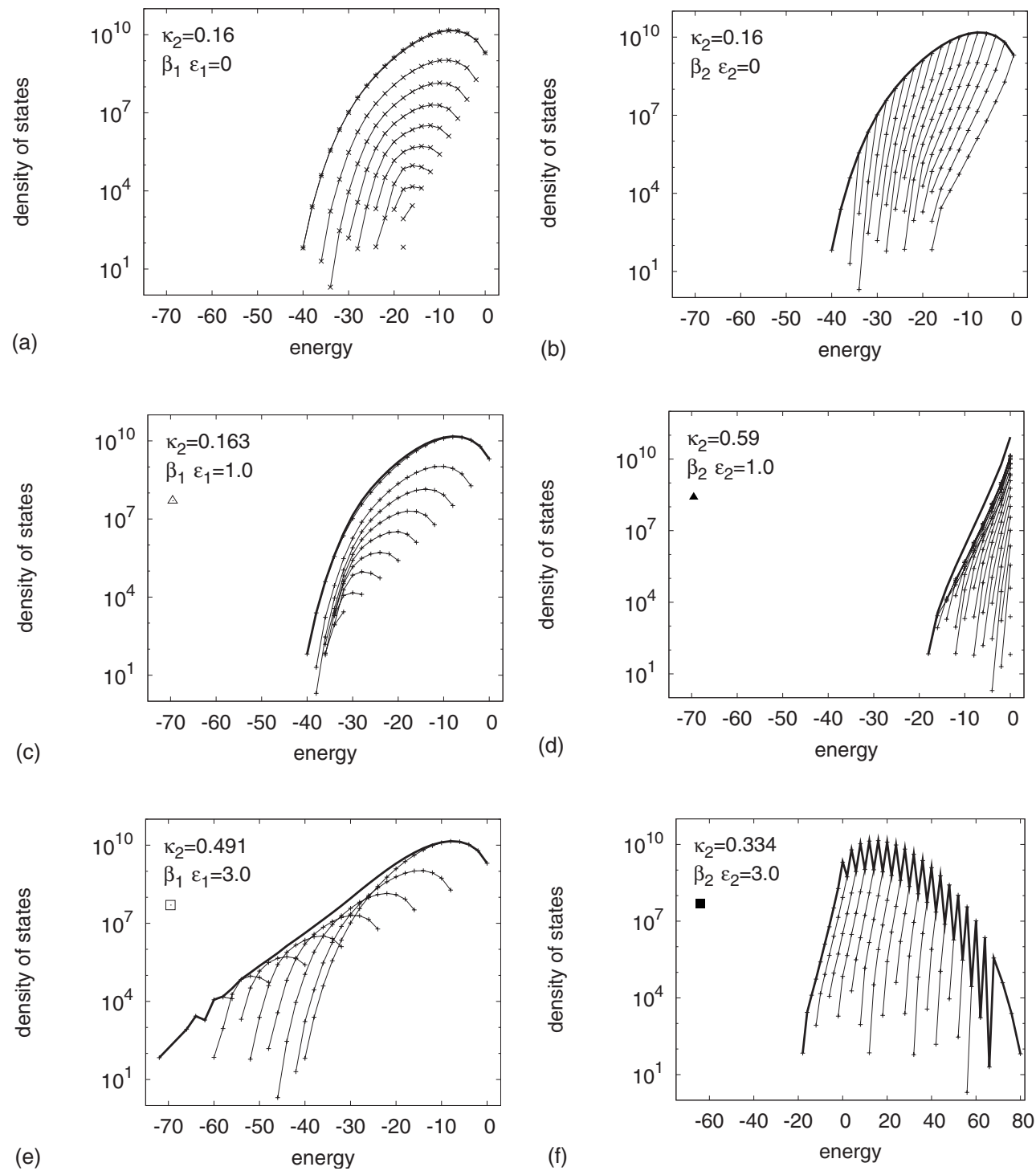

FIG. 7. Total number of conformations as a function of energy, that is, the density of states (thick line), in logarithmic scale, and relevant subdensities (crossed thin lines) for uncoupled (left-hand side) and coupled (right-hand side) $\beta$ hydrogen bonds, with fixed lattice coordination reduction $z / z_{h}=7 / 3$ and chain length $N=16$. Subdensities in (a), (c), and (e) correspond to the number of conformations with a given number of hydrogen bonds, $B$, which are gradually left shifted as the hydrogen bond strength increases and their energies are decreased accordingly by $\epsilon_{1} B$. Subdensities in (b), (d), and (f) correspond to the number of conformations with a given number of contacts not satisfying the hydrogen bond condition, $C^{\prime \prime}$, which are gradually right shifted as the hydrogen bond strength increases and their energies are increased accordingly by $\epsilon_{1} C^{\prime \prime}$. Different panels in each side correspond to different values for the hydrogen bond strength: (a) $\epsilon_{1}=0.0$ and (b) $\epsilon_{2}=0.0$; (c) $\epsilon_{1}=1.0$ and (d) $\epsilon_{2}=1.0$; (e) $\epsilon_{1}=3.0$ and (f) $\epsilon_{2}=3.0$. Different symbols in (c)-(f) match corresponding points in Fig. 5(b), as in Fig. 6.

of hydrogen bonds, $B$, and of not-viable contacts, $C^{\prime \prime}$, shows how the convexity of the total density of states, in logarithmic scale, is differently affected when subdensities corresponding to given numbers of hydrogen bonds are differently shifted to lower energies as $\epsilon_{1}$ increases in uncoupled hydrogen bonds, as opposed to the case when subdensities corresponding to given numbers of not-viable contacts are differently shifted to higher energies as $\epsilon_{2}$ is likewise increased in coupled hydrogen bonds (Fig. 7). For uncoupled hydrogen bonds, in which case the energy of all conformations with $B$ hydrogen bonds is decreased by $\epsilon_{1} B$, the total density of states, shown as a thick line in each panel, becomes even more concave for $\alpha_{1}$ (not shown) or is little affected for $\beta_{1}$ when the hydrogen bond strength increases from (a) $\epsilon_{1}=0$ to (c) $\epsilon_{1}=1$. For coupled hydrogen bonds, in which case the energy of all conformations with $C^{\prime \prime}$ not-viable contacts is increased by $\epsilon_{2} C^{\prime \prime}$, the total density of states becomes more convex both for $\alpha_{2}$ (not shown) and, particularly, $\beta_{2}$ when $\epsilon_{2}$ is increased by the same amount (b) and (d). For (e) $\epsilon_{1}=3$ the density of states becomes more convex, due to the continuous shift of subdensities to lower energies, which is consistent with the increase in its $\kappa_{2}$ value. For (f) $\epsilon_{2}=3$, on the other hand, the continuous shift of subdensities to higher energies populates previously empty energy levels, increas- 
ing the average energy of the system at infinite temperature and, therefore, increasing $\Delta E^{*}$ while decreasing $\kappa_{2}$ [see Eq. (5)].

Simulations with geometrically realistic, threedimensional models should be useful to verify to what extent the present results are general. An investigation of the effect of coupled versus uncoupled hydrogen bonds on the density and subdensities of states might also turn out to be approachable by approximate analytical models, similar to the ones that have been used to describe protein folding and collapse as a diffusion process along one or a few reaction coordinates, e.g., [38,39]. The present enumeration results, however, already demonstrate that collapse cooperativity might be strongly dependent on the assumption of enthalpically favorable hydrogen bonds, independently of their local environment, as opposed to another, maybe more reasonable, scenario in which internal hydrogen bonds become favorable, or at least more favorable, when buried inside the protein globule. This observation corroborates our previous suggestion that the requirement of hydrogen bond formation upon chain collapse, independently of sequence, might contribute to protein folding two-state behavior when collapse and folding occur concomitantly [1] and is also consistent with a cooperative unspecific protein collapse when collapse and folding are not concomitant or when folding, but not collapse, is abolished by suitable mutations, as suggested by recent experimental results $[14,15]$.

\section{CONCLUSION}

The present enumeration results demonstrate that, even for geometrically identical polypeptide models, collapse cooperativity might be drastically dependent on basic assumptions underlying the implementation of internal hydrogen bonds. It is apparent that previous simulations suggesting a one-state, continuous transition, might simply reflect the use of uncoupled, energetically favorable bonds. In more realistic implementations it is likely that hydrogen bonds should be coupled to hydrophobic interactions, in such a way that they would only be favorable, or at least more favorable, when buried. It is indicated that in this case collapse cooperativity could be significantly increased and become more consistent with recent experimental observations that suggest a two-state transition for the rapid contraction of some proteins and nonfolding peptides.

\section{ACKNOWLEDGMENTS}

This research was supported by CNPq through the Millennium Institute for Structural Biology in Biomedicine and Biotechnology (MISB3). One of the authors (A.F.P.A.) receives support from $\mathrm{CNPq}$ and one of the authors (M.A.A.B.) receives support from FAPESP.
[1] Marco Aurelio A. Barbosa, L. G. Garcia, and A. F. Pereira de Araújo, Phys. Rev. E 72, 051903 (2005).

[2] Y. Zhou, C. K. Hall, and M. Karplus, Phys. Rev. Lett. 77, 2822 (1996).

[3] E. I. Shakhnovich, G. Farztdinov, A. M. Gutin, and M. Karplus, Phys. Rev. Lett. 67, 1665 (1991).

[4] L. G. Garcia, W. L. Treptow, and A. F. Pereira de Araújo, Phys. Rev. E 64, 011912 (2001)

[5] J. Chahine, H. Nymeyer, V. B. P. Leite, N. D. Socci, and J. N. Onuchic, Phys. Rev. Lett. 88, 168101 (2002).

[6] P. J. Flory, Principles of Polymer Chemistry (Cornell University Press, New York, 1953).

[7] A. Y. Grosberg and A. R. Khokhlov, Statistical Physics of Macromolecules (AIP, New York, 1994).

[8] H. S. Chan and K. A. Dill, Annu. Rev. Biophys. Biophys. Chem. 20, 447 (1991).

[9] J. P. K. Doye, R. P. Sear, and D. Frenkel, J. Chem. Phys. 108, 2134 (1998)

[10] H. Zhou, J. Zhou, Z. Ou-Yang, and S. Kumar, Phys. Rev. Lett. 97, 158302 (2006).

[11] J. Skolnick and A. Kolinski, J. Mol. Biol. 221, 499 (1991).

[12] J. J. Chou and E. I. Shakhnovich, J. Phys. Chem. B 103, 2535 (1999).

[13] M. Knott and H. S. Chan, Chem. Phys. 307, 187 (2004).

[14] S. J. Hagen and W. A. Eaton, J. Mol. Biol. 301, 1019 (2000).

[15] L. Qiu, C. Zachariah, and S. J. Hagen, Phys. Rev. Lett. 90, 168103 (2003).

[16] G. D. Rose, P. J. Flemming, J. R. Banavar, and A. Maritan,
Proc. Natl. Acad. Sci. U.S.A. 103, 16623 (2006).

[17] A. Yang and B. Honig, J. Mol. Biol. 252, 351 (1995).

[18] A. Yang and B. Honig, J. Mol. Biol. 252, 366 (1995).

[19] H. J. Dyson, P. E. Wright, and H. A. Scheraga, Proc. Natl. Acad. Sci. U.S.A. 103, 13057 (2006).

[20] P. J. Fleming and G. D. Rose, Protein Sci. 14, 1911 (2005).

[21] J. Borg, M. H. Jensen, K. Sneppen, and G. Tiana, Phys. Rev. Lett. 86, 1031 (2001).

[22] J. R. Banavar, M. Cieplak, and A. Maritan, Phys. Rev. Lett. 93, 238101 (2004).

[23] J. R. Banavar, T. X. Hoang, A. Maritan, F. Seno, and A. Trovato, Phys. Rev. E 70, 041905 (2004).

[24] T. X. Hoang, A. Trovato, F. Seno, J. R. Banavar, and A. Maritan, Proc. Natl. Acad. Sci. U.S.A. 101, 7960 (2004).

[25] A. Trovato, J. Ferkinghoff-Borg, and M. H. Jensen, Phys. Rev. E 67, 021805 (2003).

[26] H. Kaya and H. S. Chan, Proteins 40, 637 (2000).

[27] H. S. Chan, S. Shimizu, and H. Kaya, Methods Enzymol. 380, 350 (2004)

[28] A. Kolinski, A. Godzik, and J. Skolnick, J. Chem. Phys. 98, 7420 (1993).

[29] A. F. Pereira de Araújo, Proc. Natl. Acad. Sci. U.S.A. 96, 12482 (1999).

[30] Marco Aurelio A. Barbosa and A. F. Pereira de Araújo, Phys. Rev. E 67, 051919 (2003).

[31] A. F. Pereira de Araújo, A. L. C. Gomes, A. A. Bursztyn, and E. I. Shakhnovich, Proteins: Struct., Funct., Bioinf. (to be published). 
[32] P. L. Privalov, Adv. Protein Chem. 33, 167 (1979).

[33] A. F. Pereira de Araújo, Protein Pept. Lett. 12, 223 (2005).

[34] D. K. Klimov and D. Thirumalai, Folding Des. 3, 127 (1998).

[35] L. G. Garcia and A. F. Pereira de Araújo, Proteins: Struct., Funct., Bioinf. 62, 46 (2006).

[36] M. Hao and H. A. Scheraga, J. Phys. Chem. 98, 4940 (1994).
[37] M. Hao and H. A. Scheraga, J. Mol. Biol. 277, 973 (1998).

[38] J. D. Bryngelson and P. G. Wolynes, Biopolymers 30, 177 (1990).

[39] T.-L. Chiu and R. A. Goldstein, J. Chem. Phys. 107, 4408 (1997). 



\section{Anexo III: Entropic reduction effect imposed by hydrogen bond formation on folding}





\title{
Entropy reduction effect imposed by hydrogen bond formation on protein folding cooperativity: Evidence from a hydrophobic minimalist model
}

\author{
Marco Aurélio A. Barbosa, ${ }^{1,2}$ Leandro G. Garcia, ${ }^{1}$ and Antônio F. Pereira de Araújo ${ }^{1, *}$ \\ ${ }^{1}$ Laboratório de Biologia Teórica, Departamento de Biologia Celular, Universidade de Brasília, Brasília-DF 70910-900, Brazil \\ ${ }^{2}$ Instituto de Física, Departamento de Física Geral, Universidade de São Paulo, São Paulo-SP 05508-900, Brazil
}

(Received 28 February 2004; revised manuscript received 24 August 2005; published 1 November 2005)

\begin{abstract}
Conformational restrictions imposed by hydrogen bond formation during protein folding are investigated by Monte Carlo simulations of a non-native-centric, two-dimensional, hydrophobic model in which the formation of favorable contacts is coupled to an effective reduction in lattice coordination. This scheme is intended to mimic the requirement that polar backbone groups of real proteins must form hydrogen bonds concomitantly to their burial inside the apolar protein core. In addition to the square lattice, with $z=3$ conformations per monomer, we use extensions in which diagonal step vectors are allowed, resulting in $z=5$ and $z=7$. Thermodynamics are governed by the hydrophobic energy function, according to which hydrophobic monomers tend to make contacts unspecifically while the reverse is true for hydrophilic monomers, with the additional restriction that only contacts between monomers adopting one of $z_{h}<z$ local conformations contribute to the energy, where $z_{h}$ is the number of local conformations assumed to be compatible with hydrogen bond formation. The folding transition abruptness and van't Hoff-to-calorimetric-enthalpy ratio are found to increase dramatically by this simple and physically motivated mechanism. The observed increase in folding cooperativity is correlated to an increase in the convexity of the underlying microcanonical conformational entropy as a function of energy. Preliminary simulations in three dimensions, even though using a smaller relative reduction in lattice effective coordination $z_{h} / z=4 / 5$, display a slight increase in cooperativity for a hydrophobic model of 40 monomers and a more pronounced increase in cooperativity for a native-centric Go-model with the same native conformation, suggesting that this purely entropic effect is not an artifact of dimensionality and is likely to be of fundamental importance in the theoretical understanding of folding cooperativity.
\end{abstract}

DOI: 10.1103/PhysRevE.72.051903

PACS number(s): 87.15.Cc, 87.10.+e

\section{INTRODUCTION}

One of the most remarkable experimental observations on folding thermodynamics of small proteins is the cooperative, two-state character of the process. Global properties that reflect different aspects of the three-dimensional organization of the molecule, like amount of secondary structure, rigid asymmetrical environment around aromatic side chains, burial of tryptophane residues, etc., vary concomitantly within a relatively narrow range of a given control parameter, such as temperature, pressure or denaturant concentration. Moreover, the van't Hoff enthalpy $\Delta H_{\mathrm{vH}}$, obtained from the temperature derivative of an effective equilibrium constant taken directly from the value of monitored properties under the assumption of two-state behavior, agrees reasonably well with the actual enthalpy of denaturation obtained calorimetrically, $\Delta H_{\text {cal }}$ [1]. The value of different monitored properties therefore indeed reflects, to a good approximation, the equilibrium constant between two macroscopically distinguishable thermodynamic states: the native and the denatured macroscopic states. The native state is thermodynamically dominant, i.e., has a lower free energy, at physiological temperature while the denatured state dominates at high temperatures. Around the transition temperature the system absorbs a significant amount of heat, implying abrupt changes in enthalpy and entropy. Since the entropy is the temperature

*Electronic address: aaraujo@unb.br derivative of the Gibbs free energy it is natural to consider the folding process as analogous to a first-order, or two-state, phase transition, as defined by a discontinuity in the first derivative of the thermodynamic potential $[2,3]$.

Simple minimalist protein models, which take chain connectivity and excluded volume into account explicitly, have been able to reproduce protein folding two-state behavior in the sense that the equilibrium population of microstates shifts, as the temperature is increased, from a unimodal distribution dominated by low energy conformations, corresponding to the macroscopic native state, to unimodal distribution dominated by high energy conformations, corresponding to the denatured macroscopic state, passing through, around the transition temperature, a bimodal distribution where both macroscopic states are distinguishable (e.g., Ref. [4], reviewed in Refs. [5-7]). In other words, around the transition temperature there are two free energy minima separated by a free energy maximum along the energy coordinate or, equivalently, there is a convex region in the microscopic entropy as a function of energy $[3,8]$. It has become apparent, however, that the transition observed in these models tends to be less abrupt than in real proteins and that the ratio between model quantities intended to be analogous to the van't Hoff and calorimetric folding enthapies, with reasonable interpretations of experimental calorimetric data, is usually far below 1 [9-11]. Additionally, it is not trivial to introduce physically motivated terms to normally used energy functions in order to improve cooperativity $[11,12]$. 
In the present study we investigate possible entropic effects on protein folding thermodynamic cooperativity of the well known requirement of hydrogen bond formation between backbone carbonyl and nitrogen polar groups as they become buried inside the protein apolar core during folding (e.g., Ref. [13]). We imagine that the number of local backbone conformations adopted by apolar monomers participating in favorable hydrophobic interactions must be smaller than the total number of possible local conformations, since they must be compatible with hydrogen bond formation of adjacent backbone polar groups. This simple idea is implemented in lattice models in which the formation of hydrophobic contacts is coupled to an effective reduction in lattice coordination.

\section{METHODS}

We use the two-dimensional square lattice, with $z=3$ local conformations per monomer, as well as lattice extensions with diagonal step vectors (covalent bonds) of the form $\{ \pm 1, \pm 1\}$ resulting in $z=5$ (when angles between adjacent bonds smaller than $90^{\circ}$ are forbidden) and $z=7$. Favorable hydrophobic interactions can only occur between monomers which happen to be in one of $z_{h} \leqslant z$ local conformations compatible with hydrogen bond formation. The hydrophobic energy function [14], consisting of the sum over monomers of their hydrophobicities multiplied by the number of contacts they are making, now becomes

$$
E\left(\vec{h}, \vec{c}^{\prime}\right)=-\sum_{i} h_{i} c_{i}^{\prime}=-\vec{h} \cdot \vec{c}^{\prime},
$$

where $\vec{c}^{\prime}=\left\{c_{1}^{\prime}, \ldots, c_{N}^{\prime}\right\}$ represents the number of viable contacts made by each monomer in a given structure, where the prime reminds the viability restriction that only contacts involving monomers in one of the $z_{h}$ local conformations are counted, and $\vec{h}=\left\{h_{1}, \ldots, h_{N}\right\}$ is the sequence of hydrophobicities, as usual. Note that in this simple implementation the hydrogen bond restriction is actually imposed on all nonneutral interactions, not necessarily hydrophobic.

Three two-dimensional conformations of 24 monomers shown in Figs. 1(a)-1(c) are used as native structures. The structure shown in Fig. 1(a), which will be called n24D2a, has been used in previous studies and was originally selected because it is structurally segregated, i.e., most of its monomers are completely buried or completely exposed, a property already shown, both in two and three dimensions, to be crucial for appropriate native structures to the hydrophobic function [14-16]. Hydrophobicities are either 1 (hydrophobic) or -1 (hydrophilic) for monomers that are respectively buried or exposed in the native structure while the hydrophobicity of both neutral extremities is 0 . The resulting native energy is $E^{*}=-24$. Structures shown in Figs. 1(b) and 1(c), n24D2b and n24D2c, correspond to different contact matrices (the set of all contacts), contact vectors (the number of contacts made by each monomer) although having the same segregation, compactness and energy, for their designed sequences, as n24D2a. Their use is intended to provide an indication of the eventual dependence of our results on topological details of the native structure.
Two sets of local conformations for a given monomer are considered to be compatible with hydrogen bond formation. In the first set, step vectors (covalent bonds) connecting the monomer to its neighbors along the sequence must be in the square lattice, giving $z_{h}=3$. Since most adjacent step vectors form right angles in the native structures, we also use a set of hydrogen bond conformations where adjacent step vectors must form an angle of $90^{\circ}$, giving $z_{h}=2$, except for monomers not satisfying this restriction in the native structure. Effective lattice coordination reductions, as measured by $z_{h} / z$, ranged therefore from $2 / 7$ (the largest reduction) to $3 / 3$ (the original model with no reduction). Standard Monte Carlo simulations, as detailed elsewhere [4,14,17], were performed but with a move set consisting of end moves and "generalized" kink and crankshaft moves, resulting from the exchange between adjacent and next to adjacent step vectors, respectively. Application to shorter, completely enumerable, chains confirmed that correct thermodynamics are reproduced by this move set not only for $z=3$ but also for $z=5$ and $z=7$. It is important to emphasize that the resulting twodimensional model is not "native-centric," or "teleological" [9], since it has no explicit bias, either global or local, towards the native structure.

The density of states for each model, $g(E)$, representing the number of model conformations as a function of energy $E$, was estimated from long Monte Carlo trajectories by standard histogram techniques $[18,19]$. Heat capacity curves obtained from $g(E)$ were then used to compute two folding quality parameters: the cooperativity index proposed by Klimov and Thirumalai, $\Omega_{c}$ [20], which measures the transition sharpness, or abruptness, and Chan's $\kappa_{2}$ [9], which is intended to be analogous to the ratio between experimental van't Hoff and calorimetric enthalpies and is a measure therefore of the so called calorimetric cooperativity. In our notation [16], with the energy itself taken as order parameter,

$$
\Omega_{c}=\frac{T_{f}^{2} C_{V}\left(T_{f}\right)}{\left(-E^{*}\right) \Delta T},
$$

where $\Delta T$ is the width of the heat capacity peak at its half maximal height, and

$$
\kappa_{2}=\frac{\Delta H_{\mathrm{vH}}}{\Delta H_{\mathrm{cal}}}=\frac{2 T_{f} \sqrt{C_{V}\left(T_{f}\right)}}{-E^{*}},
$$

where the calorimetric enthalpy is $\Delta H_{\text {cal }}=-E^{*}=24$ in all twodimensional models since they have the same native energy, -24 , and the same average energy, 0 , at high temperature.

We have also performed simulations with a chain of 40 monomers in three dimensions whose native structure, called n40D3a and shown in Fig. 1(d), was already used in previous studies $[15,21]$. The lattice has not been extended in this case, however, and only standard moves have been used. Lattice coordination reduction is therefore less pronounced, with $z_{h} / z=4 / 5$, where local conformations corresponding to an angle of $90^{\circ}$ between adjacent covalent bonds are assumed to be compatible with hydrogen bond formation. As already described for the two-dimensional model, this restriction is not applied to monomers between covalent bonds forming an angle of $180^{\circ}$ in the native structure. In addition 

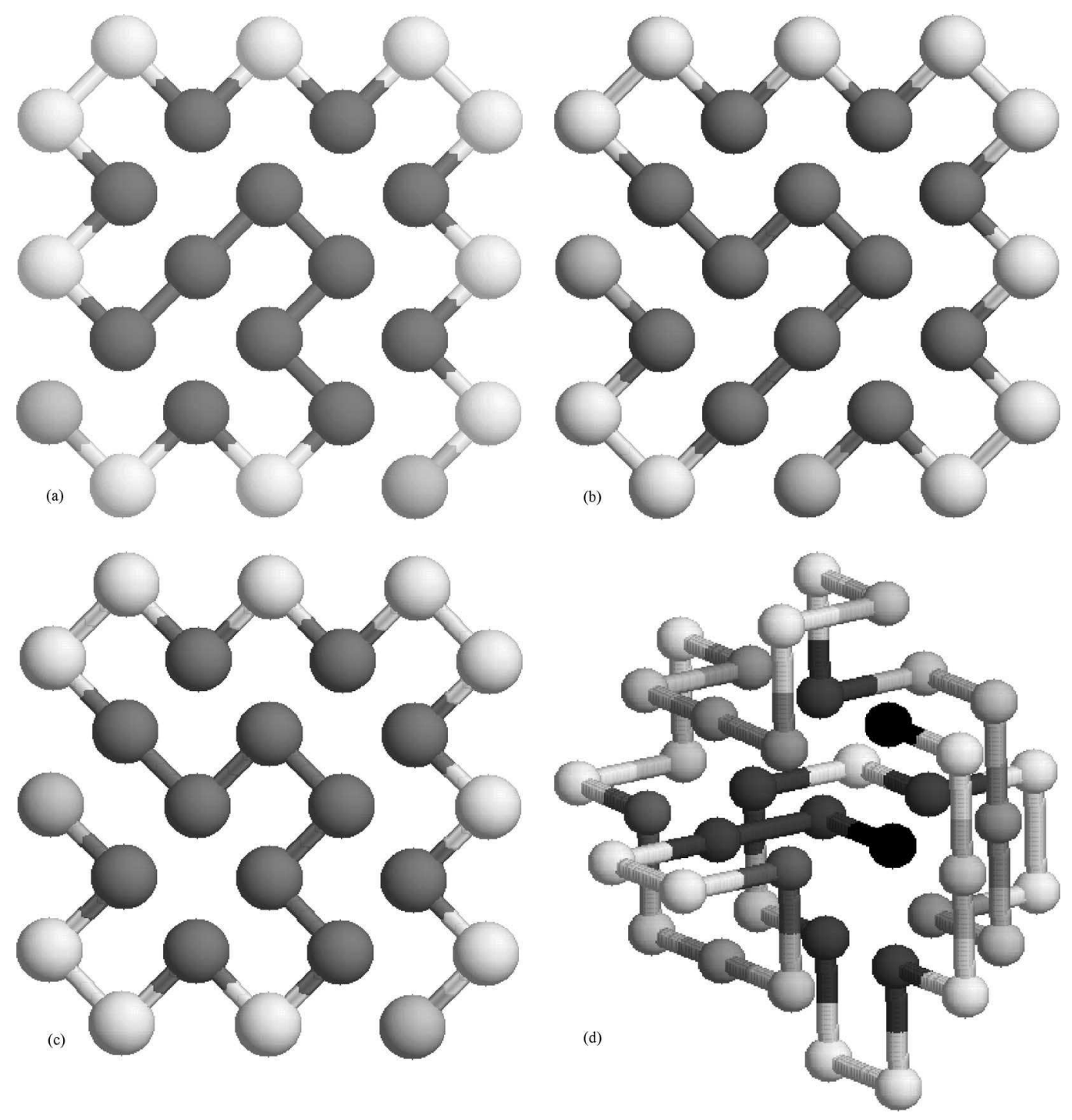

FIG. 1. Two-dimensional conformations of 24 monomers used as native structures in the simulations: n24D2a (a), n24d2b (b), and n24D2c (c). Buried monomers (dark gray) are hydrophobic, exposed monomers (white) are hydrophilic and both extremities (light gray) are neutral. Hydrophobicity values of $1,-1$, and 0 , for hydrophobic, hydrophilic, and neutral monomers, respectively, result in the same native energy $E^{*}=-24$. The conformation of 40 monomers shown in (d) was used in all simulations in three dimensions. Monomer hydrophobicities, represented by different tones of gray, were obtained from the deviation in the number of native contacts from their average value in the native structure, resulting in $E^{*}=-105$. For the Go potential all 33 native contacts have energy -1 while non-native contacts are neutral and $E^{*}=-33$.

to the hydrophobic energy function, which was previously described to result in a collapse transition above the folding temperature and, as a consequence, in poor calorimetric cooperativity, we have also used a native-centric Go-type energy function for which cooperativity is more pronounced [21].

\section{RESULTS AND DISCUSSION}

Figure 2 shows heat capacity curves for all six combinations of $z$ and $z_{h}$ for n24D2a (a), n24D2b (b), and n24D2c (c). Folding transition temperatures $T_{f}$, defined by the position of absorption peaks, and corresponding heat capacity maxima $C_{V}\left(T_{f}\right)$ are shown in Table I for all plots shown in
Fig. 2. Corresponding cooperativity parameters $\Omega_{c}$ and $\kappa_{2}$ are shown in the same table. The general behavior is similar for the three two-dimensional native conformations. For fixed $z_{h}, C_{V}\left(T_{f}\right)$ becomes larger but $T_{f}$ becomes smaller as $z$ increases. For fixed $z$, both $T_{f}$, only slightly for $z=5$ and $z$ $=7$, and $C_{V}\left(T_{f}\right)$ increase when $z_{h}$ decreases. The quantity

$$
C_{V}\left(T_{f}\right)=\frac{E^{* 2} \kappa_{2}^{2}}{4 T_{f}^{2}},
$$

obtained directly from Eq. (3), is also plotted in Fig. 2, with $E^{*}=-24$, for $\kappa_{2}=0.6, \kappa_{2}=0.8$, and $\kappa_{2}=1.0$. These curves permit direct visualization of $\kappa_{2}$ values for different heat capacity peaks and emphasize opposite effects on calorimetric co- 

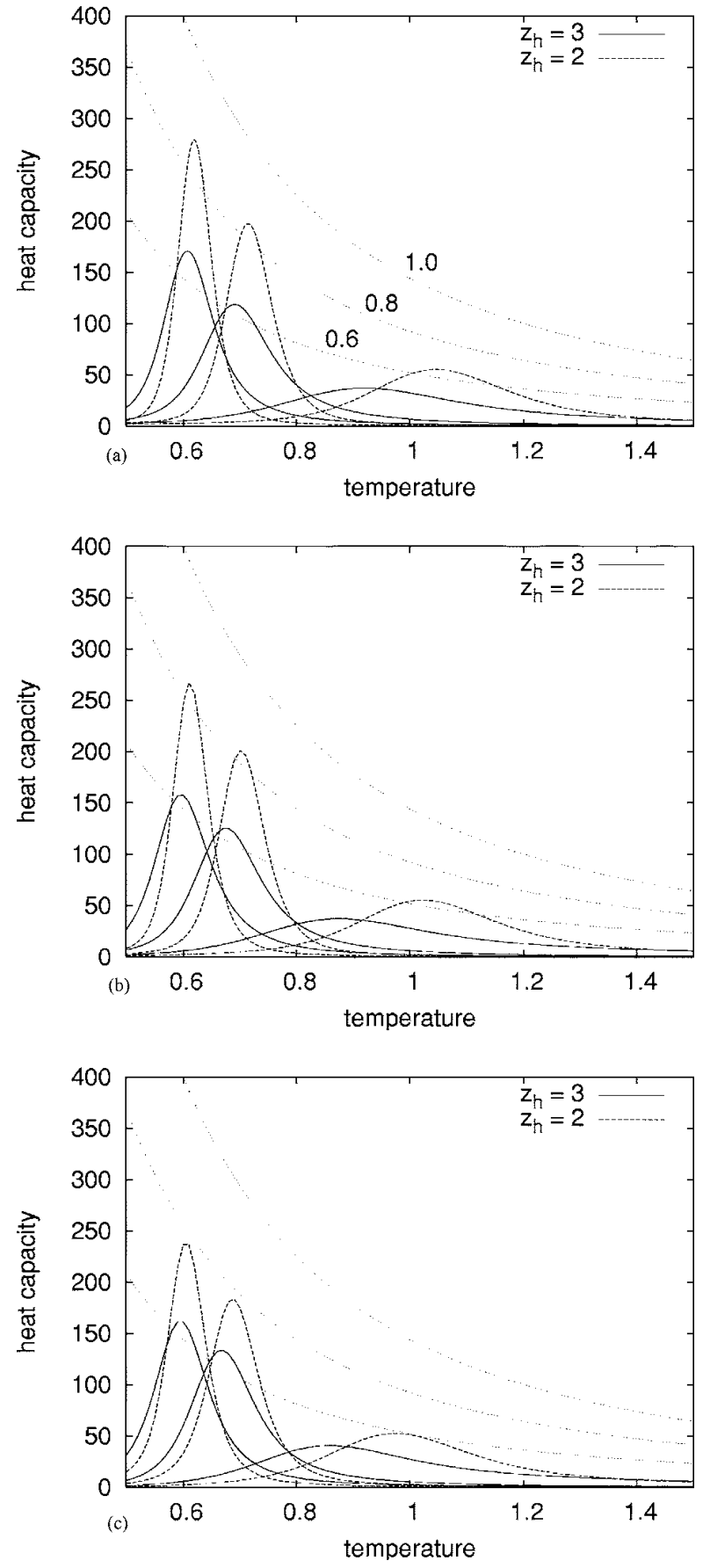

FIG. 2. Heat capacity curves for n24D2a (a), n24D2b (b), and n24D2c (c), obtained by the simple histogram technique from long Monte Carlo trajectories of $10^{8}$ or $10^{9}$ time steps ( 1 time step equals $N=24$ move attempts), recorded at $10^{4}$ time steps intervals, at temperatures close to $T_{f}$. Appropriate conformational sampling was checked by small control simulations at different temperatures. Heat capacity curves are plotted with two types of lines, depending on $z_{h}$. For each $z_{h}, z$ increases from 3 to 5 and then to 7 as the heat capacity maximum shifts to lower temperatures. Monotonically decreasing curves represent the expression of Eq. (4) for $\kappa_{2}$ values of $0.6,0.8$ by 1.0 , as labeled in (a), and indicate the height of absorption peaks that would correspond to the given $\kappa_{2}$ value.
TABLE I. For each combination of $z$ and $z_{h}$, the table shows $T_{f}$ and $C_{V}\left(T_{f}\right)$ obtained directly from the heat capacity curves shown in Fig. 2 and cooperativity parameters $\kappa_{2}$ and $\Omega_{c}$ for the three twodimensional native conformations under consideration.

\begin{tabular}{llllllll}
\hline \hline$z / z_{h}$ & & $3 / 3$ & $5 / 3$ & $7 / 3$ & $3 / 2$ & $5 / 2$ & $7 / 2$ \\
\hline$T_{f}$ & n24D2a & 0.92 & 0.69 & 0.61 & 1.05 & 0.72 & 0.62 \\
& n24D2b & 0.87 & 0.68 & 0.60 & 1.02 & 0.70 & 0.61 \\
& n24D2c & 0.86 & 0.67 & 0.60 & 0.97 & 0.69 & 0.61 \\
& & & & & & \\
$\kappa_{2}$ & n24D2a & 0.47 & 0.63 & 0.66 & 0.65 & 0.84 & 0.86 \\
& n24D2b & 0.44 & 0.63 & 0.62 & 0.63 & 0.83 & 0.83 \\
& n24D2c & 0.46 & 0.64 & 0.63 & 0.59 & 0.77 & 0.78 \\
$\Omega_{c}$ & n24D2a & 3.3 & 16.3 & 25.2 & 8.5 & 44.0 & 64.6 \\
& n24D2b & 3.1 & 16.9 & 20.1 & 8.0 & 42.9 & 57.0 \\
& n24D2c & 3.5 & 18.4 & 21.0 & 6.7 & 34.7 & 45.0 \\
\hline \hline
\end{tabular}

operativity of the smaller $T_{f}$ and larger $C_{V}\left(T_{f}\right)$ resulting from an increase of $z$.

Small differences are observed in the exact numerical values, however. $\Omega_{c}$, which ranges from 10 to 100 in real twostate proteins [20], increases in the case of n24D2a from $\Omega_{c}(3 / 3)=3.3$, for the original model with $z=z_{h}=3$, to $\Omega_{c}(7 / 2)=64.6$, for $z=7$ and $z_{h}=2$ while $\kappa_{2}$ becomes as high as $\kappa_{2}(7 / 2)=0.86$ for this most cooperative model, significantly closer to unity than the original value of $\kappa_{2}(3 / 3)$ $=0.47$. Folding transition temperatures and cooperativity parameters are consistently lower for $\mathrm{n} 24 \mathrm{D} 2 \mathrm{~b}$ when compared to n24D2a with the same $z / z_{h}$ ratio. Maybe more significantly, calorimetric cooperativity does not always increase with $z / z_{h}$, as could be suggested by the results for n24D2a. For $n 24 \mathrm{D} 2 \mathrm{~b} \quad \kappa_{2}(7 / 2)=\kappa_{2}(5 / 2)=0.83$ and $\kappa_{2}(5 / 3)=0.63$ $>\kappa_{2}(7 / 3)=0.62$. It appears therefore that there is an optimal $z / z_{h}$ combination which happens to be slightly dependent on native topology. Since the conformational entropy of real unfolded proteins has been estimated from calorimetric data to correspond to around eight conformations per monomer [1] while backbone hydrogen bonds can be formed in $\alpha$-helical or $\beta$-strand local conformations, it is interesting to note the $z / z_{h}$ values in the present study do not seem unrealistic. Folding temperatures for $\mathrm{n} 24 \mathrm{D} 2 \mathrm{c}$ tend to be very similar to the corresponding temperatures for $\mathrm{n} 24 \mathrm{D} 2 \mathrm{~b}$ but its cooperativity parameters for $z_{h}=3$ tend to be higher, in some cases being actually even higher than corresponding values for $\mathrm{n} 24 \mathrm{D} 2 \mathrm{a} \quad\left[\kappa_{2}(5 / 3)=0.64, \Omega_{c}(3 / 3)=3.5\right.$, and $\Omega_{c}(5 / 3)$ $=18.4]$. For $z_{h}=2$, however, cooperativity parameters have consistently the lowest values among the three conformations for n24D2c. This observation certainly results from the fact that three monomers are connected by covalent bonds with an angle of $180^{\circ}$ in n24D2c [Fig. 1(c)] and are therefore restricted as in $z_{h}=3$ instead of $z_{h}=2$, while for the other two conformations this is the case for only one monomer [Figs. 1(a) and 1(b)].

The hydrogen bond effect can be seen more clearly in the entropy function obtained directly from the density of states of the models, $S(E)=\ln (g(E))$, as shown in Fig. 3 for n24D2a. The most obvious effect of increasing $z$ is the ex- 

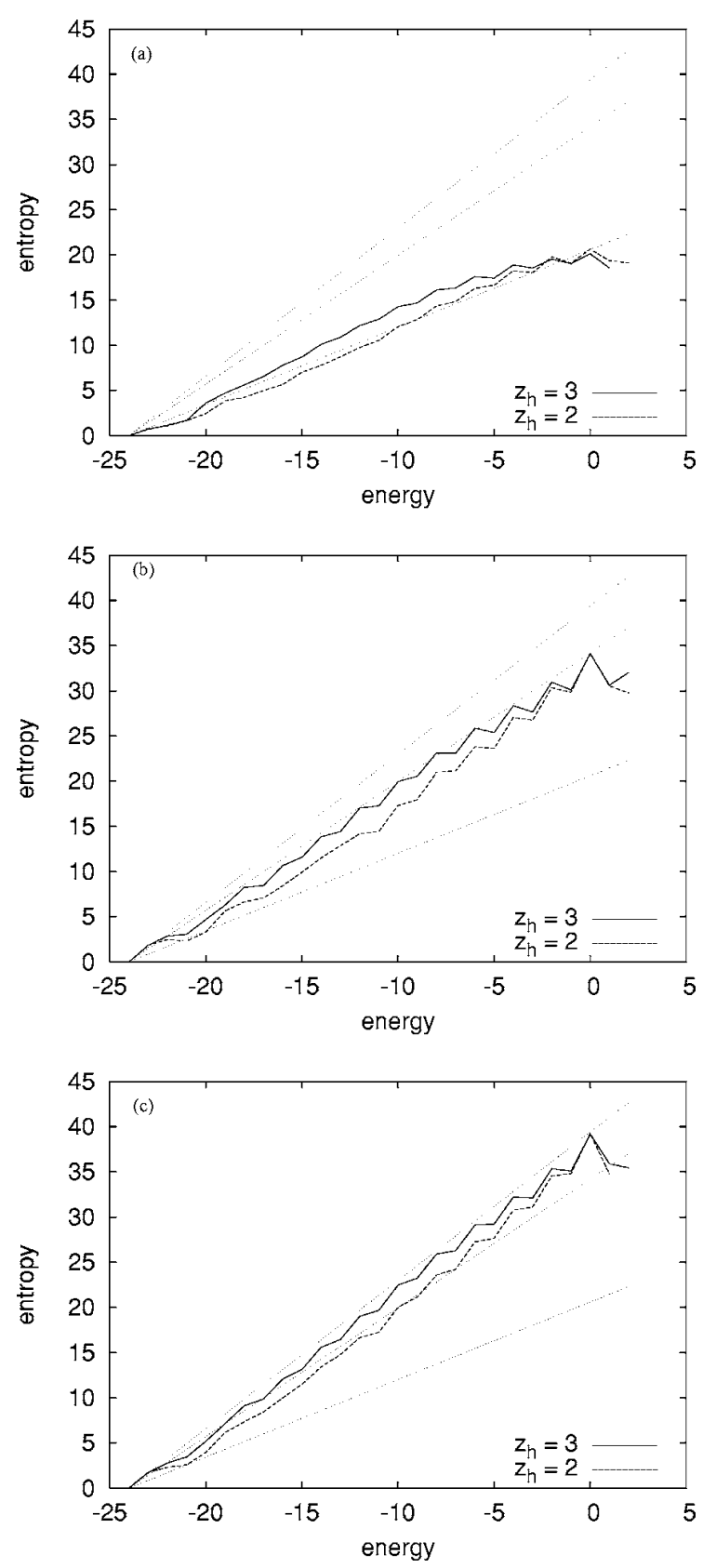

FIG. 3. Microscopic entropies, $S(E)=\ln (g(E))$, for n24D2a obtained by the simple histogram technique and used to generate the heat capacity curves shown in Fig. 2(a). Each panel contains two curves corresponding to $z_{h}=3$ and $z_{h}=2$ and a single value of $z=3$ (a), $z=5$ (b), and $z=7$ (c). Straight lines connecting points $\left(E^{*}\right.$ $=-24,0)$ and $(E=0, S(0))$, for $z_{h}=2$, which actually would be essentially identical for $z_{h}=3$, facilitate the visualization of the increase in concavity as $z_{h}$ decreases. Repetition of three straight lines in all diagrams facilitates the comparison between different values of $z$.

pected increase in the maximal entropy, which happens to correspond to unfolded conformations with $E=0$ in these models, and a directly related decrease in $T_{f}$, which in itself contributes to a decrease in cooperativity. Since the entropy of low energy conformations is not affected as much, how-
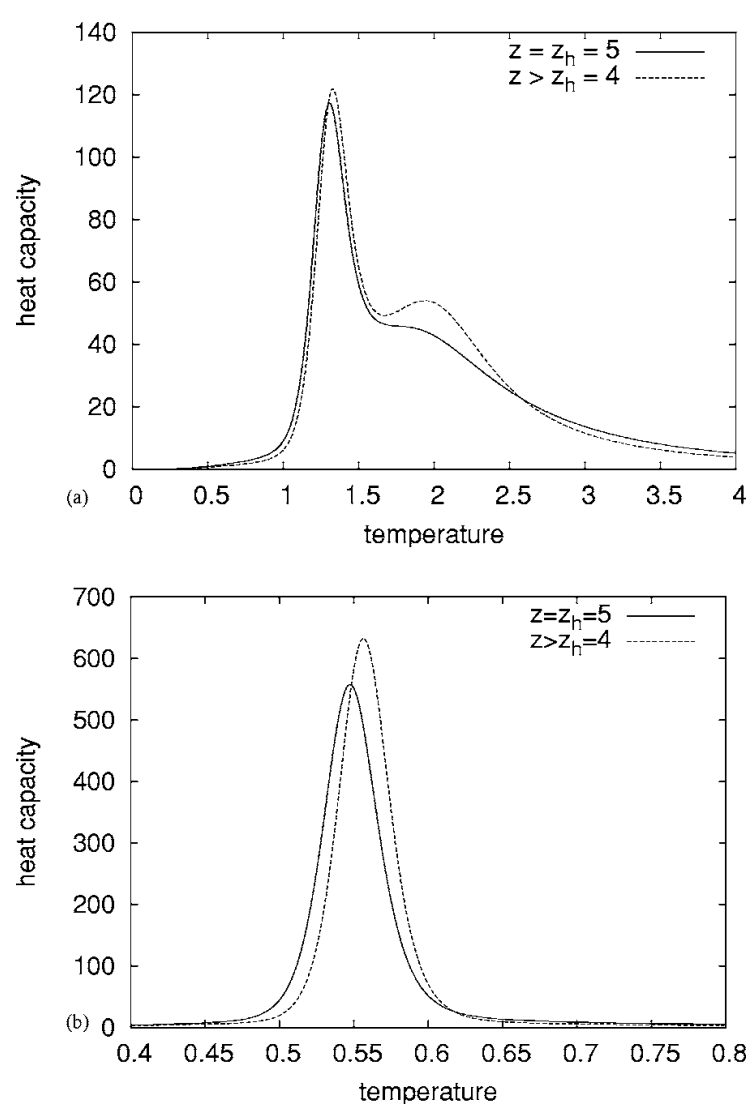

FIG. 4. Heat capacity curves for the three-dimensional model with native conformation n40D3a and hydrophobic (a) and Go (b) potentials. These curves were obtained from long trajectories of up to $4 \times 10^{9}$ time steps ( 1 time step $=N=40$ move attempts) at different temperatures by standard histogram techniques. Each panel contains two curves corresponding to the presence or absence of effective lattice coordination reduction. Note the difference in scale between the two panels.

ever, the net result is a significant increase in the convexity of the curve, a sufficiently sharper heat capacity peak and an overall increase in calorimetric cooperativity. This distinctive entropic effect on low energy conformations, when compared to their high energy counterparts, is similar to the entropic reduction of low energy conformations previously observed in a homopolymer model with a more explicit, spinlike consideration of hydrogen bonds [22]. The stronger temperature dependence of $\Omega_{c}$ on $z$ when compared to $\kappa_{2}$, as seen in Table I, is consistent with the major dependence of the transition sharpness on the entropy of the unfolded state [10]. The behavior of the calorimetric cooperativity, on the other hand, appears to be more significantly affected by the convexity itself. Straight lines connecting the points $\left(E^{*}\right.$ $=-24, S(-24)=0)$ and $(E=0, S(0))$ are shown in order to facilitate visualization of convexities. Their inclinations would correspond to the inverse transition temperatures of perfectly two-state transitions between two macroscopic states with $E=-24$ and $E=0$. We note that the most important feature of the density of states for the cooperative models is not the number of conformations in itself but the convexity of the microscopic entropy curve, $S(E)=\ln (g(E))$. In 
particular, the number of conformations does not have to be 0 for essentially all intermediate energy values between $E$ $=E^{*}$ and $E=0$, as could be suggested by a parabolic (concave) microscopic entropy derived from a hypothetical Gaussian density of states [10], but can actually increase continuously as it is almost unavoidable in any polymeric system.

Figure 4 shows heat capacity curves for the threedimensional model with the hydrophobic (a) and Go (b) energy functions. As previously described $[15,21]$, the shoulder on the heat capacity curve for the hydrophobic energy function (a) corresponds to a compaction (or expansion) transition at a higher temperature than the folding transition. Calorimetric cooperativity is correspondingly small, with $\kappa_{2}$ $\approx 0.27$, because a significant amount of heat is absorbed by the unfolded state while the chain expands [21]. As seen by the second curve in the same panel, lattice coordination reduction does not significantly affect the folding transition peak, and there is only a slight increase in the cooperativity parameter $\kappa_{2} \approx 0.28$. The compaction transition shoulder, however, is more significantly affected and becomes more pronounced. This result is very informative since it indicates that the implemented lattice coordination reduction mainly affects compaction, as could actually be expected, and not the folding transition in itself. When both transitions occur concomitantly, however, as for the two-dimensional models described above, an increase in the cooperativity of the compaction transition would automatically result in a corresponding increase in the folding transition. This hypothesis is also consistent with a more significant increase in calorimetric cooperativity upon lattice coordination reduction for the Go potential with the same three-dimensional native structure, as shown in Fig. 4(b). In this case folding and compaction occur concomitantly [21] and cooperativity increases from $\kappa_{2} \approx 0.79$ to $\kappa_{2} \approx 0.85$.

\section{CONCLUSION}

We have investigated the effect of lattice coordination reduction upon chain compaction on the folding cooperativity of minimalist hydrophobic protein models. Coordination reduction is intended to mimic a purely entropic effect resulting from the requirement that polar groups in the protein backbone must form hydrogen bonds concomitantly to their burial inside the apolar internal region of the globular structure. The effective dependence of monomer hydrophobicity on local conformation can be considered to take into some account many-body interactions, being similar in this general sense to the environment-dependent hydrogen bond enthalpies investigated by Chan and co-workers [12]. The explicit modification of conformational entropy additionally suggests that the observed effect might be related to so called "capillarity models," also studied by Chan [10] after ideas previously developed by Freire and co-workers [23], according to which the polymer chain consists of a priori cooperative segments. A more extensive investigation, possibly involving sequence optimization [24], different structures, chain lengths, and $z_{h} / z$ combinations, would be useful to determine the limits of coordination reduction on thermodynamic folding cooperativity and to clarify possible relations with these previously proposed schemes. The corresponding effect on folding kinetics [25] must also be investigated. Additionally, since lattice coordination reduction appears to increase folding cooperativity mainly through its effect on chain compaction, as could actually be expected, studies using even simpler, homopolymeric models are likely to provide interesting insight. Our present results, however, already show that this very simple and physically motivated mechanism can dramatically affect the behavior of minimalist models, suggesting that an analogous entropic effect caused by hydrogen bond formation is likely to be of fundamental importance in any theoretical attempt to understand protein folding cooperativity.

\section{ACKNOWLEDGMENTS}

This research has been supported by the Brazilian Government agency "Conselho Nacional de Pesquisa" (CNPq). M.A.A.B. has been supported by FAPESP.
[1] P. L. Privalov, Protein Folding, edited by T. E. Creighton, (Freeman, New York, 1992).

[2] M. Karplus and E. I. Shakhnovich, in Protein Folding, edited by T. E. Creighton (Freeman, New York, 1992).

[3] A. F. Pereira de Araújo, Protein \& Peptide Letters 12, 223 (2005).

[4] A. F. Pereira de Araújo and T. C. Pochapsky, Folding Des. 1, 299 (1996).

[5] K. A. Dill, S. Bronberg, K. Yue, K. M. Fiebig, D. Yee, P. D. Thomas, and H. S. Chan, Protein Sci. 4, 561 (1995).

[6] E. I. Shakhnovich, Curr. Opin. Struct. Biol. 7, 29 (1997).

[7] J. N. Onuchic, Z. Luthey-Schulten, and P. G. Wolynes, Annu. Rev. Phys. Chem. 48, 545 (1997).

[8] M. Hao and H. A. Scheraga, J. Mol. Biol. 277, 973 (1998).

[9] H. Kaya and H. S. Chan, Proteins 40, 637 (2000).
[10] H. S. Chan, Proteins 40, 543 (2000).

[11] H. S. Chan, S. Shimizu, and H. Kaya, Methods Enzymol. 380, 350 (2004).

[12] H. Kaya and H. S. Chan, Phys. Rev. Lett. 85, 4823 (2000).

[13] S. Miller, J. Janin, A. M. Lesk, and C. Chotia, J. Mol. Biol. 196, 641 (1987).

[14] A. F. Pereira de Araújo, Proc. Natl. Acad. Sci. U.S.A. 96, 12482 (1999).

[15] L. G. Garcia, W. L. Treptow, and A. F. Pereira de Araújo, Phys. Rev. E 64, 011912 (2001).

[16] Marco Aurélio A. Barbosa and A. F. Pereira de Araújo, Phys. Rev. E 67, 051919 (2003).

[17] W. L. Treptow, M. A. A. Barbosa, L. G. Garcia, and A. F. Pereira de Araújo, Proteins 49, 167 (2002).

[18] N. D. Socci and J. N. Onuchic, J. Chem. Phys. 103, 4732 
(1995).

[19] A. M. Ferrenberg and R. H. Swendsen, Phys. Rev. Lett. 63, 1195 (1989).

[20] D. K. Klimov and D. Thirumalai, Folding Des. 3, 127 (1998).

[21] L. G. Garcia and A. F. Pereira de Araújo, Proteins (to be published).
[22] J. Borg, M. H. Jensen, K. Sneppen, and G. Tiana, Phys. Rev. Lett. 86, 1031 (2001).

[23] E. Freire and K. P. Murphy, J. Mol. Biol. 222, 687 (1991).

[24] A. F. Pereira de Araújo, J. Chem. Phys. 114, 570 (2001).

[25] H. Kaya and H. S. Chan, Proteins 52, 510 (2003). 